UNIVERSIDADE DE SÃO PAULO

FACULDADE DE FILOSOFIA, CIÊNCIAS E LETRAS DE RIBEIRÃO PRETO DEPARTAMENTO DE PSICOLOGIA PROGRAMA DE PÓS-GRADUAÇÃO EM PSICOLOGIA

\title{
AVALIAÇÃO MULTIMÉTODOS DA TOMADA DE DECISÃO, REGULAÇÃO EMOCIONAL E PERSONALIDADE EM JOVENS ADULTOS
}

Tese apresentada ao Programa de PósGraduação em Psicologia da Faculdade de Filosofia, Ciências e Letras de Ribeirão Preto da Universidade de São Paulo, como parte das exigências para obtenção do título de Doutor em Psicologia, Área de concentração: Psicologia em Saúde e Desenvolvimento.

RIBEIRÃO PRETO - SP 


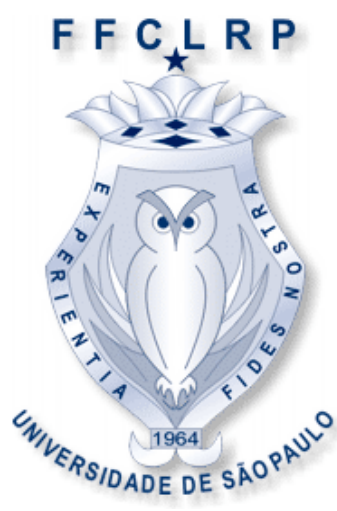

\section{AVALIAÇÃO MULTIMÉTODOS DA TOMADA DE DECISÃO, REGULAÇÃO EMOCIONAL E PERSONALIDADE EM JOVENS ADULTOS}

\section{ANDRÉ LUIZ DE CARVALHO BRAULE PINTO}

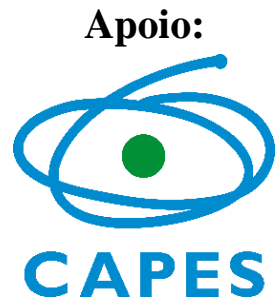

Tese apresentada ao à Faculdade de Filosofia, Ciências e Letras de Ribeirão Preto da Universidade de São Paulo, para obtenção do título de Doutor em Psicologia,

Área de concentração: Psicologia em Saúde e Desenvolvimento.

Orientadora: Profa. Dra. Sonia Regina Pasian (FFCLRP/USP).

Coorientador: Prof. Dr. Leandro Fernandes Malloy-Diniz (UFMG).

RIBEIRÃO PRETO - SP 
Autorizo a reprodução e divulgação total ou parcial deste trabalho, por qualquer meio convencional ou eletrônico, para fins de estudo e pesquisa, desde que citada a fonte.

\section{FICHA CATALOGRÁFICA}

Pinto, André Luiz de Carvalho Braule

Avaliação multimétodos da tomada de decisão, regulação emocional e personalidade em jovens adultos. Ribeirão Preto, 2020.

190 p. : il. ; $30 \mathrm{~cm}$

Tese de Doutorado, apresentada à Faculdade de Filosofia Ciências e Letras de Ribeirão Preto/USP. Área de concentração: Psicologia.

Orientadora: Pasian, Sonia Regina.

1. Avaliação psicológica; 2. Regulação Emocional; 3. Tomada de decisão; 4. Personalidade; 5. Evidências psicométricas; 6. Abordagem multimétodos. 
Nome: André Luiz de Carvalho Braule Pinto

Título: Avaliação multimétodos da tomada de decisão, regulação emocional e personalidade em jovens adultos.

Tese apresentada ao Programa de Pós-Graduação em Psicologia da Faculdade de Filosofia, Ciências e Letras de Ribeirão Preto da Universidade de São Paulo, como parte das exigências para obtenção do título de Doutor em Psicologia. Área de concentração: Psicologia em Saúde e Desenvolvimento.

Aprovado em: __ _ _ $/ 2020$.

\section{Banca Examinadora}

Prof. Dr. Instituição:

Julgamento: Assinatura:

Prof. Dr. Instituição:

Julgamento: Assinatura:

Prof. Dr. Instituição:

Julgamento: Assinatura:

Prof. Dr. Instituição:

Julgamento: Assinatura:

Prof. Dr. Instituição:

Julgamento: Assinatura: 


\section{Dedicatória}

Dedico este trabalho à minha amada mãe, que através de seu exemplo, ensinou aos filhos a importância das difíceis decisões que tomamos na vida e a necessidade de lidar com as consequências. 


\section{AGRADECIMENTOS}

À minha amada Mãe, por ser um firme exemplo de dedicação e luta na busca por dias melhores. Se algo foi por mim realizado do qual posso me orgulhar, os louros todos são seus.

Aos meus Irmãos Adriano, Felipe, Karen e Arielson, ter crescido com vocês foi um grande aprendizado para minha formação humana e na busca por respostas sobre questões fundamentais.

À minha querida companheira de jornada Roberta Alencar, que durante os períodos mais difíceis esteve comigo, incentivando e cuidando. Minha incentivadora mais constante, minha crítica mais contumaz. Obrigado por não largar minha mão, e obrigado pelo maior presente da vida, nosso Isaac.

À minha querida orientadora Dra. Sonia Regina Pasian, pela confiança nesse projeto e por suas palavras de incentivo durante a caminhada rumo ao aperfeiçoamento das ideias aqui discutidas, sua atenção e dedicação foram os maiores estímulos para o aprimoramento de minha formação científica.

Ao professor coorientador Dr. Leandro Fernandes Malloy-Diniz, sua gentileza, presteza, parceria e palavras de animo foram fundamentais para prosseguir com a escrita dos manuscritos gerados por esta pesquisa.

Ao Programa de Pós-Graduação em Psicologia da Faculdade de Filosofia, Ciências e Letras de Ribeirão Preto da Universidade de São Paulo, a acolhida de professores e colegas foi uma das melhores experiências que tive ao longo do caminho. Mentes maravilhosas, pessoas calorosas.

À CAPES/CNPq pela concessão da bolsa de Doutorado durante parte da minha formação, sem a qual a estadia em Ribeirão Preto teria sido improvável.

A todos os participantes do estudo online e do estudo presencial, por dedicarem parte do seu tempo a fim de contribuir com o avanço do conhecimento em nosso contexto amazônida. Tempo é vida. E foi a partir de uma parcela da vida de vários indivíduos que este trabalho pôde ser realizado.

Aos meus Amigos e Irmãos Rubens Tadeu, Fabiano Ribeiro, Thales Leonardo, Wellington Marcondes, Mario Covas, Hélio por suportarem as ausências em grande parte desse período e sempre apoiarem 
Aos amigos de pós-graduação Eduardo Risk, Marina Noronha, Nicholas Areco, Rafael Mulle. Com vocês as aulas foram enriquecedoras e os dias na USP muito mais divertidos.

Aos colaboradores Gabriel Mouta, Gabriela Fernandes, Julio Balbi, Ully Sabina, Denise Albuquerque, Pedro Moss, Rosa Mirtes, Maelson Alves, Talita Ros pelo apoio durante a divulgação da pesquisa e trocas durante os sábados de estudo, regados a café com canela e bolo, fizeram dessa jornada mais enriquecedora e ajudaram a amadurecer muitas das discussões aqui apresentadas. 


\section{RESUMO}

Pinto, A. L. C. B. (2020) Avaliação multimétodos da tomada de decisão, regulação emocional e personalidade em jovens adultos. (Tese de Doutorado). Faculdade de Filosofia, Ciências e Letras de Ribeirão Preto, Universidade de São Paulo, São Paulo.

Estudos recentes indicam que processos racionais e afetivos estão mais relacionados do que supunham antigos filósofos e teóricos da ciência psicológica. Evidências empíricas indicam que, mais do que fenômenos antagônicos, processos cognitivos e afetivos interagem entre si, e com outros fenômenos psicológicos, influenciando o comportamento de maneira complexa. Nesse sentido, este trabalho teve como proposta geral examinar possíveis relações entre tomada de decisão, regulação emocional e características de personalidade em adultos, utilizando uma abordagem multimétodos (autorrelato, desempenho e medidas implícitas). Para tanto, esta pesquisa foi dividida em duas etapas, compreendendo dois estudos. O Estudo I visou explorar as inter-relações entre variáveis de regulação emocional, caracterizando perfis de estratégias de regulação em adultos jovens, posteriormente vinculadas a variáveis afetivas. Dessa forma, buscou-se validar a presença de perfis de regulação emocional na população estudada. Participaram desta pesquisa 1165 sujeitos de ambos os sexos (855 mulheres, 73,4\%) com idade média de 26,72 anos (DP = 8,35) que responderam ao Questionário de Regulação Emocional (ERQ), a Escala de Dificuldades de Regulação Emocional (DERS), Escala de Afetos Positivos e Negativos (PANAS); Escala de Afetos (EA) e a Following Affective States (FAST) em uma plataforma online. A amostra foi dividida em três subamostras. A subamostra $I(n=375)$ recuperou três perfis de regulação emocional distintos: a) perfil adaptado; b) perfil regulador inconsciente e c) perfil desregulado. A subamostra II $(\mathrm{n}=390)$ retornou o mesmo número de perfis, demonstrando sua consistência. A subamostra III $(n=400)$ indicou a importância da reavaliação cognitiva, e dificuldades de consciência como diferenciadores dos perfis e que os perfis identificados se mostraram estáveis ao longo do tempo e se relacionaram com variáveis afetivas como afetos positivos e negativos e atenção às emoções. O Estudo II visou a associação entre variáveis de regulação emocional, tomada de decisão e indicadores afetivos e cognitivo de personalidade, bem como se diferentes perfis de regulação emocional apresentavam diferenças nos processos de tomada de decisão. Nesse estudo, participaram 92 jovens adultos, de ambos os sexos $(63$ mulheres, 68,5\%) com idade média de 25,7 (DP = 6,45) que tomaram parte no estudo I. Os participantes responderam à Escala de Estilos de Decisão (DSS), ao Iowa Gambling Task (IGT) e ao Método de Rorschach (R-PAS). Os resultados indicaram que é possível relacionar os construtos do mesmo domínio à partir de métodos diferenciados. Observou-se especialmente 
relações entre dificuldades de regulação emocional (DERS) e atenção às emoções (FAST) e variáveis do Método de Rorschach. Também foi possível observar poucas relações entre estilos de tomada de decisão (DSS), o desempenho no IGT e o Rorschach o que pode sugerir que diferentes métodos avaliam aspectos diferentes dos processos de tomada de decisão. Os resultados também permitiram avaliar o relacionamento entre regulação emocional e tomada de decisão, apontando que variáveis afetivas estão relacionadas aos estilos preferencias de tomada de decisão e influenciam no desempenho em tarefas que avaliam tomada de decisão em situações de incerteza, em especial, a tendência a ignorar as próprias emoções negativas. Por fim, as análises indicaram que os perfis de regulação emocional se diferenciam em relação ao estilo intuitivo de tomada de decisão e ao indicador $(\mathrm{CF}+\mathrm{C})$ - FC no Método de Rorschach, que pode ser interpretado como um indicador de impulsividade. Em conjunto, os resultados empíricos dos dois estudos permitiram confirmar algumas das hipóteses levantadas, indicando que uma abordagem multimétodos permite a investigação de fenômenos complexos como a inter-relação entre processos de tomada de decisão, regulação emocional e personalidade.

\section{(CAPES).}

Palavras-chave: Avaliação psicológica; Regulação Emocional; Tomada de decisão; Personalidade; Evidências psicométricas; Abordagem multimétodos. 


\section{$\underline{\text { ABSTRACT }}$}

Recent studies indicate that rational and affective processes are more related than previously thought by philosophers and theorists of psychological science. Empirical evidence indicates that, more than antagonistic phenomena, cognitive and affective processes interact with each other, and with other psychological phenomena, influencing behavior in a complex way. In this sense, this work had as a general proposal to examine possible relations between decision making, emotional regulation and personality characteristics in adults, using a multimethod approach (self-report, performance and implicit measures). To this end, this research was divided into two stages, comprising two studies. Study I aimed to explore the interrelationships between variables of emotional regulation, characterizing profiles of regulatory strategies in young adults, later linked to affective variables. Thus, we sought to validate the presence of profiles of emotional regulation in the studied population. 1165 subjects of both sexes participated (855 women, $73.4 \%)$ with an average age of 26.72 years $(\mathrm{SD}=8.35)$ who answered the Emotional Regulation Questionnaire (ERQ), the Regulation Difficulty Scale Emotional (DERS), Positive and Negative Affections Scale (PANAS); Scale of Affections (EA) and Following Affective States (FAST) on an online platform. The sample was divided into three subsamples. Subsample I $(n=375)$ recovered three distinct emotional regulation profiles: a) adapted profile; $b)$ unconscious regulatory profile and c) unregulated profile. Subsample II $(n=390)$ returned the same number of profiles, demonstrating its consistency. Sub-sample III $(n=400)$ revealed the importance of cognitive reassessment, and difficulties in awareness as differentiating profiles and that the identified profiles were stable over time and were related to affective variables such as positive and negative affects and attention to emotions. Study II aimed at the association between variables of emotional regulation, decision making and affective and cognitive indicators of personality, as well as whether different profiles of emotional regulation showed differences in decision-making processes. In this study, 92 young adults participated, of both sexes (63 women, $68.5 \%$ ) with an average age of 25.7 ( $\mathrm{SD}=6.45)$ who took part in study I. The participants responded to the Decision (DSS), the Iowa Gambling Task (IGT) and the Rorschach Method (R-PAS). The results indicated that it is possible to relate the constructs of the same domain using different methods. It was observed especially relationships between difficulties in emotional regulation (DERS) and attention to emotions (FAST) and variables of the Rorschach Method. It was also possible to observe few relationships between decision-making styles (DSS), performance at IGT and Rorschach, which may suggest that different methods evaluate different aspects of decision-making processes. The results also made it possible to evaluate the 
relationship between emotional regulation and decision making, pointing out that affective variables are related to the preferred styles of decision making and influence the performance in tasks that evaluate decision making in situations of uncertainty, in particular, the tendency to ignore your own negative emotions. Finally, the analyzes indicated that the profiles of emotional regulation differ in relation to the intuitive style of decision making and the indicator $(C F+C)$ $F C$ in the Rorschach Method, which can be interpreted as an indicator of impulsivity. Together, the empirical results of the two studies confirmed some of the hypotheses raised, indicating that a multi-method approach allows the investigation of complex phenomena such as the interrelationship between decision-making processes, emotion regulation and personality.

Key-words: Psychological assessment; Emotion regulation; Decision making; Personality; Psychometric evidences; Multimethods approach. 


\section{LISTA DE FIGURAS}

Figura 1. Modelo Modal de Regulação Emocional proposto por Gross (2014)......................... 38

Figura 2. Resultados da busca inicial na literatura científica..................................................51

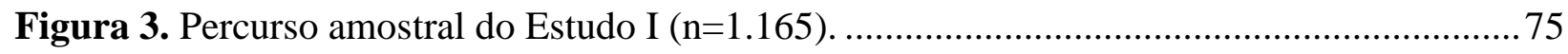

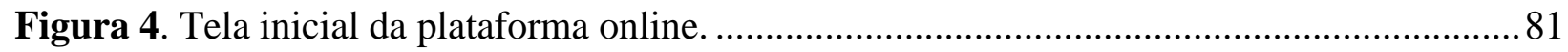

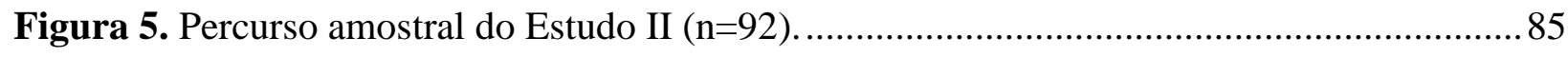

Figura 6. Diagrama de caixa de bigodes para variáveis afetivas do Estudo $1(\mathrm{n}=1165)$.......... 101

Figura 7. Perfis latentes de regulação emocional para subamostra I $(n=375)$....................... 105

Figura 8. Perfis latentes de regulação emocional identificados a partir da subamostra II ( $\mathrm{n}=390)$. 106

Figura 9. Estabilidade temporal dos perfis latentes observados no teste e reteste $(n=268) \ldots . .107$

Figura 10. Comparações nas variáveis afetivas em função do perfil de regulação emocional observado.

Figura 11. Diagrama de caixa de bigodes para as variáveis das escalas afetivas e estilos de decisão no Estudo II. 113

Figura 12. Diagrama de caixa de bigodes para as variáveis do IGT no Estudo II 115

Figura 13. Diagrama de caixa de bigodes para as variáveis afetivas do R-PAS no Estudo II...117

Figura 14. Diagrama de caixa de bigodes para as variáveis de tomada de decisão do R-PAS no Estudo II. 


\section{LISTA DE TABELAS}

Tabela 1. Caracterização sociodemográfico em termos de idade, escolaridade, classe econômica, sexo e estado civil dos participantes do Estudo I $(n=1.165)$. 76

Tabela 2. Caracterização sociodemográfica de idade, escolaridade e classe socioeconômica da amostra do Estudo I $(n=1.165)$ em função do sexo dos participantes.

Tabela 3. Caracterização sociodemográfico em termos de idade, escolaridade, classe econômica, sexo e estado civil dos participantes do Estudo II $(\mathrm{n}=92)$.

Tabela 4. Esquema de recompensas e punições no IGT-Br para as primeiras 10 escolhas por baralho.

Tabela 5. Variáveis afetivas e de tomada de decisão selecionadas para o Estudo II a partir do Método de Rorschach (R-PAS) de acordo com suas definições teóricas apresentadas no Manual do instrumento.

Tabela 6. Coeficientes de precisão dos fatores da PANAS, EA, ERQ, DERS e DSS por meio da consistência interna $(\alpha)$, confiabilidade composta e teste-reteste. .. 96

Tabela 7. Coeficientes de precisão do IGT a partir da Teoria da Generazibilidade $(n=92)$ para o escore de Tendência geral e Tendência geral Bl 2-5.

Tabela 8. Precisão entre avaliadores independentes para variáveis afetivas e relacionadas à tomada de decisão no Rorschach R-PAS (n=30) por meio do Coeficiente de Correlação Intraclasse (ICC).

Tabela 9. Estatística descritiva, medidas de tendência central e teste de normalidade das escalas de regulação emocional, dificuldades de regulação, afetos positivos e negativos e atenção às emoções utilizados no Estudo I ( $\mathrm{n}=1165)$.

Tabela 10. Estatística descritiva das escalas de regulação emocional, atenção às emoções e afetos para cada subamostra de participantes e análise de variância (ANOVA) para comparação entre as médias em função das subamostras.

Tabela 11. Estatísticas dos índices de ajuste dos dados para modelos de perfis latentes encontrados na análise de perfis latentes (LPA) para as subamostras I $(\mathrm{n}=375)$ e subamostra II $(\mathrm{n}=390)$.

Tabela 12. Análise de regressão linear usando os perfis de regulação emocional como desfecho e as variáveis componentes dos perfis de regulação emociona observados nas análises de perfis latentes para a subamostra III $(\mathrm{n}=400)$.

Tabela 13. Estatísticas descritivas para PANAS, EA e FAST nos perfis de regulação emocional obtidos a partir da subamostra III $(n=400)$. 108 
Tabela 14 Estatística descritiva, medidas de tendência central e teste de normalidade das escalas de regulação emocional, dificuldades de regulação, afetos positivos e negativos, atenção às emoções e estilos de decisão utilizados no Estudo II $(n=92)$.

Tabela 15. Estatísticas descritivas, medidas de tendência central e teste de normalidade das variáveis do Iowa Gambling Task (IGT) para o estudo II $(\mathrm{n}=92)$.

Tabela 16. Estatísticas descritivas, medidas de tendência central e teste de normalidade das variáveis selecionadas a partir do Método de Rorschach (R-PAS) (n=92).

Tabela 17. Correlações entre variáveis afetivas avaliadas por autorrelato e por desempenho no R-PAS ( $=92)$. 120

Tabela 18. Correlação entre variáveis relativas à tomada de decisão, retiradas da DSS e IGT (Estudo II, $\mathrm{n}=92$ ). 122

Tabela 19. Correlação entre variáveis relativas à tomada de decisão envolvidas na DSS, IGT e R-PAS (n=92). 123

Tabela 20. Correlação entre regulação emocional e tomada de decisão $(n=92)$.

Tabela 21. Correlação entre indicadores das escalas afetivas e relativos à tomada de decisão no R-PAS (n=92). 127

Tabela 22. Correlação entre estilos de decisão (DSS), desempenho no IGT e variáveis afetivas do R-PAS ( $\mathrm{n}=92$ ).

Tabela 23. Correlações entre variáveis afetivas e de tomada de decisão no R-PAS (n=92)......130

Tabela 24. Resultados da análise de regressão linear usando o escore de Tendência geral no IGT como critério $(n=92)$.

Tabela 25. Resultados da análise de regressão linear usando o escore de Tendência geral B1 2-5 do IGT como critério $(\mathrm{n}=92)$.

Tabela 26. Escores médios das variáveis DSS, IGT e R-PAS e análise de variância (ANOVA) em função dos perfis de regulação emocional $(n=92)$. 


\section{SUMÁRIO}

1. INTRODUÇÃ

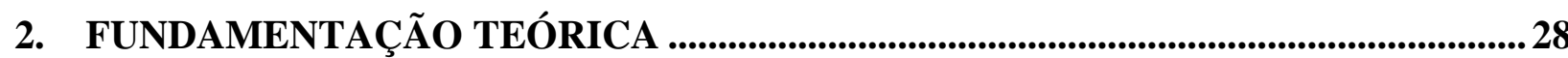

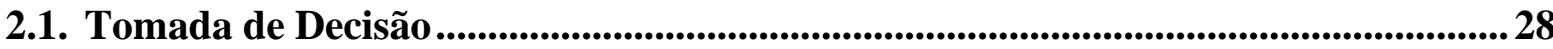

2.2. Regulação Emocional ......................................................................................................................... 37

2.3. Personalidade

2.4. Tomada de Decisão, Regulação Emocional e Personalidade ....................................50

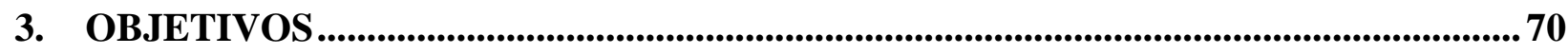

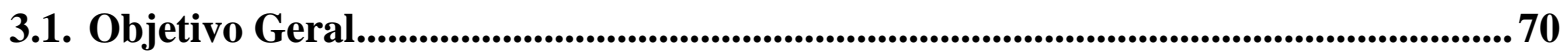

3.2. Objetivos Específicos ..................................................................................................... 70

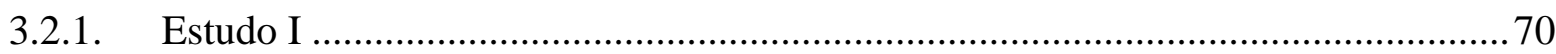

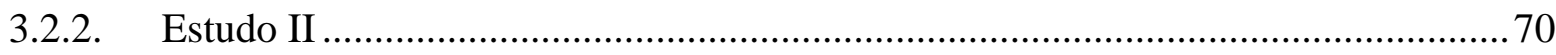

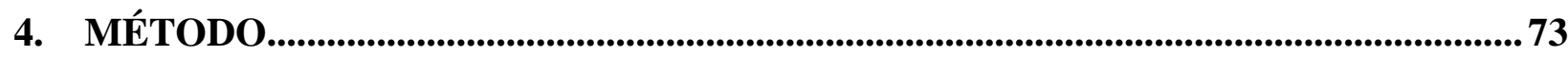

4.1. Delineamento metodológico ............................................................................................73

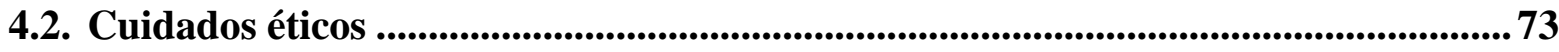

4.3. ESTUDO I - Perfis de regulação emocional e sua relação com variáveis afetivas. 75

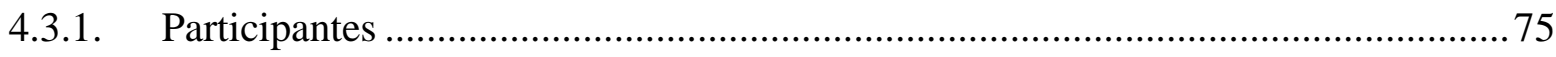

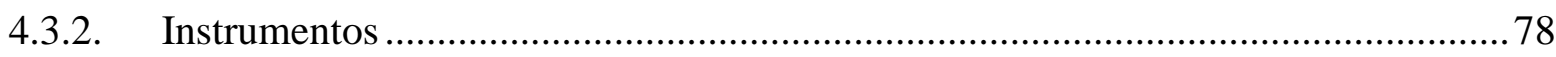

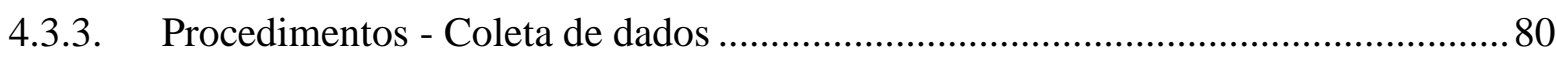

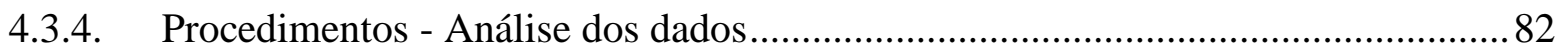

4.4. Estudo II - Relação entre Tomada de Decisão e Regulação Emocional................... 84

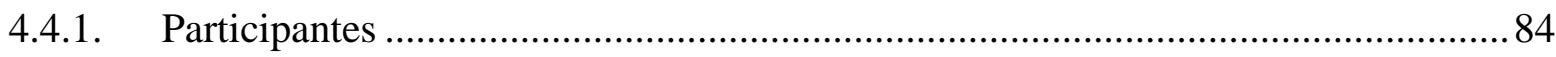

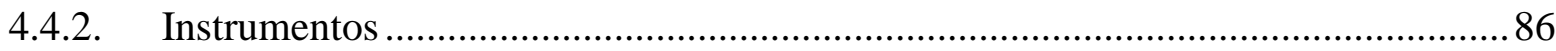

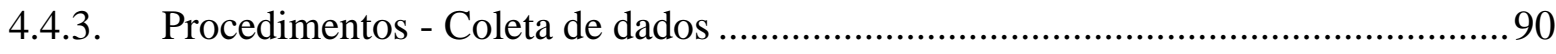

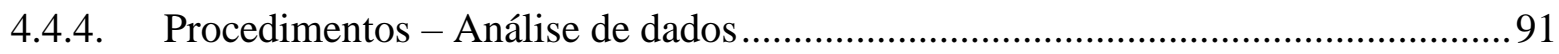

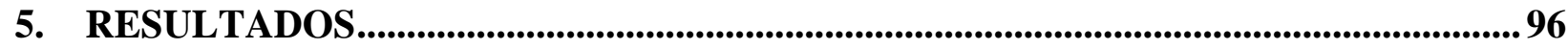

4.1. Resultados relativos à precisão dos instrumentos avaliativos......................................96 


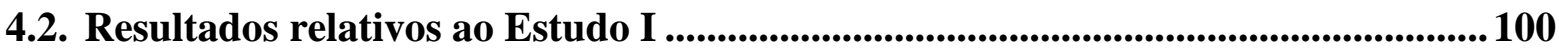

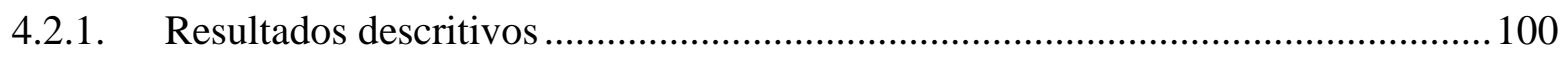

4.2.2. Análises relativas a perfis latentes de regulação emocional ............................... 102

4.3. Resultados relativos ao Estudo II..................................................................... 110

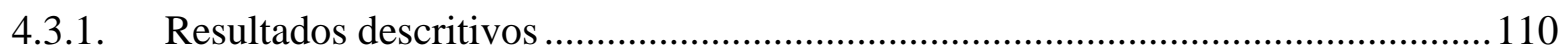

4.3.2. Análises de associações entre variáveis do mesmo domínio ............................... 118

4.3.3. Relações entre variáveis de diferentes domínios.............................................. 124

4.3.4. Relação entre indicadores de tomada de decisão e perfis de regulação emocional 132

6. DISCUSSÃO

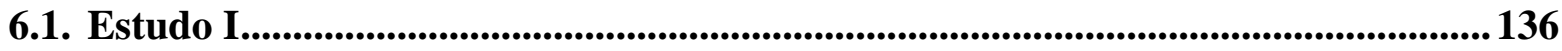

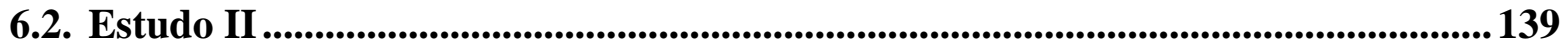

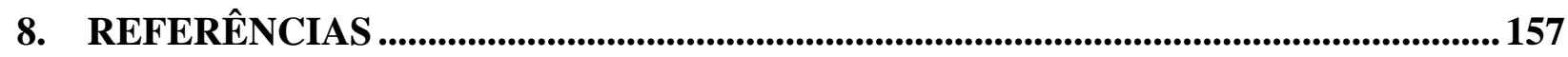

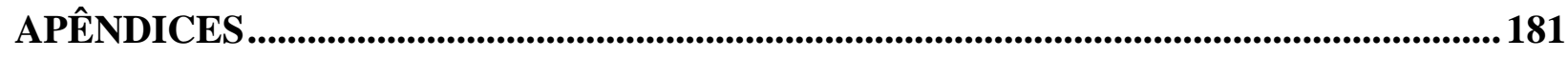

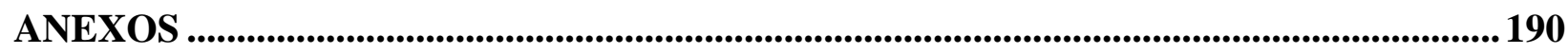




\section{APRESENTAC̄̃̃O}

Dizem que não é o pesquisador que escolhe seu objeto de estudo, mas sim o objeto que escolhe o pesquisador. Também é comum o comentário de que se diga que a pesquisa tem uma implicação profunda para o próprio pesquisador. Diante dessas afirmações, refleti sobre quais as motivações que fundamentam, entre tantas outras possibilidades, as escolhas que tomei no curso dessa pesquisa.

Certamente o desejo de fazer pesquisa é muito antigo. Em minha trajetória, ainda criança na escola pública, com todos os seus percalços, a curiosidade por entender o mundo já estava presente nos livros de arqueologia roubados da estante de minha mãe. E é talvez nessa época, que estejam as raízes mais antigas da curiosidade por problemas de tomada de decisão e regulação de emoções.

Ainda na quinta série, experimentei o dilema que pode ser considerado a memória mais remota que tenho da necessidade de regular emoções ao tomar uma decisão. Nessa época, estudando em escola longe de casa, tinha que pegar ônibus todos os dias. Minha avó, alheia aos dilemas que a vida impõe a um pré-adolescente dos anos 1990, me entregava o dinheiro para todas as passagens de ônibus da semana.

Para uma mente racional, a questão era simples: o dinheiro daria para uma semana de idas e vindas até a escola que ficava no centro da cidade. Porém, para a mente de um garoto de 12 anos havia um grande desafio, não contabilizado pela minha avó. A escola tinha uma cantina, em que as crianças mais abastadas compravam o próprio lanche. Também havia uma banca de revista entre a parada de ônibus e o portão da escola. Talvez a questão nunca tenha passado pela cabeça de minha avó, mas como fazer o dinheiro render quando tantas tentações estavam no caminho?

Algumas vezes, a vontade de comer um lanche diferente era mais forte do que a percepção de que de casa até a escola eram duas horas de caminhada. Outras vezes, a vontade de comprar a nova revista com os heróis da infância era mais forte do que a percepção de que de casa até a escola eram duas horas de caminhada...Em algumas semanas, não gastar o dinheiro era uma verdadeira batalha. Emoções surgiam, quer eu me privasse de uma revista, quer eu comprasse e tivesse que lidar com o caminho de volta para casa. Em todo caso, as escolhas tinham prós e contras, recompensas e consequências.

Já na pós-graduação, o interesse por compreender processos cognitivos e afetivos tomou forma concreta, resultando no envolvimento com pesquisas cujo escopo buscava integrar aspectos relacionados à percepção de emoções e processos de regulação emocional. Nesse 
sentido, a presente tese é fruto do caminho e curiosidades alimentados por muitas experiências pessoais e incentivo por parte daqueles que conviveram comigo ao longo da formação como pesquisador.

Nesse texto, na introdução, serão apresentadas questões gerais sobre regulação emocional, tomada de decisões e personalidade que surgiram ao longo das últimas décadas e que apontaram para a necessidade de integração entre diversas disciplinas. Inicialmente apresentamos, brevemente, os modelos oriundos da economia e matemática que sustentaram o conhecimento sobre o processo de tomada de decisão e como as contribuições da psicologia e da neuropsicologia colocaram em pauta o papel de traços psicológicos (como a personalidade) estados afetivos (como as emoções) nos processos racionais. Uma linha crescente de evidências empíricas deixa claro como os processos decisórios são influenciados por processos afetivos bem como os influenciam. Dado que é muito comum que indivíduos empreguem recursos para controlar suas emoções, uma implicação lógica desse processo é que a forma como controlamos nossas emoções pode alterar nossas decisões.

$\mathrm{Na}$ fundamentação teórica, tratamos de aprofundar os conceitos fundamentais para essa pesquisa. São apresentadas as definições dos construtos teóricos, de acordo com a perspectiva a ser adotada nesse trabalho, as principais pesquisas na área, bem como uma discussão que pautou a escolha dos instrumentos de mensuração e algumas questões técnico/metodológicas relacionadas à aspectos psicométricos que precisaram ser superadas para possibilitar que o estudos fosse efetivamente conduzido. Ao final do capítulo, foram apresentados dados de uma revisão sistemática de pesquisas que tem como escopo principal a investigação integrativa dos processos de tomada de decisão, regulação emocional e de personalidade. Demonstrou-se, desse modo, a necessidade de uma perspectiva investigativa pautada em múltiplos métodos de avaliação de tais processos.

É com base nessa revisão sistematizada da literatura científica que foram traçados os objetivos deste estudo e as principais hipóteses de trabalho que buscamos apresentar no capítulo sobre método. Nesta parte do trabalho apontamos diversas decisões técnicas tomadas durante a investigação. Em especial, a necessidade de métodos mais sofisticados de análise estatística, incluindo análises robustas para o tratamento dos dados e técnicas de estimação de precisão que fossem mais alinhadas aos instrumentos utilizados. Essa necessidade levou a desenvolvimento de respostas técnicas que estavam em aberto na literatura científica da área, e podem constituir em contribuições que não estavam no escopo inicial deste trabalho.

Por fim, os principais achados foram apresentados e discutidos de acordo com uma perspectiva integrativa, buscando recorrer à literatura científica de base comportamental, 
neuropsicológica e neurocientífica, central nos estudos sobre regulação emocional, tomada de decisão e personalidade. Os achados permitiram identificar padrões de uso (perfis) de estratégias de regulação emocional, que podem influenciar as decisões dos indivíduos em tarefas complexas de tomada de decisão em situações de ambiguidade. Além disso, os processos afetivos captados por estímulos visuais podem servir de importantes indicadores de processos interativos da personalidade, afetos e decisões.

Dessa forma, parte das questões que aquela criança, lá no início do caminho, vivenciava, foi retomada e respondida com um nível de complexidade que ela jamais poderia antever àquela época. Entretanto, muitas questões e dúvidas ainda permanecem em aberto e espero que sirvam de estímulo para os leitores na busca por suas respostas. 
INTRODUÇÃO 


\section{INTRODUCÃ̃}

Estudos relacionando a interação entre processos cognitivos e afetivos, ou mais especificamente, entre Tomada de Decisão e Regulação Emocional tem ganhado destaque nos últimos anos, e são de fundamental importância para compreensão de comportamentos complexos relacionados à adaptação dos seres vivos ao seu meio ambiente (Loewenstein \& Lerner, 2003). Apesar disso, compreendê-los como processos interdependentes não tem sido a prática durante os últimos dois milênios, mesmo no campo científico e, em especial no campo da psicologia (Lazarus, 1999; Loewenstein \& Lerner, 2003; Zajonc, 1980).

O ponto de partida para essa aparente relação antagônica entre os conceitos pode ser rastreado até o movimento da Filosofia Estoica, cuja tese era de que humores e estados emocionais eram características irracionais e primitivas, devendo ser evitadas por aqueles que quisessem se tornar sábios, privilegiando o uso da razão como aspecto superior da experiência humana. Tais preceitos encontram-se também na filosofia platônica e aristotélica e, posteriormente, influenciaram Tomás de Aquino, a visão do catolicismo e a cultura ocidental de maneira que, mesmo no campo científico, está visão pode ser observada (Lazarus, 1999).

Entretanto, diferentes áreas científicas demonstram a necessidade de estudar ambos os processos em interação. Por exemplo, no campo da Economia observou-se a necessidade de levar em consideração os processos afetivos durante a tomada de decisão. Os modelos econômicos e matemáticos que dominaram a temática durante décadas, propunham que ao tomar decisões os indivíduos fariam um elaborado cálculo de suas opções e sempre escolheriam a que trouxesse mais benefícios. Essa linha teórica conhecida como Teoria do Valor Esperado - TVE que foca no conceito de utilidade das decisões (Von Neumann \& Morgenstern, 1945), foi bastante questionada, pois aparentemente os tomadores de decisões agiam irracionalmente em diversas situações, contrariando as previsões da teoria.

Os trabalhos de Kahneman e Tversky (2013) demonstraram que, em diversas situações, a ideia de "agente racional" não se ajustava aos dados empíricos. Apontaram que erros sistemáticos durante processos de Julgamento e Tomada de Decisões eram cometidos, mesmo por especialistas, o que abriu caminho para a inclusão de processos psicológicos no estudo da tomada de decisão, dando origem a Teoria do Prospecto. A ideia geral é que dois sistemas, simultaneamente, avaliam as situações que envolvem julgamentos e tomada de decisão, propostos como Sistema 1 e Sistema 2.

O Sistema 1 seria baseado em atalhos cognitivos, chamados vieses ou heurísticas, que ocorreriam de forma sistemática tornando o julgamento das situações rápido e intuitivo, sendo 
influenciado por processos cognitivos automáticos, muitos deles com bases neurais ligados a processos afetivos. O Sistema 2, seria um mecanismo deliberativo, lento e voltado para análise mais consciente e, por isso, passível de monitoramento. Dessa forma, ambos os sistemas atuariam nas diversas situações em que os indivíduos tomam decisões (Eysenck \& Keane, 2017; Kahneman, 2003).

Os trabalhos do neurologista Damásio (2012) também ofereceram suporte à noção de que Tomada de Decisão e emoções são processos em interação. A partir de casos clínicos, o pesquisador observou que pacientes com lesões específicas em regiões cerebrais relacionadas aos processos afetivos, apresentavam prejuízos em tarefas diárias de tomada de decisão, embora não apresentassem dificuldades cognitivas em testes padronizados, o que o levou a formular a Hipótese do Marcador Somático (HMS). De acordo com esta teoria, situações de ambiguidade estimulam o surgimento de "estados corporais" que depois orientam as decisões do indivíduo, sendo estes estados ligados ao processamento emocional por meio de estruturas cerebrais, como a amígdala e o córtex pré-frontal ventromedial.

Parece existir, na contemporaneidade, consenso de que fatores emocionais estão envolvidos em processos de tomada de decisão, visto que consequências de uma escolha podem envolver perdas e ganhos, com repercussões emocionais que levam a fenômenos bem documentados. Exemplos dessas repercussões seriam os processos de aversão ao risco (a tendência dos indivíduos de, em cenários de incerteza, adotarem atitudes mais conservadoras) e o viés de impacto (indivíduos superestimam o impacto que um evento negativo terá sobre a própria vida). Entretanto, as relações entre emoções e os processos cognitivos envolvidos na tomada de decisão não são lineares, mas intrinsecamente complexas (Eysenck \& Keane, 2017; Loewenstein \& Lerner, 2003).

As emoções tanto precedem as decisões (emoções antecipadas), como são consequências imediatas destas (emoções imediatas). Além disso, ambas são preditoras da satisfação com as consequências de uma decisão (Eysenck \& Keane, 2017). Assim, o que nos modelos "racionais" da tomada de decisão pode ser considerado resultado abaixo do esperado, nos modelos teóricos atuais entende-se como ativação de sistemas emocionais. Dessa forma, uma explicação integrativa das decisões humanas deve levar em consideração os estados afetivos (Grecucci \& Sanfey, 2014).

A literatura científica da área aponta fortes associações entre os construtos Tomada de Decisão e Regulação Emocional (Grecucci \& Sanfey, 2014; Mitchell, 2011). Os achados empíricos evidenciam que emoções desagradáveis se associam a baixa autoconfiança, maior aversão a riscos e hipervigilância. Por outro lado, emoções positivas e prazerosas vinculam-se a 
maiores níveis de autoconfiança, otimismo e cooperação entre indivíduos. Na medida em que predomina uma diretriz emocional (positiva ou negativa) e esta diretriz varia em intensidade (Hackenbracht \& Gasper, 2013), o indivíduo tenderá a ser por ela influenciado, sendo relevante examinar os processos cotidianos de regulação dos afetos conduzidos nos mais variados contextos da vida.

Com frequência, diante de experiências emocionais intensas, ou mesmo desagradáveis, os indivíduos podem sentir a necessidade de regular tais vivências. O controle exercido para modificar as emoções ficou conhecido como processo de regulação emocional (Gross, 2014). Constitui um dos diversos fenômenos relacionados aos processos afetivos, compreendendo estratégias para modificar a influência das emoções sobre os comportamentos. Tem, portanto, valor adaptativo para os indivíduos, com impacto sobre cognições, qualidade de vida e eventuais psicopatologias (Suchy, 2011).

A Regulação Emocional tem importante potencial para explanar determinados fenômenos relativos à forma como os indivíduos tomam decisões, uma vez que, ao modificar a experiência emocional, esta pode alterar escolhas (Grecucci \& Sanfey, 2014). Apesar disso, estudos empíricos que exploraram o potencial explicativo que o controle das emoções pode exercer sobre as decisões são reduzidos, embora diversos trabalhos teóricos apontem esta relação (Heilman, et al., 2010; Mitchell, 2011).

Em uma revisão da literatura científica sobre diferenças individuais nos estudos acerca da tomada de decisão, Mohammed e Schwall (2009) observaram que, historicamente, houve relutância em incluir variáveis psicológicas na formalização de teorias sobre processo de julgamento e tomada de decisão. Isso porque desvios sistemáticos das previsões teóricas foram interpretados como erros de julgamento e não como parte do processo de decisão. Apesar disso, reconheceu-se a influência de pelo menos três áreas ligadas a diferenças individuais nas Tomadas de Decisão, além dos processos afetivos: variáveis cognitivas, motivacionais e de personalidade (Mohammed \& Schwall, 2009).

Foi possível identificar estilos cognitivos como variáveis relacionadas a preferências por tarefas complexas ou simples, estratégias racionais ou intuitivas para tomada de decisão, necessidade de cognição e tolerância à ambiguidade. No tocante a variáveis motivacionais, geralmente se destaca o nível de atividade individual, podendo estar orientado para ação ou para seu status atual, mantendo suas intenções, evitar procrastinação ou persistir frente ao fracasso. Por fim, variáveis de personalidade parecem estar relacionadas a fenômenos como aversão ao risco versus abertura a novas experiências, impulsividade, autoestima, entre outras (Mohammed \& Schwall, 2009). 
Dada a complexidade do construto personalidade, Mohammed e Schewall (2009) argumentam que instrumentos de avaliação focados em seus componentes (traços de personalidade), tais como os baseados no Modelo do Big Five (McCrae \& Costa, 2008), não identificam variáveis relevantes para os processos de tomada de decisão. Isso porque, além de focarem em grupos heterogêneos de características para formar fatores, esse tipo de instrumental apresenta limites para indicar "estados" que podem estar por trás de inclinações para determinadas escolhas durante tarefas de tomada de decisão. Por tanto, estes autores estimulam os pesquisadores a buscarem alternativas técnicas para avaliar variáveis associadas a personalidade, caminhando além do Modelo Big Five e métodos de autorrelato.

Para lidar com esse desafio técnico-teórico, o recurso aos métodos projetivos de avaliação psicológica tem relevante papel no estudo de processos funcionais da personalidade (Bornstein, 2015a; Meyer, 2017). Notadamente, o Método de Rorschach (Rorschach, 1942), tradicionalmente, constitui instrumento capaz de oferecer diversos e complexos indicadores, tanto relacionados a características estáveis da personalidade (variáveis estruturais) quanto transitórias (variáveis dinâmicas, funcionais) (Bornstein, 2015a; Pasian, 2010). Trata-se de método avaliativo capaz de fornecer informações da dinâmica entre processos cognitivos e afetivos (Bornstein, 2015a, 2015b; Muzio, 2016), como funções executivas em suas relações com afetos (Clyne, 2000), processos de decisão e variáveis da personalidade (Tibon-Czopp, Appel, \& Zeligman, 2016) e regulação emocional (relação entre controle cognitivo e afetos) (Malone et al., 2013).

Em síntese, pode-se depreender a existência de processos psicológicos complexos que relacionam a tomada de decisão com a regulação emocional e a personalidade dos indivíduos. O relacionamento entre esses processos de natureza psicológica foi sistematicamente ignorado pelas teorias econômicas clássicas voltadas ao processo de tomada de decisão, que idealizavam um modelo de agente racional que maximizaria a utilidade das escolhas humanas. Nesse contexto devem ser destacadas aqui as investigações científicas realizadas por Kahneman e Tversky (2013), as quais tiveram como principal contribuição identificar características psicológicas envolvidas nas decisões, porém, a variabilidade individual foi interpretada como erro humano. Somente mais tarde, essas supostas falhas nos processos decisórios foram identificadas como valiosas fontes de informação para compreender como as pessoas tomam decisões no mundo real. A partir desse movimento, os processos de julgamento humano e de tomada de decisão foram identificados como processos psicológicos superiores complexos, abrindo perspectivas para novas pesquisas na área, integrando diferentes perspectivas teóricas e técnicas (Mohammed \& Schwall, 2009). 
No campo científico, no entanto, o debate sobre a melhor abordagem para estudar relações complexas, tais como as relativas aos objetos de estudo aqui propostos, não é conclusivo. Uma das possibilidades para a ciência psicológica se constituiria em abordagem com múltiplas fontes de informação, conhecida como multimétodos (Eid \& Diener, 2006). Os fenômenos psicológicos apresentam múltiplos componentes (fisiológicos, fenomenológicos, cognitivos, sociais), organizados em diferentes níveis de análise (biológicos, psicológicos, sociais, culturais), sendo necessárias múltiplas fontes de informação para estudar suas relações (Eid \& Diener, 2006). No caso de processos de tomada de decisão, regulação emocional e personalidade, Lempert e Phelps (2014) sugerem que a investigação necessita levar em consideração, não apenas múltiplos níveis, mas também múltiplos componentes da cada uma das variáveis psicológicas de maneira integrada.

Em um estudo visando investigar a relação entre regulação emocional e tomada de decisão em situação de risco e de incerteza, Heilman et al. (2010) utilizaram estratégias de indução de emoções através da exibição de filmes, questionários de autorrelato para avaliar o estado afetivo, além de estratégias de regulação emocional e tarefas comportamentais neuropsicológicas para avaliar processos de tomada de decisões. Em estudo posterior, estes mesmos autores solicitaram que 48 estudantes respondessem a um questionário de autorrelato sobre regulação emocional, realizassem uma tarefa cognitiva de tomada de decisão e posteriormente realizaram uma entrevista estruturada para avaliar a aprendizagem dos participantes durante a tarefa de tomada de decisão.

Ao tentar compreender as bases neurais da tomada de decisão e regulação de emoções, Martin e Delgado (2011) também utilizaram estratégias investigativas diversas. Após dividirem os 34 participantes em dois grupos, ensinaram aos mesmos diferentes estratégias de regulação emocional. Em seguida, pediram que os sujeitos realizassem escolhas que levavam a ganhos e perdas dentro de uma máquina de ressonância magnética funcional. Dessa forma, os pesquisadores utilizaram dados comportamentais e biológicos na investigação. Em outro experimento para investigar o impacto que a regulação emocional tem sobre a aversão ao risco, Sokol-Hessner, Camerer e Phelps (2013) solicitaram que 47 colaboradores realizassem uma tarefa de tomada de decisão enquanto o nível de atividade da sua amígdala era aferido por ressonância magnética funcional.

Acerca da associação entre tomada de decisão e personalidade, Mohammed e Schwall (2009) comentam que a maioria dos estudos da área são realizados com escalas de avaliação baseadas no Modelo Big Five, utilizando instrumentos de autorrelato. Estes autores sugerem que esta é uma limitação na área, dado que processos situacionais e menos estáveis de personalidade 
interagem contribuindo com os processos de tomada de decisão, sendo necessários múltiplos métodos articulados para sua adequada investigação.

Dessa forma, dada a complexidade que o fenômeno da tomada de decisão possui em suas associações com os processos de regulação emocional e variáveis da personalidade, o presente estudo buscou avançar nesse campo investigativo e avaliar, de modo empírico e sistematizado, a possível interação entre esse conjunto de variáveis. Certamente foi necessário selecionar recortes das mesmas, pautados em evidências da literatura científica da área, a partir de uma abordagem multimétodos. O trabalho, portanto, foi estruturado a partir do uso de diversos instrumentos de avaliação psicológica, incluindo processos de autorrelato, tarefas neuropsicológicas e métodos projetivos, buscando integrar estas diferentes fontes de informação em um modelo analítico sobre as tomadas de decisão das pessoas. 


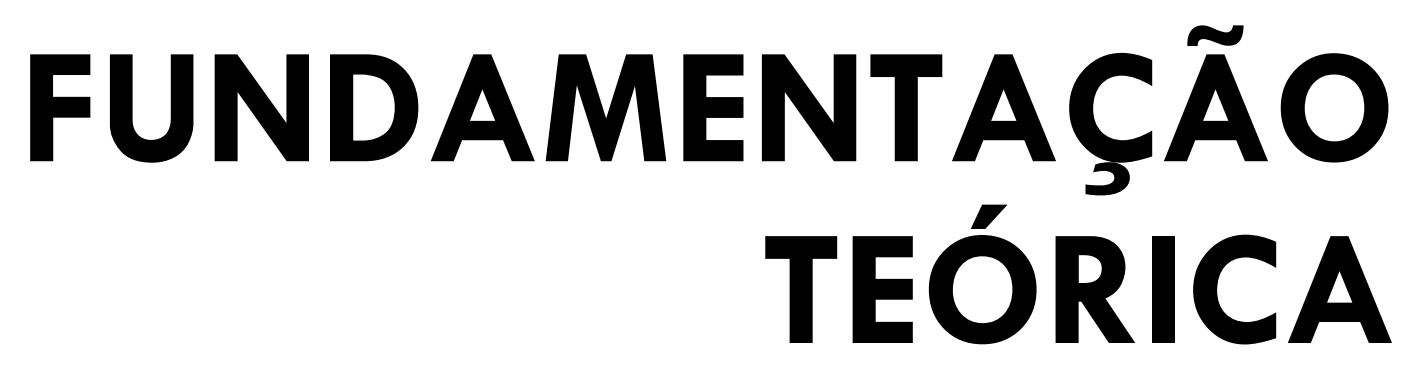




\section{FUNDAMENTACÃ̃ TEÓRICA}

Para a adequada organização deste trabalho, optou-se por iniciar a fundamentação teórica pela definição dos construtos de Tomada de Decisão, regulação emocional e personalidade, buscando destacar o conceito e as principais questões de interesse para esta pesquisa. Também são apresentadas as principais características do processo de avaliação psicológica, bem como breve descrição técnico-científica dos instrumentos utilizados para operacionalizar a presente investigação. Em seguida, apresentamos os resultados da revisão sistemática acerca dos estudos que buscam avaliar o relacionamento conjunto das três variáveis de interesse.

\subsection{Tomada de Decisão}

A Tomada de Decisão pode ser definida como o processo de avaliação e de seleção de uma dentre várias opções possíveis e disponíveis ao indivíduo em determinado contexto sociocultural, numa etapa de sua vida. As consequências (pessoais) advindas dessas tomadas de decisão determinam a qualidade do processo (Eysenck \& Keane, 2017; Kluwe-Schiavon et al., 2018). Classicamente são reconhecidas três importantes variáveis envolvidas no processo decisório: a complexidade da decisão/tarefa, o ambiente em que a decisão deve ser tomada, ou seja, seu contexto e, por fim, as diferenças individuais, características dos tomadores de decisão (Hamilton, Shih, \& Mohammed, 2016; Mohammed \& Schwall, 2009).

Diversos modelos teóricos, em variadas áreas científicas, surgiram para compreender e tentar explicar como as pessoas tomam decisões. Historicamente, um dos primeiros modelos conhecidos adveio da área da Matemática e Economia, pautando-se na ideia de que os indivíduos tomariam decisões com base nas consequências de suas ações, concebendo que a pessoa seria completamente racional ao avaliar suas opções e escolheria sempre a melhor. Essa proposta ficou conhecida como Teoria do Valor Esperado - TVE (Von Neumann \& Morgenstern, 1945).

Posteriormente, os trabalhos de Kahneman e Tversky (2013) colocaram em dúvida a hegemonia teórica da TVE, ao demonstrar que, em diversas situações da vida, a ideia de agente racional não fazia sentido. Propuseram, então, a Teoria do Prospecto. Eles apontaram que as decisões humanas são pautadas por heurísticas e vieses cognitivos e nem sempre os indivíduos tomavam a melhor decisão do ponto de vista racional, sendo claramente influenciados por suas características individuais. Nas considerações de Mohammed e Schwall (2009), apesar do avanço que a Teoria do Prospecto introduziu na compreensão dos processos de tomada de decisão, inserindo a discussão sobre a importância de variáveis individuais (como o processo 
emocional), a variabilidade observada nas decisões individuais foi, frequentemente, tratada como erro no processo e não como importante fonte de informação. Os fatores emocionais passaram a constituir, desse modo, relevante variável nos estudos sobre Tomada de Decisão. Em síntese: toda decisão tem, como consequência, uma resposta afetiva a ela atrelada (Eysenck \& Keane, 2017).

Kermer, Driver-Linn, Wilson e Gilbert (2006) identificaram que pessoas que antecipam possíveis perdas associadas a escolhas, tendem a reações emocionais negativas e, com isso, favorecem aumento da aversão à eventual perda, interferindo em seu processo analítico a respeito da decisão a ser tomada. Além disso, Marroquín, Boyle, Nolen-Hoeksema e Stanton (2016) demonstraram que a forma como os indivíduos incorporam emoções aos seus processos cognitivos influencia sua visão de futuro. Estes achados empíricos, entre outros, sustentam existir sobreposição entre as vias neurais relacionadas aos processos de Tomada de Decisão e de geração e Regulação de Emoções. Em revisão da literatura científica da área, Mitchell (2011) encontrou fortes evidências de que grande parte das estruturas neurais, relativas aos processos de Tomada de Decisão, seria compartilhada por processos relacionados aos afetos.

Em consonância a estes achados, uma terceira teoria citada no campo dos processos decisórios trata justamente da intersecção entre emoção e cognição: a Hipótese do Marcador Somático (HMS) (Damásio, 2012). De acordo com a HMS, situações de ambiguidade estimulam o surgimento de "estados corporais" (marcadores somáticos), que são processados em regiões cerebrais específicas, especialmente o córtex pré-frontal dorsolateral, medial e orbito-frontal (Bechara et. al., 1999, 2000). Posteriormente, estas informações orientam as decisões do indivíduo, a partir da influência destes processos fisiológicos e afetivos. O fato de mecanismos afetivos estarem conectados a regiões cerebrais ligadas às funções executivas levou ao desenvolvimento da perspectiva de funções executivas "quentes" e "frias".

Estudos iniciais com pacientes que apresentavam lesões nas três regiões supracitadas indicavam preservação das funções cognitivas como atenção, memória e inteligência, porém com grandes dificuldades de planejamento e tomada de decisões cotidianas. Sinalizavam uma espécie de miopia para o futuro, apontando a relação destas áreas com o processamento emocional (Bechara et al., 1994, 2000). Posteriormente, o estudo sobre desenvolvimento destas funções ligadas à afetividade em adolescentes apontou diferentes trajetórias desenvolvimentais ao longo do ciclo vital, reforçando a possibilidade de dois sistemas ligados às funções executivas (Peterson \& Welsh, 2014).

O conjunto dessas duas perspectivas investigativas evidenciou a existência de um grupo de habilidades de flexibilidade cognitiva, memória de trabalho e controle inibitório, as quais 
ficaram conhecidas como funções executivas "frias". Por outro lado, habilidades como retardar a gratificação, autorregulação afetiva, tomada de decisão em situações de risco ficaram relacionadas às funções executivas denominadas "quentes" (Peterson \& Welsh, 2014). Grande parte da pesquisa empírica para testar o modelo proposto pela HMS para Tomada de Decisão utiliza o Iowa Gambling Task (IGT) como recurso técnico para investigar os processos internos do indivíduo. Constitui uma das tarefas neuropsicológicas mais utilizadas na avaliação de aspectos relativos à Tomada de Decisão baseada em desempenho (Schmitz et al., 2018).

O Iowa Gambling Task (IGT) foi desenvolvido por Bechara, Damasio, Damasio e Anderson (1994) com o objetivo de avaliar processos de tomada de decisão em pacientes com lesão no córtex pré-frontal, que apresentavam dificuldades em cognição social e escolhas orientadas para o futuro, mas não demonstravam dificuldades em outros processos cognitivos (Bechara et al., 2000). Nesse instrumento, o indivíduo passa por situação que simula um jogo em que deve escolher cartas de quatro baralhos diferentes (A, B, C e D). O respondente inicia a atividade com uma quantia de dinheiro e tem como objetivo acumular a maior quantidade de dinheiro possível e evitar perdas durante a seleção de 100 cartas. Cada baralho apresenta recompensas e punições que são desconhecidas pelo indivíduo e são caracterizados como baralhos vantajosos (C e D) ou desvantajosos (A e B) (Areias et al., 2013; Bechara, 2004; Verdejo-Garcia et al., 2006).

O indivíduo deve escolher uma carta por vez e receberá a recompensa ou a punição, a partir do critério interno da atividade, automaticamente oferecida a ele. Seu comportamento durante a tarefa deve ser guiado apenas pelo feedback das perdas e dos ganhos, oferecido pelo aplicador. O desempenho é avaliado a partir de duas perspectivas: escores primários e escores descritivos (Bechara, 2007, 2016). Os escores primários avaliam a relação entre as escolhas vantajosas e desvantajosas ao longo da tarefa e se dá pelo cálculo $[(\mathrm{C}+\mathrm{D})-(\mathrm{A}+\mathrm{B})]$. O principal escore é a Tendência Geral, retirada do desempenho diante das 100 cartas selecionadas. Posteriormente, com o objetivo de avaliar a aprendizagem do indivíduo ao longo da tarefa, são calculados escores para cinco blocos de 20 cartas, utilizando o mesmo cálculo para a variável Tendência Geral. Os escores descritivos estão relacionados à quantidade de cartas que o indivíduo escolheu de cada baralho (Bechara, 2007, 2016). O IGT funciona, assim, como atividade para mensurar os processos de Tomada de Decisão do indivíduo, baseado em estados emocionais (Suchy, 2011).

Posteriormente o IGT foi adaptado para versão computadorizada (Bechara, 2007, 2016). Tem sido largamente utilizado em processos de investigação de possíveis déficits funcionais em indivíduos com lesões cerebrais (Bechara et al., 1994; Cardoso et al., 2014), com diversos 
transtornos psiquiátricos (Filardi et al., 2011; Must et al., 2013; Sallum et al., 2013), comportamentos de risco e abuso de substâncias (Kovács et al., 2017; Xiao et al., 2013) e também em pessoas saudáveis (Bull et al., 2015).

No Brasil, a adaptação transcultural do IGT consta no trabalho de Malloy-Diniz et al. (2008). Nesse estudo, os pesquisadores compararam o desempenho de três grupos de 25 adultos: um grupo respondeu a versão inglesa do IGT, um segundo grupo a versão em português e um terceiro grupo (clínico) com diagnóstico de Transtorno de Déficit de Atenção e Hiperatividade (TDAH) respondeu a adaptação em português. Os resultados apontaram inexistir diferenças estatisticamente significativas entre primeiro e segundo grupos de adultos, ofertando similaridade técnica às duas versões do IGT. Por sua vez, a comparação com o grupo clínico demonstrou particularidades relevantes no desempenho na tarefa, mostrando a sensibilidade do instrumento em identificar dificuldades no processamento decisório. Estes resultados demonstraram que a adaptação do instrumento para o contexto brasileiro foi adequada, conseguindo diferenciar grupos de adultos com dificuldades na tomada de decisão.

Apesar de sua ampla utilização em pesquisas no mundo, o instrumento recebeu críticas importantes quanto aos indicadores psicométricos que sustentam as interpretações dos seus escores (Buelow \& Suhr, 2009; Gansler, Jerram, et al., 2011; C.-H. Lin et al., 2013). Especificamente, em uma revisão compreensiva da literatura científica da área, Buelow e Suhr (2009) apontaram questões quanto à validade de construto, ausência de informações acerca da precisão do IGT e sobre a relação de seus indicadores com variáveis de personalidade e afetividade. O primeiro questionamento se refere a quais processos relacionados à Tomada de Decisão estão envolvidos nas respostas ao IGT. As autoras argumentaram que, condizente com a teoria HMS, tanto processos cognitivos "frios", quanto processos afetivos "quentes" estariam ligados ao desempenho na tarefa. Os demais questionamentos fomentaram diferentes estratégias de investigação para responder à ausência de estudos de precisão, bem como as relações com variáveis afetivas de personalidade.

A investigação realizada por Brand, Recknor, Grabenhorst e Bechara (2007) estudou indivíduos saudáveis $(\mathrm{n}=97)$ para avaliar se a Tomada de Decisão (a partir do IGT) estaria de alguma forma associada com diferentes medidas de funcionamento cognitivo. Observaram correlações negativas entre os últimos blocos no IGT e variáveis do Wisconsin Card Sort Test (WCST) que avalia funções executivas, mas não encontraram correlações com indicadores do potencial de inteligência. Também não identificaram associações entre resultados na fase inicial do IGT com sinais do funcionamento executivo (a partir do WCST). Esses achados levaram a hipótese de existência de dois processos distintos de Tomada de Decisão avaliados pelo IGT: no 
início, quando a pessoa ainda não desenvolveu conhecimento sobre a tarefa, avaliaria Tomada de Decisão em situação de ambiguidade. Já mais adiante, quando o indivíduo tem experiência com o problema, avaliaria Tomada de Decisão em situação de risco, constituindo contextos específicos para escolhas, daí possíveis diferenças no comportamento individual ao longo da atividade. Ilustraram, dessa forma, influência do contexto no processo de Tomada de Decisão, mesmo dentro de uma prova específica como o IGT, sendo necessário levar em consideração essas informações na interpretação dos achados.

Outro estudo que procurou examinar o embasamento teórico-técnico do IGT foi o desenvolvido por Buelow e Blaine (2015). Investigaram a relação entre diferentes medidas de Tomada de Decisão, buscando indicadores de validade para o IGT. Por meio de análise de componentes principais $(\mathrm{n}=112)$ de seus achados, identificaram que o IGT avalia diferentes componentes do processo de Tomada de Decisão, comparativamente a outros instrumentos utilizados. Em uma análise fatorial exploratória $(n=108)$ e posteriormente em uma análise confirmatória $(n=170)$, os pesquisadores reportaram que os blocos 2 a 5 do IGT carregaram fortemente em um fator isolado, enquanto o bloco 1 apresentou carga fatorial integrada ao escore do Columbia Card Task (CCT). Concluíram que o IGT avalia aspectos diferenciados da Tomada de Decisão, as quais não se sobrepõem a outras medidas já existentes na literatura científica da área, apontando a necessidade de cuidados interpretativos a respeito dos seus indicadores técnicos.

No tocante às evidências de precisão do IGT, Buelow e Suhr (2009) apontaram ausência de informações sobre confiabilidade do instrumento em seu manual e também na literatura científica disponível até aquele momento. Não apenas o IGT, mas diversas medidas neuropsicológicas apresentam limitadas evidências de precisão, o que coloca dúvidas sobre seu alcance técnico (Frazen, 2002; Hedge, Powell, \& Sumner, 2018; Howieson \& Howieson, 2019). No Brasil, o trabalho realizado por Cardoso et al. (2010) buscou avaliar a estabilidade temporal a partir das respostas de cinquenta universitários. Os participantes responderam ao instrumento em duas sessões com intervalo de um a seis meses. As análises de correlação indicaram relação positiva moderada $(r=0,43, p=0,002)$ entre dois momentos avaliativos (fidedignidade testereteste). Os autores argumentaram que, a despeito das dificuldades de estabelecer estudos de estabilidade temporal (precisão) com o IGT, seus resultados aproximam-se aos encontrados em outras medidas consideradas padrão-ouro na avaliação das Funções Executivas, atendendo às expectativas técnicas de um instrumento de medida psicológica.

Gansler, Jerram, Vannorsdall e Schretlen (2011) também buscaram avaliar evidências de validade de construto do IGT a partir de sua relação com outras medidas de funções executivas. 
Os pesquisadores solicitaram que adultos da população em geral americana $(n=214)$ respondessem a uma bateria neuropsicológica. Em seguida, os autores estimaram a consistência interna do IGT por meio da correlação de Pearson entre os dados de seus blocos de itens. Os resultados indicaram correlação em torno de 0,219 a 0,547entre os diferentes escores, apontando baixa consistência interna no instrumento como um todo. Por sua vez, Lin et al. (2013) compararam os resultados de 72 universitários em três aplicações consecutivas do IGT durante a mesma sessão, com intervalo de alguns minutos, observando diferenças significativas entre os baralhos A e B, mas não para os escores totais, nem para os blocos, o que foi interpretado como evidência de um efeito de aprendizagem durante a tarefa.

No contexto da China e com estudantes universitários $(n=40)$, na faixa etária entre 19 a 22 anos, Xu, Korczykowski, Zhu e Rao (2013) investigaram a correlação de diferentes aplicações do IGT, com intervalo de duas semanas entre as mesmas. Os resultados indicaram baixa correlação entre resultados da primeira e da segunda aplicação do IGT, mas correlação forte entre a segunda e a terceira. Os autores interpretaram estes achados como evidência de efeito forte da prática, o que limitaria a precisão do instrumento. Posteriormente, Buelow e Barnhart (2018) também investigaram a fidedignidade (método teste-reteste) do IGT em amostra de 98 universitários americanos, relacionando os achados com outras medidas de Tomada de Decisão. Os resultados indicaram fraca correlação entre os escores da primeira aplicação e da segunda do IGT, sinalizando limite na possibilidade informativa desse instrumento no tocante à estabilidade dos processos envolvidos na Tomada de Decisão.

Muitos estudos relativos à precisão do IGT utilizaram primordialmente o método do testereteste. Entretanto, é fundamental que um método de estimação seja ponderado em relação ao construto e aos fenômenos psicológicos ali envolvidos, dificilmente estáveis como desejado pelos princípios psicométricos. Essa ponderação de resultados no campo dos instrumentos neuropsicológicos permanece um desafio constante (Frazen, 2002; Hedge et al., 2018). Segundo Frazen (2002), o uso do produto momento de Pearson permanece como mais utilizado, no entanto, uma estimativa mais eficiente estaria ligada a estimadores que levam em consideração a variância observada nos escores. Hedge et al. (2018) destacaram que mesmo as medidas cognitivas, bem consolidadas experimentalmente, costumam apresentar baixa correlação no teste-reteste.

Além disso, com relação ao construto, Frazen (2002) indica que as próprias características deste, como estabilidade ou instabilidade, podem influenciar os indicadores de precisão a depender do método utilizado. Slick (2006) observa que, embora algumas medidas possam ser influenciadas pelo efeito de exposição, testes relacionados à resolução de problemas podem não 
refletir o mesmo construto em aplicações diferentes. Dessa forma, baseado na ideia de que a correlação entre diferentes aplicações de um mesmo instrumento pode não ser uma boa estimativa, alternativas técnicas precisam ser pensadas para examinar as características de precisão de instrumentos neuropsicológicos.

Por fim, há que se considerar a influência de variáveis afetivas e de personalidade nos resultados do IGT, como apontado por Buelow e Suhr (2009). Pode-se inicialmente destacar o estudo realizado por Bechara, Damasion, Tranel e Damasio (1997) onde compararam o desempenho no IGT de um grupo clínico $(n=6)$ composto por pacientes com lesão cerebral na região ventromedial e um grupo controle $(n=10)$. Enquanto respondiam ao IGT, os participantes foram monitorados em sua resposta galvânica da pele (Skin Conductance Response - SCR), que é considerada uma medida de resposta afetiva (Coan \& Allen, 2007). Os resultados indicaram que durante a seleção de baralhos desvantajosos houve maior SCR nos participantes do grupo controle. Além disso, os participantes do grupo clínico apresentaram pior desempenho no IGT, o que foi interpretado pelos autores como indicador de influência afetiva no processo de seleção das cartas. Posteriormente, Wagar e Dixon (2006) confirmaram esses achados em amostra de 24 universitários do Canadá. Os participantes responderam ao IGT enquanto tinham sua SCR monitorada. Os resultados indicaram intensa ativação da resposta galvânica da pele a partir do bloco 3. Além disso, a intensidade da SCR antecipava a escolha de baralhos desvantajosos, quando comparada com a seleção dos baralhos vantajosos, e essa diferença correlacionou-se com a preferência pelo segundo grupo de escolhas (vantajosas).

Em outra série de experimentos, de Vries, Holland e Witteman, (2008) avaliaram o quanto o humor pode influenciar resultados no IGT. Um grupo de 53 estudantes universitários holandeses respondeu a um questionário sobre afetos positivos e, em seguida, ao IGT. Os resultados apontaram correlação entre humor e o bloco 2 do IGT, mas não com os demais blocos deste instrumento. No segundo experimento, 52 estudantes foram alocados a duas condições ambientais específicas. Na primeira condição, os estudantes assistiram a um filme para indução de humor positivo, e na segunda, a um filme para humor negativo. Em seguida, ambos os grupos responderam ao IGT. Os autores compararam o desempenho dos participantes e identificaram melhor desempenho no bloco 2 para o grupo de humor positivo. No terceiro experimento, os autores replicaram o segundo estudo, em outra amostra de 32 participantes. O conjunto dos resultados indicou que o estado de humor influencia as escolhas durante o processo de tomada de decisão no IGT.

Werner, Duschek e Schandry (2009) também investigaram o papel das emoções e da regulação emocional no desempenho no IGT. Os pesquisadores solicitaram que 64 jovens 
adultos de uma universidade alemã respondessem ao questionário de ansiedade-traço (State-Trait Anxiet Inventory - STAI-T), um questionário sobre regulação emocional (Scales for Emotion Experience - SEE) e ao IGT, enquanto coletavam informações da condutividade da pele em eletrocardiograma (ECG). Os pesquisadores identificaram correlação positiva e estatisticamente significativa entre ansiedade e desempenho no IGT, além de correlação negativa entre e regulação emocional e o resultado no IGT. Também observaram correlação positiva moderada entre ansiedade e dados fisiológicos, além de fraca correlação negativa entre regulação emocional e os mesmos indicadores. As conclusões do estudo indicaram que reações emocionais captadas pelo STAI-T contribuem para a resolução de problemas do IGT, enquanto o uso de estratégias de regulação emocional diminui a resposta emocional necessária para a atividades proposta pelo IGT.

Para testar o papel da regulação emocional em situação de laboratório e naturalística, Heilman, Crişan, Houser, Miclea e Miu (2010) elaboraram dois experimentos. No primeiro estudo os autores manipularam o estado afetivo dos participantes utilizando dois filmes para induzir medo e nojo (duas condições), e orientaram subgrupos a utilizaram estratégias de reavaliação cognitiva, supressão emocional e sem qualquer controle (três condições), formando um total de seis condições em que 60 participantes foram alocados aleatoriamente. Os participantes responderam a versão estendida da Escala de afetos positivos e negativos (PANAS$\mathrm{X}$ ), em seguida foram expostos aos filmes, posteriormente foram reavaliados com escalas específicas da PANAS e responderam ao Questionário de Regulação Emocional (ERQ). Em seguida, todos os participantes responderam ao IGT e a Balloon Analogue Risk Task (BART) que também avalia tomada de decisão em situação de risco. Os pesquisadores realizaram uma análise de variância sobre os resultados, constando efeito estatisticamente significativo da reavaliação cognitiva nos resultados da BART e escore mais elevado no bloco 3 do IGT. Para o segundo experimento, os pesquisadores convidaram 44 participantes logo após a realização de importantes exames acadêmicos. Como no primeiro experimento, os sujeitos responderam a PANAS-X, ERQ, BART e IGT. Os resultados da análise de variância indicaram que os participantes que apresentaram níveis elevados de afetos negativos reduziram as escolhas arriscadas no BART, enquanto os que se utilizaram mais de reavaliação cognitiva apresentaram mais comportamentos de risco. Para os resultados do IGT, os autores observaram que os indivíduos que se utilizaram de reavaliação cognitiva também apresentaram maiores escores no bloco 3, como no primeiro experimento. Em conjunto, estes resultados indicaram que a regulação emocional pode apresentar impacto nos processos de tomada de decisão avaliados pelo IGT. 
Suhr e Hammers (2010) apontam que afetos negativos e personalidade, em conjunto com dificuldades nas funções executivas, podem estar relacionados a desempenho abaixo do esperado em sujeitos normais. Para investigar essa possibilidade, os pesquisadores solicitaram que 58 adultos jovens de uma universidade americana realizassem uma bateria de rastreio e hábitos relacionados ao consumo de substâncias. Em seguida responderam a Behavior Activation Scale (BAS) que avalia busca por objetivos, a Behavior Inibition Scale (BIS) que avalia motivação para evitar situações aversivas (características de personalidade), a PANAS e, por fim, um teste de inteligência (Wechsler Abbreviated Scale of Intelligence Matrix Reasing subtest), o IGT e o WCST. Enquanto os participantes respondiam ao IGT, os níveis de oxigenação cerebral foram obtidos por meio de espectroscopia por infravermelho proximal (near-infrared spectroscopy NIRS), uma técnica de neuroimagem. Os participantes foram divididos em dois grupos, a partir do desempenho no IGT, separando-se aqueles com resultados bons e ruins. A comparação entre os grupos indicou que indicadores relativos à inteligência e à personalidade foram as variáveis com maiores diferenças entre estes agrupamentos de participantes. Além disso, o grupo com pior desempenho o IGT apresentou menor oxigenação na região pré-frontal dorsolateral direita, responsável por habilidades como flexibilidade cognitiva, planejamento e raciocínio abstrato.

Ainda com enfoque no papel que variáveis afetivas e de personalidade podem exercer sobre resultados do IGT, Buelow e Suhr (2013) pediram a 53 estudantes universitários americanos que respondessem a Behavior Activation Scale (BAS) que avalia busca por objetivos, a Behavior Inibition Scale (BIS) que avalia motivação para evitar situações aversivas, a Impulsive Sensation Seeking, uma subescala da Zuckerman-Kuhlman Personality Questionnaire que avalia busca por sensações, a PANAS e a versão computadorizada do IGT. Uma análise de variância com medidas repetidas indicou que os participantes tenderam a evitar os baralhos A e B e a selecionar o baralho C. Não foram observadas diferenças entre a seleção dos baralhos B e D. Os pesquisadores observaram correlações negativas fracas entre impulsividade e seleção do baralho D. Estes resultados foram bastante sugestivos de relação entre características de personalidade e a seleção dos baralhos no IGT (decisões em situações de risco).

De maneira geral, o conjunto de evidências disponíveis demonstra que os processos de Tomada de Decisão avaliados pelo IGT indicam importante participação de componentes afetivos e características de personalidade. O modelo da Hipótese do Marcador Somático de Damásio (2012) parece fornecer um suporte teórico promissor para explanar a relação entre as Funções Executivas e o funcionamento afetivo, visto que os processos relacionados aos afetos e, mais especificamente à regulação emocional, contribuem para a tomada de decisão (Buelow \& Suhr, 2013; Hammers \& Suhr, 2010; Heilman et al., 2010; Werner et al., 2009). 


\subsection{Regulação Emocional}

As emoções fazem parte das experiências diárias e, conforme as situações, os indivíduos sentem a necessidade de regulá-las (Gross, 2014) favorecendo ou dificultando sua adaptação aos diferentes contextos. A regulação emocional (RE) é um dentre diversos fenômenos relacionados aos processos afetivos, compreendendo estratégias para modificar a influência das emoções sobre os comportamentos. Tem, portanto, valor adaptativo para os indivíduos, com impacto sobre as cognições, a qualidade de vida e eventuais psicopatologias (Suchy, 2011).

A regulação emocional pode ser entendida como uma série de estratégias, cognitivas e/ou comportamentais utilizadas para controle da experiência emocional, seja antes do surgimento de uma emoção ou quando a mesma já se encontra em curso (Gross \& John, 2003). Dificuldades em controlar as próprias emoções estão presentes em diversas experiências emocionais negativas e em transtornos psicológicos, como na ansiedade social, transtornos de personalidade e transtornos de estresse pós-traumático, geralmente relacionando-se às dificuldades com a duração, a frequência e o tipo de emoções experimentadas (Gross, 2014; Gross \& Jazaieri, 2014). Também estão presentes em comportamentos sociais de risco (Kiekens et al., 2019), e variam ao longo do ciclo vital, tanto em função do sexo, quanto do contexto cultural (Gardener, Carr, MacGregor, \& Felmingham, 2013; Mcrae, Ochsner, Mauss, Gabrieli, \& Gross, 2008; Matsumoto, Yoo, \& Nakagawa, 2008).

Existe grande diversidade de estratégias para equilibrar a influência de uma emoção em determinado contexto social ou mesmo modificar inteiramente a experiência emocional. Comumente, tais estratégias são agrupadas em duas grandes categorias: "estratégias antecedentes", focadas em comportamentos que antecipam o surgimento de uma emoção, e estratégias "focadas na resposta", que tem por objetivo controlar uma experiência emocional já em curso (Gross, 2014; John \& Eng, 2014). Segundo Gross (2014), observam-se pelo menos cinco grupos de estratégias de regulação emocional, que se diferenciam pelo processo utilizado para modular a resposta afetiva ou por seu momento de implementação durante o processo afetivo (Figura 1). 


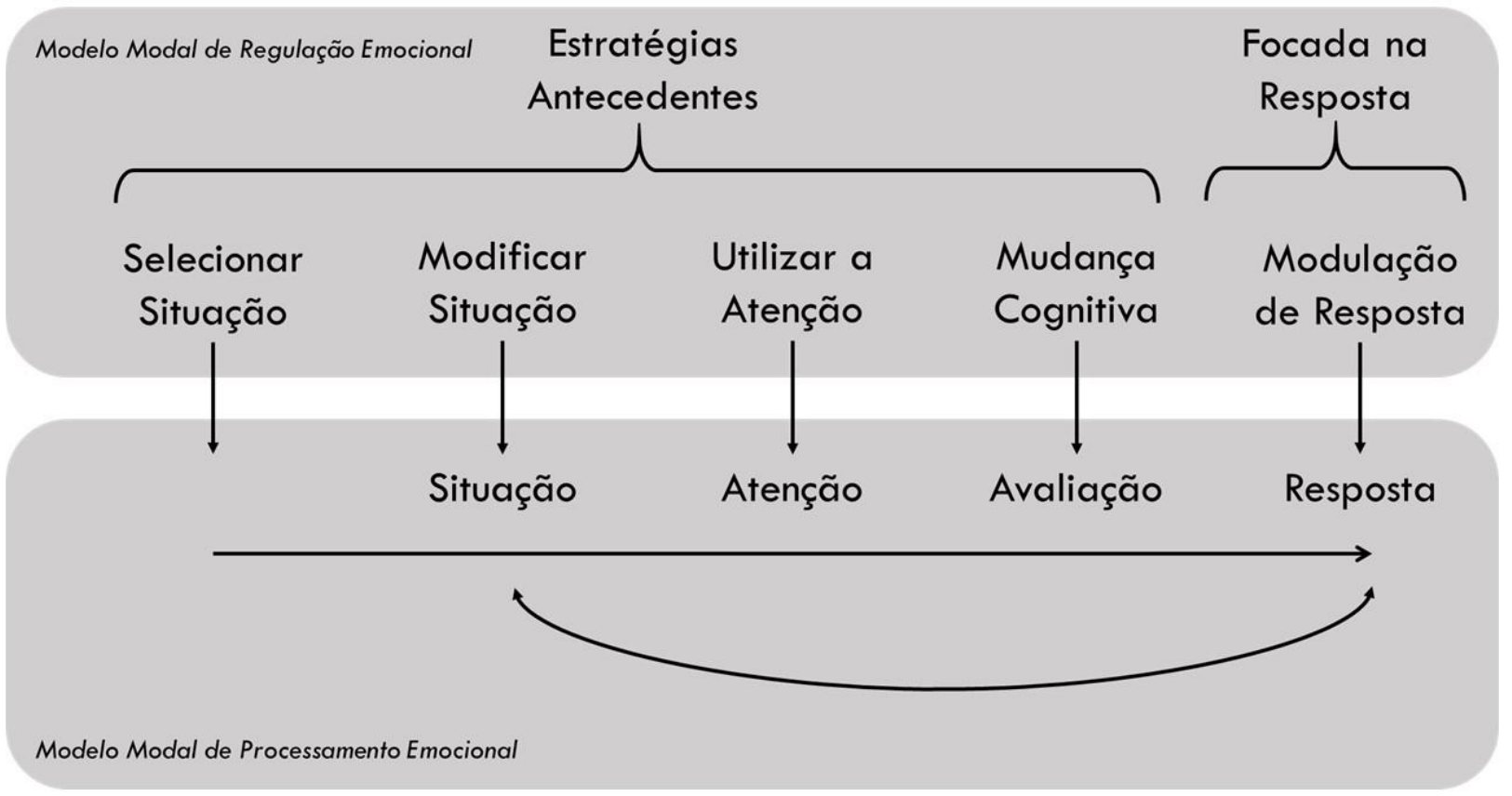

Figura 1. Modelo Modal de Regulação Emocional proposto por Gross (2014).

Estratégias que visam evitar o surgimento de emoções focam no início do processo afetivo. Assim, a seleção de situações atua como forma de evitar momentos potencialmente difíceis para o indivíduo. Por exemplo, se há desconforto em meio a multidões, ele pode selecionar situações em que não lide com muitas pessoas. Às vezes, o indivíduo já se encontra na situação, dessa forma, ele pode implementar ações que modifiquem a mesma. Exemplo disso seria, em uma discussão emocionalmente difícil, o sujeito falar de tal forma a não permitir espaço para o outro. Quando não é possível evitar ou modificar a situação, uma terceira possibilidade seria a utilização da atenção, mais especificamente os processos de desatenção. Por exemplo, colocar o foco da atenção no celular quando outra pessoa está passando uma bronca (Gross, 2014).

Estratégias que visam mudar a experiência emocional quando ela já está em curso, enquadram-se nas duas últimas classes de regulação emocional. Uma possibilidade é a mudança cognitiva, ou seja, o indivíduo busca reinterpretar a situação, de modo a produzir um novo impacto na experiência emocional. Exemplo disso seria, ao se sentir chateado por uma bronca dos pais, o adolescente pensar que essa bronca foi dada para o seu bem. Às vezes, não há possibilidades de utilização de outras estratégias para regular os sentimentos, de modo que pode restar ao indivíduo suprimir ou reprimir suas emoções. Isso é exemplificado quando um indivíduo tenta não demonstrar suas emoções (Gross, 2014). 
Com o objetivo de avaliar diferenças individuais relacionadas ao uso de estratégias de regulação emocional, Gross e John (2003) desenvolveram o Questionário de Regulação Emocional (Emotional Regulation Questionnaire - ERQ), objetivando examinar um processo antecedente (denominado como reavaliação cognitiva) e um focado na modulação da resposta (supressão emocional). Esse instrumento avaliativo conta com adaptações para Alemanha, Itália, Reino Unido, Austrália, Espanha, totalizando mais de 15 países, incluindo o Brasil (Boian et al., 2009; Gómez-Ortiz et al., 2016; Sala et al., 2012; Spaapen et al., 2014).

Estudos com a ERQ demonstram que, assim como a proporção de afetos positivos e negativos apresentam diferenças em função do sexo (Andreano et al., 2014; Stevens \& Hamann, 2012), também é possível observar diferenças no uso de estratégias de regulação emocional entre homens e mulheres. Estas diferenças foram reportadas no estudo original de Gross e John (2003), bem como podem ser encontradas em outros contextos culturais (Kwon et al., 2013; Matsumoto et al., 2008).

Pelos achados disponíveis até o momento, expectativas socioculturais exercem relevante efeito sobre o estilo de comportamento de regulação emocional masculino, favorecendo maior utilização de estratégias de supressão afetiva (Gross \& John, 2003). Os pesquisadores não observaram diferenças entre homens e mulheres com relação ao uso de reavaliação cognitiva como estratégia de regulação emocional. Em estudo transcultural de grande porte, envolvendo 23 países e 3.386 participantes, Matsumoto, Yoo e Nakagawa (2008) observaram os mesmos padrões no processo de regulação emocional em função do sexo, ou seja, homens apresentaram significativo maior uso da supressão emocional.

Ao examinar os fatores da ERQ em grupos culturais específicos, foram identificadas diferenças estatisticamente significativas e importantes. Em culturas orientadas por valores de longo prazo, tais como as culturas orientais, os indivíduos tendem a apresentar relação positiva entre o fator de reavaliação cognitiva e supressão emocional, enquanto em culturas ocidentais, orientadas por valores mais individualistas, emergiram correlações negativas entre os fatores da ERQ.

No campo da regulação emocional podem existir variadas estratégias técnicas e teóricas para abordagem do fenômeno, com destaque para o exame de eventuais dificuldades dos indivíduos nesse processo. Um instrumento avaliativo bastante utilizado nesse campo é a Escala de Dificuldades de Regulação Emocional (Difficulties in Emotion Regulation Scale - DERS), desenvolvida por Gratz e Roemer (2004). Esse instrumento multidimensional tem por objetivo avaliar dificuldades de regulação das emoções em seis áreas específicas: a) consciência acerca das emoções experimentadas; b) clareza sobre os processos emocionais; c) não aceitação das 
respostas emocionais; d) dificuldades em controlar impulsos; e) dificuldades de engajamento em comportamentos orientados para objetivos; f) acesso limitado a estratégias de regulação emocional. Essa escala avaliativa pode ser entendida como estratégia para aferir competências disponíveis no indivíduo para regular suas emoções (John \& Eng, 2014).

A literatura científica aponta a DERS como instrumento útil para acessar dificuldades de regular emoções em quadros psicopatológicos. Vale destacar, por exemplo, que a DERS apresentou resultados convergentes com transtornos psicológicos diversos (Hallion et al., 2018; Lougheed \& Hollenstein, 2012), traços de ansiedade (Cancian et al., 2018), histórico de tentativas de suicídio (Kiekens et al., 2019), transtornos de personalidade (Borges \& Naugle, 2017), e comportamentos impulsivos e de risco (Nicole H. Weiss et al., 2012). Em conjunto, estas evidências empíricas demonstram a capacidade da DERS em avaliar componentes importantes relacionados à desregulação de processos afetivos.

Estudos acerca dos processos de regulação emocional receberam crescente atenção nas duas últimas décadas, geralmente, com o objetivo de evidenciar que determinadas estratégias de regulação emocional favorecem resultados positivos em diversos processos psicológicos, como aumento no bem-estar subjetivo, diminuição de sintomas de ansiedade e depressão. Por outro lado, quando há utilização de estratégias desadaptativas, podem emergir processos psicopatológicos, como elevado nível de estresse psicológico, sintomas de ansiedade e depressão (Aldao et al., 2010; Extremera \& Rey, 2015; Gross \& Jazaieri, 2014; Gross \& John, 2003; John \& Eng, 2014; John \& Gross, 2004).

Apesar dessas evidências empíricas, pesquisas posteriores apontaram que a utilização de estratégias de regulação emocional consideradas mal adaptativas, poderia ser benéfica em determinados contextos específicos, sendo necessário relativizar os resultados iniciais (Aldao \& Nolen-Hoeksema, 2012; Kalokerinos et al., 2017; Le \& Impett, 2013). Pode-se evidenciar que os indivíduos usualmente utilizam tanto estratégias consideradas adaptativas, quanto desadaptativas, para controlar suas reações afetivas (Aldao et al., 2014). Assim, uma avaliação estática de seu comportamento pode não refletir adequadamente os processos naturalísticos de regulação das emoções.

Houve uma linha investigativa que procurou examinar a consistência individual no padrão de regulação emocional, solicitando que voluntários adultos respondessem a um questionário diversas vezes ao dia, durante suas atividades rotineiras. Os resultados apontaram o uso de diversificadas estratégias simultâneas para regular emoções no cotidiano, vinculadas ao contexto ambiental (Aldao \& Nolen-Hoeksema, 2012; Brans et al., 2013; Heiy \& Cheavens, 2014). Notaram que a regulação emocional foi mais efetiva quando o indivíduo recorreu a diferentes 
estratégias, mas com menor uso de formas consideradas desadaptativas à situação específica de vida (Aldao et al., 2014). Dessa forma, há crescente evidência de uma interação dinâmica na utilização de estratégias de regulação emocional, que altera sua efetividade conforme variáveis socioambientais.

Passou, então, a ser explorada a forma como indivíduos apresentam diferentes estratégias de regulação emocional (Dixon-Gordon et al., 2015; Heiy \& Cheavens, 2014). Inicialmente, pesquisadores buscaram identificar quantas estratégias são usualmente implementadas pelos indivíduos para controlar suas reações afetivas. Em um estudo com adolescentes $(\mathrm{n}=177)$ com idade média de 13 anos, Lougheed e Hollenstein (2012) identificaram que um repertório limitado de estratégias de regulação emocional estava associado a problemas internalizantes de comportamento. Em outro estudo, Heiy e Cheavens (2014) acessaram o uso de estratégias de regulação emocional de 92 estudantes universitários americanos durante 10 dias. Identificaram que, em média, as pessoas utilizavam 15 estratégias diferentes para controlar experiências negativas de vida, e 16 estratégias para regular suas emoções em experiências positivas.

A investigação científica a respeito das estratégias de regulação emocional tende a se encontrar sistematizada em dois tipos de estudos: aqueles que focalizam uma única estratégia como foco de pesquisa versus estudos que avaliam a complexa relação entre diversas estratégias de regulação emocional. A primeira pode ser considerada uma abordagem centrada nas variáveis e a segunda centrada no indivíduo (Chesney et al., 2019; Morin et al., 2016). Dentre os delineamentos possíveis para pesquisa dessa temática, está a análise de perfis latentes (Latente Profile Analysis - LPA). Tal estratégia analítica não corresponde a nova abordagem em pesquisa (Gibson, 1959). Ela faz parte de um grupo de técnicas de análises estatísticas multivariadas, denominado Gaussian Finite Mixture Modeling (GFMM) e tem por objetivo identificar subgrupos distintos de indivíduos a partir de determinadas características (Morin et al., 2016; Oberski, 2016). Esses grupos apresentariam determinado perfil, ou seja, diferentes combinações ou repertórios de estratégias de regulação emocional. Por exemplo, um indivíduo que evidencie combinação interna das estratégias de reavaliação cognitiva elevada e baixa ruminação, seria diferente de outro que apresentasse ambas as estratégias em níveis elevados, bem como de um terceiro com baixo nível de reavaliação cognitiva e alto nível de ruminação.

Estudos diversos têm aplicado abordagens analíticas diferentes com o objetivo de identificar perfis de regulação emocional. Um dos primeiros estudos nessa perspectiva, conduzido por Eftekhari, Zoellner e Vigil (2009) examinou um grupo de mulheres com histórico de eventos potencialmente traumáticos, e outro grupo sem esse histórico. Usando análise de cluster com os resultados da ERQ, os autores identificaram quatro grupos de padrões: alta 
regulação emocional; alta reavaliação cognitiva + baixa supressão emocional; reavaliadores moderados + baixa supressão afetiva; baixa regulação emocional. Perceberam que mulheres com pouco ou reduzido uso de estratégias de regulação emocional reportaram mais sintomas de ansiedade, depressão e níveis de estresse pós-traumático, em contraste com aquelas de elevada ou moderada regulação emocional, que reportaram menos sintomas. Os pesquisadores concluíram que o perfil de regulação emocional com baixa utilização de estratégias de regulação aumentava as chances da pessoa pertencer ao grupo com histórico de trauma.

No mesmo caminho de identificar padrões de utilização de conjuntos de estratégias de regulação emocional, Dixon-Gordon, Aldao e De Los Reyes (2015) solicitaram a 531 estudantes de duas universidades públicas americanas que recordassem seis situações em que se sentiram ansiosos, deprimidos ou com raiva. A seguir deveriam assinalar, em uma escala de zero a quatro pontos, o quanto utilizaram das diferentes estratégias para regular essas emoções. Recorreram à análise de classes latentes (Latent Classes Analysis - LCA) para exame dos achados, identificando cinco categorias de participantes: baixo reguladores, alto reguladores, reguladores adaptativos, ruminadores e evitadores. Assim, como no estudo citado anteriormente, o padrão de uso de diferentes estratégias de regulação emocional estava associado a menos sintomas de ansiedade, menor medo de avaliação social negativa e menos indicadores de personalidade borderline.

O transtorno de estresse pós-traumático (TEPT) também foi estudado por Chesney e Gordon (2017), com objetivo de verificar características relativas ao processo de regulação emocional nestes casos. Avaliaram 98 pessoas da comunidade em geral de uma cidade americana com TEPT e, por meio da análise de cluster hierárquico, identificaram quatro perfis distintos, relacionados a diferentes usos de estratégias de regulação emocional. Embora os perfis não se diferenciassem em termos de presença ou ausência de sintomas de TEPT, os autores observaram que os perfis estavam relacionados a diferentes severidades dos sintomas avaliados, o que confirmou a positiva e direta associação entre estratégias de regulação emocional e sinais psicopatológicos.

Frente a importância dos processos de regulação emocional, De France e Hollenstein (2017) conduziram dois estudos para validar nova escala de autorrelato nesse campo. Trata-se do Regulation of Emotion System Survey (RESS) que examina seis diferentes estratégias de regulação emocional. No primeiro estudo, os pesquisadores examinaram 1.582 estudantes do primeiro semestre de psicologia (idade entre 16 e 33 anos; $M=18,2$ ) com diversos instrumentos, dentre eles a RESS, recorrendo à análise de perfis latentes. Identificaram três perfis de indivíduos: reguladores médios, propensos à supressão e engajados. No estudo seguinte, com 
103 estudantes, contatados via internet, o mesmo processo analítico foi utilizado, reportando um quarto perfil, dos que utilizavam múltiplas estratégias de regulação emocional. Observaram presença dos três primeiros estilos de regulação emocional nos dois trabalhos, evidenciando consistência dos achados entre duas amostras de estudantes.

A fim de investigar divergências encontradas em trabalhos anteriores, Chesney et al. (2019) decidiram conduzir dois estudos: identificar perfis de regulação emocional em estudantes $(n=176)$ e, posteriormente, replicar a pesquisa $(n=147)$ para tentar validar os perfis encontrados, a partir de uma análise de perfis latentes (LPA). Os resultados do primeiro estudo levaram a uma solução de quatro perfis distintos de regulação emocional nos estudantes: adaptativo, supressor, não aceitação e desadaptativo. Já na segunda pesquisa encontraram uma solução de seis perfis de regulação emocional. Os autores argumentaram que um destes perfis, no entanto, continha poucos participantes e não diferia muito dos demais, optando por uma solução de cinco perfis, os anteriormente encontrados e um do tipo: altamente regulador. Em ambos os estudos, os perfis que se utilizavam de estratégias de regulação adaptativa reportaram menos sintomas de depressão e ansiedade que os que utilizavam poucas estratégias, ou faziam uso de estratégias desadaptativas de regulação emocional.

Pelo exposto até o momento, nota-se divergência entre achados reportados na literatura científica sobre os processos de regulação emocional, o que merece a devida explanação. Para Chesney et al. (2019) esta diversidade de resultados deriva de componentes metodológicos das pesquisas realizadas. A primeira questão está relacionada à forma de exame dos processos de regulação emocional. Nota-se que cada trabalho reporta técnicas particulares para estudar o tema. Assim, Eftekhari, Zoellner e Vigil, (2009) e Dixon-Gordon, Aldao e De Los Reyes, (2015) solicitaram que os participantes reportassem o quanto fizeram uso de uma lista de estratégias de regulação emocional, enquanto Chesney e Gordon (2017) e De France e Hollenstein (2017) utilizaram diferentes instrumentos de autorrelato.

Uma segunda questão metodológica envolvida no campo dos estudos sobre regulação emocional está relacionada ao tipo de análises de dados conduzidas em cada estudo. Alguns autores adotaram análise de cluster, enquanto outros recorreram a diferentes tipos de análises de variáveis latentes (LCA ou LPA), o que pode justificar a variabilidade nos resultados encontrados.

Apesar dessas questões de diversidade metodológica, as evidências empíricas referidas até o momento apontam consistência quanto à presença de pelo menos três tipos de perfis de regulação emocional, a saber: baixo, elevado e intermediário uso de estratégias regulatórias das emoções (Chesney et al., 2019; De France \& Hollenstein, 2017). Certamente há que se 
considerar nessa análise o contexto socioambiental e cultural dos indivíduos, de modo a possibilitar o exame de sua possibilidade (ou não) de adaptação às situações. Essa adaptabilidade, por sua vez, está claramente relacionada com variáveis da personalidade humana, como explorado no tópico a seguir.

\subsection{Personalidade}

Apesar dos muitos investimentos científicos no campo da personalidade, até hoje inexiste consenso entre pesquisadores acerca de uma definição desse construto. De maneira geral, cada área científica enfatiza variáveis relacionadas aos seus interesses específicos, sendo que alguns autores destacam traços estáveis de personalidade ao longo do tempo, outros apontam a necessidade de entendê-la como tipos diferenciados, alguns ainda destacam aspectos transitórios (Cohen et al., 2014). Segundo Hall, Lindzey e Campbell (2000), “a personalidade é definida pelos conceitos empíricos específicos que fazem parte da teoria da personalidade empregada pelo observador" [p. 33. ênfase no original]. Por sua vez, o dicionário de Psicologia da Associação Americana de Psicologia (APA) define personalidade como "padrão de pensamentos, sentimentos e comportamentos...” (pg.782) relacionado às diferenças individuais (Vanderbos, 2010).

Pesquisas sobre a personalidade humana fazem parte da história da Psicologia de maneira geral (Friedman \& Schustack, 2004) e da área de avaliação psicológica em particular (Cohen et al., 2014). Isso porque o construto personalidade tem impacto em diversos fenômenos sociais, podendo-se destacar desde taxas de mortalidade e divórcio até engajamento no trabalho. A personalidade possui efeitos tão importantes na vida dos indivíduos, quanto outras variáveis psicológicas e socioeconômicas (Pinon, 2019; Roberts et al., 2007; Tisu et al., 2020). Por isso, processos de avaliação da personalidade apresentam vital importância para a compreensão do comportamento humano (Grucza \& Goldberg, 2007).

Tradicionalmente, a avaliação da personalidade recorre a ferramentas classificadas em dois tipos: instrumentos objetivos e métodos projetivos (Cohen et al., 2014). Os métodos objetivos têm como premissa a utilização de frases curtas que expressam a manifestação comportamental de uma determinada característica, em que o indivíduo deve marcar o grau em que a experimenta, concorda ou o caracteriza, recorrendo ao autorrelato (Lucas \& Baird, 2006). Por outro lado, as técnicas projetivas são vistas como métodos de levantamento de informação, sem respostas fechadas, nas quais o indivíduo deverá executar uma tarefa, como montar uma pirâmide colorida, interpretar uma mancha de tinta ou compor um desenho. A partir das 
respostas, são listados indicadores relativos ao funcionamento psicológico do respondente (Cohen et al., 2014).

Embora a pesquisa científica, em sua maioria, recorra ao uso do autorrelato como forma de avaliação da personalidade, com boa capacidade preditiva sobre os fenômenos relacionados (Lucas \& Baird, 2006), há grande debate atual acerca das consequências do uso generalizado do autorrelato (Baumeister et al., 2007), além de modelos demonstrando o poder incremental da utilização de múltiplas técnicas (Schmitt et al., 2015). O uso de instrumentos baseados no comportamento para compreensão das características de personalidade (Bornstein, 2015a), como o caso do Método de Rorschach, consiste em proposta interessante e historicamente válida no mundo todo (Meyer, 2017).

O Método de Rorschach (1921/1978) suscita amplo debate desde que Hermann Rorschach lançou sua monografia "O Psicodiagnóstico: um teste diagnóstico baseado na percepção” em 1921 (Weiner, 2000). Sendo fruto da curiosidade e inventividade do seu autor, o método encontrou adeptos entusiastas e críticos ferrenhos desde sua criação. Embora a ideia de utilizar manchas de tinta para avaliar aspectos psicológicos existisse anteriormente, foi Hermann Rorschach quem primeiro sistematizou os dados acerca desse tipo de experiência para examinar a personalidade (Vaz, 1997).

Os avanços acumulados ao longo do tempo a partir do Rorschach, em suas várias perspectivas teóricas, sugerem que se trata de instrumento baseado em análises de desempenho típico (Bornstein, 2012; Meyer, 2017). Segundo essa perspectiva, a instrução do Método de Rorschach convida o respondente a resolver o problema originado pela pergunta: "O que isso poderia ser?" O avaliador pode, então, obter informações da personalidade em ação, ou seja, ver e acompanhar o comportamento do indivíduo, ao invés de acessar apenas o que ele afirma fazer, pensar ou sentir. Esta premissa permanece compatível com a noção de que o Método de Rorschach permite acessar informações não disponíveis por instrumentos baseados em autorrelato (Azoulay et al., 2007; Piotrowski , 1957), configurando-se, portanto, como forma de avaliação com importante validade incremental para o estudo da personalidade (Meyer, 2017).

As diferentes formas de entender o que é importante durante a aplicação e apuração das respostas ao Rorschach deram origem a diferentes sistemas avaliativos (Hisatugo, 2019; Pasian, 2000). A partir da prática empírica e de insights teóricos, diversos pesquisadores contribuíram para o refinamento do Método de Rorschach e sua utilização. Dentre as tradições com foco nos aspectos perceptivos, o Sistema Compreensivo de Exner (CS) teve como principal contribuição sistematizar os estudos com o Rorschach a partir de intenso programa de pesquisa, unificando as interpretações existentes nos cinco sistemas mais utilizados nos Estados Unidos em um único 
referencial, abrangente e com foco em dados empíricos (Anastasi \& Urbina, 2000; Weiner, 2000). Entretanto, após a morte de John Exner em 2006, a evolução constante de pesquisas com o método acabou por gerar o Rorschach Performance Assessment System (R-PAS), com foco na análise e levantamento de evidências empíricas disponíveis em perspectiva internacional (Meyer \& Eblin, 2012).

Atualmente o sistema R-PAS conta com ricas revisões sistemáticas da literatura científica, oferecendo evidências seguras para a interpretação dos resultados (Meyer \& Eblin, 2012). A distribuição dos códigos de classificação (específicos e combinados) das respostas produzidas diante do Rorschach e, em especial do R-PAS, fornece informações acerca de diversas características da personalidade do respondente. No R-PAS (Meyer et al., 2011) há dois grupos de códigos de classificação das respostas: os códigos cognitivos e os temáticos. Os códigos cognitivos referem-se a processos peculiares de pensamento ou linguagem (disruptivos ou ilógicos), em diferentes graus de severidade, que interferem nos comportamentos do respondente. Os códigos temáticos referem-se a conteúdos presentes nas respostas, tais como representação abstrata, justificativa em conhecimento pessoal, movimento cooperativo, autonomia, movimento agressivo, conteúdo agressivo ou mórbido, linguagem oral-dependente, indicando aspectos significativos das vivências do indivíduo (Meyer et al., 2011).

Assim, o potencial de informações do Rorschach foi (e continua a ser) grandemente discutido ao longo dos anos, sendo possível entendê-lo como uma bateria de provas, em que é possível organizar suas variáveis para levantar as mais diversas informações do funcionamento mental dos indivíduos (Weiner, 2000; Yazigi \& Gazire, 2002). Tradicionalmente ele tem sido relacionado à avaliação de aspectos da personalidade. Além disso, busca-se identificar indicadores relativos a saúde mental ou a psicopatologia e transtornos neurológicos diversos, comparando respostas de indivíduos não pacientes com grupos diagnosticados (por critérios seguros) como portadores de dificuldades psiquiátricas ou com lesões cerebrais. O próprio Hermann Rorschach inaugurou o uso de seu método como um instrumento neuropsicológico (Caputo, 1999).

A história do Método de Rorschach como instrumento privilegiado para informar sobre o funcionamento neuropsicológico humano tem longa tradição, porém ainda marginal e pouco explorada, se comparada ao uso para fins de compreensão da personalidade (Acklin \& Wu-Holt, 1996). Na visão de Caputo (1999), no âmbito da neuropsicologia o Método de Rorschach apresenta três períodos distintos: os anos iniciais do instrumento, em que havia profundo interesse por sua aplicação; intenso descrédito do método na década de 1960, com críticas aos 
fundamentos psicométricos; e o período atual, com perspectivas futuras promissoras, pouco exploradas.

Acklin e Wu-Holt (1996) sugerem que a possível associação entre o Rorschach e a investigação neuropsicológica permanecia inexplorada, apesar de seu grande potencial, e discutem a aplicação da Psicologia Cognitiva para compreender os processos envolvidos no método. Piotrowski (1957) já sinalizava, em suas análises dos casos de Rorschach, indicadores de alterações neuropsicológicas. Posteriormente, um importante passo foi dado por Exner, que ao proferir suas palestras e workshops sobre o sistema compreensivo, costumava utilizar uma linguagem cognitiva para se referir aos processos mentais envolvidos nas fases de resposta e de sua clarificação (Acklin, 1994; Acklin \& Wu-Holt, 1996). Essa tendência pode ser percebida também no texto de Weiner (2000), ao abordar os processos mentais envolvidos nas interpretações dos indivíduos: "Numa linguagem contemporânea, esses elementos da produção de respostas ao Rorschach caracterizam o instrumento como uma tarefa de estruturação cognitiva que envolve processos de atenção, percepção, Tomada de Decisão e análise lógica” (p. 16).

Ao aplicar o paradigma da Psicologia Cognitiva ao Método de Rorschach, torna-se possível identificar processos mentais que concorrem para as respostas do indivíduo para a pergunta “O que isso poderia ser?” Durante a fase de resposta aos cartões, faz-se necessária atenção visual, reconhecimento de padrões, processos de memória, processos perceptivos, todos organizados pelo lobo pré-frontal (Acklin \& Wu-Holt, 1996). Ao assumir o modelo dos processos cognitivos envolvidos nas respostas do Rorschach é possível visualizar várias hipóteses acerca do funcionamento mental, as quais ficam passíveis de serem testadas, tais como a relação entre o funcionamento cognitivo e emocional para a adaptação geral do indivíduo ao contexto em que se encontra (Muzio, 2004; Schott, 2014).

Essa possibilidade interpretativa foi originalmente apresentada pelo próprio Hermann Rorschach, ao sugerir que inteligência e emoção estavam presentes nos processos de resposta a seu método (Rorschach, 1942; Schott, 2014). A estratégia de Exner organizar informações do Rorschach em módulos interpretativos embasados em um sumário de variáveis relativas ao campo afetivo e cognitivo caminha nessa direção (Weiner, 2000). Cabe destacar, entretanto, que essa divisão das variáveis é apenas didática, pois há íntima relação entre ambos os processos (Muzio, 2004; Resende, 2008; Schott, 2014).

Muzio (2004) e Meyer (2016) sugerem que há evidências suficientes para relacionar variáveis do Rorschach a diversos processos cognitivos e afetivos. Exemplo é o trabalho publicado por Malone et al. (2013), os quais utilizaram uma bateria de instrumentos de autorrelato para avaliação da personalidade, testes de inteligência e o Rorschach, numa 
abordagem multimétodo. Objetivaram investigar variáveis do Rorschach associadas a processos de modulação afetiva (regulação emocional) em amostra clínica de 88 pacientes de um hospital psiquiátrico. Os investigadores observaram que elevação na variável FC do Rorschach associouse negativamente com indicadores de agressão e psicose, enquanto CF se mostrou positivamente associada a afetos depressivos, ideação suicida, estresse, ansiedade e isolamento social, entre outras dificuldades psicológicas. Os resultados foram interpretados como indicativos de que variáveis cromáticas do Rorschach representam formas de expressão e vivência afetiva.

Ao examinarem a produção científica no campo do Método de Rorschach e o suporte empírico para suas evidências interpretativas, o estudo de metanálise de Mihura, Meyer, Dumitrascu e Bombel (2013) trouxe evidências de validade para as hipóteses interpretativas: a) cor acromática relaciona-se a afetos negativos e irritabilidade; b) a proporção do uso da forma e da cor $(\mathrm{CF}+\mathrm{C}>\mathrm{FC})$ está relacionada a impulsividade e reatividade emocional; c) ambas as variáveis prévias estão associadas a maior engajamento com vivência emocional. Em conjunto, essas evidências meta-analíticas dão suporte para a noção de que características afetivas dos indivíduos se relacionam com respostas cromáticas no Rorschach. Em direção similar, Matsuda (2019) avaliou 39 estudantes universitários japoneses com o Rorschach e relacionou seus dados ao desempenho em uma tarefa implícita de regulação emocional e a um questionário de autorrelato. Os resultados indicaram associação estatisticamente significativa e positiva entre respostas FC no Rorschach e a tarefa de desempenho em regulação emocional, mas não com o autorrelato, evidenciando relações entre variáveis representativas da afetividade no Rorschach com indicadores de regulação emocional.

A literatura científica da área também permite identificar outros estudos que examinaram associações de indicadores do Sistema Compreensivo (SC) do Rorschach e Funcionamento Executivo (FE). Exemplo disso é o trabalho realizado por Clyne (2000), que utilizou o Rorschach (SC) e o Wisconsin Card Sorting Test (WCST) em amostra de universitários de ambos os sexos, não pacientes dos Estados Unidos. Encontrou correlação positiva e significativa entre o estilo extratensivo no Rorschach (WSumC $>$ M) e as respostas perseverativas no WCST, que, segundo Muzio (2004), podem ser indicativo de dificuldades de resolução de problemas, relacionadas ao uso de feedback fornecido pelo ambiente.

Ainda utilizando o Rorschach e o WCST, Paulus, Perry e Braff (1999) avaliaram 50 pacientes com diagnóstico de esquizofrenia, com idade entre 20 e 52 anos $(\mathrm{M}=36,3 ; \mathrm{DP}=8,2)$, de ambos os sexos, classificando-os em dois grupos de acordo com resultados em uma tarefa experimental onde mudavam (ou não) de estratégia quando perdiam em um jogo. Os achados sugeriram que WCST e Rorschach diferenciavam os participantes que conseguiam, 
espontaneamente, modificar suas estratégias de ação daqueles que permaneciam utilizando a mesma estratégia, mesmo quando estavam perdendo no jogo. Entretanto, a relação entre os escores no WCST e no Rorschach não foram lineares, mostrando que o funcionamento da personalidade avaliado pelo Rorschach e estratégias cognitivas avaliadas pelo WCST podem ser bastante complexos. Esses achados apontaram a viabilidade de extração de informações sobre o funcionamento executivo do indivíduo a partir de variáveis do Rorschach (SC).

Associações entre variáveis de personalidade e do funcionamento executivo têm sido reforçadas por estudos em Neurociências com técnicas de neuroimagem (Asari et al., 2010; Cristofanelli, Pignolo, Ferro, Ando \& Zennaro, 2016; Giromini, Porcelli, Viglione, Parolin \& Pineda, 2010; Giromini, Viglione, Zennaro \& Cauda, 2017; Ishibashi et al., 2016). O trabalho desenvolvido por Giromini et al. (2010), recorrendo a neuroimagem, avaliou 20 estudantes de uma universidade americana, com idade entre 18 e 27 anos, de ambos os sexos. Identificou relação entre variáveis do Rorschach vinculadas a respostas de movimento humano e características pessoais de empatia. Na continuidade dessa linha investigativa, Giromini et al. (2017) trabalharam com 26 voluntários saudáveis, universitários americanos. No interior de uma máquina de ressonância magnética, os voluntários observavam as imagens do Rorschach e foram orientados a pensarem em uma única resposta por vez. Os pesquisadores observaram intensa atividade de processamento visual, processos atencionais top-down e bottom-up, além de processamento emocional. Essa abordagem metodológica também foi trabalhada por Ishibashi et al. (2016), com amostra maior de indivíduos japoneses $(n=40)$, não pacientes, de ambos os sexos, chegando a resultados semelhantes. Seus dados apontaram importante atividade da região orbitofrontal diante dos cartões cromáticos do Rorschach.

Ainda nesse campo torna-se importante destacar o trabalho desenvolvido por Asari et al. (2010) que avaliou a atividade cerebral de 68 voluntários japoneses, de ambos os sexos, utilizando uma máquina de ressonância magnética funcional enquanto respondiam ao Rorschach. Os resultados indicaram maior atividade em regiões relacionadas ao processamento afetivo, e parecem ser moduladas pela atividade da amígdala. Hiraishi e Haida (2012), por usa vez, utilizaram uma técnica de espectroscopia por infravermelho próximo (near-infrared spectroscopy) para acompanhar 17 adolescentes japoneses, em sua maioria homens $(\mathrm{n}=14)$, sem histórico de transtornos psiquiátricos, submetidos ao Rorschach e outras tarefas visuais para avaliação da personalidade. Os pesquisadores identificaram claro aumento de atividade no córtex pré-frontal desses voluntários. Em outro estudo Aizawa et al., (2018) encontraram resultados semelhantes com ativação das regiões pré-frontais. Os pesquisadores compararam as respostas de 29 estudantes japoneses, sem histórico de transtornos mentais, em duas tarefas: uma 
consistindo em três cartões do Rorschach (I, IV e V) e a outra consistindo em imagens simples. Em seguida os participantes deveriam responder à pergunta “com o que isso se parece?”. Os resultados demonstraram maior ativação nas regiões pré-frontais para o Rorschach, quando comparada com a outra tarefa.

Diante da literatura científica levantada até o momento, notam-se evidências consistentes sobre a qualidade das informações obtidas com o Rorschach para acessar características da personalidade e também sobre o funcionamento executivo em indivíduos de diferentes regiões do mundo. Resta, portanto, explorar com maior detalhamento a relação entre estas variáveis, como mostra o próximo tópico.

\subsection{Tomada de Decisão, Regulação Emocional e Personalidade}

As evidências correlacionais e de neuroimagem indicam que variáveis relacionadas à personalidade, avaliadas pelo Rorschach, estão associadas a processos afetivos e cognitivos. Tais processos, por sua vez, dependem do funcionamento de regiões cerebrais envolvidas tanto no controle afetivo, quanto na resolução de problemas. Ao discutir interações entre variáveis associadas a funções executivas (FE) e estratégias de regulação emocional (RE), Suchy (2011) identificou que elas emergem das mesmas estruturas neurais relacionadas ao córtex pré-frontal, embora também envolvam outras regiões que tratam de processos cognitivos e afetivos. Compartilhar o mesmo desenvolvimento anatômico faz com que esses sistemas estejam relacionados ao ativar essa região cerebral.

Dada a complexidade da relação entre processos de Tomada de Decisão, regulação emocional e sua vinculação com características de personalidade, buscou-se, por meio de levantamento da literatura científica, sistematizar evidências disponíveis no campo. Desse modo foi realizada, em agosto de 2019, busca nas bases de dados científicas PsycINFO, PubMED, Web of Science e Scielo, selecionando-se apenas artigos publicados. Pesquisaram-se os termos "Decision Making” AND "Emotional Regulation" AND "Personality”, em inglês, e os termos “Tomada de Decisão" AND "Regulação Emocional” AND "Personalidade” em português. Cabe destacar que não houve delimitação quanto ao período da publicação pesquisado, na perspectiva de um recorte panorâmico sobre o tema. Foi identificado um total de 167 artigos, os quais foram organizados com auxílio do software de manejo de referências disponível no Mendeley.

Os resumos foram lidos com o objetivo de avaliar se os trabalhos se enquadravam ao contexto da pesquisa, utilizando como critério de inclusão neste atual levantamento: pesquisas empíricas sobre a relação entre aspectos da Tomada de Decisão, regulação emocional e 
personalidade. Artigos escritos em inglês, português, francês e espanhol foram mantidos. Aplicou-se como critério de exclusão, na análise dos resumos: o tema do trabalho não estar relacionado ao escopo de interesse dessa revisão; artigos de revisão de literatura científica e de metanálise; artigos escritos em outras línguas que não as especificadas anteriormente.

Buscou-se a versão completa dos artigos selecionados de modo a identificar suas principais características. Foram sistematizadas e sumarizadas informações referentes a: autores, ano de publicação, delineamento metodológico, características dos grupos estudados (clínicos ou não clínicos), instrumentos utilizados e principais achados. Na figura 2 visualiza-se a distribuição dos artigos identificados após a aplicação dos critérios de inclusão e exclusão no presente levantamento da literatura científica.

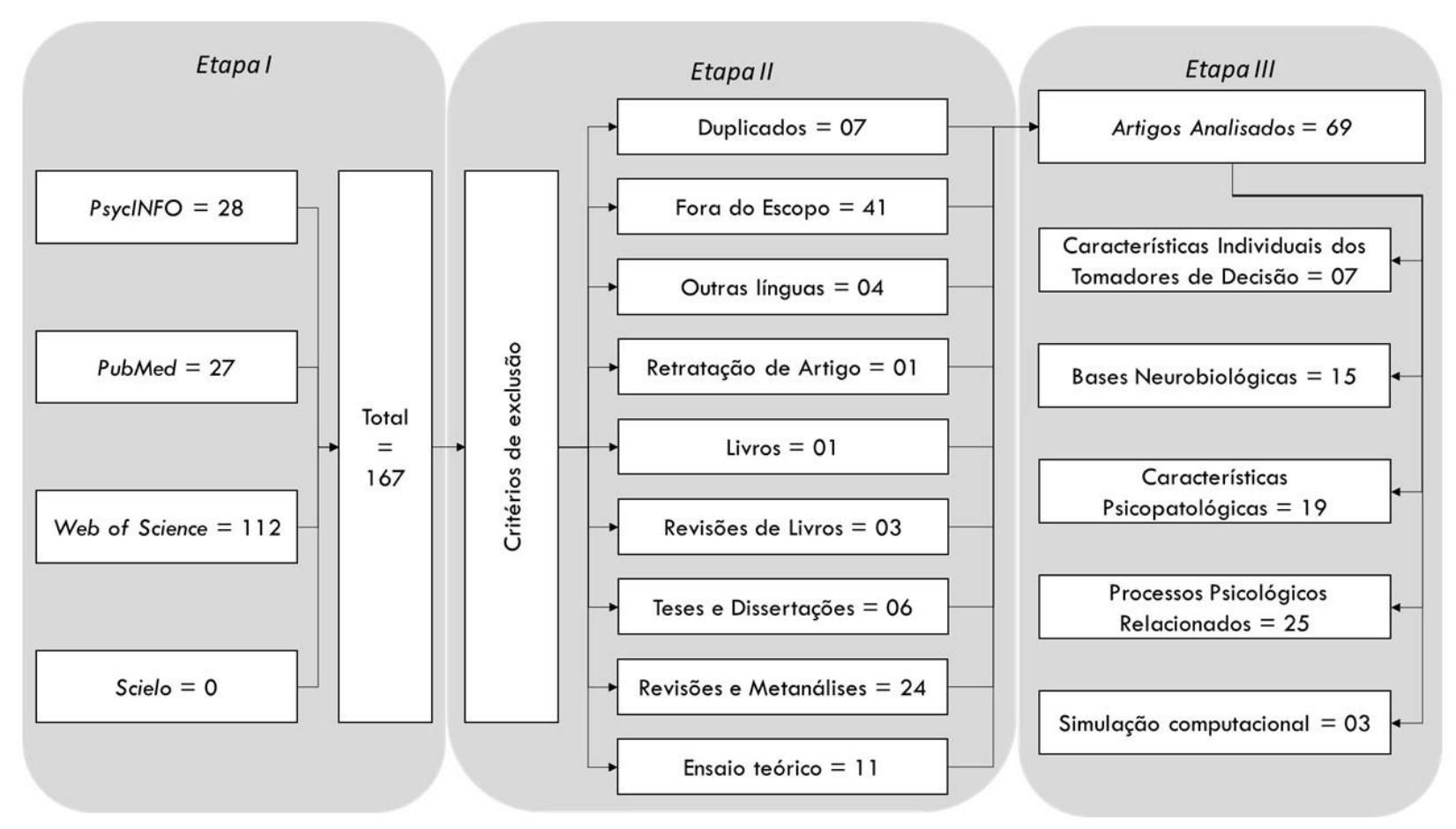

Figura 2. Resultados da busca inicial na literatura científica.

Nota: Etapa I = Coleta de informações; Etapa II = aplicação dos critérios de inclusão/exclusão; Etapa III = Leitura dos artigos na íntegra.

Posteriormente, os 69 artigos selecionados foram lidos na íntegra, buscando-se sintetizar o conjunto dos principais achados. Para tanto, foram criadas categorias que compartilhavam as mesmas características de acordo amostras, procedimentos metodológicos e objetivos dos estudos. Dessa forma, nos próximos tópicos serão descritas os principais achados e suas 
implicações para o estudo da inter-relação entre tomada de decisão, regulação de emoções e personalidade.

\subsubsection{Características individuais dos tomadores de decisões}

O levantamento da literatura científica na área sobre Tomada de Decisão, regulação emocional e personalidade apontou estudos que procuraram estudar as eventuais associações dessas variáveis em grupos específicos de indivíduos, em especial aqueles que precisam, em seu cotidiano, tomar decisões com imediato impacto em seu contexto. Assim, alguns estudos procuraram compreender como características individuais moldam processos decisórios individuais dependentes dessas variáveis psicológicas para exercer adequadamente suas atividades laborais. Estes agentes estudados foram apostadores profissionais, jogadores de poker (Palomäki et al., 2013), grupos táticos ou policiais (Young, 2016; Young et al., 2018), aviadores (Ceschi et al., 2019) e investidores no mercado de ações (Jalilvand et al., 2018; Kranz et al., 2014; Richards et al., 2018). Procurar-se-á descrever, de forma breve, cada um desses grupos estudados.

Palomäki et al. (2013) testaram a hipótese de relação entre diferentes formas de regulação emocional (especificamente a ruminação e autorreflexão) e examinaram jogadores de poker experientes e inexperientes em situações de tomada de decisões. Para tanto, avaliaram 354 indivíduos finlandeses, em sua maioria homens $(\mathrm{n}=331)$, com idade entre 17 e 62 anos $(\mathrm{M}=$ 28,4; DP 7,7) por meio de uma escala de nível de experiência no jogo (sendo classificados entre Experientes e Inexperientes), uma escala de autorruminação e autorreflexão, e uma escala de crença na sorte. Em seguida, os participantes responderam a dois cenários em que deveriam tomar decisões baseados nas regras do jogo de poker online. Os resultados indicaram que indivíduos com mais experiência relataram menores níveis de ruminação e menor probabilidade de acreditar que podiam alterar sua própria sorte. Para jogadores experientes, a autorreflexão esteve associada a melhores decisões, enquanto para os jogadores inexperientes, a ruminação teve papel importante no seu processo de tomada de decisão. Os autores sugerem que estes resultados podem indicar que os processos de tomada de decisão ocorrem em vias diferentes para jogadores experientes e inexperientes no contexto de poker.

Outro grupo que frequentemente necessita tomar decisões com impactos importantes são policiais, grupos táticos e negociadores. Com objetivo de explorar o perfil psicológico de policiais que utilizam de estratégias de negociação em situações de crises, Young (2016) conduziu uma pesquisa exploratória com 514 negociadores dos Estados Unidos, sendo 76,5\% dos participantes do sexo masculino, com média de idade de 41,31 anos (DP =7,45). Os 
participantes responderam a diversas questões acerca das características de suas atividades e questionários de autorrelato abordando características de personalidade, regulação emocional e estilos de tomada de decisão. Os resultados indicaram que, comparados à população em geral, negociadores tendem a apresentar elevado nível de aceitação como estratégia de regulação emocional. Além disso, apresentaram baixos níveis de conscienciosidade, amabilidade, extroversão e neuroticismo, e altos níveis de abertura à experiência, quando comparados à população em geral. Não foram observadas diferenças importantes quanto ao estilo de decisão dos participantes.

Posteriormente, Young et al. (2018) compararam agentes das Forças Táticas Especiais (Special Weapons And Tactics - SWAT) $(\mathrm{n}=277)$ com negociadores $(\mathrm{n}=514)$ e policiais de patrulha $(\mathrm{n}=72)$ dos Estados Unidos, com o objetivo de investigar a relação entre características de personalidade, estilos de decisão e regulação emocional. Os resultados indicaram que o desempenho positivo dos agentes estava significativamente relacionado a um estilo racional e negativamente relacionado a um estilo evitativo na tomada de decisão. Agentes com estilos de dramatização como estratégia de regulação emocional apresentaram mais resultados negativos em seu cotidiano de trabalho.

Outro contexto pesquisado foi o de mercado de ações, o qual demanda diariamente relevantes decisões financeiras. Kranz et al. (2014) investigaram características individuais (processos cognitivos e regulação emocional) associadas às decisões dos profissionais traders (investidores que operam diariamente nos mercados de capitais). Os pesquisadores coletaram informações sobre características de personalidade, tomada de decisão e regulação emocional de 196 traders ativos na bolsa de valores do mercado alemão e cruzaram esses dados com mais de 215 mil decisões individuais dos profissionais ao longo de algumas semanas. Os resultados indicaram heterogeneidade de características individuais em relação à tomada de decisão. Apesar dessa diversificação nos achados, notaram que a estratégia de regular emoções pela supressão emocional apresentou correlação negativa com o número de ordens de compra de ações realizadas, e a tendência à reflexão mostrou relação positiva com a qualidade das decisões tomadas.

O estudo desenvolvido por Jalilvand et al. (2018) procurou diferenciar investidores profissionais daqueles com pouca experiência. Os autores identificaram na literatura científica três fatores que contribuem para a tomada de decisão: características psicológicas, fatores econômicos e conhecimento do funcionamento dos mercados financeiros. Em seguida elaboraram um questionário e enviaram para 561 investidores, subdivididos em dois grupos: investidores profissionais e com pouca experiência. Os resultados indicaram que investidores 
com maior experiência tendem a recorrer a pensamento analítico, enquanto investidores com menos experiência relataram maior influência de suas características psicológicas ao tomar decisões. Investidores, por princípio, almejam lucros e evitam perdas, mesmo quando esse comportamento impacta nos ganhos em longo prazo.

Ainda no campo financeiro, Richards et al. (2018) avaliaram o processamento lógico, estilos de decisão e disposição pessoal em 4.125 investidores, sendo 89,36\% do sexo masculino com idade média de 53,27 anos. Os resultados demonstraram que participantes com maior tendência a tomar decisões, apresentaram maior efeito de disposição, ou seja, buscaram vender suas ações para realizar lucros. Além disso, os participantes que apresentaram maior uso de reavaliação cognitiva como estratégia de regulação emocional demonstraram menor tendência a este viés. Estes resultados indicam que a tomada de decisão pode ser influenciada pelo estilo decisório e que essa relação pode ser alterada pelo uso de estratégias de regulação emocional.

No campo da aviação, os tomadores de decisões precisam realizar análises rápidas e acuradas em situações emergenciais, a fim de evitar graves acidentes. Com o objetivo de desenvolver um instrumento para avaliar habilidades não técnicas relacionadas a esta área, Ceschi et al. (2019) entrevistaram 70 especialistas em aviação e identificaram três componentes essenciais para sucesso em suas funções: habilidades sociais, cognitivas e emocionais. Posteriormente realizaram uma análise fatorial confirmatória com as respostas de 211 participantes, trabalhadores da área de aviação, sendo em sua maioria do sexo masculino (79\%), com idades entre 31 e 60 anos. Os resultados demonstraram que o modelo de três fatores apresentou bons índices de ajuste para explanar o comportamento dos especialistas em aviação em situações de tomada de decisão.

Esse conjunto de estudos aponta para a inter-relação entre processos de regulação emocional e características de personalidade modificando e interagindo com processos de tomada de decisão. Isso pode favorecer ou dificultar os desfechos vivenciados, como situações de risco ou que apresentam potencial de perdas monetárias ou de vida.

\subsubsection{Processos Psicológicos relacionados à Decisão}

Muitos estudos focaram principalmente na relação entre as variáveis personalidade, regulação emocional e comportamento decisório, de maneira a compreender suas possíveis associações. Estas relações podem sofrer alterações a depender do período do desenvolvimento (Gillath \& Shaver, 2007; Helmsen et al., 2012; Kuhnle et al., 2014; Locander et al., 2014; Lopes et al., 2012; Zimmermann, 2010), de acordo com características como neuroticismo (Moeller \& Robinson, 2010; Pinquart et al., 2008), bem-estar subjetivo (Sul et al., 2013), bem como em 
relação ao uso de estratégias desadaptativas (Gonzalez et al., 2011; N H Weiss et al., 2019), tipos de comportamento de risco (Dvorak et al., 2013; Magar et al., 2008; Miller et al., 2017; Panno et al., 2018; Rose \& Segrist, 2014), e as estratégias utilizadas para regulação emocional (Kim \& Kanfer, 2009; Lopes et al., 2011; Miranda \& Kim, 2015; Reynolds et al., 2015).

Durante a infância, a capacidade de identificar emoções em si e no outro é vista como um importante fator de adaptação ao contexto escolar em várias culturas (Lopes et al., 2012), enquanto a desregulação emocional e utilização de estratégias desadaptativas estão relacionadas a comportamentos agressivos, tanto em meninas quanto em meninos (Helmsen et al., 2012). Isso pode ser explicado pelos estilos de apego desenvolvidos na mais tenra idade que podem alterar o processo decisório ao longo de toda à vida (Gillath \& Shaver, 2007).

$\mathrm{Na}$ adolescência, a impulsividade interage com dificuldades de perceber e regular emoções, alterando a percepção dos riscos de um comportamento e aumentando sua frequência, o que pode explicar por que essa população apresenta mais comportamentos de risco (Zimmermann, 2010). Já durante o período de adultez, observa-se que o estilo de decisão pode exercer importante papel na escolha profissional (Farnia et al., 2018), porém, de maneira geral, tanto o estilo deliberativo, quanto o intuitivo contribuem para a tomada de decisão (Locander et al., 2014). Há também diferenças culturais relacionadas ao estilo de decisão, os valores professados pelos sujeitos, e maior ou menor arrependimento após o processo de tomada de decisão (Kuhnle et al., 2014).

O neuroticismo e o bem-estar subjetivo parecem exercer papeis importantes durante o processo decisório. Em um estudo com o objetivo de compreender o desempenho desse traço de personalidade e reações à punição após escolhas, Moeller e Robinson (2010) identificaram que indivíduos com altos níveis de neuroticismo mudaram mais rapidamente suas escolhas após um feedback negativo sobre as consequências de suas decisões. Em outro estudo, observaram relevante associação entre traços de neuroticismo, baixa amabilidade e a atitude de ambivalência na decisão de ter filhos (Pinquart et al., 2008). Houve também evidências de que a adequada utilização de estratégias de regulação emocional se correlacionou negativamente com conflitos interpessoais (Lopes et al., 2011). Em complemento, indivíduos com altos níveis de bem-estar subjetivo tenderam a fazer escolhas que os aproximam dos outros mesmo em detrimento de ganhos financeiros (Sul et al., 2013), o que indica como variáveis afetivas podem alterar o processo de escolha e as decisões individuais.

Outra característica bastante estudada é a impulsividade e suas inter-relações com regulação emocional e comportamentos de risco. De maneira geral, alguns comportamentos de risco podem servir como estratégias desadaptativas de regulação emocional, sendo este o caso do 
abuso de álcool. Gonzalez et al. (2011) investigaram o papel da impulsividade na relação entre abuso de álcool e depressão em jovens adultos. Estes pesquisadores identificaram que urgência negativa é a única característica de impulsividade que media a relação entre depressão e abuso de álcool. De maneira geral, nessa faixa etária, o álcool teria uma função de regulação emocional, porém com prejuízo no processo de tomada de decisão a curto prazo. Durante o processo de validação de uma escala de dificuldades para regular emoções positivas, Weiss et al. (2019) demonstraram moderada correlação entre os fatores da DERS-P e trações de urgência positiva e urgência negativa, ambos relacionados a traços de impulsividade.

A impulsividade está envolvida em diversos tipos de comportamento de risco e tomada de decisão. Desde o consumo excessivo de álcool (Miller et al., 2017), sexo de risco (Dvorak et al., 2013), compras compulsivas (Rose \& Segrist, 2014), risco ao volante (Hayley et al., 2017). Em todos estes casos, a utilização adequada de estratégias de regulação emocional apresentou alguma diminuição destes comportamentos de risco.

Magar et al. (2008) investigaram a influência de componentes cognitivos e afetivos da autorregulação sobre diferentes comportamentos de risco e nos processos de tomada de decisão. Avaliaram 134 universitários que responderam a questionários de regulação emocional, atividades relativas a funções executivas, além de instrumentos sobre comportamentos de risco e tomada de decisão. Os resultados indicaram que a reavaliação cognitiva foi um preditor de menor comportamento de risco como fumar e beber, enquanto dificuldades executivas estiveram relacionadas a decisões mais arriscadas em cenários hipotéticos. O conjunto de resultados indicou diferentes vias pelas quais processos de regulação emocional e funções executivas alteraram a tomada de decisão.

A propensão ao comportamento de risco se manifesta de forma bastante específica em função do sexo dos indivíduos, como pode ser depreendido pela literatura científica da área. Interessados em compreender tais particularidades, Panno et al. (2018) solicitaram que 149 estudantes, de ambos os sexos, respondessem a um questionário sobre ansiedade traço, um inventário sobre depressão e a uma tarefa de tomada de decisão. As análises indicaram que traços de ansiedade mediaram a relação entre sexo e comportamentos de risco. Os achados sugeriram que, embora mulheres apresentem menor propensão ao risco, a presença de traços de ansiedade pode alterar essa relação. Buelow (2015) investigou o efeito de características de personalidade, humor e funções executivas no desempenho de 489 pessoas em uma tarefa de tomada de decisões cognitivas (frias) e baseada em emoções (quente). Os resultados indicaram não haver diferenças no desempenho de tomada de decisões quente e fria em função do sexo dos participantes, nem de sua idade. Também não foi observada relação estatisticamente significativa 
com afetos ou características de impulsividade, mas houve correlação negativa entre memória de trabalho e desempenho na tomada de decisão. Por outro lado, erros no WCST correlacionaram-se de modo estatisticamente significativo e direto com decisões mais arriscadas, sugerindo forte influência das funções executivas no processo decisional. Entretanto, alguns estudos parecem contradizer estes achados e não foram capazes de identificar tais particularidades de desempenho (Schreiber et al., 2012).

A partir dos achados deste atual levantamento da literatura científica pode-se apontar que os estudos focalizaram as estratégias de regulação emocional, com ênfase em suas formas metacognitivas e principalmente focadas no controle atencional. Em uma série de experimentos utilizando diferentes amostras e métodos correlacionais e experimentais, Rovenpor e Isbell (2018) investigaram como a crença na capacidade de controlar os próprios afetos influencia em decisões sobre se engajar ou evitar situações emocionalmente mobilizadoras. Seus resultados demonstraram que essa crença exerce dois papeis diferenciados, a saber: a) quando aliada à consciência afetiva, a crença de controlar as próprias emoções está associada a seleção de situações positivas (maior capacidade de regular emoções); b) quando associada à confiança, a crença de controle está mais associada a seleção de situações negativas. Para os pesquisadores, este aparente paradoxo está relacionado a diferentes mecanismos que as crenças de controle exercem sobre o indivíduo, o que leva a diferentes decisões e atitudes.

Kim e Kanfer (2009) investigaram como a realização de tarefas cognitivas influencia na redução do humor negativo. Para tanto, os autores realizaram um experimento com 136 jovens adultos, que responderam a um questionário de busca por sensações e foram expostos a um clip (breve vídeo) que induziu afeto negativo. Em seguida, os sujeitos foram alocados em três situações diferentes para tomarem decisão: a) realizar uma escolha em situações de risco; b) realizar uma escolha após um tempo de espera; c) realizar primeiro uma tarefa cognitiva de memorização e depois a tarefa de tomada de decisão. Participantes que fizeram a tarefa de julgamento logo após a exposição ao vídeo fizeram julgamentos mais arriscados que os demais grupos. O terceiro grupo apresentou escolhas menos arriscadas. Os autores sugerem que a demanda cognitiva da tarefa de memorização ajudou os participantes a regularem suas emoções negativas.

O mindfullness, ou atenção plena, parece um importante componente regulatório com impacto em comportamentos sociais (Miranda \& Kim, 2015; Passanisi et al., 2019). Por se tratar de um processo sofisticado de manutenção da atenção por meio do controle cognitivo, sua utilização pode estar relacionada ao desenvolvimento de características cognitivas de alta ordem, que tendem a diminuir a influência de mecanismos bottom up (Sistema I) e aumentam os 
mecanismos top down (Sistema II), embora ainda haja resultados contraditórios quanto a esse papel (Reynolds et al., 2015).

Para avaliar o papel da autorreflexão, uma característica associada aos sistemas regulatórios, Calvillo e Burgeno (2015) conduziram dois estudos. No estudo I, 184 estudantes fizeram uma jogada no "Jogo do Ultimato" (UG), em seguida responderam ao teste de reflexão cognitiva (CRT7) e ao Inventário Racional-Experiencial (REI-40). Os resultados mostraram que $54,3 \%$ dos participantes aceitaram ofertas injustas, sendo que altos escores no CRT se correlacionaram com a aceitação deste tipo de oferta. No estudo II, 306 participantes fizeram 20 jogadas no UG, em seguida responderam a uma versão estendida do CRT17. Novamente os resultados demonstraram que escores elevados no CRT estavam associados a maior probabilidade de aceitação de respostas injustas. Os autores interpretaram o conjunto desses achados como indicador de que maior autorreflexão pode levar a aceitação das ofertas, dado que estas estão associadas a menor ativação do sistema bottom up (Sistema I).

\subsubsection{Bases neurobiológicas do comportamento decisório}

Uma abordagem comum de investigação na área é a integração de informações biológicas e comportamentais durante a execução de tarefas em que os sujeitos precisam tomar decisões. Essa perspectiva permite investigar processos implícitos que ocorrem em momentos de aparente irracionalidade (Lockenhoff, Rutt, Samanez-Larkin, O’Donoghue \& Reyna, 2019) e em situações de risco (Chen, Rusch, Dawson, Rizzo, \& Anderson, 2015; Werner, Duschek \& Schandry, 2009). Além disso, alguns estudos de base neuropsicológica sobre os processos de tomada de decisão procuram examinar possível associação entre comportamentos observados e a circuitaria neural que sustenta tais mecanismos. Nesse campo, os métodos utilizados nas pesquisas variaram desde estudos genéticos (Buckholtz et al., 2008), passando por estudos de lesão cerebral (Anderson et al., 2006; Chen et al., 2015). Também há uma linha investigativa voltada aos mecanismos neurais envolvidos em traços individuais, como: alexitimia (Sutherland et al., 2013), desejabilidade social (B. L. Hughes \& Beer, 2012), agressividade (Kumari et al., 2014), neuroticismo (Harenski et al., 2009; Servaas et al., 2015), psicopatia (G. M. Brennan et al., 2018; Han et al., 2012) e impulsividade (Kerr et al., 2015; Leshem \& Yefet, 2019; Muhlert \& Lawrence, 2015).

Buckholtz et al. (2008) investigaram a relação entre variações genéticas, responsividade afetiva e traços de personalidade. Para tanto, coletaram material genético de 123 participantes, com média de idade de 29,23 anos (DP = 0,72), de ambos os sexos. Em seguida, os participantes responderam a um questionário de personalidade e realizaram uma tarefa de reatividade 
emocional, dentro de uma máquina de ressonância magnética. As análises genéticas demonstraram que variações nos genes responsáveis pela produção de Monoamina Oxidase A (MAOA) relacionam-se com diferenças nas conexões das regiões ventromedial e amígdala, que por sua vez estão associadas a traços de personalidade referentes à evitação de danos e dependência de reforço, fenômenos relacionados à tomada de decisão.

Com o objetivo de investigar o impacto de mudanças na personalidade e experiências afetivas sobre decisões, Anderson et al. (2006) avaliaram 51 pacientes com lesão cerebral, registrados no departamento de Neurociências Cognitivas da Universidade de Iowa. Os pacientes foram divididos em grupos, de acordo com a localização da região da lesão: o Grupo 1 foi composto por pacientes com lesão na região ventromedial $(n=7)$, o Grupo 2 envolveu casos com lesão pré-frontal não ventromedial $(n=14)$ e o Grupo 3 reuniu pacientes com lesões em outras regiões fora da área pré-frontal. Os pesquisadores observaram que pacientes do Grupo 1 apresentaram maiores alterações nas variáveis relacionadas à personalidade e na reatividade emocional. Além disso, a diminuição da afetividade foi o maior preditor de dificuldades nas tarefas diárias.

$\mathrm{Na}$ tentativa de examinar processos neurofisiológicos envolvidos e o impacto de lesões cerebrais nas tomadas de decisão em situações de risco, Chen et al. (2015) também compararam três grupos de indivíduos no Departamento de Neurologia da Universidade de Iowa. Um grupo $(n=11)$ possuía dano no córtex pré-frontal ventromedial, o segundo grupo $(n=12)$ com lesão em outras regiões cerebrais e um grupo controle $(n=14)$, todos com idade média de 63 anos, escolaridade elevada ( $M=14$ anos). Enquanto estavam em uma máquina de ressonância magnética, os participantes foram solicitados a realizar uma tarefa num simulador de direção, que lhes apresentava duas situações. Na primeira, um motorista virtual realizava uma manobra arriscada, enquanto na outra não havia essa manobra. Os participantes foram comparados em termos de condutividade da pele, ativação cerebral e realização de manobras arriscadas (decisão de risco). Os resultados indicaram que, na condição arriscada, os pacientes com lesão na região ventromedial demonstraram mais suscetibilidade à pressão social, realizando manobras mais arriscadas. Também demonstraram respostas epidérmicas mais prolongadas que os demais grupos. Esses achados indicaram que a excitação emocional, mediada pelo córtex pré-frontal ventromedial, participou de modo relevante em decisões pessoais de risco, ou seja, indivíduos com lesão nessa região cerebral demonstraram maior propensão a se deixar levar por pressões sociais, envolvendo-se mais em situações de risco.

$\mathrm{Na}$ busca de evidências sobre possível influência da idade na tomada de decisões, Lockenhoff et al. (2019) estudaram 120 participantes entre 18 e 84 anos. Os pesquisadores 
conectaram os indivíduos em eletrodos, sendo estimulados por sequência de choques em sete diferentes intensidades. Os participantes passaram por duas condições: na primeira, eles poderiam escolher a ordem em que receberiam os choques, na segunda, houve uma sequência predeterminada para os estímulos. As reações emocionais foram mensuradas durante a tarefa em nível fisiológico e posteriormente, em retrospectiva, por meio de autorrelato. Os resultados indicaram não haver relação entre idade e o processo decisório. Os participantes tiveram preferência por uma sequência decrescente de intensidade dos choques e, nestas condições, a resposta afetiva tendeu a decrescer, mesmo que, no geral, as sequências tivessem a mesma quantidade de choques.

Com objetivo de examinar associações entre estados afetivos, regulação emocional e tomada de decisões (a partir do desempenho no IGT), Werner et al. (2009) investigaram participantes $(n=64)$ de uma universidade alemã, de ambos os sexos, com idades entre 19 e 32 anos $(M=23,47 ; D P=3,02)$. Eles responderam a uma escala de traços de ansiedade, outra de experiências emocionais e responderam ao IGT enquanto sua frequência galvânica era monitorada. Os resultados indicaram que os traços de ansiedade estavam mais relacionados a níveis elevados de resposta galvânica da pele e associados ao melhor desempenho no IGT. Por sua vez, as experiências relacionadas à regulação emocional estiveram inversamente relacionadas à frequência galvânica da pele e pior desempenho no IGT. Os autores interpretaram estes achados como condizentes com a Hipótese do Marcador Somático (HMS), na medida em que sinais afetivos claramente permearam o processo de tomada de decisão dos indivíduos. Quando havia maior regulação emocional, diminuindo indicadores afetivos, os participantes realizaram escolhas mais arriscadas no IGT, obtendo pior desempenho.

O papel da região ventromedial como região de processamento afetivo e alterações de personalidade foi evidenciado por Sutherland et al. (2013) ao estudarem indivíduos com alexitimia, condição caracterizada por dificuldades em identificar e expressar suas emoções. Seus dados apontaram que pessoas com altos níveis de alexitimia apresentaram menor conectividade entre a ínsula e o córtex pré-frontal ventromedial em grupos de fumantes $(n=24$; sendo 12 do sexo feminino), quando comparados com grupo controle de não fumante ( $\mathrm{n}=20$, sendo 10 do sexo feminino). Além disso, estes níveis elevados de alexitimia predisseram maiores níveis de desejo por nicotina durante momentos de abstinência. $\mathrm{O}$ conjunto de resultados sugere que dificuldades afetivas características do quadro de alexitimia estão diretamente relacionadas às regiões ventromedial e impactam em comportamentos de risco.

Hughes e Beer (2012) procuraram identificar mecanismos neurais envolvidos no comportamento de mentir sobre seus próprios conhecimentos para se mostrar melhor do que 
realmente é, processo psicológico reconhecido na literatura científica como cognições egoístas ou desejabilidade social. Solicitaram a 18 estudantes que respondessem a um questionário sobre conhecimentos e informassem o quanto estavam familiarizados com os assuntos, sendo que enquanto realizavam a tarefa estavam em uma máquina de ressonância magnética. Metade dos participantes foi informado de que alguns dos itens do questionário tratavam de assuntos falsos, sendo impossível que tivessem familiaridade com eles. Os resultados indicaram que o grupo em que havia a possibilidade de relatarem familiaridade com assuntos inexistentes foi mais conservador nas notas atribuídas ao próprio conhecimento. Além disso, apresentaram maior ativação no córtex orbitofrontal, medial e cingulado anterior dorsal, áreas relacionadas à tomada de decisão.

As alterações observadas em sujeitos com traços de neuroticismo podem estar relacionadas, por sua vez, aos circuitos que codificam expectativas e recompensas em situações sociais. Servaas et al. (2015) solicitaram que 120 voluntários, de ambos os sexos, com idade entre 18 e 25 anos $(M=20,8 ; D P=2,0)$ respondessem a um questionário de personalidade. Em seguida participaram de 25 rodadas do Jogo do Ultimato (em que o sujeito deve aceitar ou rejeitar propostas financeiras), enquanto o nível de atividade cerebral era monitorado por um aparelho de ressonância magnética funcional. Embora, os autores não tenham encontrado diferenças na atividade cerebral de participantes com altos níveis de neuroticismo durante as ofertas injustas, observaram alterações nos circuitos de motivação e recompensa, indicando possíveis alterações funcionais.

A literatura científica ainda aponta as pessoas com traços de psicopatia como outro grupo de indivíduos com particularidades no processamento emocional. Com foco nessa característica, Han et al. (2012) compararam a percepção de emoções em faces de indivíduos com elevados traços de psicopatia $(n=16)$ e outro grupo com baixos níveis nesse traço de personalidade $(n=16)$. Os participantes foram recrutados em uma universidade americana e na comunidade local, tendo idade entre 17 e 35 anos. Os achados não apontaram alterações na percepção de emoções expressas em faces. Entretanto, a ativação na região da amígdala foi muito inferior no grupo com altos traços de psicopatia do que no grupo de comparação, indicando diferenças funcionais na reatividade cerebral a pistas afetivas nestes indivíduos. De maneira inversa, sujeitos com altos níveis de neuroticismo apresentaram reatividade extremamente elevada da amígdala quando comparados com indivíduos com traços de psicopatia, indicando que traços de personalidade têm impacto diferente na ativação de regiões cerebrais relacionadas às emoções (Harenski et al., 2009). 
Alterações observadas em indivíduos com traços de psicopatia podem estar ligadas a fatores ambientais, como eventual histórico de abuso na infância, favorecendo maior propensão a comportamentos agressivos ao longo da vida. Em uma investigação nesta área, conduzida por Kumari et al. (2014), foram avaliados 57 voluntários, sendo 14 pacientes com transtorno de personalidade antissocial, 13 com diagnóstico de esquizofrenia, ambos com histórico de comportamentos violentos; e 15 com diagnóstico de esquizofrenia, mas sem histórico de comportamentos violentos, além de 15 voluntários saudáveis do Reino Unido. Os participantes foram avaliados em relação a histórico pregresso de abusos físicos, sexuais e negligência durante a infância, bem como histórico de envolvimento em situações de violência física. Foram avaliadas diferenças volumétricas na região cerebral do cingulado anterior, relacionada a controle da impulsividade e da tendência à violência. Os resultados indicaram que pacientes com pior histórico de abusos durante a infância apresentaram menor volume nessa região cerebral, quando comparados com pacientes sem histórico de comportamentos violentos e ao grupo controle.

Ainda na mesma direção temática, Brennan et al. (2018) investigaram a hipótese de que situações ambientais estariam relacionadas às reações agressivas de indivíduos com traços psicopáticos. Propuseram a 76 adolescentes e jovens de uma cidade americana, com idade entre 14 e 24 anos, um experimento envolvendo exclusão social. Os participantes responderam a um questionário sobre traços de psicopatia em jovens e um de risco de comportamentos impulsivos. Em seguida, enquanto estavam ligados a uma máquina de eletroencefalografia (EEG), os participantes realizaram uma tarefa no computador em que jogavam com mais duas crianças um jogo em que deveriam interagir com uma bola virtual, como num jogo de baseball. Em determinado momento, as outras crianças passam a exclusivamente jogar a bola uma para a outra, excluindo o participante do experimento. Posteriormente, os participantes responderam a um questionário avaliativo sobre raiva. Os resultados indicaram que traços de psicopatia estavam associados a maiores reações à exclusão social percebida durante o jogo eletrônico, medida por dados eletroencefalográficos. Além disso, elevados traços de psicopatia, em conjunto com elevada reação cerebral, foi um preditor de elevado nível de raiva, indicando que comportamentos impulsivos podem ser respostas a aspectos fisiológicos, de personalidade e contextuais do ambiente.

Kerr et al. (2015) investigaram relações entre traços de impulsividade e regulação emocional em 10 mulheres que responderam a inventários de personalidade e impulsividade. Em seguida realizaram uma tarefa com recompensas afetivas e ficaram em estado de relaxamento por alguns segundos em uma máquina de ressonância magnética. Os resultados indicaram que 
mulheres com traços elevados de impulsividade tiveram maior atividade no córtex cingulado anterior e amígdala antes da recompensa, comparativamente a outras com escores rebaixados. Maior conectividade entre essas regiões mostrou correlação negativa com impulsividade.

Dificuldades de controle emocional podem estar relacionadas a menor volume de matéria cinzenta no córtex pré-frontal dorsomedial (dmPFC) e lobo temporal direito e no núcleo accumbens, conforme observado em estudo de Muhlert e Lawrence (2015). Utilizando uma técnica de ressonância eletromagnética funcional, estes investigadores avaliaram a relação de traços de impulsividade e neuroticismo com o volume de matéria cinzenta em um grupo de 152 voluntários, sendo 109 mulheres, com idade média de 23,6 anos ( $D P=5,4)$, em uma universidade do Reino Unido. Os achados sugerem que traços de impulsividade apresentam substratos neurobiológicos importantes.

Leshem e Yefet (2019) avaliaram diferenças de mecanismos neurais em tarefas de controle inibitório, com e sem estímulos emocionais, em um grupo de 100 estudantes universitários em Israel, sendo 81 mulheres, com idade entre 18 e 37 anos $(M=23)$. Em seguida, os participantes responderam a um instrumento avaliativo de impulsividade e um de ansiedade, depressão e estresse. Os estudantes foram classificados em um grupo com alta impulsividade e outro grupo com baixa impulsividade. As análises indicaram que indivíduos com altos níveis de impulsividade foram piores em ambas as tarefas de controle inibitório. Entretanto, diante de estímulos afetivos, os participantes com altos níveis de impulsividade foram capazes de manter a atenção por mais tempo, do que o grupo com baixos níveis de impulsividade. Os pesquisadores concluíram que os traços de impulsividade parecem estar relacionados de maneira diferenciada diante de estímulos puramente cognitivos ou emocionais.

Dessa forma, o conjunto de evidências neurobiológicas indicou que as relações observadas entre processos de tomada de decisão, características de personalidade e regulação emocional podem estar fortemente associadas circuitos neuronais compartilhados, especialmente as regiões da amígdala e do córtex-prefrontal ventromedial. Estas associações, em conjunto, dariam suporte à hipótese de direta interação entre traços de personalidade e respostas afetivas diante de específicos estímulos ambientais.

\subsubsection{Características psicopatológicas e tomada de decisão}

O uso de grupos de indivíduos com características psicopatológicas tem como principal objetivo a comparação com outros agrupamentos de pessoas (outros grupos clínicos ou controles), buscando identificar, pela contraposição de suas respostas a diferentes atividades empíricas, alterações em mecanismos relacionados aos processos de tomada de decisão. A 
literatura científica coleciona claras evidências de que pacientes psiquiátricos apresentam alterações importantes em tomada de decisão, regulação emocional e funcionamento da personalidade. Os estudos focalizaram diferentes transtornos psiquiátricos (Gansler et al., 2009; Gansler, Lee, et al., 2011; Gartenschlager et al., 2017), transtorno de personalidade narcisista (Muñoz Centifanti et al., 2013), transtorno bipolar (Ibraheim et al., 2017; Soloff et al., 2019), jogo patológico e abuso de substâncias (Kapsomenakis et al., 2018; Potenza et al., 2003; Smoski et al., 2011; Verdejo-García et al., 2007, 2010), estresse pós-traumático (Tull et al., 2019), transtorno de personalidade borderline (Cackowski et al., 2014; De Panfilis et al., 2019; C. D. Hughes \& Rizvi, 2019; Smoski et al., 2011; Vega et al., 2013), entre outros.

Estudos de neuroimagem com pacientes psiquiátricos demonstraram que comportamentos agressivos estão relacionados a maior lateralização da atividade do córtex orbitofrontal quando comparados com grupo controle (Gansler et al., 2009), porém a utilização de estratégias de autocontrole tende a diminuir esta ativação (Gansler, Lee et al., 2011). Gartenschlager et al. (2017), por exemplo, pediram a 32 pessoas com e sem histórico de diagnóstico de transtorno mental para responderem a um questionário relacionado a mindfullness, depressão e ansiedade. Em seguida, esses colaboradores ficaram por 30 minutos em uma máquina de ressonância magnética, com o objetivo de investigar como características de mindfullness estariam associadas a regiões cerebrais quando o indivíduo está em repouso. Os resultados indicaram atividade cerebral aumentada em regiões relacionadas à integração de informações sensórias e memória, com decréscimo em regiões cerebrais relacionadas ao funcionamento emocional. Os autores interpretaram esses achados como indicadores de que a atenção plena tende a diminuir a intensidade da reatividade no processamento emocional. Outro estudo (Muñoz Centifanti et al., 2013), por sua vez, focalizou o comportamento agressivo em pacientes com personalidade narcisista, identificando diferenças na reatividade emocional associadas a particularidades no processamento das emoções destes indivíduos. Narcisistas com instabilidade emocional foram mais propensos a apresentarem comportamento agressivo de maneira reativa, enquanto narcisistas com estabilidade emocional evidenciaram comportamentos agressivos de maneira proativa.

Outro grupo de pacientes psiquiátricos caracterizado por fortes alterações do humor são os casos de transtorno depressivo e transtorno bipolar. Interessados em compreender a relação entre regulação emocional, trauma e tomada de decisão em pacientes depressivos, Huh, Baek, Kwon, Jeong e Chae (2016) pediram a 50 pacientes com diagnóstico de depressão que respondessem a um questionário sobre regulação emocional, experiências traumáticas e, em seguida, realizassem uma tarefa de tomada de decisão. Estes pesquisadores identificaram que a regulação emocional 
desadaptativa é o fator mais importante a afetar os padrões de aversão ao risco, que está altamente relacionada a traços de ansiedade e comportamentos de ruminação. A presença de histórico de trauma na infância foi o fator mais importante para os padrões de aversão à perda.

Ibraheim et al. (2017) buscaram compreender o papel da desregulação emocional no transtorno de personalidade bipolar (TPB) em adolescentes $(n=185)$, comparando-os com 367 pacientes sem este diagnóstico e com 146 adolescentes não pacientes. Os resultados indicaram que os adolescentes com TPB apresentaram maiores escores de desregulação que o grupo de pacientes sem diagnóstico de TPB e o grupo controle. As características mais marcantes incluíram dificuldades nas estratégias de regulação emocional e no controle dos impulsos. Essa dificuldade pode estar associada a menor ativação do córtex cingulado anterior (ACC). Um estudo de neuroimagem demonstrou que a menor ativação do ACC está associada a maior letalidade em tentativas de suicídio, sugerindo grande perda do controle inibitório (Soloff et al., 2019).

Outro grupo de casos psiquiátricos estudados quanto a regulação emocional e tomada de decisão é o de pacientes que sofrem compulsão, os quais apresentam alterações relacionadas aos sistemas de controle inibitório, como em indivíduos propensos ao jogo patológico e abuso de sustâncias. Em avaliações de personalidade, jogadores patológicos apresentaram características mais elevadas de busca por risco, neuroticismo e impulsividade. Tendem ainda a ter parcial consciência das próprias emoções, interferindo em suas tomadas de decisão, o que parece estar associado a menor atividade do córtex orbitofrontal (Kapsomenakis et al., 2018; Potenza et al., 2003).

Investigações com usuários de múltiplas substâncias demonstraram altos níveis de impulsividade e déficits em processos de tomada de decisão em situações de incerteza (VerdejoGarcía et al., 2010). Em grande medida, o uso de substâncias ilícitas foi associado a características de personalidade vinculadas a fortes necessidades de busca de sensação e urgência (Verdejo-García et al., 2007). Entretanto, essas dificuldades podem estar associadas à avaliação do nível de estresse associado ao contexto. Um estudo com pacientes com e sem comorbidade com transtorno de estresse pós-traumático (TEPT) identificou que indivíduos com sintomas de TEPT apresentaram maior comportamento de risco do que aqueles sem sintomas. Esses achados sugerem que alterações na tomada de decisão também dependem da situação ambiental em que são realizadas (Tull et al., 2019).

O estresse parece ter um papel importante na perda de controle emocional observada em pacientes com transtorno de personalidade borderline. Nessa diretriz, por exemplo, Cackowski et al. (2014) investigaram o impacto do estresse sobre o controle da impulsividade. Em um estudo 
quase experimental, os pesquisadores pediram a 31 pacientes com diagnóstico de Transtorno de Personalidade Borderline e 30 indivíduos não pacientes que respondessem a uma série de instrumentos sobre regulação emocional, tomada de decisão, personalidade, impulsividade e controle inibitório. Os grupos passaram por duas condições: uma em repouso e outra após indução de estresse. Os resultados indicaram que, na condição de estresse, os participantes do grupo clínico reportaram níveis mais elevados de impulsividade e tiveram pior desempenho na tarefa de controle inibitório, mas não apresentaram diferenças estatisticamente significativas nos processos de tomada de decisão. Os investigadores sugeriram que o controle cognitivo tende a reduzir em situações de estresse, aumentando a impulsividade do indivíduo.

Essas dificuldades de controle em situações estressantes e reatividade emocional podem estar associadas a alterações na amígdala e hipocampo (Smoski et al., 2011). Pacientes borderline podem apresentar avaliações enviesadas sobre suas experiências emocionais, julgando-as de maneira mais negativa, tanto ao prever, quanto ao recordá-las (Hughes \& Rizvi, 2019). O estudo de Vega et al. (2013) também identificou padrões alterados nos mecanismos de recompensa em casos borderline, correlacionados com dificuldades nos processos de decisão. Prejuízos nas atividades de regulação emocional, relacionadas a ausência de planejamento, catastrofização e ruminação pareceram fortemente presentes nestes pacientes (Badoud et al., 2015). Apesar disso, a utilização de estratégias de regulação emocional (como reavaliação cognitiva) mostrou-se eficiente para diminuir a reatividade emocional na tomada de decisão (De Panfilis et al., 2019).

Dessa forma, o estudo com grupos psicopatológicos permitiu avançar na compreensão de como os processos psicológicos relacionados à inter-relação entre tomada de decisão, regulação emocional e personalidade estão implicados, especialmente em casos extremos. Pacientes com transtornos mentais costumam apresentar importantes alterações comportamentais em termos de tomada de decisão, realçando a relevância desta área de investigação científica. O conjunto de estudos identificados neste levantamento da literatura científica permitiu reconhecer que processos psicopatológicos estão associados a alterações neuronais que, por sua vez, podem se manifestar em alterações nos processos psicológicos avaliados por instrumentos padronizados de exame, justificando-se investimentos nesta área.

\subsubsection{Simulação computacional em processos decisórios}

Um dos campos mais recentes e atuais está relacionado ao uso de simulações computacionais para compreender a inter-relação entre as muitas variáveis envolvidas nos processos decisórios. Nesse sentido, alguns pesquisadores têm utilizado dados relativos às 
características de personalidade e regulação emocional com objetivo de desenvolver inteligência artificial para interagir com seres humanos. Com esse objetivo, Fonooni (2007) aperfeiçoou um modelo de tomador de decisão, inserindo aspectos emocionais no processo de escolha das informações. Dessa forma, segundo o autor, a experiência do ser humano com a máquina tende a ser mais aproximada.

Além disso, o uso de simulação pode ajudar a compreender como indivíduos orientam seus comportamentos a partir de pistas ambientais e as integram com características individuais no processo de tomada de decisão. Chohra e Madani (2016), através de uma simulação de computador, investigaram a tomada de decisões em função de diferentes características de personalidade e variados estímulos ambientais. Os resultados indicaram que as decisões tomadas foram diferentes a depender da inter-relação de características de personalidade, sistemas motivacionais e dos tipos de emoções que a situação provocou, bem como sua intensidade.

Por fim, a simulação pode auxiliar a compreensão das complexas relações existentes nos processos de tomada de decisão. Por exemplo, Bouazza e Bendella (2017) realizaram estudos de simulação com modelos computacionais acerca da influência da regulação emocional e características de personalidade. Estes investigadores, "ensinaram" o computador a manejar emoções em situações estressantes, levando em consideração traços como humor e personalidade. Os resultados indicaram que estratégias de regulação emocional tendem a ser afetadas por características de personalidade que podem aumentar ou diminuir a persistência dos afetos.

Ainda conte com poucos estudos, esta linha investigativa da inteligência artificial parece promissora. Seus métodos sofisticados e robustos podem favorecer a compreensão de como a inteligência artificial pode interagir com indivíduos humanos e sua natural complexidade. Desta forma, fazem-se necessários modelos teóricos que levem em consideração tanto processos cognitivos, quanto afetivos, para que possam mimetizar a experiência humana.

\subsection{Síntese da literatura científica e hipóteses de trabalho}

O conjunto de evidências da literatura científica levantada até o momento permitiu identificar inter-relações entre processos de tomada de decisão, os modos de regulação emocional e as características de personalidade dos indivíduos, independentemente de sua faixa etária ou contexto sociocultural. Diversos traços de personalidade pareceram favorecer ou dificultar estratégias específicas de equilibração afetiva, interferindo em escolhas realizadas nos mais variados contextos da vida. Os estudos de natureza neurobiológica apontaram que o 
compartilhamento de estruturas neurais envolvidas no processamento cognitivo e afetivo fundamenta base constitucional dos processos decisórios.

A diversidade de linhas investigativas e de métodos de trabalho utilizados nas pesquisas realizadas ainda não permite um quadro geral consistente sobre a área, mas fica clara a necessidade de se trabalhar numa proposta multimétodos em novos estudos, como pretendido neste atual trabalho. A literatura científica aponta lacuna e necessidade de se levar em consideração tanto características de personalidade, quanto de regulação emocional para melhor compreender os processos de tomada de decisão dos seres humanos. Com base nestas perspectivas, formulamos as seguintes hipóteses de trabalho:

Hipótese 1: Espera-se identificar padrões de diferentes disposições de regulação emocional e dificuldades de regulação que caracterizam perfis de regulação emocional. De acordo com a literatura, espera-se que pelo menos 3 perfis de regulação emocional emerjam empiricamente, sendo um perfil caracterizado por níveis baixos de regulação emocional, outro perfil moderado e, por fim, um terceiro com altos níveis de utilização de estratégias de regulação;

Hipótese 2: Espera-se que estes perfis de regulação emocional se relacionem com diferentes níveis de afetos positivos e negativos, bem como, com diferenças na propensão dos indivíduos a seguirem estas emoções;

Hipótese 3: Espera-se relacionar informações de um mesmo processo psicológico a partir de diferentes métodos de levantamento de informações. Em especial, espera-se que as variáveis de autorrelato de processos afetivos apresentem correlações moderadas com as variáveis afetivas no Método de Rorschach, bem como, variáveis de autorrelato e de desempenho no IGT relacionemse com variáveis de tomada de decisão no Método de Rorschach;

Hipótese 4: Espera-se observar relacionamento importante entre as variáveis de tomada de decisão e regulação afetiva a partir dos diferentes métodos utilizadas. De acordo com a literatura, espera-se que variáveis afetivas e de regulação emocional estejam associadas de maneira fraca com variáveis de tomada de decisão;

Hipótese 5: Por fim, espera-se que os diferentes perfis de regulação emocional, apresentam padrões divergentes em relação aos processos de tomada de decisão, dado que a literatura indica que os afetos, e forma como os controlamos influenciam nos processos decisórios. 
\begin{tabular}{ll|l} 
Pág in a & 69
\end{tabular}

OBJETIVOS 


\section{OBJETIVOS}

\subsection{Objetivo Geral}

Este trabalho teve como proposta geral examinar possíveis relações entre tomada de decisão, regulação emocional e características de personalidade, levando em consideração diferentes níveis de informação (autorrelato, desempenho e medidas implícitas) em adultos. Para tanto, foram elaborados dois estudos:

a) Estudo I: buscou explorar inter-relações entre variáveis de regulação emocional, caracterizando perfis de estratégias de regulação em adultos jovens, posteriormente vinculadas a variáveis afetivas.

b) Estudo II: procurou avaliar eventuais associações entre perfis de regulação emocional, variáveis do processo de tomada de decisão (fornecidas por instrumento neuropsicológico), e indicadores afetivos e cognitivos da personalidade de adultos (Método de Rorschach, sistema RPAS).

\subsection{Objetivos Específicos}

\subsubsection{Estudo I}

a) Caracterizar indicadores de processos de Regulação Emocional em adultos por meio do padrão geral de respostas à Escala de Afetos Positivos e Afetos Negativos (PANAS), Escala de Afetos (EA), Questionário de Regulação Emocional (ERQ), Escala de Dificuldades de Regulação Emocional (DERS) e Following Affective States Test (FAST);

b) Identificar padrões de regulação emocional (ERQ e DERS) e relacionar estes perfis a indicadores da vivência dos afetos (PANAS, EA e FAST).

\subsubsection{Estudo II}

a) Caracterizar indicadores de estilos e desempenho em processos de tomada de decisão em adultos jovens, por meio do padrão geral de respostas à Escala de Estilos de Decisão (DSS) e Iowa Gambling Task (IGT);

b) Caracterizar padrões de resposta de adultos jovens ao Método de Rorschach (R-PAS), em função de variáveis afetivas e de tomada de decisão; 
c) Examinar possíveis associações entre indicadores do Método de Rorschach (R-PAS) e variáveis relativas a estilos de tomada de decisão a partir de autorrelato (DSS) e do próprio desempenho (IGT) em adultos jovens;

d) Explorar relações entre variáveis afetivas e cognitivas do Método de Rorschach (R-PAS) e indicadores de Regulação Emocional derivados do Questionário de Regulação Emocional (ERQ), Escala de Afetos Positivos e Afetos Negativos (PANAS), Escala de Dificuldades de Regulação Emocional (DERS) e Escala de afetos (EA);

e) Identificar eventuais especificidades de perfis de regulação emocional em adultos jovens frente ao desempenho no Método de Rorschach (R-PAS) e no IGT. 
Pág ina | 72

MÉTODO 


\section{MÉTODO}

\subsection{Delineamento metodológico}

Este trabalho foi planejado para ser realizado em dois estudos, ambos de natureza quantitativa, transversal, descritivo-interpretativa e correlacional (Cozby, 2003). São pautados pelo uso de instrumentos de avaliação psicológica, com foco nas seguintes variáveis: tomada de decisão, regulação emocional e características de personalidade, além de dados sociodemográficos. Para cada estudo são apresentados: participantes, instrumentos, procedimentos de coleta e análise de dados, iniciando-se pelas questões éticas pertinentes aos dois estudos.

O presente trabalho fundamenta-se nos princípios teóricos da área de Avaliação Psicológica, conforme diretrizes profissionais elaboradas pela International Test Commission (ITC, 2016) e pelo Conselho Federal de Psicologia no tocante ao Sistema de Avaliação de Testes Psicológicos, SATEPSI (CFP, 2018). Esses princípios também se encontram detalhados nos respectivos instrumentos, respeitando-se suas especificidades técnicas e teóricas para exploração e análise dos dados, pautadas em procedimentos quantitativo-descritivos e interpretativos.

\subsection{Cuidados éticos}

Inicialmente o projeto de Doutorado foi submetido à apreciação e análise pelo Comitê de Ética em Pesquisa com Seres Humanos da FFCLRP-USP. Após sua aprovação (ANEXO 1), foram iniciados contatos com potenciais participantes por meio de contatos eletrônicos (e-mail) e por redes sociais, de modo a operacionalizar o processo de coleta de dados.

Cabe destacar que os procedimentos não previam desconforto aos participantes, exigindo apenas sua dedicação e tempo para as atividades. O pesquisador disponibilizou-se a minimizar eventual desconforto, antes, durante e após os procedimentos de coleta dos dados, com orientações pontuais sobre as necessidades emergentes. Dessa forma, buscou estar em consonância com as resoluções que regulamentam a pesquisa com humanos no Brasil, base para qualquer processo de avaliação psicológica.

Os direitos dos participantes foram garantidos, podendo solicitar informações sobre os resultados, bem como devolutivas individuais sobre os principais achados (APÊNDICE A), em formato compatível com o viável para o contexto existente (relatórios individuais com os 
resultados do Estudo I). Caso fossem identificadas quaisquer necessidades emergentes de cuidado em termos de saúde mental em algum participante, embora não fosse o foco do estudo, seria efetivada pelo pesquisador responsável a devida orientação e encaminhamento individual a serviços específicos de saúde mental. No entanto, este tipo de ação não se mostrou necessária neste trabalho.

No Estudo I foram realizadas aplicações online dos instrumentos de avaliação psicológica, por meio da plataforma para formulários de pesquisa Lime survey (https://goo.gl/JhrJzc), após a devida autorização do respondente por meio do Termo de Consentimento Livre Esclarecido - TCLE (APÊNDICE B). No Estudo II a coleta de dados ocorreu de forma individual, correspondendo a uma parte da amostra do primeiro estudo (APÊNDICE C). 


\subsection{ESTUDO I - Perfis de regulação emocional e sua relação com variáveis afetivas.}

\subsubsection{Participantes}

Para o Estudo I foram incluídos voluntários com idade superior a 18 anos e inferior a 60 anos, que livremente concordaram com o convite à pesquisa e que devidamente confirmaram isso pelo registro eletrônico de sua concordância no Termo de Consentimento Livre e Esclarecido (TCLE). Não foram controladas outras variáveis sociodemográficas. Assim, após a coleta de dados foram excluídos os respondentes que não atendiam à faixa etária do estudo, bem como aqueles que solicitaram exclusão de seus dados ou que não os completaram de forma integral.

A amostra do Estudo I, por fim, ficou composta por um total de 1.165 adultos, de ambos os sexos, com idade mínima de 18 e máxima de 60 anos. Trata-se de amostra de conveniência, obtida por meio de respostas ao convite eletrônico para participação na pesquisa, por meio de acesso à plataforma on-line para registro de dados. O percurso amostral pode ser visto na Figura 3.

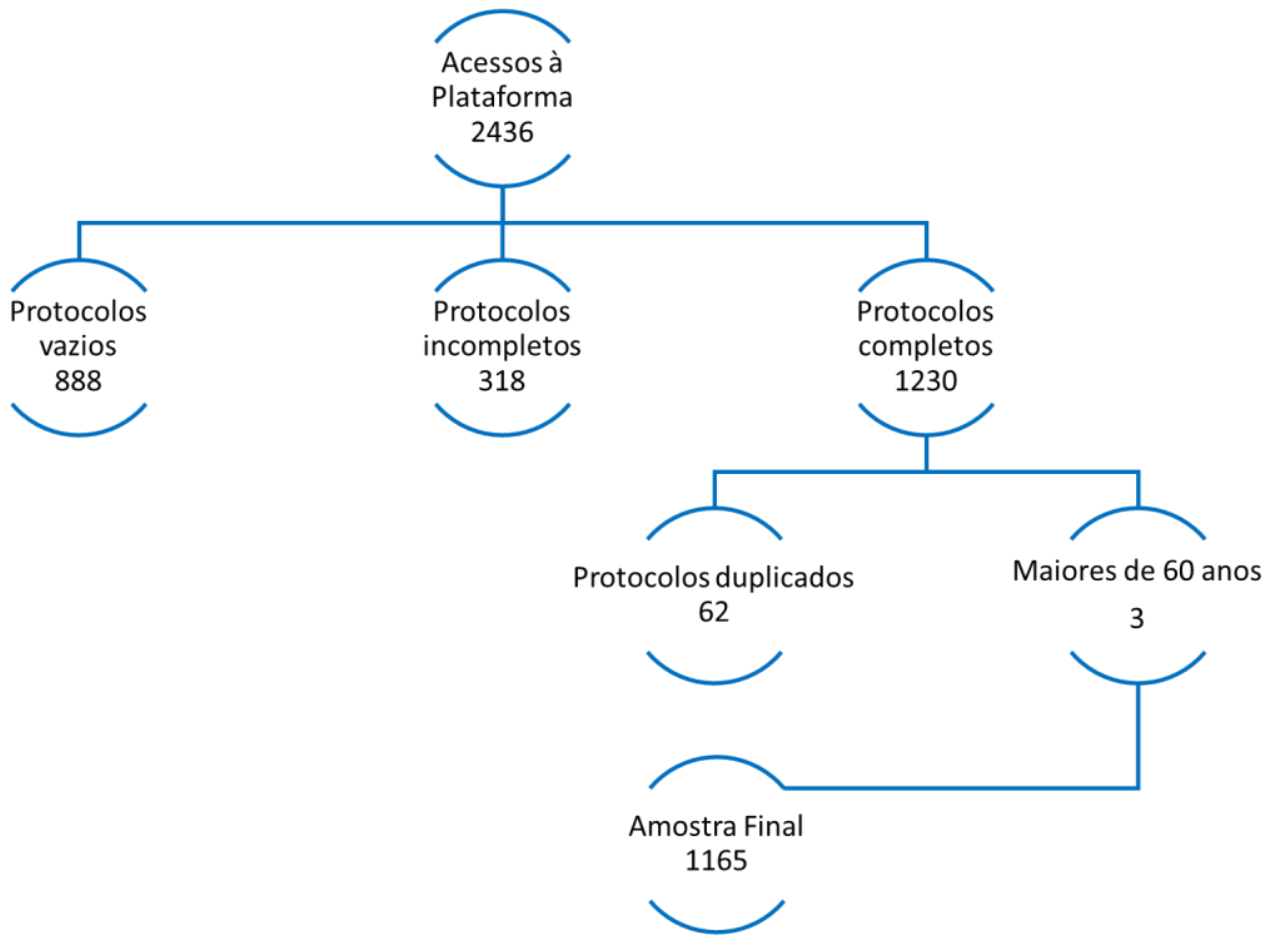

Figura 3. Percurso amostral do Estudo I $(n=1.165)$.

A caracterização dos participantes do Estudo I pode ser visualizada, em suas principais variáveis, na tabela 1. Os dados referentes à idade, escolaridade (em anos de estudo) e de pontuação total na avaliação econômica estão expressos em valores médios e desvio-padrão. Já 
as classes econômicas e a distribuição da origem dos participantes (em termos de Estados da Federação) aparecem em sua frequência simples e porcentagem total de indivíduos.

Tabela 1. Caracterização sociodemográfico em termos de idade, escolaridade, classe econômica, sexo e estado civil dos participantes do Estudo I $(n=1.165)$.

\begin{tabular}{|c|c|c|}
\hline Variáveis & Média & Desvio Padrão \\
\hline Idade & 26,72 & 8,35 \\
\hline Escolaridade* & 16,48 & 4,30 \\
\hline Classe Econômica (soma pontos) ${ }^{* *}$ & 31,84 & 10,96 \\
\hline Sexo & $f$ & $\%$ \\
\hline Feminino & 855 & 73,4 \\
\hline Masculino & 310 & 26,6 \\
\hline Classe Econômica** & $f$ & $\%$ \\
\hline Não informada & 1 & 0,001 \\
\hline A & 148 & 12,7 \\
\hline B1 & 166 & 14,2 \\
\hline B2 & 345 & 29,6 \\
\hline $\mathrm{C} 1$ & 267 & 22,9 \\
\hline $\mathrm{C} 2$ & 183 & 15,7 \\
\hline D-E & 55 & 4,7 \\
\hline Estado Civil & $f$ & $\%$ \\
\hline Casado (a) & 170 & 14,6 \\
\hline Divorciado(a)/Separado(a) & 30 & 2,6 \\
\hline Solteiro (a) & 850 & 73 \\
\hline União Estável & 67 & 5,8 \\
\hline Viúvo (a) & 4 & 0,3 \\
\hline Outros & 44 & 3,8 \\
\hline Unidade Federativa & $f$ & $\%$ \\
\hline $\mathrm{AL}$ - Alagoas & 7 & 0,6 \\
\hline AM - Amazonas & 806 & 69,2 \\
\hline AP - Amapá & 6 & 0,5 \\
\hline BA - Bahia & 12 & 1,0 \\
\hline CE - Ceará & 10 & 0,9 \\
\hline DF - Distrito Federal & 3 & 0,3 \\
\hline ES - Espírito Santo & 4 & 0,3 \\
\hline GO - Goiás & 6 & 0,5 \\
\hline MA - Maranhão & 15 & 1,3 \\
\hline MG - Minas Gerais & 30 & 2,6 \\
\hline MS - Mato Grosso do Sul & 9 & 0,8 \\
\hline
\end{tabular}




$\begin{array}{lcc}\text { MT - Mato Grosso } & 1 & 0,1 \\ \text { PA - Pará } & 57 & 4,9 \\ \text { PB - Paraíba } & 6 & 0,5 \\ \text { PE - Pernambuco } & 3 & 0,3 \\ \text { PR - Paraná } & 57 & 4,9 \\ \text { RJ - Rio de Janeiro } & 20 & 1,7 \\ \text { RO - Rondônia } & 7 & 0,6 \\ \text { RR - Roraima } & 5 & 0,4 \\ \text { RS - Rio Grande do Sul } & 15 & 1,3 \\ \text { SC - Santa Catarina } & 3 & 0,3 \\ \text { SE - Sergipe } & 2 & 0,2 \\ \text { SP - São Paulo } & 122 & 10,5\end{array}$

Nota: *Escolaridade expressa em anos de estudo.

**Conforme Critério de Classificação Econômica Brasil (2016).

O número de participantes do Estudo I é compatível com seus objetivos, oferecendo-lhe suporte técnico. Em termos de síntese das características dos participantes, nota-se que a média etária do total da amostra foi 26,72 anos de idade $(D P=8,35)$. Dessa forma, a amostra caracteriza-se por adultos jovens, em período de vida economicamente ativo. O nível de escolaridade alcançou média de 16,48 anos de estudo $(D P=4,3)$ indicando grupo de elevada escolaridade, em sua maioria com ensino superior completo. Além disso, o nível econômico apresentou valores médios de 31,84 pontos $(D P=10,96)$, representando, segundo o Critério Brasil (Associação Brasileira de Empresas de Pesquisa, 2016) classe econômica elevada em termos de poder aquisitivo.

Observou-se o predomínio de pessoas solteiras $(n=850 ; 73,3 \%)$, com dispersão entre as demais possibilidades de estado civil. Com relação à caracterização da amostra em função do sexo, há claro predomínio de mulheres $(n=875)$, correspondendo a 73,4\% dos participantes deste estudo. No entanto, as características sociodemográficas permaneceram muito semelhantes para o sexo feminino e sexo masculino (tabela 2), sendo possível constituir uma amostra total compatível com o esperado para os objetivos pretendidos neste trabalho.

Tabela 2. Caracterização sociodemográfica de idade, escolaridade e classe socioeconômica da amostra do Estudo I $(n=1.165)$ em função do sexo dos participantes. 


\begin{tabular}{lcccc}
\hline \multirow{2}{*}{ Variáveis } & \multicolumn{2}{c}{$\begin{array}{c}\text { Feminino } \\
(n=855)\end{array}$} & \multicolumn{2}{c}{$\begin{array}{c}\text { Masculino } \\
\end{array}$} \\
& Média & DP & Média & DP \\
\hline Idade & 26,3 & 8,29 & 27,23 & 7,57 \\
Escolaridade* & 16,3 & 4,37 & 16,6 & 4,17 \\
Classe Econômica (somatória pontos) & 31,46 & 10,53 & 32,98 & 11,61 \\
\hline
\end{tabular}

Nota: * Escolaridade em anos de estudo; DP = Desvio padrão.

Visto que o Estudo I envolveu procedimento de coleta de dados on-line, isso possibilitou ampla variedade de participantes, moradores em diferentes localidades das unidades federativas do Brasil. Dos 27 Estados, 23 estão representados nesta amostra, embora com variados níveis de adesão. Em sua grande maioria os participantes são oriundos das regiões Norte e Sudeste do país. Embora, o número de participantes seja baixo em algumas regiões, a coleta on-line dos dados apresentou vantagens na questão da variabilidade de locais de moradia dos voluntários. Reiss e Reips (2016) e Wachelke et al. (2014) destacam como uma das vantagens dos estudos on-line justamente a possibilidade de incluir participantes de diferentes regiões territoriais, como ocorreu na presente amostra do Estudo I.

\subsubsection{Instrumentos}

a) Questionário Sociodemográfico e Escala Critério de Classificação Econômica Brasil (ABEP, 2016): permite caracterizar a amostra quanto a idade, sexo, situação socioeconômica. O Critério de Classificação Econômica Brasil tem por objetivo estimar o poder aquisitivo dos participantes. A classificação é feita a partir de níveis (A, B1, B2, C1, C2, D-E), sendo que o nível A corresponde ao mais elevado padrão econômico e o nível E o mais baixo padrão econômico, definido a partir da pontuação total no instrumento (ANEXO A).

b) Questionário de Regulação Emocional (ERQ): instrumento composto por 10 itens em escala do tipo Likert, sendo possível escolher entre "discordância total" (1) a "concordância total" (7). Foi originalmente elaborado por Gross e John (2003b) e traduzido para o português do Brasil por Boian et al. (2009). A ERQ busca avaliar duas estratégias de regulação emocional: supressão emocional ("Eu controlo as minhas emoções não as expressando") e reavaliação cognitiva ("Quando estou perante uma situação estressante, procuro pensar de uma forma que me ajude a ficar calmo"), por meio de escores específicos para cada uma dessas estratégias. O instrumento tem demonstrado positivas evidências de validade e fidedignidade em diversos contextos 
culturais (John \& Eng, 2014; Matsumoto, Yoo \& Nakagawa, 2008). No Brasil vem sendo estudado por Batistoni, Ordonez, Silva, Nascimento e Cachiboni (2013) e Gouveia et al. (2018), apresentando boas evidências de validade e precisão.

c) Escala de Dificuldades de Regulação Emocional (DERS): Desenvolvida por Gratz e Roemer (2004), a escala é composta por 36 itens que fazem afirmações sobre formas de sentir emoções e devem ser respondidos em uma escala Likert de 1 a 5, conforme a frequência com que o indivíduo se sente daquela maneira. Avalia seis dimensões de dificuldades de regular emoções, a saber: a) falta de acesso a estratégias para controlar as emoções (Estratégias - "Quando estou chateado, eu acredito que ficarei assim por muito tempo"); b) ausência de clareza sobre emoções (Clareza - "Eu tenho dificuldades de compreender meus sentimentos"); c) reduzido conhecimento das emoções (Consciência - "Presto atenção a como estou me sentindo"); d) dificuldade para controlar impulsos (Impulso - "Eu experimento minhas emoções como sufocantes e sem controle"); e) dificuldade para se engajar com objetivos (Objetivos - "Quando estou chateado tenho dificuldades em fazer meu trabalho"); f) não aceitação de respostas emocionais (Não aceitação - "Quando estou chateado, fico com raiva de mim mesmo por me sentir assim"). A DERS foi validada em diversos países, apresentando suficientes indicadores psicométricos. No Brasil, Miguel, Giromini, Colombarolli, Zuanazzi e Zennaro (2016) investigaram suas propriedades psicométricas, encontrando valores de precisão considerados positivos, bem como evidências de validade de construto.

d) Escala de Afetos Positivos e Afetos Negativos (PANAS): foi proposta por Clark e Watson (1994) como método de investigação de vivências afetivas, a partir do relato de intensidade e frequência de afetos positivos ("amável”) ou negativos ("humilhado"). É uma escala de autorrelato com respostas do tipo Likert, variando entre os pontos 1 "nem um pouco" a 5 "extremamente", composta por 20 itens. O respondente deve ler uma série de adjetivos relacionados a estados afetivos e definir o quanto experimentou cada um dos estados em um determinado período (em nosso estudo, foi utilizado um período de quinze dias). A escala foi adaptada para o uso no Brasil por Giacomoni e Hutz (1997) e posteriormente refinada e normatizada por Zanon e Hutz (2014).

e) Escala de Afetos (EA): Desenvolvida por Zanon, Bastianello, Pacico e Hutz (2013) no contexto do Brasil. A EA está composta por dois fatores, afetos positivos ("Me sinto confiante no dia a dia") e afetos negativos ("Muitas vezes, eu fico nervoso"), sendo constituída por 20 frases 
que descrevem sentimentos e emoções passadas e presentes. A escala apresentou bons indicadores de validade convergente e divergente em seus estudos iniciais.

f) Following Affective States Test (FAST): Instrumento de autorrelato desenvolvido por Gasper e Bramesfeld (2006) e adaptado para o Brasil por Pinto e Pasian (no prelo). É composto de 16 itens, com objetivo de avaliar a propensão a seguir ou a evitar o uso de informações de natureza emocional na tomada de decisão. A FAST avalia quatro dimensões: seguir afetos positivos SAP ("Presto muita atenção aos meus sentimentos positivos"), ignorar afetos positivos - IAP ("Não deixo meu bom humor influenciar minhas decisões"), seguir afetos negativos - SAN ("Sempre me entrego às minhas emoções negativas"), ignorar afetos negativos - IAN ("As pessoas nunca devem ser influenciadas pelos seus sentimentos negativos aos tomar decisões"). Os itens são apresentados como série de afirmações acerca de sua inclinação para seguir ou ignorar seus afetos numa escala do tipo Likert, variando entre 0 (discordo fortemente) e 6 (concordo fortemente). As pontuações atribuídas são somadas para se criar um escore, que varia de 0 a 24 pontos para cada dimensão da FAST. O estudo original reportou indicadores de precisão variando de 0,60 a 0,72 (Gasper \& Bramesfeld, 2006).

\subsubsection{Procedimentos - Coleta de dados}

Após a devida análise e aprovação do projeto pelo Comitê de Ética em Pesquisa da Faculdade de Filosofia Ciências e Letras de Ribeirão Preto da Universidade de São Paulo (CAAE: 62744516.3.0000.5407), fez-se divulgação online da pesquisa em listas de e-mails de instituições de ensino e mídias sociais. Os APÊNDICES D e E ilustram esse processo.

A coleta de dados ocorreu no período de agosto de 2017 a agosto de 2019. Todo participante declarou sua concordância com o estudo mediante marcação em uma caixa de diálogo abaixo do Termo de Consentimento Livre e Esclarecido - TCLE. Foram informados acerca dos objetivos do estudo e dos procedimentos de coleta de dados, garantindo-se o sigilo de sua identidade. Também foram avisados sobre o reteste, após quinze dias, bem como sobre a possibilidade de convite futuro à participação no Estudo II deste trabalho.

Os instrumentos de avaliação psicológica previstos no Estudo I foram organizados em uma plataforma para formulários de pesquisa lime survey (https://goo.gl/JhrJzc) seguindo a seguinte ordem: ERQ, PANAS, DERS, EA, FAST, DSS e o Questionário Socioeconômico. A imagem da tela do primeiro instrumento pode ser visualizada no APÊNDICE F. Estimou-se que, para completar o processo de resposta ao conjunto de instrumentos, os voluntários levariam de 
20 a 30 minutos. A figura 4 exemplifica a tela inicial que o participante encontrou ao clicar no link.

Passados 15 dias de sua primeira resposta ao estudo, os voluntários receberam um e-mail de agradecimento pela participação na pesquisa, junto a uma solicitação para colaborar com o reteste. Neste momento receberam novo link contendo os mesmos instrumentos a serem respondidos de forma on-line.

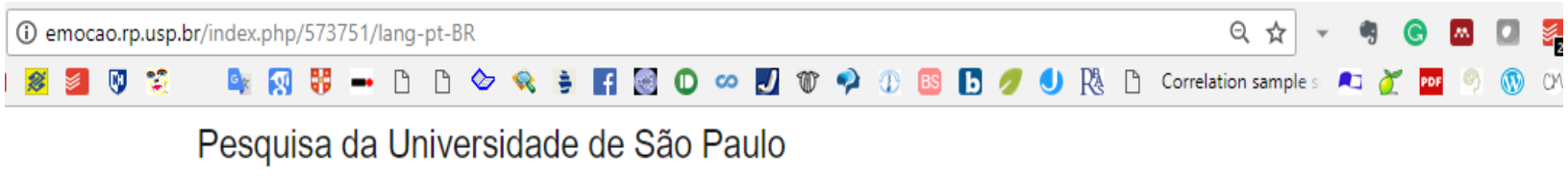

Personalidade, Regulação Emocional e Tomada de Decisão

BEM-VINDO! Por favor, use o navegador Firefox ou Chrome. Evite o Explore

Você está sendo convidado a participar como voluntário da pesquisa intitulada "Indicadores de tomada de decisão e regulação emocional no método de Rorschach, sistema R-PAS", que tem por objetivo estudar a relação entre controle das emoções, tomadas de decisão e características de personalidade de maneira a contribuir com a avaliação dessas características no contexto brasileiro. Esta pesquisa faz parte do Doutorado do psicólogo André Luiz de Carvalho Braule Pinto, sob orientação da Profa. Dra. Sonia Regina Pasian, do Departamento de Psicologia da Faculdade de Filosofia, Ciências e Letras de Ribeirão Preto, na Universidade de São Paulo (USP). Nesse trabalho você responderá um questionário com perguntas sobre suas características de vida e econômicas, além de instrumentos que solicitam informações sobre sua forma de controlar emoções e tomar decisões. Estima-se um tempo de 15 minutos para sua realização. Decorridos 15 dias você será solicitado a responder novamente informações sobre sua forma de controlar emoções, estimando-se um tempo de 10 minutos.

O risco decorrente de sua participação na pesquisa é considerado mínimo, vinculado a possível incômodo que as perguntas possam lhe causar. 0 pesquisador estará a sua disposição para quaisquer dúvidas ou necessidades. Se você aceitar participar da pesquisa não receberá benefícios diretos, mas estará contribuindo para o conhecimento científico sobre o tema. Você não terá nenhuma despesa, caso haja, você será ressarcido, porém não receberá nenhuma remuneração por participar dessa pesquisa. Você poderá desistir da pesquisa em qualquer momento, tendo o direito e a liberdade de retirar seu consentimento em qualquer fase, seja antes ou depois da coleta dos dados, independente do motivo e sem nenhum prejuízo a sua pessoa.

Os resultados da pesquisa serão analisados de modo geral, procurando-se identificar características comuns aos participantes, sendo garantido o sigilo sobre a identidade dos participantes do estudo. Após as devidas análises, os dados serão publicados, mas sua identidade não será divulgada, sendo garantido o sigilo de suas respostas.

0 pesquisador se coloca disponível para eventuais dúvidas e necessidades, pelo telefone (92) 9 9157-9945 e do e-mail braulepintoalc@usp.br.

Além disso, você poderá ter informações específicas sobre questões éticas dessa pesquisa diretamente no Comitê de Ética em Pesquisa da Faculdade de Filosofia, Ciências e Letras de Ribeirão Preto - FFCLRP-USP, no telefone (16) 3315-4811. Avenida Bandeirantes, 3900 - Bloco 23 - Casa 37 - 14040-901 - Ribeirão Preto - SP - Brasil, Fone: (16) 3315-4811, E-mail: coetp@@fflrp.usp.br

Desde já agradecidos, contamos com sua participação.

Figura 4. Tela inicial da plataforma online.

Cabe destacar que a pesquisa on-line tem se mostrado como estratégia eficaz investigação científica, principalmente pela economia de recursos e tempo em sua implementação (Reiss \& Reips, 2016; Wachelke et al., 2014). Tradicionalmente, a avaliação psicológica é realizada em situações controladas, que não ocorrem obrigatoriamente na avaliação on-line, gerando dúvidas sobre a segurança dos dados encontrados. Entretanto, diversos estudos demonstraram equivalência entre as propriedades psicométricas de instrumentos administrados de maneira tradicional (lápis e papel) e administração on-line (Di Girolamo et al., 2017; Reiss \& Reips, 2016). 


\subsubsection{Procedimentos - Análise dos dados}

Os instrumentos utilizados no Estudo I foram apurados de acordo com as diretrizes técnicas específicas de seus autores de referência. Os dados foram inicialmente tratados em termos individuais, sendo digitados em uma planilha computacional com base no Microsoft Excel. Compôs-se, assim, banco de dados a partir dos indicadores técnicos e variáveis específicas dos instrumentos utilizados, permitindo as análises estatísticas.

O conjunto desses dados foi analisado com auxílio do software livre R (versão 3.6.1) (R Core Team, 2020) e R-Studio (versão 1.3.959) (RStudio Team, 2020). Inicialmente foram verificados os pressupostos de normalidade da distribuição dos resultados pelo teste de normalidade de Shapiro-Wilk e foi explorada a presença de outliers univariados e multivariados, conjuntamente com análises gráficas, com o objetivo de identificar a adequação das análises propostas de acordo com sugestões de Ghasemi e Zahediasl (2012).

Um importante passo técnico para embasar o uso de instrumento de avaliação psicológica é, sem dúvida, a comprovação de sua fidedignidade. Tradicionalmente, a precisão de instrumentos psicológicos é compreendida como a estabilidade dos escores ao longo de diversas avaliações (Nunnally \& Bernstein, 1978; Pasquali, 2017). Embora possam ser utilizadas diversas técnicas de estimação dessa característica, corriqueiramente a precisão é reportada por meio de análises da consistência interna dos itens que compõem o instrumento, com uso frequente do coeficiente alpha de Cronbach $(\alpha)$. Entretanto, alguns autores apontam limites técnicos nesse indicador em termos de informação suficiente sobre a precisão de um instrumento de medida. Há sugestões de uso de outros parâmetros, como a confiabilidade composta (CC) (Maroco \& Garcia-Marques, 2013; Raykov, 1997). Dessa forma, optou-se por apresentar ambos os índices de fidedignidade das escalas utilizadas no Estudo I nesse trabalho.

Outra forma clássica para examinar a fidedignidade de uma medida psicológica é a estimação de sua estabilidade temporal. Nesse caso, o método de teste-reteste é utilizado, buscando-se estimar o quanto a medida se mantém ao longo do tempo. Cabe importante observação quanto a este procedimento, pois a literatura científica indica que para garantir a qualidade da informação obtida deste método, a escolha do tempo decorrido entre uma aplicação e outra deve ser orientada pela natureza da variável avaliada pelo instrumento (Watson, 2004). Com base nessas considerações, optou-se no atual trabalho por um intervalo de duas semanas entre as duas aplicações dos instrumentos do Estudo I. Isso porque a variável em foco (emoções) costuma apresentar fortes oscilações, podendo ter pouca estabilidade em maiores períodos de tempo. 
Segundo Pasquali (2017), a forma para se examinar a relação entre dados obtidos em dois momentos avaliativos é o uso de análises estatísticas de correlação entre resultados, cujos valores devem se aproximar de 1,0 para se mostrarem estáveis no tempo. Para Anastasi e Urbina (2000) a magnitude da correlação entre os dois momentos indica o quanto é possível generalizar os resultados de um teste para outros momentos, compreendendo variações nos resultados como erros não específicos. Entretanto, ao discutir a aplicabilidade do teste-reteste no contexto da avaliação da personalidade, Watson (2004) aponta para a necessidade de atenção para reais mudanças no traço latente avaliado. Dessa forma, registra a possibilidade do teste-reteste avaliar duas características: a precisão do instrumento (estabilidade temporal) ou mudanças reais no traço latente (dependability).

Após as análises de precisão, foram realizadas análises estatísticas descritivas dos dados, caracterizando os participantes em termos sociodemográficos, incluindo informações sobre idade, sexo, nível educacional e socioeconômico. Posteriormente, buscou-se descrever os resultados gerais da amostra em cada instrumento de avaliação psicológica. Em seguida, foi realizada análise de correlação de Pearson, com o objetivo de verificar as inter-relações entre variáveis afetivas, regulação emocional e variáveis socioeconômicas, idade e escolaridade. Posteriormente, para estimar os perfis de regulação emocional, foi adotado um procedimento de validação cruzada. O banco de dados foi dividido aleatoriamente em três subamostras: subamostra I, subamostra II e subamostra III.

Na subamostra I, numa perspectiva exploratória, utilizamos a análise de perfis latentes (LPA) que oferece abordagem analítica centrada em indivíduos (person-centered analysis). Tal perspectiva considera a possibilidade de que indivíduos façam parte de subpopulações, chamadas de perfis, ou classes, que se caracterizam por diferenças nas variáveis de interesse, e nem sempre refletem os mesmos parâmetros da população como um todo. A LPA foi conduzida pelo pacote tidyLPA (Rosenberg et al., 2018) e profileR (Desjardins, 2005). Para determinar o número de perfis mais adequado aos dados foram comparados os indicadores de ajuste Bayesian Information Criterion (BIC), Integrated completed likelihood (ICL) e Bootstraping (LRTS) preconizados por Nylund e Muthén (2007).

Posteriormente, em uma abordagem confirmatória, realizou-se uma validação cruzada (cross validation) a partir da solução do número de perfis estabelecidos anteriormente, em um novo conjunto de indivíduos, subamostra II, utilizando os mesmos critérios dos indicadores de ajuste da primeira etapa. Também foi verificada a estabilidade temporal da solução encontrada, comparando as respostas dos indivíduos após 15 dias (amostra reteste), estimando o nível de precisão com que os sujeitos eram agrupados em cada perfil, na primeira avaliação e no reteste. 
Para realizar a validação dos perfis, utilizamos a subamostra III, na qual foi realizada análise de regressão logística com o objetivo de verificar o peso de cada uma das variáveis dos perfis sobre sua composição. Por fim, uma ANOVA foi conduzida para verificar a validade externa dos perfis, buscando relacioná-los com a presença de afetos positivos e negativos (PANAS e EA) e com a tendência a seguir ou ignorar emoções, tanto positivas, quanto negativas (FAST). Todas as análises utilizaram como padrão de significância um valor de $p<0,05$.

\subsection{Estudo II - Relação entre Tomada de Decisão e Regulação Emocional}

\subsubsection{Participantes}

A partir da amostra do Estudo I foram identificados participantes residentes na cidade de Manaus (AM), onde foi realizada a coleta de dados (presencial) para o Estudo II. Inicialmente realizou-se contato por e-mail convidando estes voluntários para a segunda etapa da pesquisa. Nesse momento, também lhes foi enviado breve relatório individual com os resultados do Estudo I, de modo a incentivar os participantes a seguirem na nova etapa. Houve um interesse por parte de 37,46\% dos participantes $(\mathrm{n}=302)$. Destes, 113 chegaram a agendar horário para o novo processo de coleta de dados. Porém, apenas 92 participantes efetivamente compareceram ao local e ao horário agendado, sendo estes que compõe a amostra do Estudo II. A Figura 5 ilustra o percurso amostral do Estudo II. 


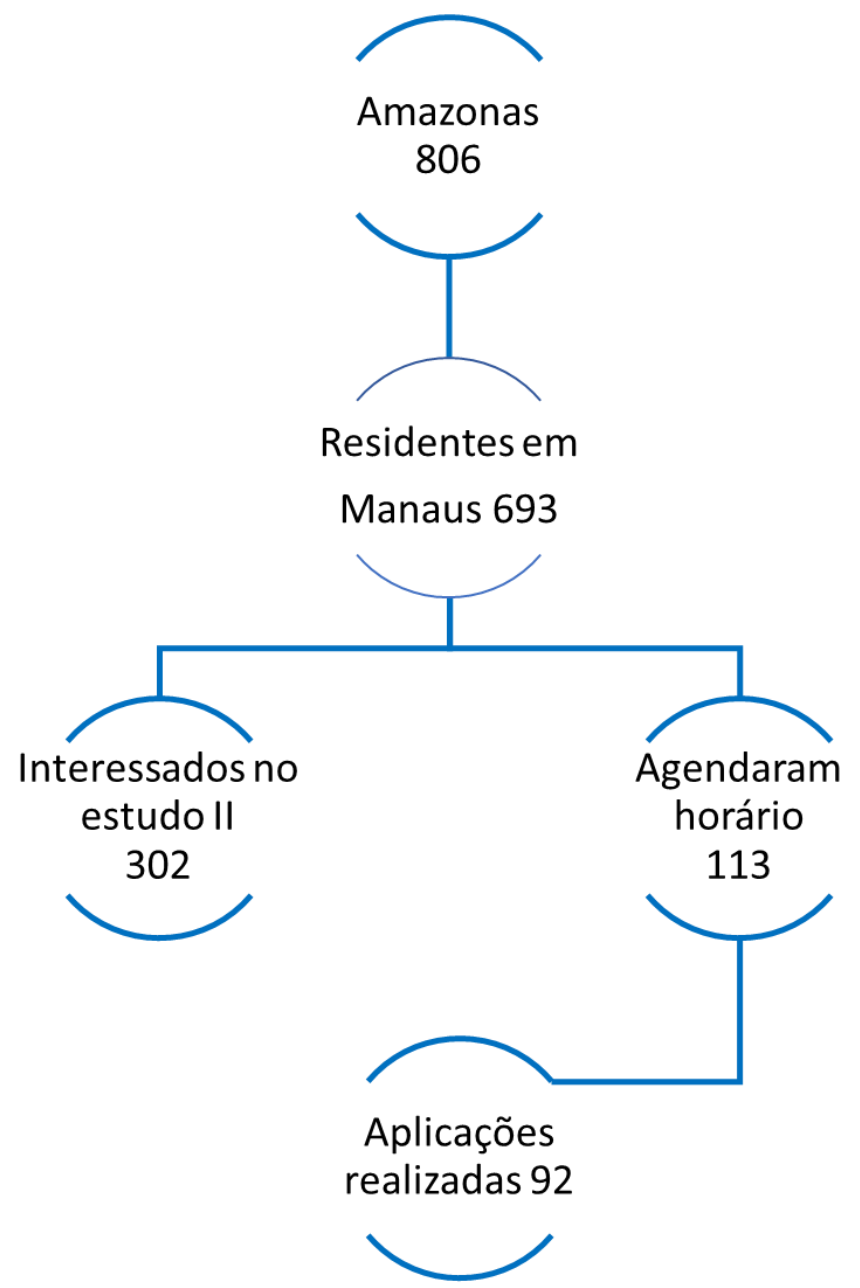

Figura 5. Percurso amostral do Estudo II (n=92).

A caracterização dos participantes do Estudo II pode ser visualizada na tabela 3. Idade, escolaridade e pontuação no questionário socioeconômico estão em valores médios e desviopadrão. O sexo dos participantes, a estratificação socioeconômica e estado civil aparecem em frequência e porcentagem.

Tabela 3. Caracterização sociodemográfico em termos de idade, escolaridade, classe econômica, sexo e estado civil dos participantes do Estudo II $(n=92)$.

\begin{tabular}{lcc}
\hline Variáveis & Média & Desvio Padrão \\
\hline Idade & 25,17 & 6,45 \\
Escolaridade* & 16,15 & 4,35 \\
Classe Econômica (soma pontos) & 31,75 & 11,06 \\
Sexo & $f$ & $\%$ \\
$\quad$ Feminino & 63 & 68,5 \\
$\quad$ Masculino & 29 & 31,5
\end{tabular}




\section{Classe Econômica}

Não informada

A

B1

B2

C1

$\mathrm{C} 2$

D-E

Estado Civil

Não informado

Casado (a)

Divorciado(a)/Separado(a)

Solteiro (a)

União Estável

Viúvo (a)

Outros
Nota: * Escolaridade em anos de estudo.
$\%$

5,8

13,8

17,2

19,5

28,7

17,2

3,4

$\%$

7,0

7,0

2,3

80,2

5,8

4,3

Os participantes do Estudo II apresentaram média etária de 25,17 anos ( $D P=6,45)$, o que reafirma a característica da amostra como composta por adultos jovens, com elevada escolaridade, em média 16 anos estudos formais $(D P=4,35)$ e classe econômica superior $(M=31,75 ; D P=11,06)$. Em sua maioria, foi composta por participantes do sexo feminino ( $\mathrm{n}=63$, $68,5 \%)$ frente a $31,5 \%$ de homens $(\mathrm{n}=29)$. O estado civil predominante foi de pessoas solteiras $(80,2 \%)$.

Frente aos objetivos delineados para o Estudo II, esta amostra de conveniência foi considerada numericamente suficiente. Foi abordada por questões de viabilidade prática na região Norte do Brasil, na cidade de Manaus (AM), por se tratar da cidade de residência do pesquisador.

\subsubsection{Instrumentos}

a) Estilos de Tomada de Decisão - (DSS): desenvolvido por Hamilton, Shih e Mohammed (2016) e adaptado para o Brasil por pesquisadores do Centro de Pesquisas em Psicodiagnóstico (CPP) da Faculdade de Filosofia, Ciências e Letras de Ribeirão Preto da Universidade de São Paulo (relatório interno, 2018). A DSS é uma escala de autorrelato que contém 10 itens que apresentam uma série de afirmações sobre formas como as pessoas preferem tomar decisões. Avalia dois estilos de tomada de decisão: estilo racional (“Considero diversos fatores quando tomo decisões") e estilo intuitivo ("Quando tomo decisões, eu confio principalmente no meu instinto"). 
b) Iowa Gambling Task (IGT): desenvolvido por Bechara et al (1994, 1999) com o objetivo de avaliar tomada de decisão, inicialmente em pacientes com lesão cerebral, e posteriormente em sujeitos saudáveis, o IGT é uma tarefa computadorizada em que quatro baralhos são apresentados em uma tela de computador (A', B', C' e D'). O participante deve selecionar uma carta por vez, de qualquer um dos baralhos da maneira que quiser até completar o número de 100 seleções. Cada vez que seleciona uma carta pode ocorrer uma recompensa, entretanto, em algumas situações, além de receber a recompensa, o participante recebe uma punição. Um cronograma de recompensas e punições pré-determinado é controlado pelo computador (Tabela 4). Segundo Bechara $(2007,2016)$ devido ao esquema de recompensas e punições, os baralhos A e B são considerados desvantajosos, pois a longo prazo, geram perdas, enquanto os baralhos C e D são considerados vantajosos, pois geram um lucro ao final da tarefa. Uma versão computadorizada desenvolvida por Malloy-Diniz et al. (2008) foi adaptada para a população brasileira e apresentou equivalência quando comparada à versão original, demonstrando validade discriminante para pacientes com TDAH, sendo posteriormente utilizada em outras populações clínicas (Malloy-diniz, 2009; Salgado, 2009). Esta versão computadorizada do IGT foi gentilmente cedida pelo Prof. Dr. Leandro Malloy-Diniz para este Estudo II.

Tabela 4. Esquema de recompensas e punições no IGT-Br para as primeiras 10 escolhas por baralho.

\begin{tabular}{|c|c|c|c|c|c|c|c|c|}
\hline Carta & \multicolumn{2}{|c|}{ Baralho A } & \multicolumn{2}{|c|}{ Baralho B } & \multicolumn{2}{|c|}{ Baralho C } & \multicolumn{2}{|c|}{ Baralho D } \\
\hline 1 & 100 & & 100 & & 50 & & 50 & \\
\hline 2 & 100 & & 100 & & 50 & & 50 & \\
\hline 3 & 100 & -150 & 100 & & 50 & -50 & 50 & \\
\hline 4 & 100 & & 100 & & 50 & & 50 & \\
\hline 5 & 100 & -300 & 100 & & 50 & -50 & 50 & \\
\hline 6 & 100 & & 100 & & 50 & & 50 & \\
\hline 7 & 100 & -200 & 100 & & 50 & -50 & 50 & \\
\hline 8 & 100 & & 100 & & 50 & & 50 & \\
\hline 9 & 100 & -250 & 100 & -1250 & 50 & -50 & 50 & \\
\hline 10 & 100 & -350 & 100 & & 50 & -50 & 50 & -250 \\
\hline Retorno cumulativo & & & & & & & & \\
\hline
\end{tabular}

c) Rorschach Performance Assessment System (R-PAS): Desenvolvido Herman Rorschach (1921/1978), o Método de Rorschach é composto de dez cartões com manchas de tintas sem forma definida, que devem ser apresentadas uma a uma para que o indivíduo responda à 
pergunta "Com o que isso se parece?" A partir das respostas, é possível sistematizar informações relativas a características de personalidade, entre as quais estão estilos de processamento cognitivo, processos perceptuais e de pensamento, manejo do estresse, representação de si e dos outros e vivências afetivas.

Existem diferentes sistemas avaliativos do Rorschach na literatura científica, fortalecendo a relevância de suas contribuições para o campo da personalidade em diferentes contextos. Neste trabalho optou-se por utilizar as diretrizes técnico-científicas do R-PAS (Meyer et al., 2017), respeitando-se seus princípios para os processos de aplicação e de avaliação das respostas dos participantes. Foram selecionadas variáveis relacionadas a processos afetivos e a tomada de decisão (Tabela 5), de acordo com a literatura científica sobre o Rorschach e conforme definições das variáveis apresentadas no manual (Meyer et al., 2017; Mihura et al., 2013; Mihura \& Meyer, 2018). Os estudos do R-PAS no Brasil se encontram em crescente proliferação, com promissores índices psicométricos de sua adequação para a realidade do Brasil (Amaro, Areco, \& Nascimento, 2017; Pianowski, Meyer, de Villemor-Amaral, Zuanazzi, \& Nascimento, 2019; Pianowski, Meyer, \& Villemor-Amaral, 2016; Rovinski, Schneider, Pariz, Santos, \& Bandeira, 2018; Vieira \& Villemor-Amaral, 2015).

Tabela 5. Variáveis afetivas e de tomada de decisão selecionadas para o Estudo II a partir do Método de Rorschach (R-PAS) de acordo com suas definições teóricas apresentadas no Manual do instrumento.

\begin{tabular}{|c|c|c|c|}
\hline $\begin{array}{l}\text { Variável } \\
\text { R-PAS }\end{array}$ & Definição & Descrição & Interpretação \\
\hline \multicolumn{4}{|c|}{ Afetividade } \\
\hline $\begin{array}{l}\text { MC - } \\
\text { PPD }\end{array}$ & $\begin{array}{l}\text { Diferença entre MC } \\
\text { e PPD }\end{array}$ & $\begin{array}{l}\text { Relaciona códigos que sugerem recursos (MC) } \\
\text { associados à elaboração ideacional (M) e } \\
\text { responsividade viva ao mundo a códigos que } \\
\text { sugerem dificuldades potenciais (PPD). }\end{array}$ & $\begin{array}{l}\text { Constitui uma medida de } \\
\text { eficiência das estratégias de } \\
\text { coping. }\end{array}$ \\
\hline $\mathrm{MC}$ & $\begin{array}{l}\text { Soma de M e } \\
\text { WSumC }\end{array}$ & $\begin{array}{l}\text { Indicador da atividade e processamento } \\
\text { psicológico = recursos psicológicos e } \\
\text { capacidade adaptativa, com base na } \\
\text { capacidade e na propensão para preencher, } \\
\text { animar e colorir seu mundo experiencial. }\end{array}$ & $\begin{array}{l}\text { Constitui uma medida da } \\
\text { capacidade de processar } \\
\text { informações e se adaptar. }\end{array}$ \\
\hline M & $\begin{array}{l}\text { Movimento } \\
\text { humano }\end{array}$ & $\begin{array}{l}\text { Representa um tipo de processo que contribui } \\
\text { para a capacidade de empatia, senso de } \\
\text { responsabilidade pessoal ativa, capacidade de } \\
\text { refletir sobre acontecimentos e experiências e } \\
\text { grau de maturidade de desenvolvimento. }\end{array}$ & $\begin{array}{lr}\text { É um indicador de } \\
\text { capacidade de refletir antes } \\
\text { de agir. Ligado aos } \\
\text { processos r cognitivos } \\
\text { superiores, sugere aplicação } \\
\text { de intencionalidade às ações. }\end{array}$ \\
\hline
\end{tabular}




$\begin{array}{ll}\text { V-Comp } & \begin{array}{l}\text { Composto de } \\ \text { vigilância }\end{array} \\ \text { R8910\% } & \begin{array}{l}\text { Porcentagem } \\ \text { respostas cartões } \\ \text { VIII-IX-X }\end{array} \\ & \text { Soma ponderada } \\ \text { WSumC } & \begin{array}{l}\text { determinante Cor } \\ \text { Cor pura }\end{array} \\ & \end{array}$

CBlend Cor misturada com sombreado e cor acromática

CF Forma com cor dominante

$(\mathrm{CF}+\mathrm{C}) / \quad$ Proporção de $\mathrm{CF}+\mathrm{C}$ SumC

$\begin{array}{ll}(\mathrm{CF}+\mathrm{C}) & \begin{array}{l}\text { Proporção de } \\ \text { - FC }\end{array} \\ \text { Forma-Cor } \\ \text { FC } & \begin{array}{l}\text { Cor com forma } \\ \text { dominante }\end{array}\end{array}$

PPD Determinantes potencialmente problemáticos

\author{
Cognição esforçada e focada, intensa \\ constrição afetiva. \\ Reflete responsividade geral a estímulos \\ coloridos/vibrantes, que representam situações \\ emocionais.
}

Relaciona-se a interesse e a consciência das características estimulantes, o que pode incluir reações emocionais.

Sugere receptividade cognitivamente passiva ou mesmo impotente a experiências ativadoras e estimulantes.

Sensibilidade emocional ou ambiental em que reações emocionalmente espontâneas podem ser comprometidas por preocupações. Sugere que a pessoa é vulnerável a experiências afetivas mistas.

Refere à predominância de cor sobre forma, indicando que a expressão afetiva se associa a controle cognitivo mais relaxado.

Indicador de relativa ausência ou relaxamento do controle cognitivo e da modulação nas reações da pessoa, especialmente quando há provocação emocional.

Indicador de impulsividade emocional que pode predispor a ações precipitadas.

Sugere menor reatividade passiva e máximo controle cognitivo.

Sensibilidade ou sintonia ambiental. Reflete capacidade de animar percepto, ver objetos estáticos em movimento. No entanto, esse tipo de sensibilidade pode ser uma desvantagem, pois estes códigos podem indicar estressores que estão fora de controle em termos de impulsos.
Indica um interesse por aspectos estimulantes e pode sugerir busca por sensações.

Indica abertura a impressões imediatas e uma vivência sem filtros, o que pode sugerir reatividade emocional.

Vulnerabilidade afetiva, sentimentos negativos.

Baixo controle cognitivo sobre a experiência afetiva.

Relaxamento do controle cognitivo sobre as reações afetivas.

Pode ser um indicador de impulsividade.

A experiência emocional é modulada por processos cognitivos sugerindo possibilidade de regulação das emoções através da racionalidade.

Experiência de ausência de controle. Poderia ser interpretado como locus de controle externo.

\section{Tomada de Decisão}

$\begin{array}{llll}\text { Dd\% Porcentagem } & \text { Reflete tendência a focar em detalhes Reflete um estilo cognitivo } \\ \text { detalhe raro } & \begin{array}{l}\text { incomuns, pequenos ou idiossincráticos no detalhista e focado em } \\ \text { ambiente da experiência. }\end{array} & \begin{array}{l}\text { observar minuciosas. } \\ \text { informações }\end{array}\end{array}$




\begin{tabular}{|c|c|c|c|}
\hline SI & $\begin{array}{l}\text { Integração do } \\
\text { espaço branco }\end{array}$ & $\begin{array}{l}\text { Indica esforço cognitivo, tentativa de } \\
\text { integração de informações complexas. }\end{array}$ & $\begin{array}{l}\text { Uso da atenção com algum } \\
\text { esforço cognitivo. }\end{array}$ \\
\hline IntCont & $\begin{array}{l}\text { Conteúdo } \\
\text { intelectualizado }\end{array}$ & $\begin{array}{l}\text { Reflete estilo intelectualizado de } \\
\text { processamento de informações. }\end{array}$ & $\begin{array}{l}\text { Estilo de processamento } \\
\text { cognitivo voltado para } \\
\text { racionalidade. }\end{array}$ \\
\hline $\mathrm{Vg} \%$ & $\begin{array}{l}\text { Porcentagem de } \\
\text { respostas vagas }\end{array}$ & $\begin{array}{l}\text { Reflete estilo de processamento cognitivo } \\
\text { vago, impressionista e relativamente ineficaz. }\end{array}$ & $\begin{array}{l}\text { Um estilo cognitivo } \\
\text { impressionista. Baseado em } \\
\text { impressões pouco precisas. }\end{array}$ \\
\hline V & Vista & $\begin{array}{l}\text { Reflete uso de nuances e sutilezas como base } \\
\text { para adquirir perspectiva, ganhar } \\
\text { distanciamento ou ver através das coisas. } \\
\text { Indica um recurso cognitivo. }\end{array}$ & $\begin{array}{l}\text { Estilo de processamento de } \\
\text { informação que utiliza um } \\
\text { distanciamento para adquirir } \\
\text { perspectiva. }\end{array}$ \\
\hline FD & Forma dimensão & $\begin{array}{l}\text { Sugere uma perspectiva avaliativa geral ou } \\
\text { capacidade de adotar uma perspectiva de } \\
\text { distanciamento. }\end{array}$ & $\begin{array}{l}\text { Estilo de processamento de } \\
\text { informação que busca um } \\
\text { distanciamento, mas envolve } \\
\text { afetos negativos. }\end{array}$ \\
\hline $\mathrm{M} / \mathrm{MC}$ & $\begin{array}{l}\text { Proporção de } \\
\text { Movimento } \\
\text { humano }\end{array}$ & $\begin{array}{l}\text { Avalia o grau em que decisões e ações são } \\
\text { influenciadas por deliberação meticulosa } \\
\text { versus reatividade espontânea. }\end{array}$ & $\begin{array}{lr}\text { Indicador unidimensional de } \\
\text { racionalidade } & \text { versus } \\
\text { reatividade. Em nível } \\
\text { elevado sugere maior } \\
\text { racionalidade e menor } \\
\text { envolvimento das emoções } \\
\text { no processo de deliberação } \\
\text { das decisões. Em níveis } \\
\text { rebaixados apontam para } \\
\text { envolvimento das emoções } \\
\text { na forma como o indivíduo } \\
\text { toma decisões. }\end{array}$ \\
\hline
\end{tabular}

Nota: Definições apresentadas foram retiradas e adaptadas a partir do Manual do R-PAS Meyer, Viglione, Mihura, Erard, \& Erdberg, (2017) e Mihura \& Meyer, (2018).

\subsubsection{Procedimentos - Coleta de dados}

O Estudo II buscou relacionar os achados do Estudo I, notadamente as variáveis afetivas e perfis de regulação emocional, com os instrumentos de tomada de decisão em situação de incerteza (IGT) e o Método de Rorschach (R-PAS). Como dito anteriormente, os participantes dessa nova etapa investigativa foram selecionados a partir dos registros de voluntários do Estudo I. O pesquisador entrou em contato (e-mail) com os possíveis voluntários, explicando novamente o trabalho e os convidou a participar do Estudo II.

Aos que consentiram em participar, foi agendado horário e local, nas dependências do Laboratório de Avaliação Psicológica do Amazonas (LAP-AM) ou do Laboratório de Medidas e Avaliação Psicológica (LAMAP), situados na Universidade Federal do Amazonas (UFAM) e Faculdade Martha Falcão - Wyden (FMF - Wyden), respectivamente, para aplicação individual dos instrumentos previstos nesta segunda etapa do trabalho. Neste processo, padronizou-se a seguinte ordem no processo de aplicação dos instrumentos: Escala Estilos de Tomada de Decisão 
(DSS), Iowa Gambling Task (IGT) e Método de Rorschach, R-PAS, conforme suas respectivas padronizações técnico-científicas.

Primeiramente os voluntários que aceitaram participar do Estudo II assinaram um novo TCLE, em seguida responderam ao IGT, em sua versão eletrônica (respondido em computador) e, em seguida, foram submetidos ao Método de Rorschach (R-PAS). O tempo utilizado para essas atividades variou de 75 a 90 minutos, em média. Ao final, os participantes foram indagados quanto a sua experiência durante toda a avaliação, com o objetivo de identificar seu nível de engajamento na tarefa, bem como eventuais desconfortos durante o processo de coleta de dados. Não houve necessidade de realizar qualquer atendimento psicológico emergencial a dificuldades advindas da participação nesta pesquisa.

Cabe destacar que os dados foram coletados pelo pesquisador responsável pelo trabalho, com auxílio de quatro estudantes finalistas de graduação e dois mestrandos do Programa de PósGraduação da Universidade Federal do Amazonas (UFAM), devidamente treinados nos procedimentos necessários. Estes colaboradores da pesquisa foram responsáveis pela aplicação do DSS nos participantes do Estudo II, sendo a seguir avaliados pelos demais instrumentos com o pesquisador principal (IGT e Rorschach). Este, por sua vez, realizou treinamento sistemático no sistema R-PAS, completando processo de certificação para coleta de dados neste sistema (https://r-pas.org/).

\subsubsection{Procedimentos - Análise de dados}

Os protocolos do IGT gerados pelo software IGT-Br, criado pela equipe do Prof. MalloyDiniz e cedido para uso nesta pesquisa, foram lançados em uma planilha eletrônica com base no Microsoft Excel. Foram calculados escores descritivos (total de cartas selecionadas para baralhos A, B, C e D) e escores primários que seguem o cálculo, já apresentado anteriormente, [(C+D)-(A + B)] e compreendem a Tendência Geral e os Blocos de 20 cartas (Bloco 1, Bloco 2, Bloco 3, Bloco 4 e Bloco 5), seguindo as diretrizes do manual do instrumento original (Bechara, 2007/2016). Além disso, considerou-se relevante examinar outro modelo de escore excluindo o Bloco 1. Conforme sugestão de Dunn et al., (2006) que apontam que o comportamento exploratório no início da tarefa e a possibilidade de utilização de todas as cartas vantajosas ao longo da tarefa podem contribuir para variabilidade excessiva dos resultados. Assim, foi calculado um escore de Tendência geral compreendendo os blocos 2 a 5 (Tendência geral Bl 2$5)$.

$\mathrm{Na}$ literatura internacional, a análise da precisão do IGT tem sido reportada primordialmente pelo método do teste-reteste e consistência interna (Gansler, Jerram, et al., 
2011). Dentre as diversas alternativas propostas na literatura da avaliação psicológica em geral (AERA et al., 2014) e da avaliação neuropsicológica em particular (Frazen, 2002; Slick, 2006), o coeficiente de generalizabilidade, estimado a partir da teoria da generalizabilidade, desponta em manuais de grandes baterias, porém ainda pouco utilizados de maneira geral (Slick, 2006). A teoria da generalizabilidade (Generalizability Theory - GT) surgiu no esteio das preocupações com a questão do erro de mensuração, que é inerente ao próprio processo de medir algo. Desenvolvida por Cronbach, Gleser, Nanda e Rajaratnam (1972) e aprimorada por Shavelson e Webb, (1991), é bastante divulgada por Brennan (2001). Apresenta uma estrutura conceitual que pode contribuir para o desenvolvimento de instrumentos de mensuração, identificando possíveis fontes de erro, utilizando para tanto, conceitos da Teoria Clássica dos Testes (TCT) e a estimação de Análise de Variância (ANOVA).

A GT parte do princípio de que os resultados de uma avaliação podem ser entendidos como a somatória da característica que se pretende avaliar e as diferentes condições (facetas) em que essa avaliação é realizada (por exemplo: itens de um teste, situação de avaliação, pontuação de juízes, entre outras). A GT utiliza a ANOVA para estimar a variância de cada uma destas condições, a fim de verificar a contribuição de cada uma delas para o erro de medida (Brennan, 2001). Dessa forma, permite identificar as melhores condições possíveis para diminuir a influência do erro no escore final. A partir da estimação das variâncias das diferentes condições e seus erros associados, é possível calcular dois tipos de coeficientes de precisão: um que leva em consideração a variância do erro relativo (Coeficiente de generalizabilidade $-E p^{2}$ ), e outro que leva em consideração a variância do erro absoluto (Coeficiende de dependabilidade $-\phi)$ (Webb et al., 2006). Essa abordagem pode ser utilizada para trabalhar com dados de instrumentos baseados em performance (Brennan, 2000; Brennan \& Johnson, 1995) e pode ser facilmente implementada por meio dos pacotes gtheory (Huebner \& Lucht, 2019).

No tocante aos dados relativos ao Método de Rorschach (R-PAS), os protocolos individuais foram codificados pelo pesquisador de acordo com as diretrizes do sistema R-PAS (Meyer et al., 2017). Posteriormente estas codificações foram inseridas no programa R-PAS online (www.r-pas.org), de modo a permitir os cálculos necessários dos indicadores técnicos, subsidiando a interpretação do protocolo, primeiramente de forma individual e depois em termos de grupos de indivíduos.

Um conjunto de 30 protocolos do Rorschach (35,8\% dos casos), selecionados aleatoriamente, foi submetido ao exame às cegas por avaliadores independentes (cinco juízes), com o objetivo de realizar análise de precisão pela concordância entre juízes. Estes avaliadores independentes eram psicólogos que atuaram como colaboradores nesta etapa do trabalho, 
devidamente treinados no R-PAS e em suas variáveis técnicas. Desta forma, cada um destes 30 protocolos selecionados recebeu uma codificação adicional, a qual foi contraposta à classificação inicialmente realizada pelo pesquisador para cada um dos casos.

Com relação à precisão das variáveis de interesse no RPAS, foi avaliado o grau de concordância entre os juízes por meio do Coeficiente de Correlação Intraclasse (Intra Class Correlation - ICC) utilizando o modelo one-way random effect (Pignolo et al., 2017), dado que os juízes que codificaram os "pares" de protocolos não foram os mesmos para todos os casos avaliados. Para classificar os valores ICC encontrados por este procedimento, recorreu-se às diretrizes apontadas por Shrout e Fleiss (1979), considerando os seguintes valores ICC: a) abaixo de $0,40=$ precisão pobre; b) entre 0,40 e $0,59=$ precisão fraca; entre 0,60 e 0,74 = boa precisão; acima de 0,75 = excelente precisão. Além disso, neste trabalho, são apresentados apenas os valores relativos às variáveis de interesse, selecionadas previamente (Tabela 5). Valores da precisão de todas as variáveis do R-PAS encontrados no presente trabalho podem ser conferidos no APÊNDICE G.

Após a sistematização dos dados do Estudo II, foram integrados ao banco de dados inicialmente elaborado no Estudo I, integrando-se as informações em planilha única. O conjunto desses dados foi analisado com auxílio do software livre R (versão 3.6.1) (R Core Team, 2020) e R-Studio (versão 1.3.959) (RStudio Team, 2020). Preliminarmente foram avaliados os pressupostos de normalidade na distribuição dos resultados e presença de valores extremos (outliers) univariados e multivariados. Em seguida, foram realizadas análises estatísticas descritivas dos achados, implicando na caracterização sociodemográfica da amostra e nos dados específicos por instrumento, de modo a permitir sua interpretação tendo por base os referenciais normativos disponíveis para adultos. O conjunto destes resultados descritivos apontou para a necessidade de utilização de estratégias de análise resilientes à presença de valores extremos, bem como a desvios da normalidade univariada.

Para Field e Wilcox (2017) uma solução adequada seria a utilização de métodos estatísticos robustos à quebra dos pressupostos das análises estatísticas paramétricas. Estes autores identificaram que a quebra destes pressupostos resulta em vieses que tornam os achados menos seguros. Mair e Wilcox (2019) apresentam alternativas robustas para a maioria dos testes paramétricos, demonstrando sua resiliência diante de valores extremos, amostras relativamente menores e distorções da normalidade. Dessa forma, escolheu-se utilizar versões robustas para as análises de correlação e análises de variância reportadas nos resultados do Estudo II.

Primeiramente, foram realizadas análises de correlação robusta, utilizando o método percentage bend correlation - (Ppb) utilizando o pacote WRS2 (Mair \& Wilcox, 2019) entre as 
variáveis representativas da afetividade obtidas por meio de autorrelato (PANAS, EA, FAST, ERQ e DERS) e pelo desempenho do R-PAS. O mesmo procedimento foi realizado para os dados relativos às variáveis representativas dos processos de tomada de decisão (autorrelato DSS, desempenho - IGT e R-PAS).

Em uma perspectiva complementar de análise, baseada nos resultados encontrados, optou-se por realizar análise de regressão linear levando em consideração as variáveis afetivas de autorrelato e de desempenho no R-PAS que apresentaram correlação com os escores de Tendência geral no IGT. Esse procedimento teve como objetivo investigar o quanto cada uma das variáveis encontradas contribuiu para o desempenho geral no processo de tomada de decisão em situações de risco.

Posteriormente, testou-se a hipótese de que os resultados apresentados no IGT poderiam estar relacionados aos perfis de regulação emocional encontrados no Estudo I. Para tanto, foi realizada análise de variância (ANOVA) entre as variáveis do IGT e R-PAS e os perfis de regulação emocional encontrados no estudo I. Para todas as análises estatísticas realizadas neste trabalho adotou-se o nível de significância de $5 \%(p<0,05)$. 
RESULTADOS 


\section{RESULTADOS}

De forma a melhor organizar os achados, inicialmente são apresentadas as informações referentes aos dados relativos à precisão dos instrumentos na amostra utilizada, por ser primordial para considerar a segurança dos resultados. Em seguida, os achados referentes ao Estudo I e ao Estudo II são reportados, começando pelas análises descritivas das variáveis de interesse, análises gráficas e de normalidade, que estabeleceram a racionalidade para as análises inferenciais utilizadas. Posteriormente são apresentados os resultados derivados das análises inferenciais utilizadas para testar as hipóteses principais. No momento em que os resultados apontaram possibilidades para novas alternativas analíticas, foram testadas hipóteses secundárias, discutidas ao final de cada tópico.

\subsection{Resultados relativos à precisão dos instrumentos avaliativos}

Em nosso estudo, estipulou-se um intervalo de tempo de duas semanas entre os dois momentos avaliativos. No entanto, dado que o convite para a nova resposta aos instrumentos foi realizado via e-mail e não pessoalmente, o tempo decorrido entre o teste e o reteste variou fortemente, ampliando-se de duas a vinte e nove semanas, com tempo médio de 4,67 semanas de intervalo $(\mathrm{DP}=6,12)$. A Tabela 6 apresenta os indicadores de precisão das escalas que compuseram o Estudo I.

Tabela 6. Coeficientes de precisão dos fatores da PANAS, EA, ERQ, DERS e DSS por meio da consistência interna $(\alpha)$, confiabilidade composta e teste-reteste.

\begin{tabular}{lccc}
\hline Instrumento & $\begin{array}{c}\text { Alpha de } \\
\text { Cronbach }(\alpha) \\
(\mathrm{n}=1.165)\end{array}$ & $\begin{array}{c}\text { Confiabilidade } \\
\text { Composta } \\
(\mathrm{n}=1.165)\end{array}$ & $\begin{array}{c}\text { Teste } \\
\text { Reteste }^{\mathrm{a}} \\
(\mathrm{n}=268)\end{array}$ \\
\hline PANAS & 0,91 & 0,87 & 0,74 \\
Afetos Positivos & 0,91 & 0,89 & 0,74 \\
Afetos Negativos & 0,93 & 0,91 & 0,85 \\
EA & 0,87 & 0,83 & 0,81 \\
Afetos Positivos & & &
\end{tabular}


ERQ

Reavaliação

0,85

0,83

0,72

Supressão

0,75

0,72

0,73

DERS

Consciência

0,78

0,75

0,76

Clareza

0,88

0,85

0,76

Objetivos

0,92

0,89

0,77

Impulsos

0,90

0,88

0,79

Estratégia

0,93

0,91

0,85

Não Aceitação

0,94

0,91

0,80

DERS Total

0,95

0,94

0,88

FAST

Seguir Afetos Positivos

0,66

0,61

0,71

Ignorar Afetos Positivos

0,72

0,68

0,64

Seguir Afetos Negativos

0,77

0,74

0,80

Ignorar Afetos Negativos

0,68

0,64

0,70

\section{DSS}

$\begin{array}{llll}\text { Racional } & 0,88 & 0,83 & 0,70 \\ \text { Intuitivo } & 0,80 & 0,77 & 0,73\end{array}$

Nota: ${ }^{a}$ Foi utilizada correlação parcial, controlando o efeito do tempo entre a primeira e a segunda aplicação.

Os índices de fidedignidade foram variados, como se nota, a depender do procedimento de utilizado. Entretanto, foi possível constatar que os índices de fidedignidade de todas as variáveis estudadas assumiram valores considerados suficientes para representar adequada precisão. Isso ocorreu quando se leva em consideração a consistência interna dos instrumentos, tanto pelo alpha de Cronbach, quanto pela confiabilidade composta. Além disso, a estabilidade temporal das medidas apresentou-se acima do teoricamente esperado para variáveis de natureza afetiva, indicando boa estabilidade temporal do conjunto de indicadores realizados com estes participantes.

A análise de precisão do IGT foi pautada nos princípios técnicos da Teoria da Generalizabilidade (GT) discutida anteriormente. Os resultados são apresentados na Tabela 7, tanto para a Tendência geral que leva em consideração todos os Blocos (1 a 5) e quanto para a Tendência geral B1 2 a 5, que excluí o Bloco 1 do cálculo. 
Tabela 7. Coeficientes de precisão do IGT a partir da Teoria da Generazibilidade $(n=92)$ para o escore de Tendência geral e Tendência geral Bl 2-5.

\begin{tabular}{ccccccc}
\hline \multirow{2}{*}{ Efeito } & \multicolumn{3}{c}{ Tendência Geral } & \multicolumn{3}{c}{ Tendência geral B1 2-5 } \\
& Df & Variância & $\%$ & Df & Variância & $\%$ \\
\hline$p$ & 85 & 8,59 & 19,4 & 85 & 12,99 & 29,5 \\
$i$ & 4 & 2,71 & 6,1 & 3 & 1,09 & 2,5 \\
$p: i$ & 340 & 32,93 & 74,4 & 255 & 29,96 & 68,0 \\
\hline $\mathrm{E} p^{2}$ & & & 0,566 & & 0,634 & \\
$\Phi$ & & 0,547 & & 0,626 & \\
\hline
\end{tabular}

Nota: $\mathrm{Df}=$ graus de liberdade $; p=$ participante $i=$ indicador; $p i=$ resíduos de interação entre pessoa e indicador; $\mathrm{E} p^{2}=$ coeficiente de generalizabilidade; $\varphi=$ coeficiente de dependabilidade.

Os resultados sugerem que o IGT apresenta índices de precisão aceitáveis quando se leva em consideração a variância para os Blocos 2 a $5\left(\mathrm{E} p^{2}=0,634\right)$, mas não quando se utiliza todos os cinco blocos $\left(\mathrm{E} p^{2}=0,566\right)$, de acordo com as orientações de Nunnally e Bernstein, (1978), ainda assim, estes valores estão acima dos valores de teste-reteste $(r=0,22)$ encontrados na literatura internacional (Buelow \& Barnhart, 2018a) e consistência interna entre 0,219 e 0,545 (Gansler, Jerram et al., 2011). O conjunto destes resultados estão de acordo com as observações de Dunn et al., (2006) os quais indicam que as escolhas no início da tarefa refletem escolhas exploratórias racionais. As análises de precisão da presente pesquisa sugerem que quando o bloco inicial é excluído há ganhos na estimativa de precisão do instrumento indicando que os escores do IGT apresentam evidências de precisão.

Em relação ao Rorschach. como pode ser notado na tabela 8, em sua maioria, os indicadores de confiabilidade entre avaliadores independentes atingiram valores considerados excelentes para a maior parte das variáveis de interesse (Kassambara, 2019). As exceções foram $\mathrm{C}(\mathrm{ICC}=0,52)$, IntCont (ICC=0,59), $\mathrm{Vg} \%(\mathrm{ICC}=0,52)$ e FD $(\mathrm{ICC}=0,47)$. Cabe destacar que estas variáveis do Rorschach quando apresentam baixa frequência nos protocolos podem interferir nos achados relativos à concordância entre examinadores independentes (Pignolo et al., 2017; Viglione et al., 2012).

Tabela 8. Precisão entre avaliadores independentes para variáveis afetivas e relacionadas à tomada de decisão no Rorschach R-PAS (n=30) por meio do Coeficiente de Correlação Intraclasse (ICC). 


\begin{tabular}{|c|c|c|}
\hline Variável & ICC & Classificação* \\
\hline \multicolumn{3}{|l|}{ Afetivas } \\
\hline MC - PPD & 0,95 & Excelente \\
\hline $\mathrm{MC}$ & 0,98 & Excelente \\
\hline M & 0,98 & Excelente \\
\hline V-Comp & 0,95 & Excelente \\
\hline $\mathrm{R} 8910 \%$ & 0,98 & Excelente \\
\hline WSumC & 0,96 & Excelente \\
\hline $\mathrm{C}$ & 0,52 & Moderado \\
\hline CBlend & 0,92 & Excelente \\
\hline $\mathrm{CF}$ & 0,87 & Bom \\
\hline$(\mathrm{CFC}+\mathrm{C}) / \mathrm{SumC}$ & 0,62 & Bom \\
\hline$(\mathrm{CF}+\mathrm{C})-\mathrm{FC}$ & 0,86 & Bom \\
\hline $\mathrm{FC}$ & 0,94 & Excelente \\
\hline PPD & 0,96 & Excelente \\
\hline \multicolumn{3}{|l|}{ Tomada de Decisão } \\
\hline $\mathrm{Dd} \%$ & 0,91 & Excelente \\
\hline $\mathrm{M} / \mathrm{MC}$ & 0,97 & Excelente \\
\hline SI & 0,93 & Excelente \\
\hline IntCont & 0,59 & Moderado \\
\hline $\mathrm{Vg} \%$ & 0,52 & Moderado \\
\hline $\mathrm{V}$ & 0,88 & Bom \\
\hline FD & 0,47 & Pobre \\
\hline
\end{tabular}

Nota: *Classificação realizada com base em Kassambara, (2019); ICC= Intraclass Correlation Coefficient;

O conjunto dos indicadores reportados permite inferir bons níveis de precisão nos instrumentos utilizados nos participantes do Estudo I e do Estudo II. Dessa forma, foi possível obter evidências empíricas de suporte (confiabilidade) para os próprios achados derivados destes instrumentos, como a seguir apresentado. 


\subsection{Resultados relativos ao Estudo I}

\subsubsection{Resultados descritivos}

Inicialmente foi investigada a presença de valores extremos e distribuição dos resultados na amostra para cada uma das variáveis relacionadas ao Estudo 1. A Tabela 9 apresenta os valores médios, desvio padrão, valores mínimos e máximos para cada instrumento utilizado, bem como estatísticas de assimetria e normalidade univariada (Shapiro Wilk).

Tabela 9. Estatística descritiva, medidas de tendência central e teste de normalidade das escalas de regulação emocional, dificuldades de regulação, afetos positivos e negativos e atenção às emoções utilizados no Estudo I (n=1.165).

\begin{tabular}{|c|c|c|c|c|c|c|c|}
\hline $\begin{array}{c}\text { Instrumento de avaliação } \\
\text { e suas variáveis }\end{array}$ & Média & DP & Min - Max & Skewness & Kurtosis & $W$ & $p$ \\
\hline \multicolumn{8}{|l|}{ ERQ } \\
\hline Reavaliação cognitiva & 29,99 & 7,12 & $6-42$ & $-0,82$ & 0,79 & 0,954 & 0,001 \\
\hline Supressão emocional & 16,26 & 5,59 & $4-28$ & $-0,10$ & $-0,65$ & 0,987 & 0,001 \\
\hline \multicolumn{8}{|l|}{ DERS } \\
\hline Consciência & 14,77 & 4,65 & $6-29$ & 0,39 & $-0,48$ & 0,976 & 0,001 \\
\hline Clareza & 12,92 & 4,86 & $3-25$ & 0,49 & $-0,60$ & 0,959 & 0,001 \\
\hline Objetivos & 15,75 & 5,71 & $5-25$ & $-0,04$ & $-1,09$ & 0,958 & 0,001 \\
\hline Impulsos & 13,83 & 5,73 & $6-30$ & 0,94 & 0,12 & 0,911 & 0,001 \\
\hline Estratégia & 19,21 & 8,55 & $8-40$ & 0,70 & $-0,54$ & 0,922 & 0,001 \\
\hline Não Aceitação & 14,91 & 7,30 & $6-30$ & 0,63 & $-0,75$ & 0,914 & 0,001 \\
\hline DERS Total & 91,58 & 27,47 & $37-169$ & 0,53 & $-0,41$ & 0,968 & 0,001 \\
\hline \multicolumn{8}{|l|}{ PANAS } \\
\hline Afetos Positivos & 29,93 & 8,03 & $10-50$ & 0,04 & $-0,58$ & 0,991 & 0,001 \\
\hline Afetos Negativos & 25,61 & 8,77 & $10-50$ & 0,40 & $-0,68$ & 0,968 & 0,001 \\
\hline \multicolumn{8}{|l|}{ EA } \\
\hline Afetos Positivos & 36,03 & 8,98 & $11-50$ & $-0,47$ & $-0,46$ & 0,967 & 0,001 \\
\hline Afetos Negativos & 30,78 & 8,90 & $10-50$ & $-0,04$ & $-0,72$ & 0,987 & 0,001 \\
\hline \multicolumn{8}{|l|}{ FAST } \\
\hline Seguir Afetos Positivos & 17,23 & 3,78 & $3-24$ & $-0,57$ & 0,55 & 0,979 & 0,001 \\
\hline Ignorar Afetos Positivos & 9,00 & 4,91 & $0-24$ & 0,40 & $-0,26$ & 0,979 & 0,001 \\
\hline
\end{tabular}




\begin{tabular}{llllllll}
\hline Seguir Afetos Negativos & 13,60 & 5,78 & $0-24$ & $-0,16$ & $-0,74$ & 0,978 & 0,001 \\
Ignorar Afetos Negativos & 14,00 & 5,33 & $0-24$ & $-0,19$ & $-0,55$ & 0,907 & 0,001
\end{tabular}

Nota: ERQ = Emotion Regulation Questionnaire; DERS = Difficulties of Emotion Regulation Scale; PANAS = Positive and Negative Affects Scale; EA= Escala de Afetos; FAST= Following Affective States Test; DP = Desvio padrão; $\mathrm{W}=$ Shapiro Wilk.

De maneira geral, a ausência de dados normativos para estes instrumentos inviabiliza interpretações a partir destes resultados de maneira que possamos indicar se estes valores estão elevados ou rebaixados na amostra avaliada no presente estudo. A estatísticas de assimetria (skwness e kustosis) em conjunto com o teste de normalidade, apontaram que as varáveis apresentam desvios em relação à distribuição normal. Dessa forma, recorremos às análises gráficas para auxiliar na adequada análise dos mesmos. A Figura 6 apresenta análises dos gráficos de caixas de bigodes das variáveis do Estudo I.

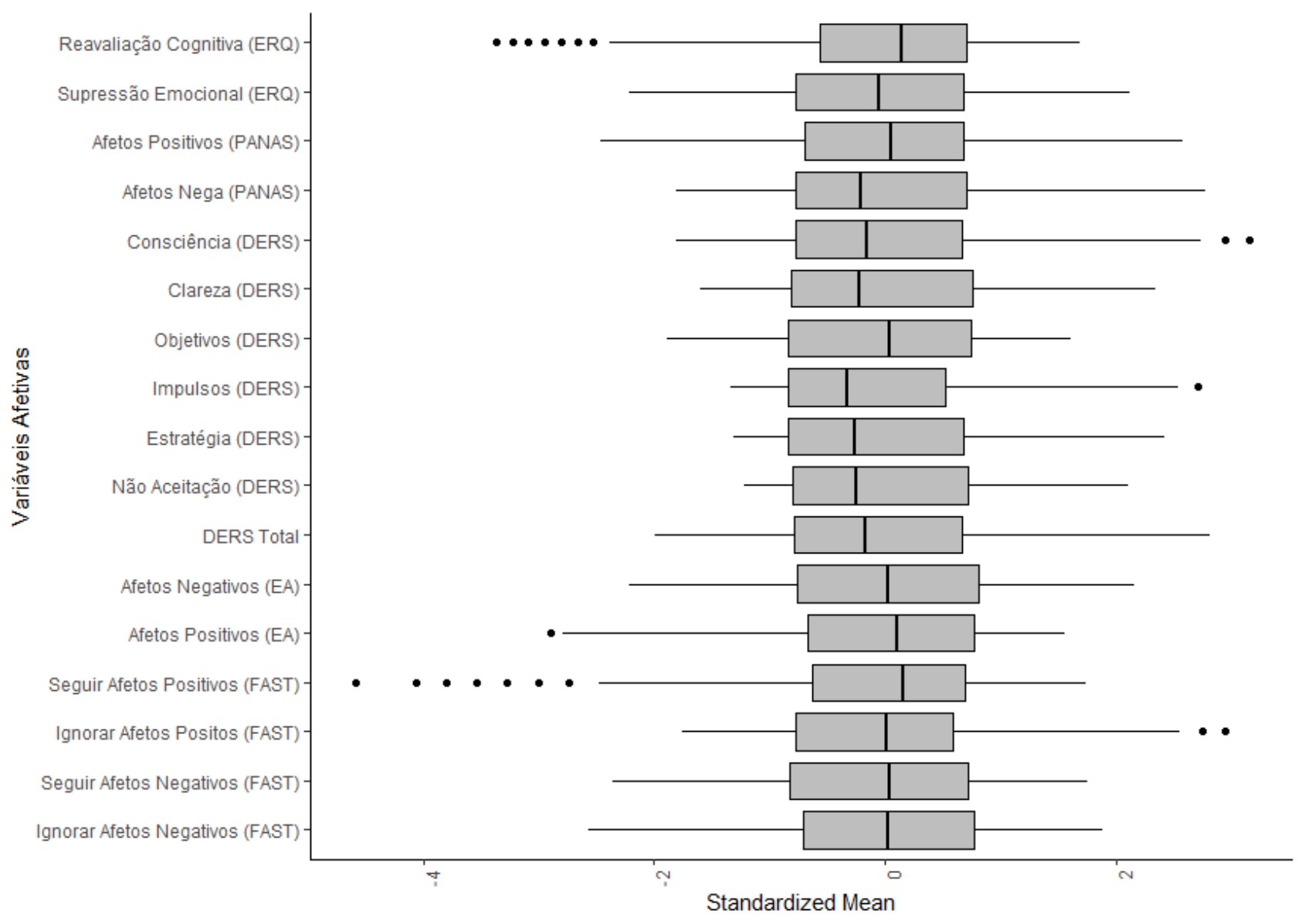

Figura 6. Diagrama de caixa de bigodes para variáveis afetivas do Estudo 1 (n=1165).

É possível observar a presença de valores extremos para as variáveis de reavaliação cognitiva (ERQ), afetos positivos (EA), consciência, impulsos (DERS), seguir e ignorar afetos 
positivos (FAST). O teste de Shapiro-Wilk para os dados univariados apontou que todas as variáveis se desviaram de uma distribuição normal, com $\mathrm{W}$ entre 0,99 e 0,91 ( $\mathrm{p}<0,001)$. Estes resultados sinalizam, portanto, assimetria nas distribuições encontradas nos resultados obtidos com estes participantes. Assim, para prosseguir com as análises de perfis latentes optou-se por seguir as orientações de Morgan, Hodge e Baggett (2016). Eles sugerem que pequenos desvios da normalidade nos dados, quando há muitos indicadores/variáveis, podem ser relativamente minimizados ao se considerar diferentes índices de ajuste, o que se buscou seguir nas próximas análises.

\subsubsection{Análises relativas a perfis latentes de regulação emocional}

A Tabela 10 apresenta os valores descritivos observados (médias, desvio padrão, valores mínimos e máximos) em cada subamostra examinada no Estudo I. Cabe recordar que a subamostra I ( $\mathrm{n}=375)$ foi utilizado em uma abordagem exploratória para investigar a quantidade de perfis latentes; a subamostra II ( $\mathrm{n}=390)$ foi utilizada em uma abordagem confirmatória, com o objetivo de verificar se o mesmo número de perfis seria observado. Enquanto a subamostra III $(n=400)$ serviu para análises de validação interna e externa dos perfis de regulação emocional em suas relações com variáveis afetivas. Além disso, utilizamos uma amostra de participantes que realizaram o reteste $(n=268)$, em que foram realizadas análises de estabilidade temporal da solução de perfis latentes encontrada.

Tabela 10. Estatística descritiva das escalas de regulação emocional, atenção às emoções $e$ afetos para cada subamostra de participantes e análise de variância (ANOVA) para comparação entre as médias em função das subamostras.

\begin{tabular}{|c|c|c|c|c|c|c|c|c|c|c|c|c|c|c|}
\hline \multirow{2}{*}{ Variável } & \multicolumn{3}{|c|}{$\begin{array}{c}\text { Subamostra } 1 \\
(n=375)\end{array}$} & \multicolumn{3}{|c|}{$\begin{array}{c}\text { Subamostra } 2 \\
(n=390)\end{array}$} & \multicolumn{3}{|c|}{$\begin{array}{c}\text { Subamostra } 3 \\
\quad(n=400)\end{array}$} & \multicolumn{3}{|c|}{$\begin{array}{l}\text { Reteste } \\
(n=268)\end{array}$} & \multirow{2}{*}{$F$} & \multirow{2}{*}{$p$} \\
\hline & M & DP & $\begin{array}{l}\text { Min - } \\
\text { Max }\end{array}$ & M & DP & $\begin{array}{l}\text { Min - } \\
\text { Max }\end{array}$ & M & DP & $\begin{array}{l}\text { Min - } \\
\text { Max }\end{array}$ & M & DP & $\begin{array}{l}\text { Min - } \\
\text { Max }\end{array}$ & & \\
\hline Idade & 27,47 & 9,33 & $18-64$ & 26,67 & 8,29 & $18-57$ & 26,69 & 7,86 & $18-61$ & 27,17 & 8,12 & $18-64$ & 0,72 & 0,91 \\
\hline \multicolumn{15}{|l|}{ ERQ } \\
\hline Reavaliação cognitiva & 29,80 & 7,21 & $6-42$ & 30,25 & 6,67 & $6-42$ & 29,92 & 7,45 & $6-42$ & 30,09 & 7,30 & $6-42$ & 0,42 & 0,65 \\
\hline Supressão emocional & 15,92 & 5,59 & $4-28$ & 16,46 & 5,43 & $4-28$ & 16,38 & 5,55 & $4-28$ & 15,96 & 5,26 & $4-28$ & 1,06 & 0,34 \\
\hline \multicolumn{15}{|l|}{ DERS } \\
\hline Consciência & 14,89 & 4,65 & $6-29$ & 14,66 & 5,23 & $6-30$ & 14,75 & 4,58 & $6-27$ & 14,91 & 5,34 & $6-30$ & 0,22 & 0,85 \\
\hline Clareza & 12,92 & 4,86 & $3-25$ & 13,44 & 5,23 & $5-25$ & 12,94 & 5,13 & $5-25$ & 12,67 & 5,22 & $5-25$ & 1,28 & 0,27 \\
\hline Objetivos & 15,75 & 5,71 & $5-25$ & 15,97 & 5,67 & $5-25$ & 15,57 & 5,77 & $5-25$ & 15,07 & 5,40 & $5-25$ & 0,48 & 0,62 \\
\hline
\end{tabular}




$\begin{array}{lllllllllllllll}\text { Impulsos } & 13,83 & 5,73 & 6-30 & 14,03 & 5,93 & 6-30 & 13,91 & 6,07 & 6-30 & 13,46 & 5,68 & 6-30 & 0,11 & 0,89 \\ \text { Estratégia } & 19,21 & 8,55 & 8-40 & 19,60 & 8,81 & 8-40 & 18,83 & 8,36 & 8-40 & 18,88 & 8,86 & 8-40 & 0,80 & 0,44 \\ \text { Não Aceitação } & 14,91 & 7,30 & 6-30 & 14,78 & 7,14 & 6-30 & 14,69 & 7,22 & 6-30 & 15,03 & 7,59 & 6-30 & 0,09 & 0,91\end{array}$

PANAS

Afetos Positivos

Afetos Negativos

EA

Afetos Positivos

Afetos Negativos

FAST

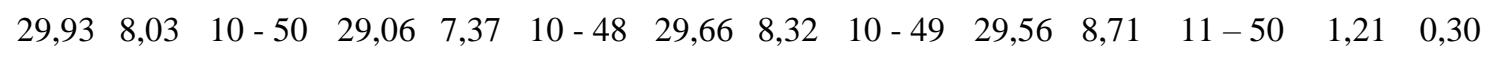

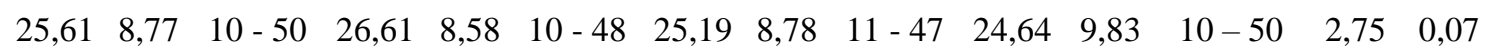

$\begin{array}{llllllllllllll}36,51 & 8,85 & 11-50 & 35,62 & 8,83 & 12-50 & 35,98 & 9,26 & 10-50 & 35,51 & 9,53 & 12-50 & 0,56 & 0,57\end{array}$

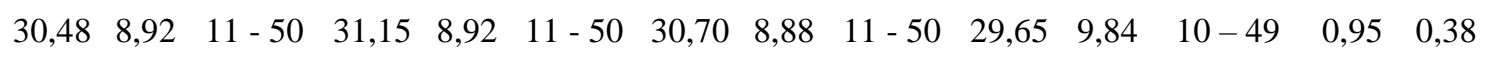

$\begin{array}{lcccccccccccccc}\text { Seguir Afetos Positivos } & 17,23 & 3,78 & 3-24 & 17,42 & 3,72 & 2-24 & 17,49 & 3,85 & 0-24 & 16,79 & 4,17 & 0-24 & 0,47 & 0,62 \\ \text { Ignorar Afetos Positivos } & 9,00 & 4,91 & 0-24 & 8,87 & 5,02 & 0-24 & 9,02 & 5,34 & 0-24 & 9,75 & 5,10 & 0-24 & 0,10 & 0,90 \\ \text { Seguir Afetos Negativos } & 13,60 & 5,78 & 0-24 & 14,23 & 5,83 & 0-24 & 13,54 & 5,86 & 0-24 & 13,31 & 5,64 & 1-24 & 0,162 & 0,19 \\ \text { Ignorar Afetos Negativos } & 14,00 & 5,33 & 0-24 & 13,65 & 5,44 & 0-24 & 13,91 & 5,40 & 0-24 & 13,12 & 5,56 & 0-24 & 0,42 & 0,66\end{array}$

Nota: $\mathrm{M}$ = média; $\mathrm{DP}=$ Desvio Padrão; Min = Mínima; Max = Máxima.

A análise de variância (ANOVA) demonstrou que não houve diferenças significativas entre as subamostras para nenhuma das variáveis de interesse. Em relação aos escores de regulação emocional (ERQ), observamos valores de reavaliação cognitiva e supressão emocional próximos à média de pontuação possível para cada uma das escalas. Já os escores de desregulação emocional (DERS), encontraram-se abaixo da média das pontuações máximas possíveis, podendo indicar as subamostras apresentaram níveis baixos de desregulação. Em termos de afetos positivos (PANAS e EA), é possível observar que estes estão ligeiramente acima dos valores observados para afetos negativos, em ambas as escalas. Por fim, a tendência a seguir emoções positivas (FAST) foi ligeiramente superior às tendências de ignorar afetos positivos e negativos bem como em relação a tendência à seguir afetos negativos.

Passadas as análises descritivas, seguimos para as análises de perfis latentes. Os índices de ajuste encontrados para o processo de estabelecimento (subamostra I) e validação cruzada (subamostra II) dos perfis podem ser observados na Tabela 11. Para a subamostra I a avaliação do índice BIC comparou diversos modelos com diferentes números de perfis, indicando os três melhores modelos, sendo indicado que o melhor modelo foi o de três perfis $(\mathrm{BIC}=-7476,508$ ). A avaliação do índice ICL reportou que os melhores modelos seriam o de dois (ICL = -7540,08), quatro (ICL $=-7542,093487)$ e três $(\mathrm{ICL}=-7545,951388)$ perfis. Pelo critério bootstraping, a comparação dos modelos indicou um bom ajuste para os modelos com dois (LRTS = 185.484261; $\mathrm{p}<0,001)$ e três perfis (LRTS $=131.316587$; $\mathrm{p}<0,001$ ), mas não para o modelo de 
quatro perfis, mostrando-se instável (LRTS = -8.992479; p>1,0). Dessa forma, seguindo critérios estabelecidos por Nylun (2007) optou-se pela solução indicada com melhor BIC.

Tabela 11. Estatísticas dos índices de ajuste dos dados para modelos de perfis latentes encontrados na análise de perfis latentes $(L P A)$ para as subamostras I $(n=375)$ e subamostra II $(n=390)$.

\begin{tabular}{ccccccc}
\hline & Classes & AIC & BIC & SABIC & ICL & Entropia \\
\hline & 1 & $18.250,297$ & $18.423,082$ & $18.283,482$ & $-18.423,082$ & 1,000 \\
Subamostra 1 & 2 & $18.153,234$ & $18.361,361$ & $18.193,206$ & $-18.391,989$ & 0,873 \\
$(n=375)$ & $\mathbf{3}$ & $\mathbf{1 8 . 1 5 5 , 2 3 4}$ & $\mathbf{1 8 . 3 9 8 , 7 0 3}$ & $\mathbf{1 8 . 2 0 1 , 9 9 4}$ & $\mathbf{- 1 8 . 5 1 2 , 7 3 1}$ & $\mathbf{0 , 7 1 8}$ \\
& 4 & $18.126,500$ & $18.405,312$ & $18.180,048$ & $-18.527,129$ & 0,760 \\
& 5 & $18.107,469$ & $18.421,624$ & $18.167,805$ & $-18.549,674$ & 0,778 \\
\hline \multirow{3}{*}{ Subamostra 2} & 1 & $19.058,786$ & $19.233,297$ & $19.093,687$ & $-19.233,297$ & 1,000 \\
$(n=390)$ & $\mathbf{3}$ & $18.991,567$ & $19.201,773$ & $19.033,607$ & $-19.250,501$ & 0,820 \\
& 4 & $18.962,131$ & $\mathbf{1 9 . 2 0 8 , 0 3 2}$ & $\mathbf{1 9 . 0 1 1 , 3 0 9}$ & $\mathbf{- 1 9 . 2 9 0 , 2 2 5}$ & $\mathbf{0 , 7 9 0}$ \\
& 5 & $18.917,866$ & $19.199,462$ & $18.974,184$ & $-19.299,336$ & 0,799 \\
& & & $19.269,029$ & $19.015,194$ & $-19.446,966$ & 0,705
\end{tabular}

Nota: $A I C=$ Akaike information criterion $;$ BIC $=$ Bayesian information criterion $;$ SA BIC $=$ Sample size-adjusted bayesian information criterion; $I C L=$ Integrated completed likelihood;

A Figura 7 ilustra os escores z estandardizados em cada uma das escalas utilizadas (valores positivos indicam maior presença da característica de regulação/desregulação, assim como valores negativos indicam menor uso da estratégia/presença da característica), para cada perfil. O primeiro perfil apresentou um padrão de baixo uso de estratégia de reavaliação cognitiva, níveis médios de utilização de supressão emocional e presença elevada de diversas dificuldades em regular emoções, sendo considerado um perfil desregulado $(\mathrm{n}=186)$. Um segundo padrão observado caracterizou-se por níveis elevados de reavaliação cognitiva e valores médios inferiores de desregulação emocional, caracterizando um perfil adaptado $(\mathrm{n}=123)$. Por fim, o perfil semelhante ao anterior, mas caracterizado por elevado nível de dificuldade de tomar consciência de suas emoções, porém com níveis bastante baixos nas demais dificuldades em regular emoções, foi considerado regulador inconsciente $(n=66)$. 


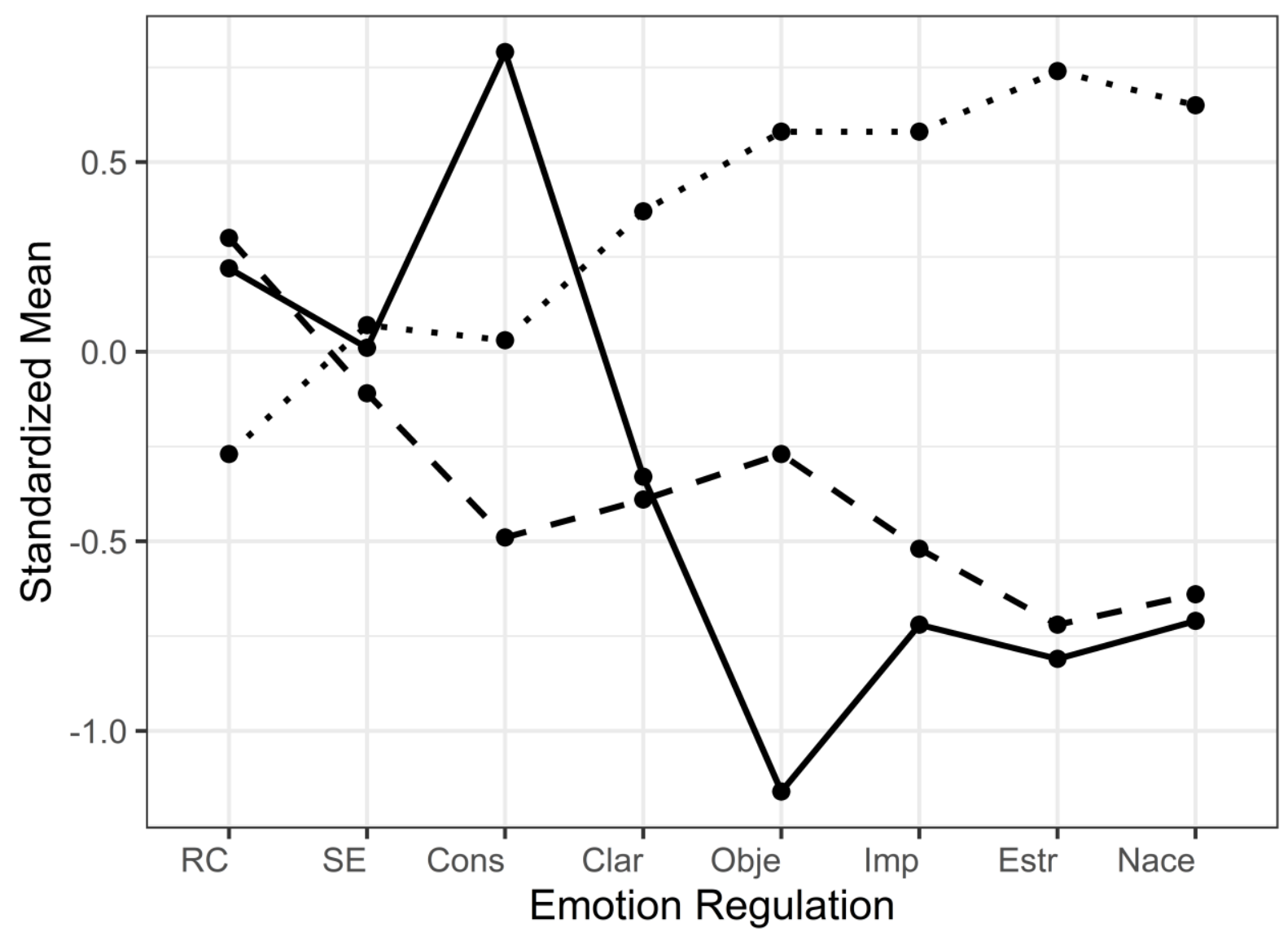

\section{Profile - D Desrregulado - Adaptado - Regulador Inconsciente}

Figura 7. Perfis latentes de regulação emocional para subamostra $I(n=375)$.

Nota: $\mathrm{RC}=$ Reavaliação Cognitiva; $\mathrm{SE}=$ Supressão emocional; Cons = Consciência; Clar = Clareza; Obje $=$ Objetivos; Imp = Impulsos; Estr = Estratégia; Nace = Não aceitação.

Para a validação cruzada, a partir da subamostra II, a avaliação do BIC indicou que os melhores modelos apresentaram três $(\mathrm{BIC}=-7750.074)$ ou quatro perfis $(\mathrm{BIC}=-7769.67211$ ) respectivamente. Pelo critério do ICL, observou-se que os modelos com dois (ICL = -7827.255) e três perfis $(\mathrm{ICL}=-7856.82567)$ apresentaram melhores indicadores. No critério bootstraping, a comparação entre os modelos indicou novamente que os modelos de dois (LTRS = 207.0447, $\mathrm{p}<0,001)$ e três perfis (LTRS $=55.0557 ; \mathrm{p}<0,05)$ ajustaram-se bem. Novamente, levando-se em consideração o critério BIC, constata-se que a solução de três perfis, mostra-se consistente (Nylun, 2007).

A Figura 8 novamente ilustra os diferentes perfis observados e os escores padronizados para cada uma das variáveis utilizadas para determinar os perfis de regulação emocional. Mais uma vez, o perfil com baixo nível de reavaliação cognitiva apresentou um claro padrão de 
desregulação emocional elevado (desregulado, $\mathrm{n}=243$ ). Um segundo padrão observado utilizouse de níveis elevados de reavaliação cognitiva e baixos níveis de desregulação emocional (adaptado, $\mathrm{n}=122$ ) e por fim, novamente, há um padrão médio de reavaliação cognitiva, com elevado nível de dificuldades de tomar consciência das próprias emoções, mas com baixa dificuldade nas demais áreas (regulador inconsciente, $\mathrm{n}=25$ ).

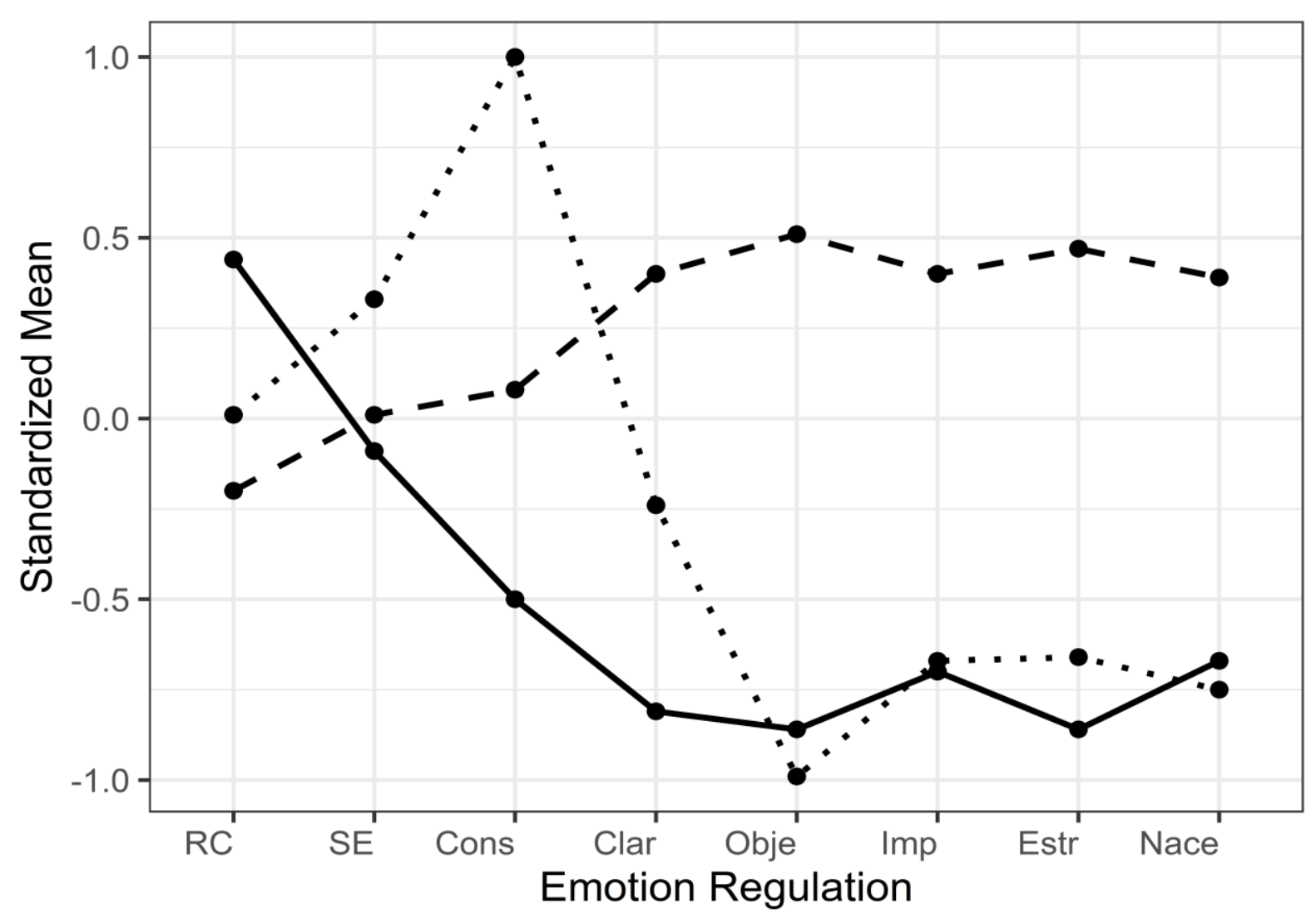

\section{Profile - Regulador Inconsciente - Desrregulado - Adaptado}

Figura 8. Perfis latentes de regulação emocional identificados a partir da subamostra II $(n=390)$.

Nota: $\mathrm{RC}=$ Reavaliação Cognitiva; $\mathrm{SE}=$ Supressão emocional; Cons = Consciência; Clar $=$ Clareza; Obje $=$ Objetivos; Imp = Impulsos; Estr = Estratégia; Nace = Não aceitação

Para verificar a estabilidade para os três perfis encontrados, foi realizada uma extensão da LPA que busca avaliar mudanças ao longo do tempo (latente profile transition analysis LPTA), ou seja, basicamente identifica a estabilidade da estimação dos perfis, em um segundo momento. Para tanto, foi utilizada a amostra de reteste, em que responderam novamente aos instrumentos, 268 participantes. Conforme pode ser visto na Figura 9, houve robusta estabilidade na estimativa dos perfis latentes, entre o momento I e o momento II. A análise indicou que os 
participantes foram identificados no mesmo perfil em $80 \%$ dos casos, sendo considerada uma excelente estabilidade.

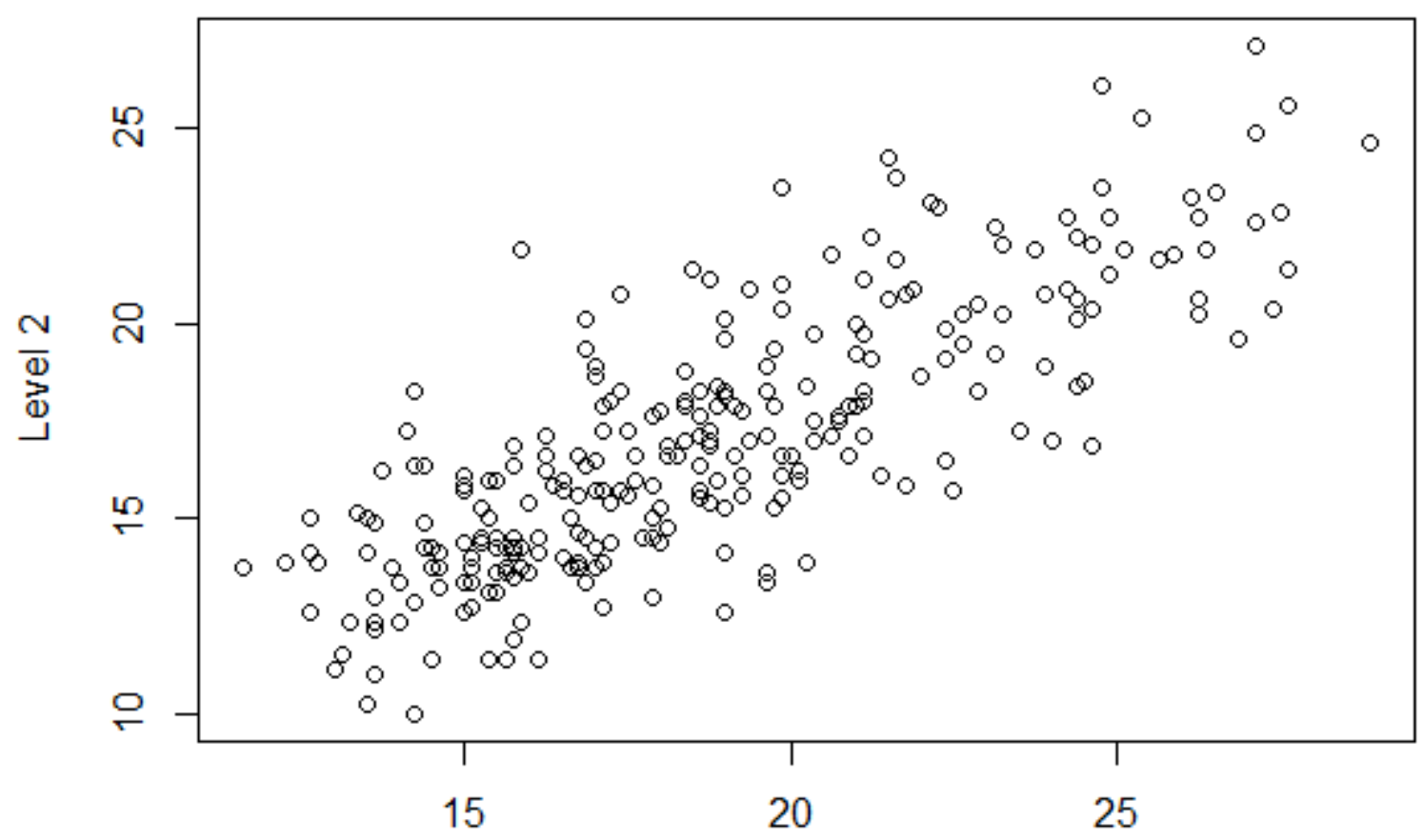

Level 1

Figura 9. Estabilidade temporal dos perfis latentes observados no teste e reteste $(n=268)$.

Para indicar onde estes perfis se diferiam em termos de validade interna e externa, utilizouse a subamostra III. Inicialmente foi realizada uma análise de regressão linear, tendo como principal objetivo identificar o papel que cada uma das variáveis que compunham os perfis tinha no estabelecimento destes. A Tabela 12 apresenta os valores dos pesos padronizados de cada uma das variáveis utilizadas para o estabelecimento dos perfis. Como pode ser constatado, o modelo geral apresentou um $\mathrm{R}^{2}=.371$; $(\mathrm{p}<0,01)$. A reavaliação cognitiva apresentou um peso muito baixo $(\beta=0,07)$, já as variáveis de desregulação emocional apresentaram maior importância no estabelecimento dos perfis, com $\beta$ variando entre 0,11 (Clareza) a $-0,53$ (Objetivos). Quando se leva em consideração as correlações de ordem zero, percebe-se que a variável Consciência apresenta a maior correlação com os perfis, o que pode indicar o seu papel nos diferentes perfis de regulação afetiva. 
Tabela 12. Análise de regressão linear usando os perfis de regulação emocional como desfecho e as variáveis componentes dos perfis de regulação emociona observados nas análises de perfis latentes para a subamostra III $(n=400)$.

\begin{tabular}{|c|c|c|c|c|c|c|c|c|}
\hline Preditor & $\mathrm{b}$ & b IC 95\% & $\beta$ & $\beta$ IC 95\% & $\mathrm{sr}^{2}$ & $\mathrm{sr}^{2} \mathrm{IC} 95 \%$ & $r$ & Fit \\
\hline (Intercepto) & $0,56^{*}$ & {$[0,11 / 1,01]$} & & & & & & \\
\hline Reavaliação Cognitiva & 0,01 & {$[-0,00 / 0,02]$} & $\mathbf{0 , 0 7}$ & {$[-0,03 / 0,17]$} & 0,00 & {$[-, 01 /, 01]$} &,$- 11 *$ & \\
\hline Supressão emocional & $-0,01$ & {$[-0,02 / 0,01]$} & $-0,04$ & {$[-0,13 / 0,05]$} & 0,00 & {$[-, 00 /, 01]$} & ,02 & \\
\hline Consciência & $0,04 * *$ & {$[0,03 / 0,06]$} & 0,3 & {$[0,20 / 0,39]$} & 0,07 & {$[, 03 /, 11]$} &, $35^{* *}$ & \\
\hline Clareza & $0,02^{*}$ & {$[0,00 / 0,03]$} & 0,11 & {$[0,00 / 0,22]$} & 0,01 & {$[-, 01 /, 02]$} &, $29 * *$ & \\
\hline Objetivos & $-0,06 * *$ & {$[-0,08 /-0,05]$} & $-0,53$ & {$[-0,65 /-0,41]$} & 0,14 & {$[, 08 /, 20]$} &,- 09 & \\
\hline Impulsos & $\mathbf{0 , 0 3 * *}$ & {$[0,01 / 0,05]$} & 0,26 & {$[0,12 / 0,39]$} & 0,02 & {$[-, 00 /, 05]$} &, $23 * *$ & \\
\hline Estratégia & $\mathbf{0 , 0 3 * *}$ & {$[0,02 / 0,04]$} & $\mathbf{0 , 3 4}$ & {$[0,18 / 0,50]$} & 0,03 & {$[, 00 /, 06]$} &, $25^{* *}$ & \\
\hline Não Aceitação & $-0,00$ & {$[-0,01 / 0,01]$} & $-0,00$ & {$[-0,12 / 0,11]$} & 0,00 & {$[-, 00 /, 00]$} &, $14 * *$ & $R^{2}=, \mathbf{3 1 7} * *$ \\
\hline
\end{tabular}

Nota. Um peso b significativo indica que o peso beta e a correlação semiparcial também são significativas. $\mathrm{b}$ representa pesos de regressão não padronizados. $\beta$ indica os pesos de regressão padronizados. $\mathrm{sr}^{2}$ representa a correlação semiparcial ao quadrado. $\mathrm{r}$ representa a correlação de ordem zero. Os colchetes são usados para incluir os limites inferior e superior de um intervalo de confiança. * indica $\mathrm{p}<0,05 ; * *$ indica $\mathrm{p}<0,01$.

Para realizar a validação externa da solução de três perfis, buscou-se diferenciá-los em termos de maior ou menor expressão de afetos positivos e negativos, bem como nas tendências a se deixar guiar por estes afetos. Dessa forma, foi realizada uma análise de variância (ANOVA), tendo como variável de agrupamento os perfis observados, e como variáveis independentes a presença de afetos positivos e negativos (PANAS e EA), e a tendência a seguir/ignorar afetos (FAST). A Tabela 13 apresenta os resultados descritivos destes instrumentos para cada perfil identificado no estudo.

Tabela 13. Estatísticas descritivas para PANAS, EA e FAST nos perfis de regulação emocional obtidos a partir da subamostra III $(n=400)$.

\begin{tabular}{|c|c|c|c|c|c|c|}
\hline & \multicolumn{2}{|c|}{$\begin{array}{l}\text { Adaptado } \\
(\mathrm{n}=154)\end{array}$} & \multicolumn{2}{|c|}{$\begin{array}{c}\text { Desregulado } \\
\quad(\mathrm{n}=185)\end{array}$} & \multicolumn{2}{|c|}{$\begin{array}{c}\text { Regulador } \\
\text { Inconsciente } \\
\quad(\mathrm{n}=61)\end{array}$} \\
\hline & Média & $\mathrm{DP}$ & Média & DP & Média & DP \\
\hline \multicolumn{7}{|l|}{ PANAS } \\
\hline Afetos Positivos & 30,82 & 7,96 & 26,27 & 8,71 & 29,36 & 7,43 \\
\hline Afetos Negativos & 23,30 & 7,73 & 32,86 & 7,94 & 19,67 & 5,74 \\
\hline
\end{tabular}


EA

Afetos Positivos

Afetos Negativos

FAST

Seguir Afetos Positivos

Ignorar Afetos Positivos

Seguir Afetos Negativos

Ignorar Afetos Negativos
38,10

8,03

28,48

7,71

18,16

3,44

16,34

4,49

16,10

3,72

8,66

5,29

9,00

5,51

11,02

4,45

10,47

4,83

13,73

5,56

14,80

,

Nota: PANAS $=$ Afetos positivos e negativos; EA $=$ Escala de Afetos; FAST $=$ Following Affective States Test

Os resultados indicaram diferenças estatisticamente significativas entre os perfis e a presença de afetos positivos $[F(1,388)=8,18 ; p=.0045]$ e afetos negativos $[F(1,388)=3,04$; $p<0,0001]$. Comparações post hoc foram realizadas, utilizando correção de Bonferroni. Os resultados indicaram que as diferenças relevantes encontradas para afetos positivos se deram entre os perfis adaptado e desregulado ( $p<0,001)$, mas não entre adaptado e regulador inconsciente $(p=0,79)$ nem entre desregulado e regulador inconsciente $(p=0,10)$. Para os afetos negativos, observaram-se diferenças entre as variáveis de todos os perfis $(p<0,009)$. Também foram notadas diferenças na propensão a seguir afetos positivos $[F(1,388)=20,33$; $p<.001]$, bem como em ignorar afetos positivos $[F(1,388)=6,19 ; p=.013]$, além de seguir afetos negativos $[F(1,388)=5,05 ; p=0,025]$, mas não na tendência a ignorar afetos negativos $[F(1,388)=0,77 ; p=0,38]$.

O teste post hoc com ajuste de Bonferroni indicou que as diferenças na variável seguir afetos positivos se deram entre o adaptado e o desregulado ( $<<0,001)$ e entre adaptado e regulador inconsciente $(\mathrm{p}<0,001)$, mas não entre os desregulado e regulador inconsciente $(\mathrm{p}=$ 1,0). Para a variável ignorar afetos positivos, o post hoc indicou que não havia diferença entre os perfis adaptado e desregulado $(\mathrm{p}=1,0)$ e desregulado e regulador inconsciente $(\mathrm{p}=0,106)$, observando-se diferença estatisticamente significativa entre adaptado e regulador inconsciente ( $\mathrm{p}=0,018$ ). Por fim, a análise comparativa indicou diferenças estatisticamente significativas entre os perfis adaptado e desregulado $(\mathrm{p}<0,001)$ e desregulado e regulador inconsciente ( $p<0,001)$, mas não entre os perfis adaptado e regulador inconsciente $(p=0,091)$. 


\section{Comparações em função dos Perfis}
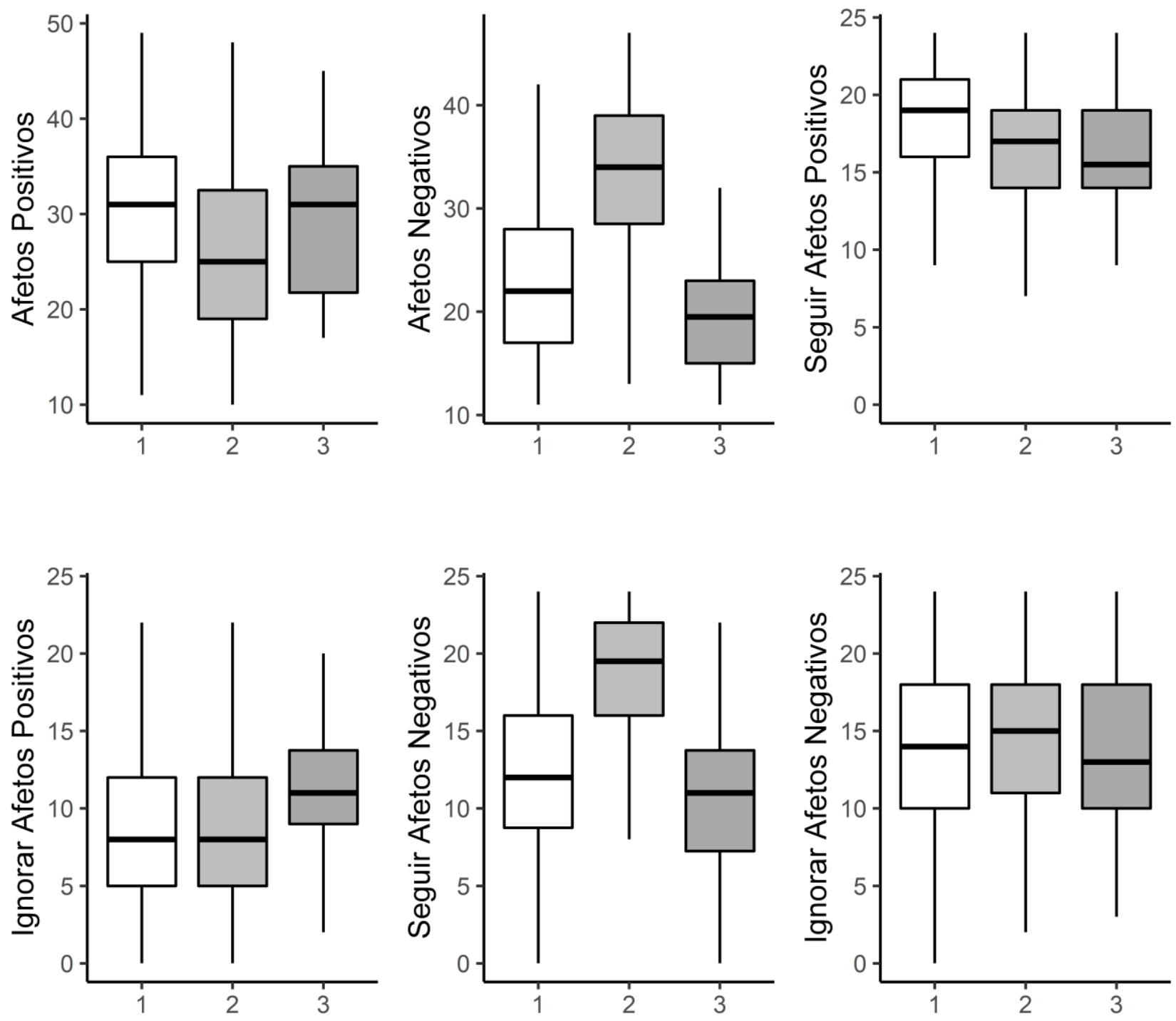

Figura 10. Comparações nas variáveis afetivas em função do perfil de regulação emocional observado.

\subsection{Resultados relativos ao Estudo II}

\subsubsection{Resultados descritivos}

Replicando aqui as estratégias técnicas usadas no Estudo I, foram realizadas análises descritivas de todas as variáveis de interesse. Para facilitar a compressão, serão primeiro reportadas as variáveis afetivas relacionadas às escalas de autorrelato, em seguida as variáveis relativas ao IGT, que avalia o desempenho na tarefa de tomada de decisão e, por fim, as variáveis relacionadas ao R-PAS (afetivas e de tomada de decisão). 
A Tabela 14 apresenta os valores médios, bem como o desvio padrão, valores mínimos e máximos para cada uma das variáveis, além dos indicadores de distorção da normalidade e um indicador robusto alternativo ao desvio padrão (Mean Absolute Desviation about median MAD). Este último foi utilizado em função das análises gráficas do Estudo I terem apontado valores extremos para algumas variáveis, fazendo-se relevante aprimorar a análise relativa à variabilidade dos achados.

Tabela 14 Estatística descritiva, medidas de tendência central e teste de normalidade das escalas de regulação emocional, dificuldades de regulação, afetos positivos e negativos, atenção às emoções e estilos de decisão utilizados no Estudo II $(n=92)$.

\begin{tabular}{|c|c|c|c|c|c|c|c|c|c|c|}
\hline Variável & Média & DP & Mediana & Min & Max & MAD & Skewness & Kurtosis & $W$ & $p$ \\
\hline \multicolumn{11}{|l|}{ ERQ } \\
\hline Reavaliação Cognitiva & 30,32 & 7,14 & 31,50 & 6 & 42,00 & 5,93 & -1.07 & 1,42 & 0,9309 & 0,0001 \\
\hline Supressão Emocional & 16,65 & 5,53 & 17,00 & 4 & 28,00 & 5,93 & -0.19 & $-0,57$ & 0,9837 & 0,3318 \\
\hline \multicolumn{11}{|l|}{ DERS } \\
\hline Consciência & 14,69 & 4,19 & 14,00 & 7 & 27,00 & 2,97 & 0.76 & 0,31 & 0,9458 & 0,001 \\
\hline Clareza & 12,79 & 4,65 & 13,00 & 5 & 24,00 & 4,45 & 0.52 & $-0,39$ & 0,9589 & 0,0066 \\
\hline Objetivos & 15,80 & 5,15 & 15,00 & 5 & 25,00 & 5,93 & -0.05 & $-0,86$ & 0,9718 & 0,0492 \\
\hline Impulsos & 13,37 & 4,96 & 12,50 & 6 & 30,00 & 3,71 & 0.96 & 0,51 & 0,9225 & 0,0001 \\
\hline Estratégia & 18,30 & 8,29 & 16,00 & 8 & 39,00 & 7,41 & 0.87 & $-0,17$ & 0,9034 & $<0,001$ \\
\hline Não Aceitação & 14,43 & 6,71 & 14,00 & 6 & 30,00 & 8,15 & 0.49 & $-0,83$ & 0,9286 & 0,0001 \\
\hline DERS Total & 89,38 & 25,29 & 48,00 & 83,5 & 157,00 & 23,72 & 0,76 & $-0,09$ & 0,9375 & 0,0003 \\
\hline \multicolumn{11}{|l|}{ PANAS } \\
\hline Afetos Positivos & 29.87 & 7.63 & 30.00 & 14.00 & 44.00 & 8.90 & -0.09 & -0.90 & 0,976 & $\mathbf{0 , 1 0}$ \\
\hline Afetos Negativos & 26.89 & 8.50 & 26.00 & 13.00 & 44.00 & 10.38 & 0.18 & -1.04 & 0,959 & 0,007 \\
\hline \multicolumn{11}{|l|}{ EA } \\
\hline Afetos Positivos & 36.30 & 8.38 & 37.00 & 13.00 & 50.00 & 7.41 & -0.48 & -0.24 & 0,968 & $\mathbf{0 , 1 0}$ \\
\hline Afetos Negativos & 30.14 & 8.61 & 30.00 & 13.00 & 46.00 & 10.38 & 0.06 & -0.93 & 0,976 & 0,02 \\
\hline \multicolumn{11}{|l|}{ FAST } \\
\hline Seguir Afetos Positivos & 17,13 & 3,80 & 18,00 & 9 & 24,00 & 4,45 & $-0,29$ & $-0,94$ & 0,9573 & 0,0052 \\
\hline Ignorar Afetos Positivos & 9,15 & 5,15 & 9,00 & 0 & 22,00 & 5,93 & 0,16 & $-0,58$ & 0,9746 & 0,078 \\
\hline Seguir Afetos Negativos & 13,95 & 5,91 & 14,00 & 0 & 24,00 & 5,93 & $-0,27$ & $-0,72$ & 0,9778 & 0,132 \\
\hline Ignorar Afetos Negativos & 13,37 & 5,49 & 14,00 & 1 & 24,00 & 5,93 & $-0,12$ & $-0,87$ & 0,9782 & 0,1405 \\
\hline \multicolumn{11}{|l|}{ DSS } \\
\hline Racional & 20,87 & 4,09 & 22,00 & 0 & 25,00 & 4,45 & -1.92 & 6,21 & 0,9070 & $<0,001$ \\
\hline Intuitivo & 14,25 & 4,10 & 14,00 & 0 & 23,00 & 4,45 & -0.45 & 0,42 & 0,9831 & 0,2992 \\
\hline
\end{tabular}

Nota: PANAS = Positive and Negative Affects Scale; EA= Escala de Afetos; FAST = Following Affective States Test $; \mathrm{ERQ}=$ Emotion Regulation Questionnaire $;$ DERS = Difficulties of Emotion Regulation Scale; DSS = Decision Style Scale $; \mathrm{DP}=$ Desvio padrão; Min= Mínimo; Máx = Máximo; $\mathrm{MAD}=$ Mean Absolute Desviation about media; $\mathrm{W}=$ Shapiro Wilk; $p<0,05$. 
As análises descritivas indicaram que para as variáveis relacionadas ao uso de estratégias de regulação emocional, os participantes tenderam a relatar mais uso de reavaliação cognitiva, quando comparado à supressão emocional (ERQ). O teste de Shapiro-Wilk indicou uma distorção da normalidade para esta variável [W $=0.930 ; p<0,001]$, mas não para supressão emocional $[\mathrm{W}=0,983 ; p=0,33]$.

Já para as variáveis de desregulação emocional, observaram-se níveis mais baixos em todos os fatores da DERS, considerando-se os valores máximos possíveis para a escala. O teste de normalidade indicou que todos os subfatores da DERS apresentaram distorções da normalidade.

Em relação aos afetos, os participantes relataram mais experiências com afetos positivos e menores níveis de afetos negativos, tanto na PANAS quanto na EA. Apesar disso, o teste de Shapiro Wilk indicou que tanto afetos positivos avaliados pela PANAS [W $=0,976 ; p=0,10]$, quanto afetos negativos avaliados pela EA $[\mathrm{W}=0,976 ; p=0,10]$, apresentaram distribuição normal, o que não ocorreu para afetos negativos (PANAS) [W $=0,959 ; p=0,007] \mathrm{e}$ afetos positivos (EA) $[\mathrm{W}=0,968 ; p=0,02]$.

Em relação à tendência a seguir ou ignorar afetos (FAST), os participantes apresentaram escores mais elevados em seguir afetos positivos, e escores mais baixos em ignorar afetos positivos. o teste de Shapiro Wilk indicou que seguir afetos positivos (SAP) não apresentou distribuição normal [W $=0,957 ; p=0,005]$, tendo as demais variáveis uma distribuição normal nestes indivíduos avaliados. Por fim, a escala de estilos de decisão (DSS) indicou uma tendência maior dos participantes a reportarem escores elevados de estilo racional quando comparado ao estilo intuitivo. Com base nesses resultados, realizamos as análises gráficas para verificar a presença de valores extremos. Estes dados constam na Figura 11. 


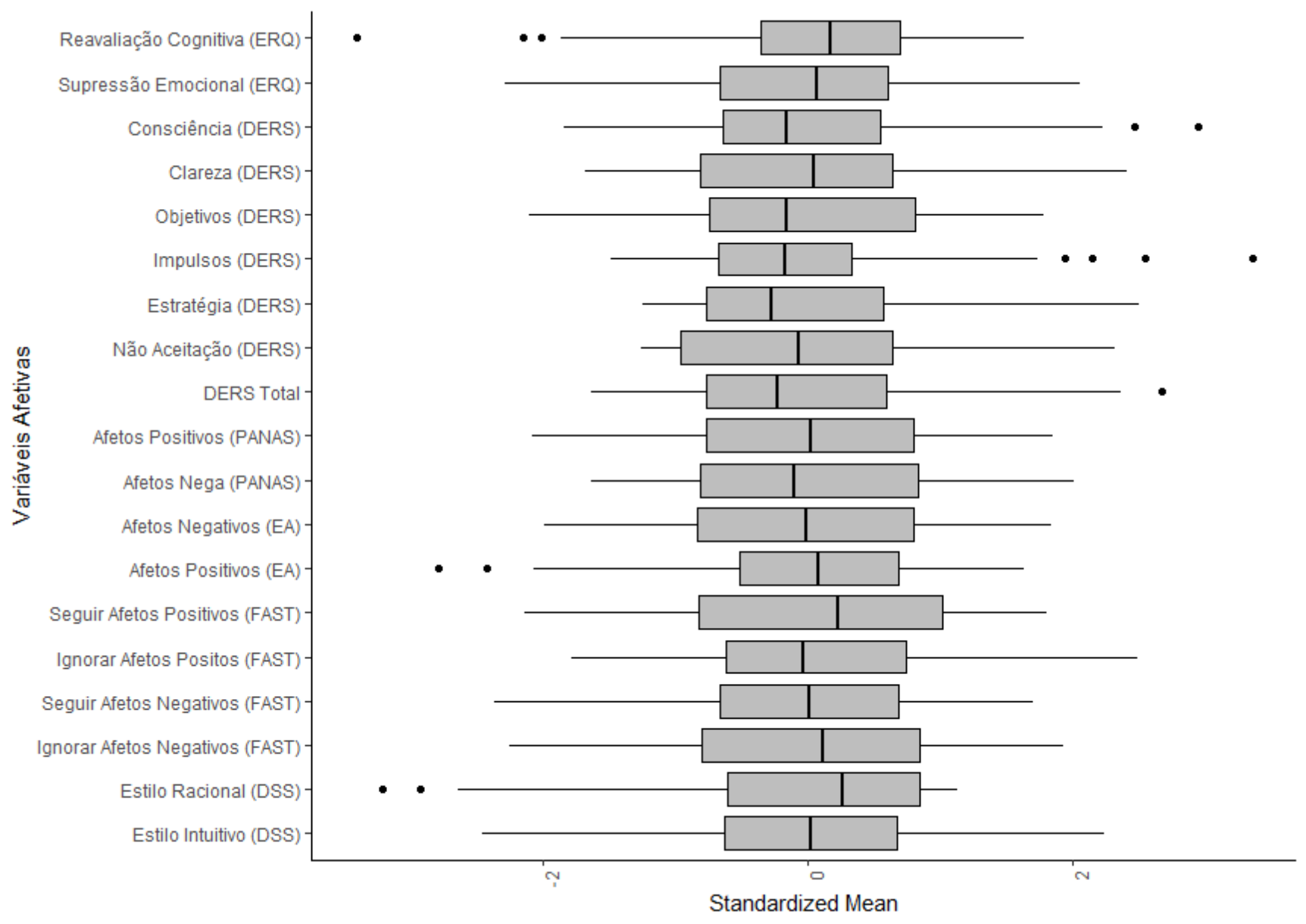

Figura 11. Diagrama de caixa de bigodes para as variáveis das escalas afetivas e estilos de decisão no Estudo II.

A Figura 11 demonstra que, para as variáveis relacionadas à regulação emocional (ERQ), apresentam-se valores extremos no fator reavaliação cognitiva. Para a desregulação emocional (DERS), a análise gráfica indica a presença de valores extremos nas variáveis consciência, impulsos e no escore total. Quanto às variáveis relativas a afetos positivos e negativos, avaliados pela PANAS e EA, observou-se a presença de valores extremos apenas na variável afetos positivos da EA. Para as variáveis avaliadas pela FAST não houve a presença de valores extremos.

A Escala de Estilos de Decisão (DSS) apresentou valores extremos em ambas as subescalas. Apesar disso, demonstrou assimetria apenas para o estilo racional, com o teste Shapiro Wilk indicando desvio da normalidade [W $=0,907 ; p<0,001]$, mas não para o estilo intuitivo [W=0,983; $p=0,29]$.

A Tabela 15 apresenta as estatísticas descritivas para as diferentes variáveis avaliadas no IGT. Novamente, recorreu-se à análise gráfica para auxiliar na compreensão destes valores a fim 
de orientar decisões das análises posteriores. Novamente, são apresentadas as médias, desvio padrão, mediana, mínima, máxima, MAD, skewness e kursosis para cada uma das variáveis.

Tabela 15. Estatísticas descritivas, medidas de tendência central e teste de normalidade das variáveis do Iowa Gambling Task (IGT) para o estudo II $(n=92)$.

\begin{tabular}{lcccccccccc}
\hline \multicolumn{1}{c}{ Variável } & Média & DP & Mediana & Min & Max & MAD & Skewness & Kurtosis & $W$ & $p$ \\
\hline Baralho A & 18,73 & 5,58 & 18,50 & 6,00 & 33,00 & 5,19 & 0,07 & $-0,49$ & 0,984 & $\mathbf{0 , 4 1}$ \\
Baralho B & 27,84 & 7,55 & 27,00 & 9,00 & 40,00 & 6,67 & $-0,08$ & $-0,50$ & 0,96 & 0,01 \\
Baralho C & 24,31 & 6,93 & 24,00 & 11,00 & 40,00 & 5,93 & 0,48 & 0,06 & 0,957 & 0,006 \\
Baralho D & 29,12 & 6,85 & 27,50 & 17,00 & 40,00 & 6,67 & 0,32 & $-1,08$ & 0,923 & $<0,001$ \\
Bloco 1 & $-1,16$ & 5,98 & $-2,00$ & $-14,00$ & 20,00 & 2,97 & 1,04 & 2,25 & 0,923 & $<0,001$ \\
Bloco 2 & 0,81 & 5,16 & 0,00 & $-14,00$ & 20,00 & 2,97 & 1,16 & 4,03 & 0,856 & $<0,001$ \\
Bloco 3 & 1,33 & 6,87 & 1,00 & $-18,00$ & 20,00 & 4,45 & 0,11 & 0,59 & 0,975 & $\mathbf{0 , 1 0 2}$ \\
Bloco 4 & 2,35 & 6,60 & 2,00 & $-10,00$ & 20,00 & 5,93 & 0,68 & 0,32 & 0,947 & 0,001 \\
Bloco 5 & 3,53 & 7,38 & 2,00 & $-20,00$ & 20,00 & 5,93 & 0,20 & 0,48 & 0,95 & 0,002 \\
Tendência Geral & 6,86 & 19,48 & 2,00 & $-30,00$ & 60,00 & 17,79 & 0,84 & 0,38 & 0,939 & $<0,001$ \\
Tendência geral Bl 2-5 & 8,02 & 18,10 & 4,00 & $-20,00$ & 64,00 & 17,79 & 0,82 & 0,08 & 0,936 & $<0,001$ \\
\hline
\end{tabular}

Nota: DP = Desvio padrão; Min= Mínimo; Máx = Máximo; MAD= Mean Absolute Desviation about media; $\mathrm{W}=$ Shapiro Wilk; $p<0,05$.

Os valores das análises descritivas indicaram médias elevadas para escolhas dos baralhos B e D, o que é compatível com a literatura. Indicando que os participantes fizeram mais escolhas seguras (Baralho D), mas tenderam a realizar escolhas arriscadas quando as punições não são frequentes (Baralho B). Além disso, observa-se um aumento das médias dos escores em relação aos blocos, o que indica que os participantes apresentaram efeito de aprendizagem ao longo da tarefa. Entretanto, quando considerados os escores de tendência geral, observa-se que os valores foram muito distantes do ponto máximo possível, o que pode sugerir um nível de dificuldade elevado. O teste de Shapiro Wilk identificou que apenas os escores para o Baralho A [W = 0,98; $p=0,41]$ e o bloco 3 [W $=0,97 ; p=0,10$ ] mantiveram-se dentro de uma distribuição normal, com as demais variáveis apresentando desvios leves nessa característica. A Figura 12 indica a presença de valores extremos para os escores dos Baralhos $\mathrm{B}$ e $\mathrm{C}$, bem como para todos os blocos e escores de Tendência geral original e do proposto para os blocos de 2 a 5 do IGT. 


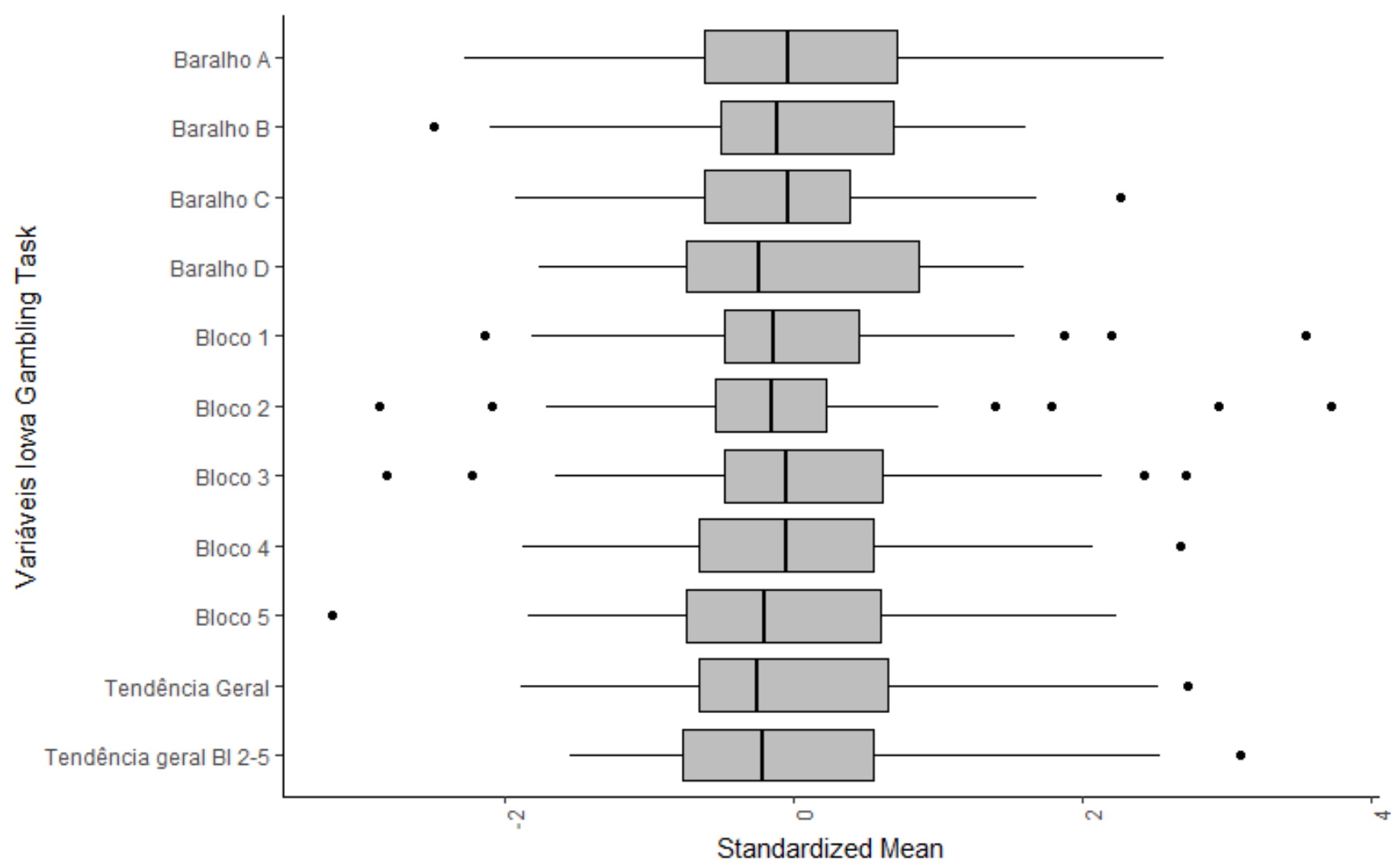

Figura 12. Diagrama de caixa de bigodes para as variáveis do IGT no Estudo II

Concluídas as análises sobre IGT, passou-se ao exame dos dados relativos ao Método de Rorschach. A estatística descritiva das variáveis selecionadas a partir do R-PAS para compor este estudo estão presentes na Tabela 16. Para as variáveis afetivas e de tomada de decisão foram reportados valores médios, desvio padrão, mediana, mínimo e máximo, MAD e skewness e kurtosis.

Tabela 16. Estatísticas descritivas, medidas de tendência central e teste de normalidade das variáveis selecionadas a partir do Método de Rorschach (R-PAS) (n=92).

\begin{tabular}{lcccccccccc}
\hline & Média & DP & Mediana & Min & Max & MAD & Skewness & Kurtosis & $W$ & $p$ \\
\hline Variáveis Afetivas & & & & & & & & & & \\
R8910\% & 98,48 & 10,89 & 74,00 & 97,00 & 131,00 & 10,38 & 0,32 & 0,18 & 0,969 & $\mathbf{0 , 2 5 6}$ \\
M & 102,30 & 14,40 & 71,00 & 103,00 & 137,00 & 14,83 & 0,24 & $-0,04$ & 0,955 & $\mathbf{0 , 0 7}$ \\
FC & 90,59 & 10,33 & 81,00 & 93,00 & 123,00 & 17,79 & 0,95 & 0,44 & 0,884 & $<0,001$ \\
CF & 89,64 & 9,29 & 82,00 & 82,00 & 119,00 & 0,00 & 0,84 & $-0,22$ & 0,842 & $<0,001$ \\
C & 111,38 & 15,17 & 95,00 & 114,00 & 148,00 & 23,72 & 0,28 & $-1,08$ & 0,896 & $<0,001$ \\
CBlend & 93,93 & 6,88 & 91,00 & 91,00 & 117,00 & 0,00 & 2,06 & 2,84 & 0,584 & $<0,001$ \\
WSumC & 96,01 & 15,42 & 70,00 & 96,00 & 139,00 & 15,57 & 0,19 & $-0,39$ & 0,965 & $\mathbf{0 , 1 6 9}$ \\
\hline
\end{tabular}




\section{Página | 116}

$\begin{array}{lcccccccccc}\text { (CF+C)/SumC } & 107,47 & 14,84 & 75,00 & 108,00 & 126,00 & 11,86 & -0,62 & -0,54 & 0,913 & 0,002 \\ \text { MC } & 99,71 & 14,35 & 63,00 & 97,00 & 135,00 & 14,83 & -0,15 & -0,42 & 0,972 & \mathbf{0 , 3 2 2} \\ \text { PPD } & 90,75 & 11,57 & 59,00 & 90,00 & 112,00 & 13,34 & -0,45 & -0,35 & 0,94 & 0,019 \\ \text { MC - PPD } & 109,14 & 12,76 & 82,00 & 107,00 & 141,00 & 13,34 & 0,32 & -0,37 & 0,973 & \mathbf{0 , 3 6 7} \\ \text { V_Comp } & 99,05 & 13,07 & 59,00 & 100,50 & 121,00 & 12,60 & -0,46 & -0,06 & 0,961 & \mathbf{0 , 1 2 3} \\ \text { CFC-FC } & 104,85 & 12,12 & 76,00 & 106,00 & 135,00 & 10,38 & -0,11 & 0,05 & 0,948 & 0,038\end{array}$

Variáveis Tomada de Decisão

\begin{tabular}{lcccccccccc} 
Dd\% & 93,84 & 12,00 & 75,00 & 95,00 & 122,00 & 14,83 & 0,09 & $-0,84$ & 0,960 & $\mathbf{0 , 1 1 5}$ \\
SI & 90,35 & 11,98 & 74,00 & 86,00 & 123,00 & 14,83 & 0,17 & $-0,68$ & 0,907 & 0,001 \\
Vg\% & 105,18 & 12,34 & 86,00 & 106,00 & 135,00 & 10,38 & $-0,03$ & $-0,77$ & 0,939 & 0,017 \\
V & 95,58 & 8,17 & 92,00 & 92,00 & 126,00 & 0,00 & 2,05 & 2,93 & 0,618 & $<0,001$ \\
FD & 115,86 & 14,69 & 88,00 & 115,00 & 148,00 & 16,31 & $-0,08$ & $-0,73$ & 0,943 & 0,023 \\
M/MC & 104,84 & 15,93 & 69,00 & 102,00 & 135,00 & 16,31 & 0,09 & $-0,67$ & 0,966 & $\mathbf{0 , 2 0 1}$ \\
IntCont & 88,60 & 9,96 & 81,00 & 81,00 & 124,00 & 0,00 & 1,23 & 1,08 & 0,780 & $<0,001$ \\
\hline
\end{tabular}

Dado que as normas brasileiras disponibilizadas no manual do R-PAS apresentam apenas os escores brutos, mas não os normalizados, novamente, as estatísticas descritivas tornaram-se pouco informativas para questões interpretativas. Dessa forma, recorreu-se às análises gráficas para exame da distribuição dos resultados (Figura 13). 


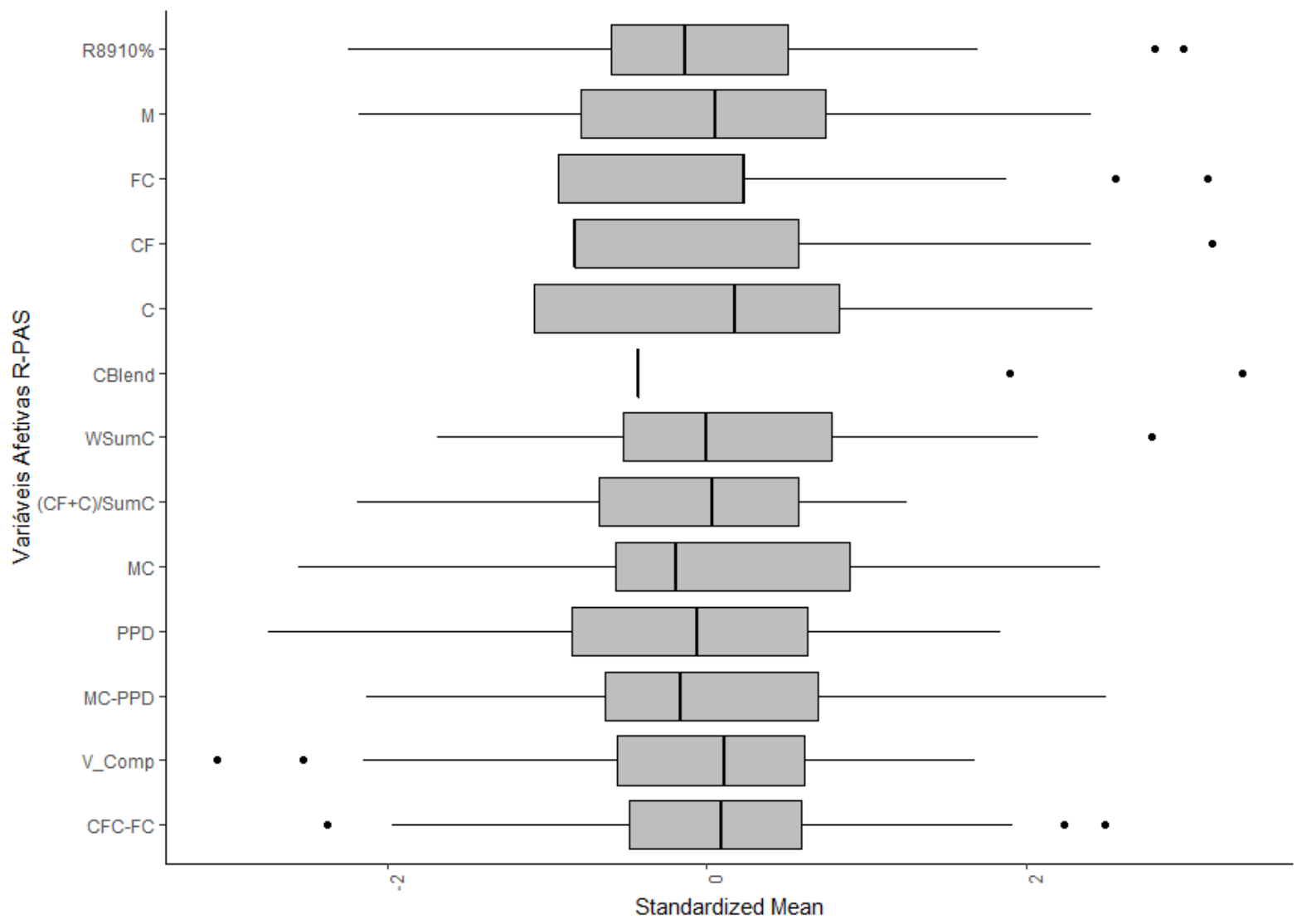

Figura 13. Diagrama de caixa de bigodes para as variáveis afetivas do R-PAS no Estudo II.

Os diagramas de caixa de bigodes indicaram a presença de valores extremos nas variáveis R8910\%, FC, CF, Cblend, WSumC, V- Comp e CFC - FC. Além disso observa-se forte desvio nas distribuições, demonstrando assimetria importante em muitas das variáveis utilizadas. O teste de Shapiro Wilk indicou que oito das variáveis apresentaram distribuição normal: R8910\% $[\mathrm{W}=0,96 ; p=0,25], \mathrm{M}[\mathrm{W}=0,95 ; p=0,07], \mathrm{WSumC}[\mathrm{W}=0,96 ; p=0,16], \mathrm{MC}[\mathrm{W}=0,97 ; p=$ 0,32], MC - PPD [W $=0,97 ; p=0,36]$ e V-Comp [W $=0,96 ; p=0,12]$. Com as demais desviando-se de uma distribuição normal.

Por fim, a Figura 15 indicou que, para as variáveis de tomada de decisão, observaram-se valores extremos em SI, $\mathrm{Vg} \%, \mathrm{~V}$ e IntCont e constatam-se distorções da normalidade importantes na distribuição das variáveis. O teste de Shapiro Wilk identificou uma distribuição normal apenas para as variáveis $\mathrm{Dd} \%[\mathrm{~W}=0,96 ; p=0,11], \mathrm{M} / \mathrm{MC}[\mathrm{W}=0,96 ; p=0,20]$. 


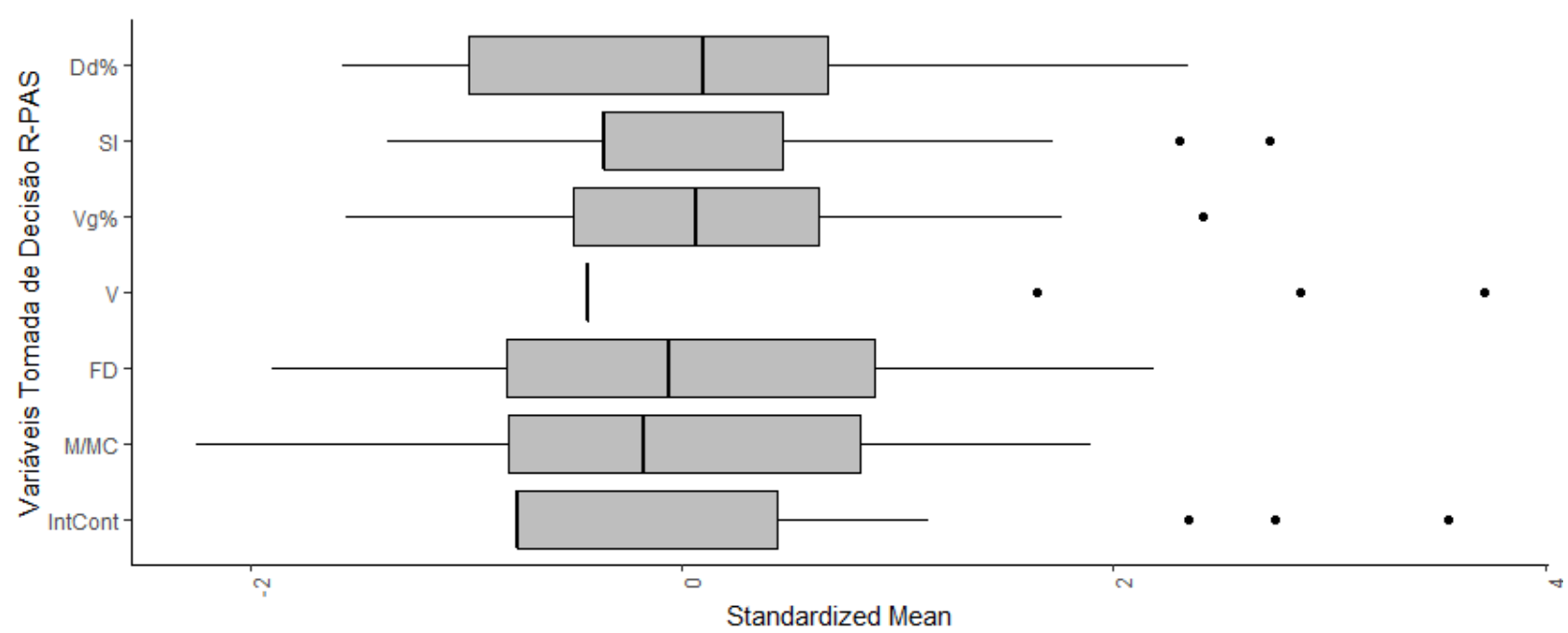

Figura 14. Diagrama de caixa de bigodes para as variáveis de tomada de decisão do R-PAS no Estudo II.

Esse conjunto de resultados exploratórios indica que as variáveis psicológicas apresentam características bastante complexas, o que demanda cuidado metodológico importante nas decisões analíticas realizadas para testar as hipóteses principais dos estudos. Dessa forma, justifica-se a utilização de métodos robustos, que têm por característica principal minimizar os efeitos dos valores extremos sobre as análises estatísticas. Estas análises passam a ser agora descritas.

\subsubsection{Análises de associações entre variáveis do mesmo domínio}

\subsubsection{Afetos e regulação emocional}

A Tabela 17 apresenta as correlações observadas entre as variáveis afetivas em nível de autorrelato e as relacionadas aos processos automáticos avaliados pelo R-PAS. Destaca-se que poucos processos demonstraram significativas associações entre os tipos de informação.

Não houve relações estatisticamente significativas entre variáveis do R-PAS com disposição afetiva, examinadas pelo PANAS e EA, nem com estratégias de regulação emocional, avaliadas pela ERQ. Entretanto, observam-se correlações negativas estatisticamente significativas entre FC e vários processos de desregulação emocional, consciência ( $P p b=-0,38$; $p<0,05)$, clareza $(P p b=-0,39 ; p<0,05)$, objetivos $(P p b=-0,38 ; p<0,05)$ e impulsos $(P p b=-0,34$; $p<$ 0,05). Também existiram relações estatisticamente significativas e positivas entre $(\mathrm{CF}+\mathrm{C}) /$ SumC e dificuldades de clareza $(P p b=0,36 ; p<0,05)$ e objetivos $(P p b=0,32 ; p<0,05)$. 
Estes resultados podem indicar que o autorrelato acerca dos afetos vivenciados e o uso habitual de estratégias de regulação emocional envolvem peculiaridades psíquicas distintas dos processos emocionais automáticos avaliados pelo R-PAS. Entretanto, as dificuldades em regular as emoções (expressas por autorrelato) também foram captadas por variáveis do Rorschach. Os achados indicaram que sinais de desregulação emocional se associaram a diminuição de escores na variável FC do R-PAS. Em complemento, quando os participantes referiram dificuldades pessoais para compreender a experiência afetiva e a ausência de objetivos, observou-se elevação na proporção de $\mathrm{CF}+\mathrm{C}$ do Rorschach, variável representativa de forte mobilização emocional e de descontrole racional.

Ao focalizar indicadores de atenção às emoções avaliados pela FAST, constatou-se correlação negativa estatisticamente significativa entre seguir afetos positivos e diversos indicadores do R-PAS, entre eles C $(P p b=-0,34 ; p<0,05),(\mathrm{CF}+\mathrm{C}) / \operatorname{SumC}(P p b=-0,34 ; p<0,05)$, MC - PPD (Ppb = -0,43; $p<0,05)$, CFC-FC $(P p b=-0,34 ; p<0,05)$ e PPD $(P p b=0,40 ; p<0,05)$. Também foram encontradas associações estatisticamente significativas entre seguir afetos negativos e MC - PPD $(P p b=-0,31 ; p<0,05)$, além de ignorar afetos negativos e V-Comp ( $P p b$ $=-0,36 ; p<0,05)$. Dessa forma, o autorrelato de atenção às emoções, especialmente as positivas, mostrou-se relacionado à diminuição de indicadores problemáticos no R-PAS. Entretanto, houve uma relação positiva importante com PPD, o que pode sugerir sensibilidade emocional. Já a tendência a seguir afetos negativos se mostrou associada à diminuição dos indicadores de adaptabilidade e de esforço cognitivo para constrição dos afetos nas variáveis do R-PAS. 
Tabela 17. Correlações entre variáveis afetivas avaliadas por autorrelato e por desempenho no $R-P A S(n=92)$.

\begin{tabular}{|c|c|c|c|c|c|c|c|c|c|c|c|c|c|}
\hline \multirow[b]{2}{*}{ Variáveis Escalas } & \multicolumn{13}{|c|}{ Variáveis R-PAS } \\
\hline & R8910\% & M & $\mathrm{FC}$ & $\mathrm{CF}$ & $\mathrm{C}$ & CBlend & WSumC & $\begin{array}{c}(\mathrm{CF}+\mathrm{C}) / \\
\text { SumC }\end{array}$ & $\mathrm{MC}$ & PPD & MC -PPD & V-Comp & CFC-FC \\
\hline \multicolumn{14}{|l|}{ ERQ } \\
\hline Reavaliação Cognitiva & $-0,299$ & 0,124 & $-0,053$ & 0,295 & 0,056 & 0,061 & 0,058 & 0,074 & 0,17 & $-0,079$ & 0,237 & $-0,028$ & 0,122 \\
\hline Supressão Emocional & $-0,300$ & 0,061 & 0,049 & 0,091 & $-0,083$ & 0,134 & $-0,073$ & $-0,046$ & $-0,084$ & $-0,254$ & 0,014 & 0,195 & $-0,06$ \\
\hline \multicolumn{14}{|l|}{ PANAS } \\
\hline Afetos Positivos & 0,124 & $-0,152$ & 0,111 & $-0,003$ & $-0,066$ & $-0,212$ & $-0,121$ & $-0,164$ & $-0,177$ & $-0,183$ & 0,011 & $-0,167$ & $-0,113$ \\
\hline Afetos Negativos & $-0,081$ & $-0,044$ & $-0,072$ & $-0,066$ & $-0,099$ & 0,088 & $-0,144$ & $-0,024$ & $-0,113$ & 0,021 & $-0,186$ & 0,167 & $-0,043$ \\
\hline \multicolumn{14}{|l|}{ DERS } \\
\hline Consciência & $-0,125$ & 0,18 & $-0,383 *$ & $-0,188$ & 0,053 & 0,083 & $-0,069$ & 0,265 & 0,009 & $-0,087$ & 0,053 & 0,102 & 0,174 \\
\hline Clareza & $-0,291$ & 0,04 & $-0,395 *$ & 0,027 & 0,144 & 0,068 & 0,081 & $0,364 *$ & 0,081 & 0,003 & 0,041 & 0,211 & 0,314 \\
\hline Objetivos & $-0,137$ & 0,061 & $-0,381 *$ & 0,265 & $-0,083$ & 0,192 & 0,00 & $\mathbf{0 , 3 2 2 *}$ & $-0,045$ & 0,2 & $-0,226$ & 0,081 & 0,268 \\
\hline Impulsos & $-0,079$ & $-0,104$ & $-0,346 *$ & 0,277 & $-0,127$ & $-0,053$ & $-0,069$ & 0,233 & $-0,127$ & 0,122 & $-0,239$ & $-0,039$ & 0,211 \\
\hline Estratégia & $-0,131$ & $-0,111$ & $-0,146$ & $-0,026$ & $-0,157$ & 0,086 & $-0,143$ & 0,061 & $-0,154$ & 0,016 & $-0,198$ & 0,053 & 0,02 \\
\hline Não aceitação & $-0,146$ & $-0,109$ & 0,002 & $-0,001$ & $-0,17$ & 0,145 & $-0,159$ & $-0,069$ & $-0,225$ & $-0,045$ & $-0,118$ & 0,068 & $-0,093$ \\
\hline DERS Total & $-0,155$ & $-0,018$ & $-0,359$ & 0,117 & $-0,169$ & 0,090 & $-0,146$ & 0,233 & $-0,141$ & 0,032 & $-0,184$ & 0,070 & 0,165 \\
\hline \multicolumn{14}{|l|}{ FAST } \\
\hline Seguir Afetos Positivos & 0,148 & $-0,017$ & 0,297 & $-0,017$ & $-0,346 *$ & $-0,148$ & $-0,269$ & $-0,343 *$ & $-0,223$ & $\mathbf{0 , 4 0 8 *}$ & $-0,432 * *$ & $-0,118$ & $-0,340 *$ \\
\hline Ignorar Afetos Positivos & $-0,116$ & 0,084 & 0,126 & $-0,125$ & $-0,047$ & 0,203 & $-0,081$ & $-0,162$ & $-0,109$ & 0,017 & $-0,073$ & $-0,148$ & $-0,131$ \\
\hline Seguir Afetos Negativos & 0,076 & $-0,167$ & $-0,018$ & 0,052 & $-0,136$ & 0,082 & $-0,046$ & $-0,015$ & $-0,125$ & 0,274 & $-0,320 *$ & 0,177 & 0,012 \\
\hline Ignorar Afetos Negativos & $-0,072$ & 0,008 & $-0,031$ & $-0,144$ & $-0,054$ & 0,054 & $-0,091$ & $-0,079$ & $-0,122$ & $-0,019$ & $-0,049$ & $-0,367 *$ & $-0,097$ \\
\hline
\end{tabular}

Nota: $* \mathrm{p}<.05, * * \mathrm{p}<.01, * * * \mathrm{p}<.001$ 


\subsubsection{Estilos de decisão e desempenho no IGT}

Os resultados apresentados na Tabela 18 ilustram os achados da análise correlacional entre indicadores da Escala de Estilos de Decisão (DSS) e a forma de processamento interno de riscos envolvidos em processos de decisão do IGT.

Os achados indicaram correlação estatisticamente significativa entre estilo racional de tomada de decisão (DSS) e maior seleção de cartas do baralho B $(P p b=0,260 ; p<0,05)$ do IGT. Já para o estilo intuitivo, observou-se correlação estatisticamente significativa com o desempenho no bloco $2(P p b=0,348 ; p<0,01)$ e no escore de Tendência geral B1 2-5 $(P p b=$ $0,238 ; p<0,01)$. Estes resultados sugerem que o estilo racional pode levar a seleção do baralho $\mathrm{B}$, dado que este inicialmente este é o melhor baralho em termos de recompensa. Já o estilo intuitivo pode levar a melhor desempenho no bloco 2, que costuma ser o ponto onde ocorre a aprendizagem para melhoria do resultado do IGT, muito mais dependente de processos afetivos do que racionais.

De maneira geral, seriam esperadas correlações estatisticamente significativas importantes entre os diversos escores do IGT entre si, tanto nos blocos quanto para a tendência geral, dado que são justamente os baralhos que contribuem para a formação dos escores. No entanto, os achados apontaram falta de consistência entre estes indicadores do IGT. Por exemplo, esperavase correlação entre os blocos 2, 3, 4 e 5. Estes resultados merecem maior exploração, porém tais investigações ultrapassam os objetivos aqui propostos. 
Tabela 18. Correlação entre variáveis relativas à tomada de decisão, retiradas da DSS e IGT (Estudo II, $n=92$ ).

\begin{tabular}{|c|c|c|c|c|c|c|c|c|c|c|c|c|c|}
\hline Variável & 01 & 02 & 03 & 04 & 05 & 06 & 07 & 08 & 09 & 10 & 11 & 12 & 13 \\
\hline \multicolumn{14}{|l|}{ 01) Racional } \\
\hline 02) Intuitivo & $-0,244^{*}$ & & & & & & & & & & & & \\
\hline 03) Baralho A & 0,017 & -0.135 & & & & & & & & & & & \\
\hline 04) Baralho B & $0,260 *$ & $-0,229$ & 0,055 & & & & & & & & & & \\
\hline 05) Baralho C & $-0,102$ & 0,223 & $-0,175$ & $-0,714 * *$ & & & & & & & & & \\
\hline 06) Baralho D & $-0,195$ & 0,102 & $-0,691 * *$ & $-0,409 * *$ & $-0,010$ & & & & & & & & \\
\hline 07) Bloco 1 & $-0,160$ & $-0,009$ & $-0,062$ & $-0,422 * *$ & $\mathbf{0 , 3 3 1} * *$ & $\mathbf{0 , 2 3 8} * *$ & & & & & & & \\
\hline 08) Bloco 2 & $-0,079$ & $0,348 * *$ & $-0,310 *$ & $-0,556 * *$ & $0,337 * *$ & $0,535 * *$ & 0,175 & & & & & & \\
\hline 09) Bloco 3 & $-0,199$ & 0,142 & $-0,405 * *$ & $-0,657 * *$ & $0,405 * *$ & $0,617 * *$ & 0,024 & $0,469 * *$ & & & & & \\
\hline 10) Bloco 4 & $-0,177$ & 0,203 & $-0,510 * *$ & $-0,571 * *$ & $0,497 * *$ & $0,540 * *$ & 0,009 & $\mathbf{0 , 3 7 0} * *$ & $0,670 * *$ & & & & \\
\hline 11) Bloco 5 & $-0,064$ & 0,049 & $-0,545 * *$ & $-0,262 * *$ & $\mathbf{0 , 4 1 9} * *$ & $\mathbf{0 , 3 1 8 * *}$ & 0,014 & 0,081 & 0,219 & 0,408 & & & \\
\hline 12) Tendência Geral & $-0,227$ & 0,209 & $-0,592 * *$ & $-0,783 * *$ & $0,620 * *$ & $0,731 * *$ & $0,352 * *$ & $\mathbf{0 , 5 8 0} * *$ & $0,777 * *$ & $0,759 * *$ & $0,544 * *$ & & \\
\hline 13) Tendência geral $\mathrm{Bl}$ 2-5 & $-0,211$ & $\mathbf{0 , 2 3 8 *}$ & $-0,592 * *$ & $-0,743 * *$ & $\mathbf{0 , 5 8 5} * *$ & $0,697 * *$ & 0,111 & $\mathbf{0 , 5 8 1} * *$ & $0,828 * *$ & $\mathbf{0 , 8 0 4} * *$ & $\mathbf{0 , 5 7 3 * *}$ & $0,956 * *$ & \\
\hline
\end{tabular}

Nota: $* \mathrm{p}<.05, * * \mathrm{p}<.01, * * * \mathrm{p}<.001$ 
A seguir procurou-se examinar as relações entre estilos de decisão (DSS), desempenho no IGT e as variáveis relativas ao R-PAS. Estes resultados são apresentados na Tabela 19.

Tabela 19. Correlação entre variáveis relativas à tomada de decisão envolvidas na DSS, IGT e $R-P A S(n=92)$.

\begin{tabular}{lccccccc}
\hline $\begin{array}{l}\text { Variáveis R-PAS } \\
\text { Instrumentos }\end{array}$ & Dd\% & SI & Vg\% & V & FD & M/MC & IntCont \\
\hline DSS & & & & & & & \\
$\quad$ Racional & $\mathbf{- 0 , 2 4 *}$ & $\mathbf{0 , 3 2 * *}$ & 0,12 & 0,16 & 0,14 & 0,08 & 0,08 \\
$\quad$ Intuitivo & 0,19 & $-0,01$ & $-0,09$ & $-0,16$ & $-0,2$ & $-0,03$ & 0,04 \\
IGT & & & & & & & \\
Baralho A & $-0,09$ & $-0,12$ & 0,04 & $-0,08$ & $-0,18$ & $-0,06$ & 0,0 \\
Baralho B & $-0,15$ & 0,21 & $-0,05$ & $-0,04$ & $-0,2$ & 0,04 & $-0,15$ \\
Baralho C & 0,12 & $-0,2$ & 0,12 & 0,14 & 0,15 & $-0,04$ & 0,03 \\
Baralho D & 0,04 & 0,04 & $-0,05$ & $-0,01$ & 0,22 & 0,01 & 0,14 \\
Bloco 1 & 0,05 & $-0,05$ & 0,02 & $-0,04$ & 0,21 & 0,06 & 0,06 \\
Bloco 2 & 0,17 & 0,04 & $-0,09$ & $-0,06$ & 0,14 & $-0,02$ & 0,10 \\
Bloco 3 & 0,14 & $-0,07$ & $-0,1$ & $-0,03$ & 0,05 & 0,10 & 0,07 \\
Bloco 4 & $-0,06$ & $-0,12$ & 0,03 & $-0,06$ & $\mathbf{0 , 2 4} *$ & $-0,09$ & 0,18 \\
Bloco 5 & 0,17 & $-0,05$ & 0,15 & 0,23 & 0,14 & 0,02 & $-0,11$ \\
TG & 0,13 & $-0,07$ & 0,04 & 0,06 & 0,22 & 0,00 & 0,10 \\
TG B12 - B1 5 & 0,15 & $-0,08$ & 0,06 & 0,09 & 0,17 & 0,00 & 0,10 \\
\hline
\end{tabular}

Nota: $* \mathrm{p}<0,05 ; * * \mathrm{p}<0,01 ; * * * \mathrm{p}<0,001$

Pode-se notar que só foram encontradas correlações estatisticamente significativas entre estilo racional e $\mathrm{Dd} \%(P p b=-0,24 ; p<0,01)$ e SI $(P p b=0,32 ; p<0,01)$. Estes resultados apontaram que um estilo de decisão mais racional está relacionado à diminuição do indicador Dd\% e aumento em SI, o que inicialmente parece contraditório. O escore de Dd\% está relacionado a um estilo cognitivo mais detalhista, por outro lado SI relaciona-se a um esforço cognitivo para focalizar a atenção. Também foi identificada associação estatisticamente significativa entre resultado no bloco 4 e $\mathrm{FD}(P p b=0,24 ; p<0,05)$. Isso sugere que o desempenho nas escolhas numa fase mais avançada do IGT, pode estar relacionado a maior distanciamento emocional que se reflete na elevação do indicador de FD no Rorschach. 
Nenhuma outra associação entre as variáveis da DSS, IGT e R-PAS se mostrou estatisticamente significativa, contrariando expectativas postuladas.

\subsubsection{Relações entre variáveis de diferentes domínios}

Conforme delineado nos objetivos deste estudo, procurou-se avaliar as possíveis associações existentes entre variáveis afetivas e de tomada de decisão, a partir dos instrumentos utilizados. A Tabela 20 apresenta os resultados das correlações encontradas entre as variáveis afetivas (em nível de autorrelato), estilos de tomada de decisão (do DSS) e desempenho no IGT. Estes achados abordam, então, as associações identificadas entre indicadores de regulação emocional e processos de decisão.

Houve correlações positivas e estatisticamente significativas entre o estilo racional de decisão e uso de estratégias de supressão emocional $(P p b=0,36 ; p<0,001)$ e ignorar afetos positivos $(P p b=0,31 ; p<0,01)$. O estilo intuitivo de decisão, por sua vez, apresentou correlação negativa estatisticamente significativa com a estratégia de reavaliação cognitiva $(P p b=-0,27$; $p<0,01$ ), além de associação positiva com dificuldades de regulação emocional, especificamente com impulsos $(P p b=0,40 ; p<0,001)$, estratégia $(P p b=0,24 ; p<0,01)$ e o escore total na DERS $(P p b=0,27 ; p<0,01)$. O estilo intuitivo apresentou também correlação estatisticamente significativa com a tendência a seguir afetos negativos $(P p b=0,30 ; p<0,01)$.

Os resultados aqui observados sugerem que o estilo racional pareceu relacionado a tentativa de controle da influência afetiva, por meio de estratégias de ignorar afetos positivos e de supressão emocional. Já o estilo intuitivo mostrou-se relacionado a indicadores mais negativos da experiência afetiva, relacionando-se com desregulação emocional. Diante da elevação do estilo intuitivo houve aumento do uso de reavaliação cognitiva. Estes achados podem sugerir que o estilo intuitivo tende a utilizar mais informações emocionais negativas para a tomada de decisão. 
Tabela 20. Correlação entre regulação emocional e tomada de decisão (n=92).

\begin{tabular}{|c|c|c|c|c|c|c|c|c|c|c|c|c|c|}
\hline \multirow{2}{*}{ Variáveis afetivas } & \multicolumn{2}{|c|}{ DSS } & \multicolumn{11}{|c|}{ IGT } \\
\hline & Racional & Intuitivo & Baralho A & Baralho B & Baralho C & Baralho D & Bloco 1 & Bloco 2 & Bloco 3 & Bloco 4 & Bloco 5 & TG & TG B12 - B15 \\
\hline \multicolumn{14}{|l|}{ ERQ } \\
\hline Supressão emocional & $0,360 * * *$ & $-0,171$ & 0,044 & 0,142 & $-0,082$ & $-0,093$ & $-0,004$ & 0,006 & 0,063 & $-0,108$ & $-0,118$ & $-0,088$ & $-0,128$ \\
\hline \multicolumn{14}{|l|}{ PANAS } \\
\hline Afetos Negativos & 0,142 & 0,149 & 0,043 & $0,225^{*}$ & $-0,003$ & $-0,268 *$ & $-0,134$ & $-0,108$ & $-0,141$ & $-0,164$ & $-0,13$ & $-0,184$ & $-0,154$ \\
\hline \multicolumn{14}{|l|}{ EA } \\
\hline Afetos Positivos & 0,022 & $-0,002$ & 0,019 & $-0,052$ & $-0,052$ & 0,174 & 0,133 & 0,071 & 0,039 & $-0,01$ & 0,019 & 0,095 & 0,033 \\
\hline Afetos Negativos & $-0,028$ & 0,201 & 0,014 & 0,097 & $-0,089$ & $-0,081$ & $-0,209$ & $-0,036$ & 0,03 & $-0,036$ & $-0,147$ & $-0,087$ & $-0,041$ \\
\hline \multicolumn{14}{|l|}{ DERS } \\
\hline Consciência & $-0,038$ & $-0,009$ & 0,163 & 0,132 & $-0,163$ & $-0,146$ & $-0,036$ & $-0,099$ & $-0,162$ & $-0,149$ & $-0,211$ & $-0,252 *$ & $-0,220 *$ \\
\hline Clareza & 0,022 & 0,076 & 0,031 & 0,089 & $-0,115$ & $-0,024$ & $-0,086$ & 0,005 & $-0,029$ & $-0,034$ & $-0,098$ & $-0,113$ & $-0,045$ \\
\hline Objetivos & $-0,02$ & 0,201 & 0,034 & 0,013 & 0,054 & $-0,115$ & $-0,294 * *$ & 0,073 & $-0,029$ & 0,048 & $-0,03$ & $-0,062$ & 0,022 \\
\hline Impulsos & $-0,123$ & $0,407 * * *$ & 0,084 & $-0,039$ & 0,131 & $-0,174$ & $-0,156$ & 0,007 & 0,03 & 0,101 & $-0,103$ & $-0,029$ & 0,03 \\
\hline Estratégia & 0,025 & $0,248^{*}$ & 0,006 & 0,094 & 0,043 & $-0,189$ & $-0,228 *$ & $-0,031$ & $-0,07$ & 0,086 & $-0,09$ & $-0,107$ & $-0,031$ \\
\hline Não Aceitação & 0,002 & 0,164 & 0,067 & $-0,019$ & $-0,041$ & $-0,056$ & $-0,086$ & $-0,04$ & 0,002 & 0,101 & $-0,083$ & $-0,061$ & $-0,009$ \\
\hline DERS total & $-0,028$ & $0,272 * *$ & 0,085 & 0,028 & 0,006 & $-0,149$ & $-0,216 *$ & 0,015 & $-0,032$ & 0,044 & $-0,13$ & $-0,113$ & $-0,027$ \\
\hline \multicolumn{14}{|l|}{ FAST } \\
\hline Seguir Afetos Positivos & $-0,103$ & 0,104 & 0,052 & 0,052 & $-0,198$ & 0,091 & $-0,032$ & 0,013 & $-0,053$ & $-0,132$ & $-0,041$ & $-0,081$ & $-0,056$ \\
\hline Ignorar Afetos Positivos & $\mathbf{0 , 3 1 1} * *$ & $-0,102$ & 0,032 & $-0,05$ & 0,075 & $-0,011$ & 0,176 & $-0,043$ & 0,082 & 0,101 & $-0,07$ & 0,05 & $-0,019$ \\
\hline Seguir Afetos Negativos & 0,001 & $0,230 *$ & $-0,131$ & $-0,032$ & 0,076 & 0,029 & $-0,154$ & 0,11 & 0,152 & $0,229 *$ & 0,045 & 0,122 & 0,171 \\
\hline Ignorar Afetos Negativos & 0,072 & $-0,027$ & $0,302 * *$ & 0,077 & $-0,189$ & $-0,153$ & 0,015 & $-0,12$ & $-0,143$ & $-0,230 *$ & $-0,305 * *$ & $-0,258 *$ & $-0,279 * *$ \\
\hline
\end{tabular}

Nota: $* \mathrm{p}<.05, * * \mathrm{p}<.01, * * * \mathrm{p}<.001$ 
Ao focalizar a análise das escolhas realizadas aos baralhos do IGT, notou-se que pouco se relacionaram com o autorrelato de afetos, segundo os instrumentos usados neste estudo. A tendência a selecionar cartas do baralho A relacionou-se de modo estatisticamente significativo com ignorar afetos negativos ( $P p b=0,30 ; p<0,01)$, enquanto o baralho B apresentou associação estatisticamente significativa com afetos negativos $(P p b=0,22 ; p<0,01)$. Por sua vez, a seleção de cartas do baralho $\mathrm{C}$ apresentou relação inversa com afetos negativos $(P p b=-0,26 ; p<0,01)$. Esses resultados apontaram que a seleção de diferentes baralhos pode ser guiada pela experiência afetiva do indivíduo. Cabe recordar que os baralhos A e B do IGT apresentam punições mais severas. Assim, a tendência a ignorar afetos negativos pode explicar maior quantidade de seleção nesses baralhos iniciais. Por outro lado, a correlação entre afetos negativos e seleção do baralho B e C podem estar relacionadas ao esquema de punição e como ela é vivenciada.

Em relação às relações com os blocos do IGT, observou-se correlação positiva estatisticamente significativa entre afetos positivos $(P p b=0,28 ; p<0,01)$, dificuldades de regulação emocional (DERS) em objetivos $(P p b=-0,29 ; p<0,01)$, estratégias $(P p b=-0,22$; $p<0,01)$ e DERS total $(P p b=-0,21 ; p<0,01)$ e o bloco 1 . Também se observou relações negativas estatisticamente significativas com reavaliação cognitiva $(P p b=-0,22 ; p<0,01)$, além de correlação positiva com seguir afetos negativos ( $P p b=0,22 ; p<0,01)$ e o bloco 4 . Por fím, ignorar afetos negativos apresentou associações negativas estatisticamente significativas na fase final do IGT, em especial com o bloco $4(P p b=-0,23 ; p<0,01)$, bloco $5(P p b=-0,30 ; p<0,01) \mathrm{e}$ com os escores de Tendência geral $(P p b=-0,25 ; p<0,01)$ e Tendência geral Bl 2-5 $(P p b=-0,27$; $p<0,01)$.

Estes resultados sugerem que as experiências afetivas negativas estão relacionadas à diminuição do desempenho no início do IGT. Desta forma, é possível depreender que as vivências de afetos negativos constituem importantes fontes de informação para o processo de tomada de decisão. Já o autorrelato de afetos positivos mostrou-se relacionado ao aumento no escore no início da tarefa proposta pelo IGT, reforçando os indicadores de associação entre experiências emocionais e processos de decisão.

A seguir foram trabalhados os resultados das análises de correlação entre variáveis afetivas derivadas de instrumentos de autorrelato e variáveis identificadas como relacionadas a processos de tomada de decisão no R-PAS. Estes dados compõem a Tabela 21. 
Tabela 21. Correlação entre indicadores das escalas afetivas e relativos à tomada de decisão no $R-P A S(n=92)$.

\begin{tabular}{|c|c|c|c|c|c|c|c|}
\hline \multirow{2}{*}{$\begin{array}{c}\text { Variáveis } \\
\text { Instrumentos autorrelato }\end{array}$} & \multicolumn{7}{|c|}{ Variáveis R-PAS } \\
\hline & $\mathrm{Dd} \%$ & SI & $\mathrm{Vg} \%$ & V & FD & $\mathrm{M} / \mathrm{MC}$ & IntCont \\
\hline \multicolumn{8}{|l|}{ ERQ } \\
\hline Reavaliação Cognitiva & $-0,260 *$ & 0,115 & 0,054 & $-0,110$ & $0,243 *$ & 0,034 & 0,002 \\
\hline Supressão emocional & $-0,094$ & 0,175 & 0,055 & 0,010 & 0,058 & 0,075 & 0,064 \\
\hline \multicolumn{8}{|l|}{ PANAS } \\
\hline Afetos Positivos & 0,078 & 0,030 & $-0,109$ & $-0,210$ & 0,146 & 0,120 & $-0,011$ \\
\hline Afetos Negativos & 0,112 & 0,109 & 0,121 & 0,100 & $-0,072$ & $-0,112$ & $-0,019$ \\
\hline \multicolumn{8}{|l|}{ EA } \\
\hline Afetos Positivos & 0,170 & 0,164 & 0,067 & $-0,120$ & $-0,188$ & $-0,149$ & $-0,082$ \\
\hline Afetos Negativos & $-0,195$ & 0,021 & $-0,052$ & $-0,070$ & 0,166 & 0,101 & 0,024 \\
\hline \multicolumn{8}{|l|}{ DERS } \\
\hline Consciência & $0,242 *$ & 0,020 & $-0,322 * * *$ & $-0,040$ & $-0,309 * * *$ & $0,242 * *$ & 0,062 \\
\hline Clareza & 0,110 & 0,150 & 0,005 & 0,080 & $-0,148$ & 0,062 & 0,119 \\
\hline Objetivos & 0,044 & 0,031 & 0,020 & 0,000 & $-0,241^{*}$ & $-0,012$ & 0,033 \\
\hline Impulsos & 0,111 & $-0,011$ & 0,029 & $-0,100$ & $-0,182$ & $-0,057$ & 0,072 \\
\hline Estratégia & 0,131 & 0,030 & 0,029 & $-0,140$ & $-0,135$ & $-0,029$ & 0,012 \\
\hline Não Aceitação & 0,066 & $-0,166$ & $-0,169$ & $-0,170$ & 0,060 & $0,241 *$ & 0,084 \\
\hline DERS total & 0,196 & 0,014 & $-0,099$ & $-0,100$ & $-0,217$ & 0,104 & 0,101 \\
\hline \multicolumn{8}{|l|}{ FAST } \\
\hline Seguir Afetos Positivos & 0,048 & $-0,04$ & $-0,065$ & $-0,130$ & 0,123 & 0,044 & 0,020 \\
\hline Ignorar Afetos Positivos & 0,132 & $-0,047$ & $-0,176$ & $-0,010$ & $-0,083$ & $0,258 *$ & $-0,012$ \\
\hline Seguir Afetos Negativos & 0,215 & 0,070 & 0,073 & $-0,150$ & 0,011 & $-0,167$ & 0,136 \\
\hline Ignorar Afetos Negativos & 0,089 & $-0,141$ & 0,069 & $-0,140$ & $-0,176$ & 0,088 & 0,019 \\
\hline
\end{tabular}

Nota: $*=\mathrm{p}<.05, * *=\mathrm{p}<.01, * * *=\mathrm{p}<.001$

Os resultados indicaram que reavaliação cognitiva apresentou correlação negativa com $\mathrm{Dd} \%(\mathrm{Ppb}=-0,26 ; p<0,01)$ e positiva com $\mathrm{FD}(\mathrm{Ppb}=0,24 ; p<0,01)$. Estes resultados sugerem que o uso de estratégia de reavaliação está relacionado à diminuição de um estilo de processamento apegado a detalhes idiossincráticos $(\mathrm{Dd} \%)$ e aumento de FD que se relaciona a um distanciamento de situações negativas.

Também emergiram correlações entre diversas dificuldades de regulação emocional e indicadores de tomada de decisão no Rorschach. Houve correlações positivas estatisticamente significativas entre dificuldades de consciência e Dd\% $(P p b=0,24 ; p<0,01)$ e $\mathrm{M} / \mathrm{MC}(P p b=$ 0,24; $p<0,01)$, bem como correlações negativas com Vg\% $(P p b=-0,32 ; p<0,01)$ e FD $(P p b=-$ 
$0,30 ; p<0,01)$. Estes resultados sugeriram associação entre dificuldades de tomar consciência acerca das próprias emoções e aumento de um estilo detalhista de análise e aumento na proporção de movimento humano, cuja elevação indica maior processamento interno sobre os afetos. Também se observou relação entre dificuldades em traçar objetivos e FD ( $P p b=-0,24$; $p<0,01$ ), indicando associação entre aumento dos processos de distanciamento observados no Rorschach e diminuição nas dificuldades de objetivos. Por fim, a não aceitação das emoções $(P p b=0,24 ; p<0,01)$ e ignorar afetos positivos $(P p b=0,25 ; p<0,01)$ relacionou-se com M/MC no Rorschach. Esta associação sugere que a negação das emoções e o esforço para ignorar experiências afetivas por meio do autorrelato se associaram com distanciamento emocional expresso no R-PAS.

$\mathrm{Na}$ sequência das análises, foram examinadas as associações entre variáveis do R-PAS e indicadores dos instrumentos relativos a estilos e tomada de decisão (respectivamente DSS e IGT). Estes dados compõem a Tabela 22.

Pode-se notar que o estilo racional se relacionou de forma estatisticamente significativa com as variáveis CBlend ( $P p b=0,42 ; p<0,01)$ e V Comp ( $P p b=0,32 ; p<0,05)$. Este achado indica que o estilo racional pareceu associado diretamente a aumento nas experiências afetivas negativas e a aumento no esforço cognitivo para constrição dos afetos.

Em relação aos resultados do IGT, observou-se correlação estatisticamente significativa e negativa entre a seleção de cartas do baralho B e a variável R8910\% do R-PAS (Ppb = -0,40; $p<0,05)$. Pode-se inferir que a escolha arriscada pareceu diretamente associada à diminuição da responsividade afetiva. Já em relação ao desempenho nos blocos, que refletem um processo de aprendizagem ao longo da tarefa, observou-se correlação positiva entre o bloco 3 e R8910\% $(P p b=0,51 ; p<0,001)$ e CF $(P p b=0,33 ; p<0,05)$ e relação entre o bloco 4 e CF $(P p b=0,46$; $p<0,01)$ e PPD $(P p b=0,33 ; p<0,05)$. Estes dados fazem pensar que as decisões exigidas no IGT, conforme vão ocorrendo (meio do teste) mobilizam vivências emocionais (R8910\%), com diminuição do controle cognitivo sobre a experiência afetiva (CF), sentida como negativa (PPD). Também se observou relação entre o final da tarefa do IGT, bloco 5 e PPD ( $P p b=0,44 ; p<0,05)$, bem como com CBlend $(P p b=-0,33 ; p<0,05)$. Isto permite inferir que, ao final, o desempenho no IGT está associado a atenção a informações negativas (PPD), ao mesmo tempo em que se observa diminuição de sensibilidade com a experiência emocional. 
Tabela 22. Correlação entre estilos de decisão (DSS), desempenho no IGT e variáveis afetivas do R-PAS (n=92).

\begin{tabular}{|c|c|c|c|c|c|c|c|c|c|c|c|c|c|}
\hline \multirow{2}{*}{$\begin{array}{l}\text { Variáveis de } \\
\text { tomada de decisão }\end{array}$} & \multicolumn{13}{|c|}{ Variáveis afetivas R-PAS } \\
\hline & $\mathrm{R} 8910 \%$ & M & $\mathrm{FC}$ & $\mathrm{CF}$ & $\mathrm{C}$ & CBlend & WSumC & $\begin{array}{c}(\mathrm{CF}+\mathrm{C}) / \\
\text { SumC }\end{array}$ & $\mathrm{M} / \mathrm{MC}$ & PPD & MC - PPD & V-Comp & $(\mathrm{CF}+\mathrm{C})-\mathrm{FC}$ \\
\hline \multicolumn{14}{|l|}{ DSS } \\
\hline Racional & $-0,225$ & 0,07 & $-0,089$ & $-0,001$ & 0,223 & $0,423 * *$ & 0,206 & 0,135 & 0,159 & $-0,174$ & 0,198 & $\mathbf{0 , 3 2 1 *}$ & 0,164 \\
\hline Intuitivo & 0,004 & $-0,116$ & $-0,062$ & 0,053 & $-0,205$ & $-0,129$ & $-0,118$ & $-0,029$ & $-0,196$ & 0,013 & $-0,204$ & $-0,076$ & $-0,019$ \\
\hline \multicolumn{14}{|l|}{ IGT } \\
\hline Baralho A & $-0,090$ & $-0,123$ & $-0,036$ & $-0,015$ & 0,012 & 0,192 & 0,073 & 0,053 & $-0,063$ & $-0,223$ & 0,079 & $-0,196$ & 0,037 \\
\hline Baralho B & $-0,406 *$ & 0,208 & $-0,021$ & $-0,248$ & 0,152 & 0,073 & 0,066 & 0,024 & 0,200 & $-0,154$ & 0,214 & 0,169 & 0,024 \\
\hline Baralho C & 0,302 & $-0,068$ & $-0,053$ & 0,245 & $-0,116$ & $-0,289$ & $-0,072$ & 0,047 & $-0,045$ & 0,176 & $-0,128$ & $-0,060$ & 0,047 \\
\hline Baralho D & 0,178 & $-0,067$ & 0,100 & 0,081 & $-0,056$ & 0,014 & $-0,053$ & $-0,100$ & $-0,098$ & 0,134 & $-0,136$ & 0,030 & $-0,082$ \\
\hline Bloco 1 & 0,022 & $-0,231$ & $-0,110$ & $-0,099$ & 0,173 & $-0,139$ & 0,078 & 0,106 & $-0,066$ & $-0,285$ & 0,206 & $-0,176$ & 0,137 \\
\hline Bloco 2 & 0,040 & $-0,016$ & 0,066 & 0,177 & $-0,193$ & 0,095 & $-0,159$ & $-0,078$ & $-0,132$ & $-0,021$ & $-0,141$ & 0,009 & $-0,107$ \\
\hline Bloco 3 & $0,519 * * *$ & $-0,036$ & 0,069 & $\mathbf{0 , 3 3 7 *}$ & $-0,280$ & $-0,082$ & $-0,166$ & $-0,097$ & $-0,119$ & 0,214 & $-0,236$ & $-0,026$ & $-0,118$ \\
\hline Bloco 4 & 0,174 & $-0,122$ & 0,065 & $0,462 * *$ & $-0,221$ & $-0,154$ & $-0,091$ & $-0,026$ & $-0,158$ & $\mathbf{0 , 3 3 7 *}$ & $-0,280$ & 0,053 & 0,000 \\
\hline Bloco 5 & 0,173 & 0,130 & 0,167 & 0,084 & 0,049 & $-0,332 *$ & 0,148 & $-0,053$ & 0,155 & $0,440 * *$ & $-0,170$ & 0,121 & 0,006 \\
\hline TG & $\mathbf{0 , 3 5 3 *}$ & $-0,073$ & 0,087 & 0,258 & $-0,137$ & $-0,152$ & $-0,062$ & $-0,067$ & $-0,089$ & 0,273 & $-0,215$ & 0,003 & $-0,043$ \\
\hline TG B12- B15 & $\mathbf{0 , 3 7 1 *}$ & 0,010 & 0,078 & $\mathbf{0 , 3 2 2} *$ & $-0,189$ & $-0,167$ & $-0,075$ & $-0,051$ & $-0,065$ & $0,359 *$ & $-0,270$ & 0,075 & $-0,051$ \\
\hline
\end{tabular}

Nota: $* \mathrm{p}<0,05 ; * * \mathrm{p}<0,01 ; * * * \mathrm{p}<0,001$ 
Por fim, a Tendência geral apresentou correlações estatisticamente significativas com $\mathrm{R} 8910 \%(P p b=0,35 ; p<0,05)$, enquanto a Tendência geral B1 2-5 com R8910\% ( $P p b=0,32$; $p<0,05), \mathrm{CF}(P p b=0,32 ; p<0,05)$ e PPD $(P p b=0,35 ; p<0,05)$. Dessa forma, os resultados apontam que o desempenho no processo de tomada de decisão se mostrou diretamente relacionado a aumento da reatividade emocional (R8910\%) e diminuição do controle cognitivo sobre os afetos (CF), possibilitando utilização de informações afetivas, especialmente as negativas (PPD).

Na sequência das análises focalizamos as correlações observadas entre as variáveis afetivas e relacionadas à tomada de decisão, a partir do R-PAS. A Tabela 23 apresenta estes resultados.

Tabela 23. Correlações entre variáveis afetivas e de tomada de decisão no $R-P A S(n=92)$.

\begin{tabular}{lccccccc}
\hline \multirow{2}{*}{ Variável afetivas } & \multicolumn{7}{c}{ Variáveis de tomada de decisão RPAS } \\
\cline { 2 - 8 } & Dd\% & SI & Vg\% J & V & FD f & M/MC & IntCont \\
\hline R8910\% & $\mathbf{0 , 2 9 7 *}$ & $-0,276$ & $-0,111$ & $\mathbf{0 , 2 9 7 *}$ & $-0,034$ & 0,096 & $-0,164$ \\
M & 0,222 & 0,018 & $-0,281$ & 0,087 & 0,104 & $\mathbf{0 , 6 7 0 * * *}$ & 0,018 \\
FC & $-0,015$ & $-0,056$ & $-0,193$ & $-0,091$ & 0,098 & 0,080 & $-0,261$ \\
CF & $-0,007$ & 0,117 & $-0,105$ & $-0,116$ & 0,126 & $-0,128$ & 0,130 \\
C & $-0,169$ & 0,144 & $\mathbf{0 , 4 9 8 * * *}$ & 0,246 & 0,039 & $\mathbf{- 0 , 4 1 1} * *$ & 0,203 \\
CBlend & $-0,079$ & 0,201 & 0,009 & 0,175 & $-0,014$ & $-0,061$ & 0,127 \\
WSumC & $-0,123$ & 0,134 & $\mathbf{0 , 4 5 5 * *}$ & 0,215 & 0,033 & $\mathbf{- 0 , 4 7 9 * * *}$ & 0,223 \\
(CF+C)/SumC & $-0,064$ & 0,119 & $\mathbf{0 , 3 1 3 *}$ & 0,155 & $-0,022$ & $-0,202$ & $\mathbf{0 , 3 0 1 *}$ \\
MC & 0,023 & 0,135 & 0,098 & 0,154 & 0,09 & 0,125 & 0,160 \\
PPD & 0,015 & $-0,014$ & $-0,021$ & 0,213 & 0,079 & 0,01 & $-0,06$ \\
MC - PPD & $-0,07$ & 0,025 & 0,097 & 0,003 & 0,106 & 0,123 & 0,188 \\
V - Comp & $-0,037$ & $\mathbf{0 , 3 1 3 *}$ & $-0,119$ & 0,213 & 0,074 & 0,287 & 0,281 \\
CFC - FC & $-0,103$ & 0,167 & $\mathbf{0 , 3 6 8 *}$ & 0,162 & 0,016 & $\mathbf{- 0 , 3 2 2 *}$ & 0,292 \\
\hline
\end{tabular}

Nota: $* \mathrm{p}<.05, * * \mathrm{p}<.01, * * * \mathrm{p}<.001 ; \mathrm{f}=$ Variáveis que apresentaram indicadores de precisão abaixo do desejado.

Foi possível identificar correlações positivas estatisticamente significativas entre R8910\% e Dd\% $(P p b=0,29 ; p<0,05)$ e V $(P p b=0,29 ; p<0,05)$, indicando associação entre a sensibilidade afetiva e estilo cognitivo mais detalhista, mas com necessário distanciamento. A variável $\mathrm{C}$ apresentou correlação positiva com $\mathrm{Vg} \%(P p b=0,49 ; p<0,001)$ e correlação negativa com M/MC $(P p b=-0,41 ; p<0,01)$, o que pode sugerir que a experiência afetiva pura se associa a 
experiência emocional mais impressionista e vaga, com menor deliberação meticulosa durante a tomada de decisão.

A variável WSumC correlacionou-se de modo significativo em termos estatísticos com $\mathrm{Vg} \%(P p b=0,45 ; p<0,05)$ e MPrp $(P p b=-0,47 ; p<0,001)$, enquanto $(\mathrm{CF}+\mathrm{C}) / \mathrm{SumC}$ apresentou correlação estatisticamente significativa com Vg\% $(P p b=0,31 ; \mathrm{p}<0,05)$ e IntCont $(P p b=0,30$; $p<0,05$ ). A variável V-Comp apresentou relação estatisticamente significativa com SI (Ppb $=0,31 ; p<0,05)$, enquanto o indicador CFC $-\mathrm{FC}$ relacionou-se de modo significativo em termos estatísticos com Vg\% (Ppb $=0,36 ; p<0,05)$ e M/MC $(P p b=-0,32 ; p<0,05)$.

O conjunto destes resultados das correlações apontou que processos afetivos de regulação e desregulação emocional interferem em processos decisionais e são influenciados pelo funcionamento da personalidade. Cabe destacar que as magnitudes das correlações identificadas foram em sua maioria consideradas fracas a moderadas. Meyer et al. (2001) observam que estes são valores comuns em pesquisas psicológicas e médicas, podendo ser interpretados como suporte para as principais hipóteses deste estudo.

Baseados nos padrões de correlação encontrados até o momento foi possível identificar variáveis afetivas e R-PAS associadas aos escores em Tendência geral e Tendência geral B1 2-5 no IGT, ou seja, indicadores relativos a formas de decisão dos indivíduos. Com base nestes achados, considerou-se relevante examinar os dados por meio de análise de regressão linear, tomando as variáveis anteriormente destacadas nas análises correlacionais como preditoras. Os resultados compõem a Tabela 24.

Tabela 24. Resultados da análise de regressão linear usando o escore de Tendência geral no IGT como critério $(n=92)$.

\begin{tabular}{rcccccccc}
\hline Preditor & $b$ & $b$ IC 95\% & $\beta$ & $\beta$ IC 95\% & $s r^{2}$ & $s r^{2} I C$ 95\% & $r$ & Fit \\
\hline (Intercepto) & 11,24 & {$[-56,84 / 79,31]$} & & & & & & \\
Consciência & $-0,90$ & {$[-1,90 / 0,11]$} & $-0,19$ & {$[-0,41 / 0,02]$} & 0,04 & {$[-0,04 / 0,11]$} & $-0,20$ & \\
Ignorar Afetos Negativos & $\mathbf{- 0 , 7 6}$ & {$[-1,55 / 0,04]$} & $-0,21$ & {$[-0,43 / 0,01]$} & 0,04 & {$[-0,04 / 0,12]$} & $\mathbf{- 0 , 2 4 *}$ & \\
R8910\% & 0,15 & {$[-0,24 / 0,54]$} & 0,09 & {$[-0,14 / 0,31]$} & 0,01 & {$[-0,03 / 0,04]$} & 0,12 & \\
CF & $-0,02$ & {$[-0,53 / 0,50]$} & $-0,01$ & {$[-0,23 / 0,22]$} & 0,00 & {$[-0,00 / 0,00]$} & 0,04 & \\
PPD & 0,06 & {$[-0,31 / 0,44]$} & 0,04 & {$[-0,18 / 0,26]$} & 0,00 & {$[-0,01 / 0,02]$} & 0,03 & \\
& & & & & & & & $R^{2}=0,101$ \\
& & & & & & & & $95 \%$ CI $[0,00 / 0,19]$
\end{tabular}

Nota. Um peso b significativo indica que o peso beta e a correlação semiparcial também são significativas. $b$ representa pesos de regressão não padronizados. $\beta$ indica os pesos de regressão padronizados. $\mathrm{sr}^{2}$ representa a correlação semiparcial ao quadrado. $r$ representa a correlação de ordem zero. Os colchetes são usados para incluir os limites inferior e superior de um intervalo de confiança. * indica $p<0,05$. ** indica $p<0,01$. 
Os resultados desta análise de regressão linear indicaram que o melhor preditor para o desempenho na Tendência geral do IGT foi ignorar afetos negativos $[b=-0,76 ; S E=0,40 ; t(79)$ $=-1,90 ; p=0,05]$. A direção dessa relação indica que, para um bom desempenho no processo de tomada de decisão, a capacidade de utilizar informações afetivas é importante. $\mathrm{O}$ achado sugere que ignorar informações afetivas negativas tem importante impacto nas decisões em situação de risco, influenciando boa parte das escolhas realizadas pelos indivíduos.

O mesmo procedimento foi realizado tomando o escore de tendência geral que considera apenas os blocos 2 a 5 para avaliação do desempenho do IGT. Os resultados estão na Tabela 25.

Tabela 25. Resultados da análise de regressão linear usando o escore de Tendência geral Bl 2-5 do IGT como critério $(n=92)$.

\begin{tabular}{rcccccccc}
\hline Preditor & $b$ & $b$ IC 95\% & $\beta$ & $\beta I C$ 95\% & $s r^{2}$ & $s r^{2} I C$ 95\% & $r$ & Fit \\
\hline Intercept) & 2,10 & {$[-60,80 / 65,01]$} & & & & & & \\
Consciência & $-0,78$ & {$[-1,71 / 0,14]$} & $-0,18$ & {$[-0,40 /-0,03]$} & 0,03 & {$[-0,04 / 0,10]$} & $-0,20$ & \\
Ignorar Afetos Negativos & $\mathbf{- 0 , 7 5 *}$ & {$[-1,49 /-0,02]$} & $\mathbf{- 0 , 2 2}$ & {$[-0,44 /-0,00]$} & 0,05 & {$[-0,04 / 0,13]$} & $\mathbf{- 0 , 2 5 *}$ & \\
R8910\% & 0,15 & {$[-0,21 / 0,51]$} & 0,09 & {$[-0,13 / 0,31]$} & 0,01 & {$[-0,03 / 0,04]$} & 0,13 & \\
CF & 0,04 & {$[-0,43 / 0,52]$} & 0,02 & {$[-0,20 / 0,24]$} & 0,00 & {$[-0,01 / 0,01]$} & 0,07 & \\
PPD & 0,10 & {$[-0,25 / 0,44]$} & 0,06 & {$[-0,16 / 0,28]$} & 0,00 & {$[-0,02 / 0,03]$} & 0,06 & \\
& & & & & & & & $R^{2}=0,110$ \\
& & & & & & & & $95 \%$ CI $[0,00 / 0,20]$ \\
\hline
\end{tabular}

Nota: Um peso b significativo indica que o peso beta e a correlação semiparcial também são significativas. $b$ representa pesos de regressão não padronizados. $\beta$ indica os pesos de regressão padronizados. $s^{2}$ representa a $^{2}$ correlação semiparcial ao quadrado. $r$ representa a correlação de ordem zero. Os colchetes são usados para incluir os limites inferior e superior de um intervalo de confiança. * indica $p<0,05$. ** indica $p<0,01$

Diante destes achados, ao levar em consideração a Tendência geral Bl 2-5 do IGT, nota-se que ignorar afetos negativos foi o melhor preditor para o desempenho em tomada de decisão $[b=$ $-0,75 ; S E=0,37 ; t(79)=-2,03 ; p=0,046]$. Pode-se inferir que informações provenientes das experiências afetivas negativas tem um papel importante sobre a tomada de decisão nas situações de incerteza. Pelos dados identificados, ignorar os afetos pode ter um impacto negativo no processo de tomada de decisão.

\subsubsection{Relação entre indicadores de tomada de decisão e perfis de regulação emocional}

De modo a responder aos objetivos delineados para este trabalho, foi realizada análise de variância (ANOVA) com medidas repetidas sobre os resultados no DSS, no IGT (relativos à tomada de decisão) e no R-PAS em função do perfil de regulação emocional identificado no Estudo I (Perfil Adaptado; Desregulado e Regulador Inconsciente). Os resultados da análise de 
variância (ANOVA) entre as variáveis tomadas em análise e os diferentes perfis de regulação emocional podem ser visualizados na Tabela 26.

Tabela 26. Escores médios das variáveis DSS, IGT e R-PAS e análise de variância (ANOVA) em função dos perfis de regulação emocional ( $n=92)$.

\begin{tabular}{|c|c|c|c|c|c|c|c|c|c|c|}
\hline \multirow[t]{2}{*}{$\begin{array}{c}\text { Instrumento e } \\
\text { Variável }\end{array}$} & \multicolumn{2}{|c|}{$\begin{array}{c}\text { Adaptado } \\
(\mathrm{n}=11)\end{array}$} & \multicolumn{2}{|c|}{$\begin{array}{l}\text { Desregulado } \\
\qquad(\mathrm{n}=30)\end{array}$} & \multicolumn{2}{|c|}{$\begin{array}{c}\text { Regulador } \\
\text { Inconsciente } \\
\quad(\mathrm{n}=49)\end{array}$} & \multirow[t]{2}{*}{$F$} & \multirow[t]{2}{*}{$g l$} & \multirow[t]{2}{*}{$p$} & \multirow[t]{2}{*}{ Efeitc } \\
\hline & Média & DP & Média & DP & Média & DP & & & & \\
\hline \multicolumn{11}{|l|}{ DSS } \\
\hline Racional & 19,27 & 4,56 & 20,65 & 3,72 & 21,69 & 1,85 & 0,92 & $(2,14)$ & 0,41 & 0,35 \\
\hline Intuitivo & 16,27 & 4,54 & 14,69 & 4,01 & 13,81 & 3,51 & 6,42 & $(2,20)$ & 0,006 & 0,42 \\
\hline \multicolumn{11}{|l|}{ IGT } \\
\hline TG & 4,90 & 23,33 & 3,00 & 15,82 & 9,41 & 20,53 & 2,00 & $(2,17)$ & 0,16 & 0,30 \\
\hline TG B12 - B15 & 8,72 & 22,91 & 6,46 & 17,08 & 8,79 & 17,98 & 0,63 & $(2,21)$ & 0,53 & 0,22 \\
\hline \multicolumn{11}{|l|}{ R-PAS } \\
\hline R8910\% & 100,36 & 11,64 & 96,23 & 10,67 & 99,51 & 10,97 & 0,60 & $(2,15)$ & 0,55 & 0,21 \\
\hline M & 101,36 & 17,15 & 101,30 & 13,70 & 103,34 & 14,62 & 0,25 & $(2,16)$ & 0,77 & 0,17 \\
\hline FC & 90,81 & 8,46 & 88,00 & 10,27 & 92,02 & 10,82 & 2,24 & $(2,16)$ & 0,13 & 0,32 \\
\hline $\mathrm{CF}$ & 91,45 & 10,93 & 92,10 & 10,93 & 87,59 & 7,39 & 0,95 & $(2,15)$ & 0,40 & 0,25 \\
\hline $\mathrm{C}$ & 111,09 & 14,58 & 113,46 & 15,77 & 110,44 & 15,24 & 0,35 & $(2,16)$ & 0,70 & 0,19 \\
\hline CBlend & 96,27 & 9,39 & 94,00 & 7,02 & 93,49 & 6,30 & & & & \\
\hline WSumC & 97,36 & 10,75 & 98,76 & 16,23 & 94,20 & 15,83 & 1,42 & $(2,17)$ & 0,26 & 0,26 \\
\hline$(\mathrm{CF}+\mathrm{C}) / \mathrm{SumC}$ & 109,71 & 14,46 & 112,37 & 13,85 & 103,13 & 15,25 & 2,45 & $(2,10)$ & 0,13 & 0,34 \\
\hline MC & 99,81 & 13,65 & 100,26 & 15,30 & 99,59 & 14,41 & 0,14 & $(2,16)$ & 0,86 & 0,17 \\
\hline PPD & 92,90 & 9,38 & 90,10 & 11,94 & 90,38 & 11,84 & 0,89 & $(2,26)$ & 0,42 & 0,23 \\
\hline MC - PPD & 107,54 & 11,96 & 110,36 & 12,64 & 109,28 & 13,04 & 0,09 & $(2,15)$ & 0,91 & 0,19 \\
\hline V-Comp & 101,45 & 12,69 & 98,93 & 16,21 & 98,85 & 11,11 & 0,94 & $(2,17)$ & 0,40 & 0,25 \\
\hline$(\mathrm{CF}+\mathrm{C})-\mathrm{FC}$ & 105,18 & 11,67 & 109,03 & 11,37 & 102,30 & 12,26 & 3,55 & $(2,16)$ & 0,05 & $\mathbf{0 , 3 5}$ \\
\hline $\operatorname{Dd} \%$ & 94,72 & 12,37 & 95,5 & 12,78 & 92,61 & 11,76 & 0,40 & $(2,17)$ & 0,67 & 0,21 \\
\hline SI & 85,09 & 10,44 & 91,10 & 13,21 & 90,83 & 11,63 & 0,99 & $(2,17)$ & 0,39 & 0,33 \\
\hline $\mathrm{Vg} \%$ & 104,27 & 16,71 & 106,33 & 12,70 & 105,46 & 10,79 & 0,18 & $(2,14)$ & 0,83 & 0,17 \\
\hline V & 96,63 & 10,99 & 95,73 & 7,78 & 95,38 & 7,99 & & & & \\
\hline FD & 109,83 & 11,54 & 119,85 & 15,94 & 101,27 & 17,39 & 2,93 & $(2,19)$ & 0,07 & 0,37 \\
\hline $\mathrm{M} / \mathrm{MC}$ & 101,27 & 17,39 & 101,73 & 12,91 & 107,37 & 16,82 & 1,48 & $(2,16)$ & 0,25 & 0,23 \\
\hline IntCont & 87,09 & 7,27 & 89,56 & 10,07 & 88,65 & 10,60 & 0,17 & $(2,15)$ & 0,83 & 0,19 \\
\hline
\end{tabular}


Primeiramente foram verificadas diferenças estatisticamente significativas entre as escolhas dos baralhos e desempenho nos blocos do IGT e os perfis de regulação emocional. No entanto, os resultados não indicaram diferenças estatisticamente significativas para a seleção dos baralhos $[F(2,10)=0,88 ; p=0,44]$ e para o desempenho nos blocos do IGT $[F(2,11)=1,51 ; p$ $=0,26]$ em função dos perfis de regulação emocional.

Houve diferenças significativas do ponto de vista estatístico entre os diferentes perfis de regulação emocional e o estilo intuitivo de decisão do $\operatorname{DSS}[F(20,2)=6,421 ; p=0,006 ; \xi=0,43]$ e a variável CFC - FC no R-PAS $[F(16,2)=3,556 ; \mathrm{p}=0,05 ; \xi=0,35]$. As comparações post hoc indicaram que para o estilo intuitivo de tomada de decisão as diferenças se deram entre os perfis adaptado e regulador inconsciente [diferença média de 3,47; $p=0,009$; IC $(95 \%)=0,87-$ $6,08]$. Estes resultados podem sugerir que em termos de processos de tomada de decisão, o perfil regulador inconsciente se diferencia do adaptado por uma diminuição na preferência por informações impressionistas. Isso pode sugerir que para indivíduos com perfil regulador inconsciente o acesso a informações afetivas (que caracterizam o estilo intuitivo) estaria de alguma maneira difícil de acessar por meios conscientes, para utilizar estratégias de regulação emocional de maneira proativa.

Para a variável do R-PAS CFC - FC a comparação post hoc indicou que as diferenças se deram entre os perfis desregulado e regulador inconsciente [diferença média de 7,58; $p=0,029$; IC $(95 \%)=0,62-14,54]$. Estes resultados podem indicar que o perfil desregulado apresenta elevado indicador de impulsividade quando comparado ao regulador inconsciente. Este achado permite inferir que a coordenação interna das emoções exerce efeito importante na sensibilidade e nas expressões afetivas, ainda que o indivíduo não tenha plena consciência deste processo regulatório. 
DISCUSSÃO 


\section{DISCUSSÃO}

\subsection{Estudo I}

O estudo I teve como objetivo identificar padrões de regulação emocional em sua interrelação dinâmica e relacionar estes perfis a indicadores de vivências dos afetos. Nesse sentido, optou-se por utilizar uma análise de dados centrada nos indivíduos. Os dados provenientes de uma subamostra de adultos jovens $(n=375)$ permitiram identificar a presença de três padrões distintos de regulação emocional: adaptado, regulador inconsciente, desregulado. Estes resultados estão em consonância com achados anteriores (De France \& Hollenstein, 2017), quando foram referidos pelo menos três perfis de regulação emocional a partir de abordagem analítica de perfis latentes semelhante a deste trabalho.

Um primeiro perfil identificado apresentou padrão de regulação emocional caracterizado pelo uso da reavaliação cognitiva e níveis baixos de desregulação emocional. Por apresentar o uso de estratégia considerada adaptativa e competências que levam a menor dificuldade para coordenar suas experiências emocionais, este perfil foi nomeado como adaptado.

Um segundo grupo de indivíduos aqui identificado recorreu prioritariamente à reavaliação cognitiva, porém com reduzida consciência de suas emoções, sem outras dificuldades de autocontrole emocional. Dificuldade em tomar consciência das próprias emoções pode ser um empecilho para estratégias eficientes de autorregulação afetiva. Entretanto, segundo Gross e John (2003), estratégias de regulação emocional podem ser processadas de forma implícita, ou seja, embora a pessoa possa não se dar conta, ela recorre a processos internos que efetivamente diminuem a intensidade e a persistência da experiência emocional. Com base nisso, nomeou-se este padrão de respostas como o perfil regulador inconsciente.

Por fim, foi possível reconhecer um terceiro perfil de indivíduos, onde notou-se reduzida reavaliação cognitiva e utilização prioritária de supressão emocional. Além disso, suas competências emocionais apresentaram-se instáveis, com altos níveis de desregulação emocional. Este grupo passou a ser denominado como correspondente a um perfil desregulado.

Para Chesney et al. (2019) e France, Hollenstein, De France e Hollenstein (2017), esperase que pelo menos três perfis de regulação emocional sejam identificados consistentemente entre adultos, embora outras pesquisas reportem números de perfis diferentes, geralmente entre quatro e cinco (Chesney et al., 2019; Chesney \& Gordon, 2017; De France \& Hollenstein, 2017; DixonGordon et al., 2015; Eftekhari et al., 2009). Estas diferenças podem estar relacionadas principalmente aos instrumentos utilizados para acessar as características de regulação 
emocional, bem como quanto ao método analítico utilizado e as próprias variações nas características amostrais.

A partir da identificação destes três perfis de regulação afetiva procurou-se checar se estes perfis seriam replicados em outro grupo com características sociodemográficas similares. Dessa forma, buscou-se realizar os mesmos procedimentos numa segunda subamostra $(n=390)$ de jovens adultos. A análise de perfis latentes neste novo grupo recuperou o mesmo número de perfis de regulação emocional observados na amostra anterior. Novamente, encontrou-se um padrão de elevada reavaliação cognitiva com baixos níveis de desregulação emocional, sugestivo de competência para regular as emoções (perfil adaptado). O segundo perfil também apresentou um padrão de uso da reavaliação cognitiva, mas com alto nível de dificuldades de consciência acerca das emoções, embora conseguindo coordená-las bem, com reduzidos níveis de desregulação emocional (regulador inconsciente). O terceiro perfil se caracterizou por reduzido uso de reavaliação cognitiva e maior recorrência de supressão emocional, associados com elevados indicadores de desregulação emocional (perfil desregulado).

A comparação entre os padrões de resposta do subamostra I e da subamostra II de jovens adultos permitiu visualizar estilos de regulação emocional consistentes, de características similares. Desta forma, possibilitariam pensar em perfis habituais de organização psíquica em jovens adultos ao lidar com componentes emocionais, como proposto pelos instrumentos utilizados neste estudo.

Estes resultados também se mostraram estáveis ao longo do tempo (grupo reteste, $\mathrm{n}=268$ ). Os dados apontaram que $80 \%$ dos participantes foram classificados no mesmo padrão de regulação emocional, quando comparadas as duas avaliações realizadas (com intervalo médio de 45 dias entre elas). Este achado merece ser destacado neste momento, visto que no Brasil há reduzida informação científica a respeito da estabilidade de padrões de regulação emocional entre jovens adultos. Além disso, os dados de estabilidade do construto regulação emocional acompanham achados internacionais da área, sobretudo ao serem contrapostos à experiência afetiva que sofre ampla variação ao longo do tempo (Gross \& John, 2003; John \& Eng, 2014).

As evidências empíricas apontam que diferentes estratégias de regulação emocional têm variados impactos no bem-estar subjetivo (Gross, 2002) e nos afetos reportados pelos indivíduos (Batistoni et al., 2013; Masumoto et al., 2016). Desta forma, procurou-se ainda examinar o papel de cada variável de regulação emocional sobre os diferentes padrões de resposta encontrados nos três perfis, como uma estratégia de checar indicadores de validade interna dos diferentes instrumentos avaliativos, utilizando para tanto uma última subamostra $(n=400)$. Os resultados da análise de regressão linear indicaram que a reavaliação cognitiva foi a estratégia de regulação 
emocional com maior influência sobre os perfis identificados. Usualmente a reavaliação cognitiva apresenta-se como mais eficaz para alterar o percurso do processo emocional, evitando que emoções desagradáveis se estabeleçam (John \& Eng, 2014; Masumoto et al., 2016).

Ao examinar as competências individuais associadas a dificuldades para regular as emoções, foi possível destacar o papel da consciência e da clareza como variáveis de maior impacto na diferenciação dos perfis identificados nos jovens adultos. Pode-se destacar, portanto, a importância do processo de compreensão individual sobre os processos afetivos para sua adequada regulação (Gratz \& Roemer, 2004). Há, no entanto, que se ponderar que, na visão destes autores, quaisquer dificuldades nos processos indicados pelo instrumento DERS levariam a problemas de regulação emocional, o que efetivamente não se configurou em todos os participantes deste trabalho. Outros pesquisadores, por outro lado, sugerem que dificuldades sinalizadas pela DERS podem não seguir o mesmo padrão de regulação emocional sinalizado por outros instrumentos (Bardeen et al., 2012; Miguel et al., 2016). Dessa forma é possível que o estilo individual de coordenar emoções esteja relacionado a outros componentes da regulação emocional que não as dificuldades examinadas pela DERS. Esta diversidade metodológica e instrumental da área de estudos sobre regulação emocional tende a acrescentar complexidade adicional para síntese compreensiva dos dados disponíveis na literatura científica.

Em uma revisão teórica sobre o tema, Braunstein, Gross e Ochsner (2017) apontaram que mesmo estratégias implícitas, ou seja, fora da consciência do sujeito, demonstram-se efetivas para regular as emoções. Assim, é possível que o componente da consciência sobre a emoção não esteja relacionado necessariamente a dificuldades de controlar afetos, mas sim a identificar suas manifestações de maneira intencional. Os atuais achados parecem alinhar-se a esta linha interpretativa, sugerindo que mesmo pessoas com dificuldades de reconhecer as próprias emoções (reduzida consciência e clareza) podem apresentar perfis satisfatórios de regulação emocional.

Ao retomar os resultados dos estilos de coordenação emocional identificados entre os jovens adultos avaliados notou-se importante presença de dificuldades em controlar impulsos, mesmo sendo amostra da comunidade, em princípio constituída por não pacientes. De maneira geral, dificuldades neste componente estão associadas a falhas na autorregulação emocional (Heatherton \& Wagner, 2011), bem como a transtornos psiquiátricos (Ibraheim et al., 2017; Nicole H. Weiss et al., 2012). Os participantes também apontaram que dificuldade em acessar estratégias psíquicas, juntamente com não aceitação das emoções, mostraram-se importantes componentes na definição dos perfis de regulação emocional, porém com menor peso que as demais variáveis. 
Por fim, buscou-se relacionar os diferentes perfis de regulação emocional em termos de vivências de afetos positivos e negativos, bem como na propensão de se deixar guiar por estes afetos. Os resultados indicaram que indivíduos com perfil adaptado de regulação emocional reportaram médias mais elevadas de afetos positivos e menos afetos negativos. O perfil regulador inconsciente reportou menos afetos negativos que o perfil desregulado, mas não apresentou diferenças estatisticamente significativas quanto aos níveis de afetos positivos, o que pode sugerir menor bem-estar subjetivo em relação ao perfil adaptado. Estes achados empíricos sugerem que a intencionalidade consciente de regular as emoções pode ter um impacto positivo no bem-estar subjetivo, acompanhando outros estudos da literatura científica (Batistoni et al., 2013; John \& Gross, 2004).

Ainda na direção de características psicológicas gerais dos padrões de regulação emocional identificados entre os jovens adultos avaliados, notou-se que o perfil adaptado apresentou maior propensão a seguir emoções positivas que os perfis regulador inconsciente e desregulado. Além disso, o perfil desregulado demonstrou maior tendência a ignorar afetos positivos e seguir afetos negativos. Estes resultados podem sugerir que perfis desregulados tendem a utilizar pistas afetivas negativas para orientar o comportamento, enquanto o perfil regulador inconsciente tende a ignorar informações provenientes de afetos positivos.

De acordo com Clore, Gasper e Garvin (2001) e Gasper e Bramesfeld (2006) a tendência a utilizar informações emocionais tem importância crucial para a adaptação dos indivíduos. Estudos experimentais indicaram que pessoas com desregulação emocional tendem a focalizar pistas emocionais negativas (Schultebraucks et al., 2016), o que pode contribuir para um padrão de comportamento considerado também como desregulado (MacIntyre et al., 2018). Além disso, a literatura científica é bastante consistente em apontar que a tendência a seguir afetos negativos está correlacionada de forma significativa e inversa com estabilidade emocional (Gasper \& Bramesfeld, 2006). Frente ao exposto até o momento, os achados reportados neste Estudo I deste trabalho vem confirmar a importância adaptativa dos padrões de regulação emocional no que concerne a suas relações com afetos e na utilização destes como orientação para os comportamentos em jovens adultos.

\subsection{Estudo II}

O estudo II teve por objetivo maior relacionar os padrões de regulação emocional e as variáveis de tomada de decisão e de personalidade. Inicialmente foram apresentados resultados concernentes ao mesmo domínio ou traço psicológico, buscando compreender as relações a partir 
dos diferentes métodos utilizados. Em seguida, foram apresentados os resultados entre diferentes domínios para os diferentes métodos utilizados.

\subsubsection{Relação entre variáveis de mesmo domínio - Afetivas}

Inicialmente buscou-se compreender as relações entre diferentes fontes de informação para as variáveis da mesma natureza, ou seja, relacionar variáveis afetivas com afetivas, e variáveis de tomada de decisão com tomada de decisão. Neste tópico serão abordadas as associações entre indicadores das vivências emocionais advindos dos instrumentos de autorrelato e do método de Rorschach R-PAS.

Diversas variáveis do Rorschach são tradicionalmente associadas a experiências afetivas, dentre elas a somatória de respostas de cor (WsumC), de modo que se supôs relevante associação deste indicador do R-PAS com afetos expressos em nível de autorrelato. Contrariando as hipóteses inicialmente formuladas para este trabalho, não foram observadas relações estatisticamente significativas entre afetos positivos / negativos e indicadores representativos do afeto no R-PAS. Entretanto, em pesquisa com pacientes com alexitimia, Porcelli e Meyer (2002) encontraram escores baixos em WsumC nestes indivíduos quando comparados a grupo controle. Além disso, Mihura et al. (2013) apontaram evidências de validade de variáveis afetivas do RPAS (entre elas a soma de respostas cor) e afetos negativos. Desta forma, há que se refletir sobre possíveis razões para os atuais achados de jovens adultos não confirmarem as expectativas inicialmente formuladas de significativa associação entre respostas cor no Rorschach e vivências afetivas expressas por autorrelato.

Ainda discordante de hipótese prevista neste trabalho, não foram encontradas associações estatisticamente significativas entre variáveis do R-PAS com estratégias habituais de regulação emocional, avaliadas pela ERQ. Uma vez que indicadores como FC e V-comp do R-PAS representam características de controle sobre as experiências emocionais (Mihura \& Meyer, 2018), os atuais resultados não confirmaram este sentido interpretativo destas variáveis. Cabe destacar que resultado semelhante foi percebido por Matsuda (2019), referindo ausência de correlações estatisticamente significativas entre variáveis do R-PAS e ERQ, evidenciando níveis de informação diferenciados entre estes instrumentos avaliativos.

Esta questão já tem sido amplamente discutida na literatura científica, visto que as atividades propostas pelos instrumentais de autorrelato e projetivos possuem natureza diversa e, portanto, acessam níveis específicos de autoconhecimento do indivíduo, envolvendo diferentes processos psicológicos. Enquanto métodos de autorrelato dependem claramente do funcionamento cognitivo, interpretar manchas de tinta (como no Rorschach), além de 
processamento associativo, exige níveis de funcionamento psicológico não obrigatoriamente conscientes, porém decisivos para a elaboração das respostas, podendo representar níveis mais profundos de organização psíquica. Ao se buscar a associação entre variáveis de natureza diversa, dificilmente se encontram relações estatisticamente significativas, o que, no entanto, não pode ser interpretado como ausência de validade para seus significados teóricos específicos (Bornstein, 2012, 2015a; Pessotto \& Primi, 2018).

Para Malone et al. (2013), as variáveis afetivas do Rorschach apresentam poucas evidências empíricas de relevante associação com indicadores advindos de instrumentos de autorrelato. Dado que o Rorschach e as escalas se utilizam de processos de respostas diferentes, pode ser precipitado concluir pela ausência de validade dos indicadores advindos deste método projetivo (Bornstein, 2012). Em complemento a esta linha interpretativa, os atuais resultados indicaram relações consistentes entre variáveis representativas de modulação afetiva do Rorschach e índices extraídos das escalas de regulação emocional. Nesse sentido, cabe destacar a variável FC do R-PAS, que representa controle cognitivo sobre as emoções, a qual apresentou correlações estatisticamente significativas e negativas com dificuldades de regulação emocional derivadas dos componentes Consciência, Clareza, Objetivos e Impulsos da DERS. Por sua vez, a variável $(\mathrm{CF}+\mathrm{C}) / \mathrm{SumC}$ do R-PAS, associada a relaxamento no controle cognitivo, demonstrou correlação estatisticamente significativa e positiva com dificuldades de Clareza e Objetivos na DERS. Na mesma direção, a variável $(\mathrm{CF}+\mathrm{C})$ - FC, indicativa de impulsividade, também apresentou correlação positiva com falta de Clareza na regulação emocional (DERS).

De maneira geral, os sinais de desregulação emocional evidenciados na DERS são interpretados como limites nas competências para lidar com emoções intensas (John \& Eng, 2014) ou podem ser oriundos de falhas no autocontrole (Heatherton \& Wagner, 2011). Estudos com pacientes borderline indicaram que este grupo clínico evidenciou maior incidência de dificuldades em controlar emoções e pior desempenho em tarefas de controle inibitório (Cackowski et al., 2014; Ibraheim et al., 2017). Por outro lado, a utilização de tarefas com demanda cognitiva com indivíduos borderline favoreceu a redução de expressões de humor negativo (Kim \& Kanfer, 2009).

Os achados empíricos do atual estudo também evidenciaram correlações estatisticamente significativas e positivas entre a tendência de seguir e ignorar emoções (conforme informações derivadas da FAST) e algumas variáveis do R-PAS, fortalecendo possibilidades interpretativas de seus indicadores. Algumas variáveis do Rorschach associadas a diminuição do controle cognitivo sobre a experiência emocional, mostraram-se significativamente correlacionadas com o seguir afetos positivos (SAP). Este fator da FAST apresentou correlação positiva com PPD e 
correlação negativa com C, $(\mathrm{CF}+\mathrm{C}) / \mathrm{SumC}, \mathrm{MC}-\mathrm{PPD}$ e $(\mathrm{CF}+\mathrm{C})$ - FC. Embora pareça contraditório que seguir afetos positivos esteja associado à disfunção na coordenação racional no Rorschach, é importante destacar que nem sempre a experiência com emoções positivas é benéfica para o indivíduo, podendo sobrecarregar seu funcionamento psíquico (Gruber et al., 2011). Ao estudar características do funcionamento socioafetivo de 2.635 adultos dos Estados Unidos e França, Gruber, Kogan, Quoidbach e Mauss (2013) identificaram que variações intensas na experiência emocional positiva não facilitavam processos de adaptação ao contexto dos indivíduos. Com base nestas considerações teóricas e empíricas, pode-se depreender que as correlações estatisticamente significativas observadas entre indicadores da FAST e do R-PAS embasem o sentido interpretativo de que redução no controle cognitivo tende a facilitar a emergência de emoções positivas, nem sempre adaptativas.

Embora este caminho analítico se mostre possível, outros resultados atuais pareceram inconsistentes com essa perspectiva. Houve correlação estatisticamente significativa e negativa entre seguir afetos negativos (SAN) e a variável MC-PPD do Rorschach, bem como entre ignorar afetos negativos (IAN) e V-Comp do R-PAS. É importante destacar que MC-PPD representa um composto que balanceia a diferença entre a presença de recursos cognitivos (MC) e a de estressores fora de controle (PPD) (Mihura \& Meyer, 2018). Já V-Comp pode ser considerado indicativo de constrição afetiva (Mihura \& Meyer, 2018). Frente a estas considerações teóricas e empíricas, poder-se-ia dizer que tendência a ignorar afetos negativos emergiu na medida em que o indivíduo sinaliza restrição em contatos com emoções, sugerindo um papel de monitoramento interno sobre a experiência emocional intensa.

O conjunto destes resultados parece apontar uma distinção importante entre o uso auto relatado de estratégias de regulação emocional, especialmente as avaliadas pela ERQ e ausência competências emocionais, ou dificuldades de regular emoções, como avaliadas pela DERS. Aliado ao fato de que os resultados apontaram para relações com seguir e ignorar experiências emocionais negativas, estes resultados indicam que as variáveis do Rorschach, podem refletir processos de dificuldades de controle afetivo, especialmente em relação às experiências negativas.

\subsubsection{Relação entre variáveis de mesmo domínio - Tomada de decisão}

Outro aspecto relevante para este estudo foi a caracterização de estilos de decisão (auto relato) do desempenho no IGT. Estilo de tomada de decisão pode ser definido como a maneira típica em que o indivíduo concretiza decisões (Hamilton et al., 2016, 2017). No atual trabalho não foram observadas muitas relações estatisticamente significativas entre estilos de tomada de 
decisão (derivados da DSS) e o padrão de respostas aos baralhos no IGT. De maneira geral, este resultado seria teoricamente esperado, dado que o desempenho no IGT é influenciado mais pelos esquemas de punição e recompensa do que pelas preferências e estilos pessoais dos indivíduos. No entanto, há que se destacar um achado intrigante: houve correlação positiva entre estilo racional e escolhas do Baralho $\mathrm{B}$, e correlação positiva entre estilo intuitivo e desempenho no Bloco 2 e na Tendência Geral B1 2-5.

A princípio estes resultados pareceram contraditórios com outros achados disponíveis na literatura científica. Thunholm (2004) afirmou, em seu trabalho, que estilos de decisão seriam independentes de habilidades cognitivas. Dessa forma, não seria esperada associação entre estilos de tomada de decisão e desempenho no IGT. Uma possível explicação para a relação observada entre o estilo racional e escolhas do Baralho B pode estar relacionada ao fato de que o estilo racional tentar utilizar diversas informações, ao mesmo tempo para tomar uma decisão. Dado que o IGT constitui-se como tarefa de elevada dificuldade (Suhr \& Hammers, 2010), a quantidade de informações que uma pessoa com estilo racional deve armazenar para realizar a escolha pode comprometer seu desempenho, especialmente em fases intermediárias da tarefa. Em um estudo com o IGT e uma tarefa de atenção, Hawthorne e Pierce (2015) identificaram que a sobrecarga dos processos atencionais aumentam as chances dos indivíduos selecionarem mais cartas do baralho B, que está associado a maiores ganhos imediatos, mas com punições maiores, o que foi interpretado pelos autores como um efeito da diminuição de recursos cognitivos.

Dessa forma, uma possível explicação para os atuais resultados no IGT seria a de que o estilo racional seria menos eficiente no início da tarefa, com poucas informações, do que ao final dela. Além disso, o fato de que as recompensas proporcionadas pelo Baralho B, são maiores, e a frequência de punições, relativamente rara, fazem deste Baralho um forte candidato à seleção constante, como observado por outros pesquisadores (C.-H. Lin et al., 2007; C. Lin et al., 2015). Já a relação entre estilo intuitivo e o desempenho no Bloco 2 e na Tendência Geral Bl 2-5 podem estar relacionados ao fato de que nesse período da tarefa do IGT, os indivíduos ainda tem poucas informações para realizar suas escolhas, dessa forma, processos de intuição podem levar a melhores escolhas no longo prazo (Bechara et al., 1994; Dunn et al., 2006; Steingroever et al., 2014)

Ao caminhar para as associações entre variáveis do R-PAS e indicadores do comportamento decisório do IGT, há que destacar pouquíssimas correlações estatisticamente significativas. Esta fraca relação entre IGT e R-PAS contraria as hipóteses inicialmente levantadas, visto que os instrumentos demandam processos de decisão e de elaboração cognitiva em suas respostas. De maneira geral, estudos científicos relacionando tarefas neuropsicológicas e 
o Rorschach indicaram associações moderadas entre diferentes indicadores técnicos (Clyne, 2000).

Nos atuais resultados, houve apenas duas correlações estatisticamente significativas: correlação positiva entre SI do Rorschach e estilo racional, além de correlação negativa entre Dd\% e estilo racional da DSS. SI é uma variável de associação do espaço branco com áreas da mancha do Rorschach, o que representa esforço de integração de informações em um todo coeso (Meyer et al., 2017; Mihura \& Meyer, 2018). Dessa forma, SI pode refletir um processo deliberado de análise lógica que se relaciona de forma direta ao estilo racional de tomar decisões, como aqui encontrado. Já a variável Dd\% do Rorschach se relaciona à busca de informações minuciosas e atenção a detalhes incomuns dos estímulos, associando-se a elementos raros e pouco relevantes do ambiente (Meyer et al., 2017; Mihura \& Meyer, 2018), o que pode comprometer o processo de decisão, piorando o desempenho no IGT, como aqui encontrado.

Dessa forma, foi possível observar que variáveis de tomada de decisão, relacionadas por diferentes métodos de investigação estão relacionadas entre si, porém estas relações são bastante complexas, uma vez que revelam diferentes aspectos do fenômeno de tomada de decisão. As variáveis de estilo de decisão, a partir do auto relato, podem estar relacionadas ao desempenho na tarefa neuropsicológica, mas também se refletir em indicadores observados no Rorschach, corroborando a ideia de que tanto aspectos conscientes quanto automáticos estão envolvidos nesses processos.

\subsubsection{Relação entre variáveis de diferentes domínios}

Outro importante objetivo deste trabalho foi investigar as relações entre as variáveis de regulação emocional, tomada de decisão e funcionamento da personalidade, através dos diferentes métodos utilizados. Observaram-se relações importantes entre estilos de decisão e variáveis representativas de vivências afetivas, por meio de autorrelato e pelo método projetivo. Desta forma, foi possível apresentar indicadores consistentes de ligações entre características do funcionamento emocional com os comportamentos decisórios, o que pode trazer implicações relevantes para a prática clínica.

De maneira geral, o estilo racional de decisão (derivado da DSS) apresentou correlações estatisticamente significativas e positivas com a estratégia de suprimir emoções (ERQ) e ignorar afetos positivos (FAST), sem associação importante com reavaliação cognitiva. Estes achados estão de acordo com o esperado para a atividade racional que busca minimizar a influência de variáveis afetivas no processo de análise das informações (Hamilton et al., 2016). 
Por sua vez, o estilo intuitivo de decisão (DSS) apresentou correlação estatisticamente significativa e negativa com reavaliação cognitiva (ERQ) e associações positivas com dificuldades em objetivos, impulsos e estratégias (DERS) e tendência a seguir afetos negativos (FAST). De maneira geral, o estilo intuitivo de tomar decisões é considerado um processo baseado em impressões e sentimentos (Hamilton et al., 2016). Dessa forma, esse conjunto de resultados com adultos jovens acompanharam as expectativas teóricas inicialmente formuladas sobre estas variáveis. O uso da reavaliação cognitiva demanda processamento lógico intenso, de maneira que sua utilização pode conflitar com os mecanismos utilizados por um estilo intuitivo de tomar decisões (Phillips, Fletcher, Marks \& Hine, 2016). Em complemento e de acordo com a teoria do afeto como informação (Schwarz, 2010), experiências emocionais negativas podem ser intensas a ponto de servir como base para tomada de decisão. Dessa forma, os resultados encontrados neste atual trabalho constituem em evidências empíricas relevantes a respeito da ligação entre processos afetivos de regulação e desregulação emocional e comportamentos decisórios em jovens adultos.

Ao focalizar as experiências afetivas dos participantes e suas associações com as respostas diante do IGT, foi possível identificar relações estatisticamente significativas entre algumas variáveis. Constatou-se correlação positiva entre ignorar afetos negativos (IAN) e desempenho no baralho A, bem como correlação entre afetos negativos (PANAS) e seleção do baralho B e correlação negativa com baralho D. Há que lembrar que conceitualmente o IGT é tarefa avaliativa da tomada de decisões afetivas (Cauffman et al., 2010), ou seja, os indivíduos são orientados por sua experiência emocional para realizar a tarefa (Shukla et al., 2019).

A correlação positiva entre a tendência a ignorar afetos negativos e a seleção do baralho A, assim como a relação entre afetos negativos e a seleção do baralho B, está de acordo com a teoria do afeto como informação (Schwarz, 2010). Cabe lembrar que o baralho A apresenta maior quantidade de punições e em grande magnitude, enquanto o baralho B contém menor quantidade de punições, mas também de elevada magnitude, de modo que se relacionam à presença de afetos negativos. Estudos que medem condutividade da pele demonstraram maior reatividade afetiva precedendo a seleção de baralhos desvantajosos (Jenkinson et al., 2008; Mardaga \& Hansenne, 2012; Wagar \& Dixon, 2006). Dessa forma, quando o indivíduo apresenta uma tendência a ignorar afetos negativos, é esperado que a seleção de cartas dos baralhos A seja maior, na medida em que a seleção de cartas dos baralhos punitivos estaria associada a afetos negativos e inversamente associada aos baralhos vantajosos.

Pode-se comprovar esta diretriz ao retomar as evidências encontradas por Buelow e Suhr (2013) na investigação de características de personalidade e estados afetivos no IGT, onde 
observaram tendência de correlação entre seleção de cartas no baralho B e afetos negativos. Entretanto, essa relação com os baralhos vantajosos foi observada apenas para o baralho D.

Segundo o manual do IGT (Bechara, 2007), alguns resultados empíricos (Buelow \& Suhr, 2013; J. A. Suhr \& Tsanadis, 2007) e a partir de revisões da literatura científica (Buelow \& Suhr, 2009), a seleção de cartas do IGT pode estar associada a variáveis de personalidade. Em um estudo com 32 participantes saudáveis, Mardaga e Hansenne (2012) identificaram que traços específicos de personalidade estão associados a diferenças na responsividade afetiva a punições e recompensas no IGT. Dessa forma, uma possível explicação para a ausência de correlações entre a seleção do baralho $\mathrm{C}$, mas a presença de correlação entre afetos negativos e a seleção do baralho D, pode se dar por essas particularidades.

Nos atuais achados também foi possível identificar relações estatisticamente significativas entre variáveis afetivas e o desempenho por Blocos do IGT. Especialmente o Bloco 1 apresentou correlação positiva com afetos positivos, e correlação negativa com dificuldades de manter objetivos, estratégias e o escore total na DERS. Dessa forma, pode-se entender que o desempenho no início da tarefa do IGT está associado a afetos positivos, enquanto escores baixos estão associados a maiores dificuldades para regular emoções. Segundo De Vries, Holland e Witteman (2008) é esperado que no ínicio da atividades, os indivíduos sejam mais fortemente guiados por afetos, dada a insuficiência de informações para a tomada de decisão. Entretanto, estes autores sugerem que o humor positivo teria maior influência sobre o padrão de desempenho no IGT, o que contrasta com os resultados aqui apresentados.

Os atuais resultados também demonstraram associações estatisticamente significativas entre variáveis afetivas e os últimos Blocos do IGT. O Bloco 4 apresentou correlação positiva com a tendência a seguir afetos negativos e correlação negativa com o uso de reavaliação cognitiva e a tendência a ignorar afetos negativos. Esta última variável também apresentou correlação com o Bloco 5. Pode-se contrapor estes achados com um estudo realizado por Shukla et al. (2019) com 44 estudantes, onde identificaram forte influência do humor negativo sobre o baixo desempenho no Bloco 1 do IGT, enquanto a indução de afetos positivos se mostrou associada a escores mais elevados. Segundo os pesquisadores, o uso de regulação emocional apresentou relação deletéria para o processo de tomada de decisão.

Em complemento, pode-se comentar que Heilman et al. (2010) encontraram correlação positiva entre reavaliação cognitiva e o desempenho no IGT. Porém, em estudo posterior com 48 estudantes, estes mesmos autores identificaram padrões diferentes de influência da reavaliação cognitiva sobre os Blocos do IGT (Heilman \& Miclea, 2015), deixando em suspenso qual 
caminho efetivo existe entre estas variáveis, dada sua variação entre diferentes grupos de indivíduos avaliados.

Em consonância com nossos achados, Werner et al. (2009) observaram associações estatisticamente significativas e negativas entre desempenho no IGT e a utilização de reavaliação cognitiva. Estes resultados podem indicar que a utilização de estratégias eficientes de regulação emocional diminuem a intensidade da experiência emocional (De Martino et al., 2010; SokolHessner et al., 2013), diminuindo sua influência sobre o processo de tomada de decisão (Heilman et al., 2010; Kusev et al., 2017).

Dado que ignorar afetos negativos apresentou associação estatisticamente significativa e direta com a seleção do baralho A, e este por sua vez está associado a menor escore nos Blocos e tendência geral do IGT, não é de admirar que a tendência a ignorar afetos negativos tenha relação com desempenho inferior no último Bloco e na Tendência Geral. É possível que estes resultados estejam relacionados ao papel que a informação do humor negativo tem sobre o processo de tomada de decisão.

Em conjunto, estes resultados são sugestivos da influência da experiência emocional sobre os processos relacionados à decisão avaliados pelo IGT. De maneira geral, a desregulação emocional pareceu favorecer mais dificuldades no início da atividade. Entretanto, a informação proveniente do feedback é um importante componente para o desempenho no longo prazo. Esta interpretação se ajusta aos atuais dados de correlação negativa entre o desempenho no IGT e dificuldades na consciência das próprias emoções. Se o indivíduo não tem acesso restrito a sua experiência emocional, pareceu difícil orientar-se pelos afetos para a tomada de decisão (Alvandi et al., 2019; Osieko et al., 2017).

Ao focalizar as associações entre informações explícitas, oriundas do autorrelato, e implícitas, aferidas pelo R-PAS, observou-se correlações estatisticamente significativas e negativas entre $\mathrm{Dd} \%, \mathrm{Vg} \%$ e reavaliação cognitiva, e correlações estatisticamente significativas e positivas com dificuldades de consciência. Já FD (R-PAS) apresentou padrão oposto, com associação estatisticamente significativa e positiva com reavaliação cognitiva e associação negativa com dificuldades de consciência e objetivos. Dessa forma, é possível inferir que Dd\% e $\mathrm{Vg} \%$ são indicadores de menor controle cognitivo durante busca por informações. Estes resultados reforçam os achados anteriormente relatados de reduzida relação destas variáveis com estilo racional, com menor consciência acerca dos processos afetivos. Por outro lado, a variável FD representa um olhar sob diferentes perspectivas para a realidade (Meyer et al., 2017), favorecendo processos reflexivos. Ao buscar dialogar com a literatura científica da área, pode-se destacar o estudo realizado por Brevers et al. (2013) que examinaram jogadores patológicos e um 
grupo controle. Eles observaram que dificuldades de auto-consciência se relacionaram a disfuncionalidades em momentos de decisão em situações de risco.

Outro resultado importante observado em nossos achados foi a que a variável FD do RPAS esteve negativamente associada a dificuldades em manter objetivos (DERS). De maneira geral, Gratz e Roemer (2004) definem este tipo de dificuldades de regulação emocional da DERS como a falha em se engajar em metas e objetivos claros e diretos por sobrecarga de emoções negativas. Dessa forma, faz sentido pensar em FD como uma atitude controlada de observação dos estímulos de forma a ponderar sobre as informações com cautela e adequada perspectiva.

Outro dado relevante a destacar neste momento foram as associações estatisticamente significativas encontradas entre a variável M/MC do R-PAS e níveis elevados de dificuldades de conciência, não aceitação e ignorar afetos positivos. Usualmente M/MC é entendida como representação da reatividade emocional (Meyer et al., 2017). Nossos resultados apontaram que este indicador se mostrou associado a menor consideração de informações afetivas durante as escolhas, ignorando afetos positivos, o que pode enviesar os processos decisórios.

Outras variáveis do R-PAS que mostraram associações estatisticamente significativas com o estilo decisional foram CBlend e V-Comp, ambas com correlações positivas com estilo racional. V-Comp é entendida como representativa de esforço cognitivo para diminuir a experiência emocional (Meyer et al., 2017). Os resultados acerca das relações com experiência afetiva, reportados anteriormente, indicaram que V-Comp relacionou-se com a tendência a ignorar afetos negativos. Dado que o estilo racional, como discutido anteriormente, refere-se a busca organizada e deliberativa por informações (Hamilton et al., 2016), é possível pensar em VComp do R-PAS como um indicador de racionalidade diante de informações afetivas negativas, ou seja, como monitoramento de respostas emocionais negativas.

Por outro lado, a variável CBlend também se relacionou positivamente com o estilo racional de decisões, o que parece contradizer seu sentido interpretativo básico (de vulnerabilidade à experiência emocional, Mihura \& Meyer, 2018). A variável CBlend do R-PAS classicamente representa a mistura de cor (experiências emocionais), sombreado (atração por detalhes e sinal de ansiedade) e cor acromática (afetividade negativa), parecendo refletir experiências afetivas negativas. Dessa forma, é possível pensar que CBlend esteja associada a ponderação sobre processos afetivos negativos, associando-se assim com o estilo racional. Porém isso implicaria em rever o sentido interpretativo de sensibilidade e reações emocionais espontâneas da variável CBlend no R-PAS (Mihura \& Meyer, 2018), o que foge às possibilidades dos dados aqui apresentados. 
Ao focalizar a relação entre variáveis do R-PAS e desempenho no IGT, observaram-se correlações estatisticamente significativas e negativas entre R8910\% e baralho B, bem como correlações positivas com Bloco 3 e os escores em tendência geral (TG e TG bl 2-bl 5). A variável R8910\% é considerada indicador de responsividade a estímulos e a situações emocionais (Meyer et al., 2017). Dessa forma, pode-se compreeender que baixo R8910\% se associe inversamente a seleção de um baralho do IGT com elevado grau de mobilização afetiva, como baralho B. Por outro lado, as correlações positivas com o bloco 3 e tendência geral do IGT, sugerem que a elevação de R8910\% favorece melhor desempenho na tarefa decisória. Dessa forma, confirma-se o sentido interpretativo desta variável do R-PAS ligado a sensibilidade emocional.

Outras variáveis do R-PAS que merecem aqui o devido destaque são CF (correlações estatisticamente significativas e diretas com bloco 3, bloco 4 e tendência geral bl 2 e bl5 do IGT) e PPD (associações estatisticamente significativas e positivas com blocos 4 e 5 e tendência geral b12 e bl5 do IGT). Estas variáveis destacadas do R-PAS se referem a mobilização e a sensibilidade emocional do indivíduo (Mihura \& Meyer, 2018). Em conjunto, nossos resultados indicam que a manutenção de informações afetivas, relacionadas à CF e PPD, podem ser um importante componente para a tomada de decisão e o desempenho no IGT.

Visto que diversas variáveis do R-PAS apresentaram correlação estatisticamente significativa com o desempenho no IGT, procurou-se identificar o peso dessa mútua influência nos achados com jovens adultos por meio de análise de regressão linear. Observou-se que, em conjunto, dificuldades de consciência, ignorar afetos negativos, R8910\%, CF e PPD explicaram cerca de $10 \%$ da variância observada no escore em Tendência Geral do IGT e $11 \%$ da variância dos resultados na Tendência Geral bl 2-5 do IGT. Além disso, a tendência a ignorar afetos negativos foi a variável com melhor predição sobre o desempenho no IGT. É importante lembrar aqui que o IGT é reconhecido como medida de tomada de decisões em situações de risco. Desta forma, pode-se argumentar que os atuais resultados reforçaram a hipótese inicial deste trabalho de que a tomada de decisões, em situações de risco, depende principalmente da identificação de sinais afetivos negativos.

Pode-se retomar neste momento a noção de que, no IGT, a avaliação do desempenho se baseia na relação entre a seleção de baralhos vantajosos e desvantajosos $[(C+D)-(A+B)]$. Desta forma, um padrão de escolhas menos arriscadas é considerado um bom desempenho neste instrumento, enquanto escolhas mais arriscadas resultam em pior escore. Ou seja, é bastante destacado o papel que as emoções apresentam sobre o desempenho dos indivíduos no IGT (De Vries et al., 2008; Shukla et al., 2019). Pesquisas empíricas e revisões da literatura científica 
apontam consistentemente o papel das emoções negativas na aversão ao risco (Campos-Vazquez \& Cuilty, 2014; Grecucci \& Sanfey, 2014; Lerner et al., 2015; Nguyen \& Noussair, 2014). Diante do exposto, cabe concluir que os atuais achados estão em consonância com os reportados por De Vries et al. (2008), comprovando o papel diferenciado dos afetos negativos e seu efeito em processos realizados ao longo do tempo, justamente o tipo de avaliação realizada por meio das atividades propostas pelo IGT, confirmando-se sua sensibilidade informativa com a amostra presentemente avaliada.

\subsubsection{Perfis de regulação emocional, tomada de decisão e personalidade}

Um dos objetivos deste trabalho voltou-se a explorar padrões de regulação emocional informados por instrumentos de natureza diferente, a saber, R-PAS (atividade interpretativa de construção de respostas) e IGT (atividade de escolhas a partir das cartas dos baralhos). Foi possível identificar estilos característicos dos jovens adultos avaliados em termos de regulação emocional, porém estes estilos não pareceram implicar em modos específicos de conduzir as escolhas das cartas no IGT. A hipótese inicialmente formulada argumentava que os processos de regulação e desrregulação emocional influenciariam claramente os processos de tomada de decisão realizados no IGT. Contudo, os achados empíricos atuais não confirmaram esta formulação esperada. Pode-se pensar que o reduzido número de participantes de cada grupo de regulação emocional tenha impactado os resultados, dado que o tamanho amostral interfere em análises de variância (A. Field, 2009). Procurou-se driblar este limite técnico pela realização de análises de variância de tipo robusto, contornando parcialmente esses problemas, mas se sabe que a capacidade do teste em identificar efeitos, quando reduzidos, ainda assim é limitada (A. P. Field \& Wilcox, 2017).

Apesar destas limitações técnicas, um dado promissor emergiu neste trabalho. O estilo de regulação emocional mostrou claro efeito sobre os estilos de decisão e sobre o padrão de respostas na variável $(\mathrm{CF}+\mathrm{C})$ - FC do R-PAS. O perfil desregulado para lidar com as emoções apresentou tendência a utilizar de maneira mais proeminente um estilo intuitivo de decisões, enquanto o perfil adaptado de regulação emocional apresentou menor tendência a se utilizar da intuição em processos decisórios. Foi possível identificar que o perfil intuitivo de decisão apresentou níveis mais elevados de afetos negativos e de desregulação emocional, como reportado no Estudo I. Dessa maneira, estes resultados confirmaram a noção de que o estilo intuitivo vale-se de informações afetivas negativas como fonte de informação para seu processo decisório. 
Cabe agora destacar as particularidades de respostas diante da variável $(\mathrm{CF}+\mathrm{C})-\mathrm{FC}$ do R-PAS e sua relação com os estilos de regulação emocional. Os achados atuais apontaram que o perfil emocional aqui denominado como regulador inconsciente apresentou maiores escores de $(\mathrm{CF}+\mathrm{C})$ - FC do que o perfil adaptado de regulação emocional. Sabe-se que a proporção de forma-cor no R-PAS é um indicador de impulsividade (Mihura et al., 2013). Além disso, em pesquisa voltada ao exame das evidências de validade das variáveis relacionadas à cor no Rorschach, Kron, Cohen, Benziman e Ben-Shakhar (2009) identificaram que a proporção de forma-cor é variável que se relaciona diretamente a falhas no controle de impulsos, os quais, por sua vez, mostraram-se associados a comportamentos de risco. Com base nestas evidências da literatura científica, pode-se inferir que os dados alcançados no atual trabalho indicariam que o perfil regulador inconsciente das emoções apresentou indícios de maior propensão a comportamentos marcados por impulsividade do que o perfil adaptado de regulação emocional. Desta forma, embora limitados, os atuais resultados confirmam a hipótese de que processos implícitos e explícitos de regulação emocional tendem a produzir diferentes padrões comportamentais em processos decisórios e, portanto, também em situações de risco, achado bastante relevante para a prática clínica cotidiana no cuidado às pessoas, em especial jovens adultos como aqui examinado. Esta perspectiva investigativa poderá ser desenvolvida de forma complementar em novos estudos, derivando caminhos promissores. 


\section{CONSIDERAÇÕES FINAIS}




\section{CONSIDERACÕES FINAIS}

Com base nos objetivos propostos para os estudos aqui apresentados, os resultados mostraram-se promissores em diversos aspectos e permitiram compreender algumas associações entre indicadores psicológicos relacionados a processos de tomada de decisão, regulação emocional e características de personalidade. Além disso, apontam para direções futuras de investigação que poderão ajudar a entender variáveis psicológicas envolvidas nesses processos.

Conforme proposto pelo Estudo I foi possível identificar evidências de complexas relações entre estratégias de regulação emocional, dificuldades nessa regulação, vivências de afetos positivos e negativos, bem como com a tendência dos indivíduos a seguirem ou ignorarem estas informações emocionais. Os atuais achados apontaram para a possibilidade de identificar e replicar três padrões de regulação emocional em jovens adultos: a) perfil desregulado, com altos níveis de desregulação emocional e subutilização de estratégias de reavaliação cognitiva; b) perfil adaptado, com uso adequado de estratégias emocionais e níveis baixos de dificuldades em regular as emoções; c) perfil regulador inconsciente, que se distingue do anterior pela dificuldade de tomar consciência de suas emoções, apesar de conseguir modulá-las adequadamente. Estes padrões mostraram-se estáveis ao longo do tempo e passíveis de serem identificados em diferentes grupos de jovens adultos, como demonstrado nos resultados. Além disso, foi possível distinguir vivências específicas de afetos positivos e de propensão a seguir/ignorar emoções em cada perfil de regulação emocional. Estes achados apontam para a necessidade de se considerar, de forma conjunta e articulada, as estratégias de regulação emocional em futuras investigações científicas voltadas a questão do processamento afetivo.

O Estudo II, por sua vez, permitiu identificar sinais sugestivos da interligação entre afetos, regulação emocional, estilos de decisão, tomada de decisão em situações de risco e características implícitas de personalidade. O trabalho conseguiu, a partir de múltiplos métodos informativos, examinar variáveis psicológicas por meio de autorrelato e processos implícitos de regulação emocional e tomada de decisão. A utilização de diversas estratégias técnicas na coleta de informações permitiu identificar mecanismos explícitos e implícitos que contribuem para o processamento de informações afetivas, os quais, por sua vez, relacionam-se com a tomada de decisões. Foi possível constatar que indicadores teoricamente relacionados a controle afetivo se associaram ao desempenho numa tarefa cognitiva, além de ser possível relacionar estas mesmas variáveis a diferentes estilos de tomada de decisão. Por fim, embora com alcance bastante limitado, foi possível identificar que os perfis de regulação emocional, identificados no Estudo I, mostraram relevante influência nos estilos de decisão e na coordenação da impulsividade 
examinada por método indireto (Rorschach), não consciente. Este conjunto de resultados reforça a necessidade uma abordagem multimétodos no estudo de variáveis complexas como é o campo da Psicologia e dos processos abordados neste trabalho.

É importante considerar algumas limitações presentes neste estudo. De maneira geral, há que destacar inicialmente seu caráter exploratório em diversas de suas hipóteses. Quando ao Estudo I, a subdivisão da amostra geral em grupos não é totalmente independente, dado que os participantes originam da mesma população, fazendo-se necessário replicar os métodos aqui utilizados em outros contextos e indivíduos. Uma segunda questão limitante refere-se à ausência de controle para variáveis psicopatológicas nos participantes deste trabalho. Há ampla literatura científica indicando que estratégias de regulação emocional estão relacionadas a diversos processos psicopatológicos, de modo que estudos futuros sobre o tema poderão se beneficiar de verificação deste tipo de variáveis na composição da amostra a ser examinada. Finalmente, há que se destacar que o presente trabalho foi realizado, em boa parte de sua coleta de dados, realizada por meio de plataforma digital on-line, como ocorreu no Estudo I. Embora existam evidências científicas de que esta forma de coleta de dados não altera achados relativos às características psicométricas dos instrumentos de avaliação psicológica utilizados, seria importante comparar tais achados com a aplicação presencial dos materiais, de forma a checar esta qualidade das informações obtidas por recursos digitais.

Com relação ao Estudo II, embora a literatura científica internacional colecione evidências relevantes sobre relações entre tomada de decisão, regulação emocional e características de personalidade, em nosso conhecimento nenhum estudo buscou compreender estas variáveis a partir de métodos de autorrelato (objetivos) e projetivos de avaliação psicológica, menos ainda no contexto do Brasil. Desta forma, considera-se que os atuais achados configuram contribuição empírica útil para o avanço do conhecimento da área na realidade nacional.

Há que se considerar, por fim, que as variáveis selecionadas para o presente trabalho, relacionadas aos processos de tomada de decisão, derivaram primordialmente de sua definição teórica, emitindo um caráter exploratório ao estudo nesse campo, a ser refinado em novas investigações. Além disso, para as comparações entre variáveis de tomada de decisão e do RPAS em função dos perfis de regulação emocional, o tamanho dos grupos foi um complicador importante. Dada a característica de conveniência da amostra, não foi possível balancear os grupos em termos de estilos de regulação emocional. Essas diferenças não permitiram investigar mais profundamente os processos psicológicos que contribuem para diferentes resultados na tomada de decisão, de modo a exigir novos estudos para examinar os achados exploratórios aqui indicados. 
Atreladas às limitações metodológicas, no entanto, há que destacar que os resultados alcançados configuram-se como promissores caminhos para futuros direcionamentos na investigação da complexa temática em foco. É possível que variáveis de nível implícito modifiquem a experiência de regulação emocional e se expressem de maneira diferente em termos de autorrelato. Será necessário investigar como essas diversas variáveis componentes dos indivíduos contribuem para os processos de tomada de decisão observados em nível comportamental. Este caminho investigativo poderá elucidar o poder preditivo dos modelos propostos para a interação entre tomada de decisão, regulação afetiva e características de personalidade, dada a importante implicação destas variáveis para a prática profissional em cuidados de saúde mental. 


\section{REFERÊNCIAS}

Acklin, M. . W., \& Wu-Holt, P. (1996). Contributions of cognitive science to the Rorschach Technique: cognitive and neuropsychological correlates of the response process. Journal of Personality Assessment, 67(1), 169-178. https://doi.org/10.1207/s15327752jpa6701_13

Acklin, M. W. (1994). Some Contributions of Cognitive Science to the Rorschach Test. Rorschachiana: Journal of the International Society for the Rorschach, 19(1), 129-145. https://doi.org/10.1027/1192-5604.19.1.129

AERA, APA, \& NCME. (2014). Standards for Educational and Psychological Testing. American Educational Research Association.

Aizawa, N., Ishibashi, M., Nakamura, Y., Uchiumi, C., Makita, K., \& Iwakiri, M. (2018). NearInfrared Spectroscopy Detects Prefrontal Activities During Rorschach Inkblot Method. Japanese Psychological Research, 60(4), 242-250. https://doi.org/10.1111/jpr.12195

Aldao, A., Jazaieri, H., Goldin, P. R., \& Gross, J. J. (2014). Adaptive and maladaptive emotion regulation strategies: Interactive effects during CBT for social anxiety disorder. Journal of Anxiety Disorders, 28(4), 382-389. https://doi.org/10.1016/j.janxdis.2014.03.005

Aldao, A., \& Nolen-Hoeksema, S. (2012). When are adaptive strategies most predictive of psychopathology? Journal of Abnormal Psychology, 121(1), 276-281. https://doi.org/10.1037/a0023598

Aldao, A., Nolen-Hoeksema, S., \& Schweizer, S. (2010). Emotion-regulation strategies across psychopathology: A meta-analytic review. Clinical Psychology Review, 30(2), 217-237. https://doi.org/10.1016/j.cpr.2009.11.004

Alvandi, E. O., Van Doorn, G., \& Symmons, M. (2019). Emotional Awareness and DecisionMaking in the Context of Computer-Mediated Psychotherapy. Journal of Healthcare Informatics Research, 3(3), 345-370. https://doi.org/10.1007/s41666-019-00050-7

Amaro, T. de C., Areco, K. N., \& Nascimento, R. S. G. (2017). Avaliação dos aspectos da Personalidade em pessoas idosas na cidade de São Paulo por meio do Rorschach Performance System ( R-PAS ). Revista Kairós Gerontologia, 20(2), 211-228.

Anastasi, A., \& Urbina, S. (2000). Testagem psicológica (7th ed.). Artmed.

Anderson, S. W., Barrash, J., Bechara, A., \& Tranel, D. (2006). Impairments of emotion and real-world complex behavior following childhood- or adult-onset damage to ventromedial prefrontal cortex. J Int Neuropsychol Soc, 12(2), 224-235. https://doi.org/10.1017/S1355617706060346

Andreano, J. M., Dickerson, B. C., \& Barrett, L. F. (2014). Sex differences in the persistence of the amygdala response to negative material. Social Cognitive and Affective Neuroscience, 9(9), 1388-1394. https://doi.org/10.1093/scan/nst127

Areias, G., Paixão, R., \& Figueira, A. P. C. (2013). O Iowa Gambling Task: Uma revisão crítica. Psicologia: Teoria e Pesquisa, 29(2), 201-210. https://doi.org/10.1590/S010237722013000200009 
Asari, T., Konishi, S., Jimura, K., Chikazoe, J., Nakamura, N., \& Miyashita, Y. (2010). Amygdalar modulation of frontotemporal connectivity during the inkblot test. Psychiatry $\begin{array}{llr}\text { Research } & - & \text { Neuroimaging, } \\ \text { https://doi.org/10.1016/j.pscychresns.2010.01.002 }\end{array}$

Associação Brasileira de Empresas de Pesquisa. (2016). Critério Brasil 2015. http://www.abep.org/criterio-brasil

Badoud, D., Billieux, J., Eliez, S., Imhof, A., Heller, P., Eytan, A., \& Debbane, M. (2015). Covariance and specificity in adolescent schizotypal and borderline trait expression. Early Intervention in Psychiatry, 9(5), 378-387. https://doi.org/10.1111/eip.12120

Bardeen, J. R., Fergus, T. A., \& Orcutt, H. K. (2012). An examination of the latent structure of the Difficulties in Emotion Regulation Scale. Journal of Psychopathology and Behavioral Assessment, 34(3), 382-392. https://doi.org/10.1007/s10862-012-9280-y

Batistoni, S. S. T., Ordonez, T. N., Silva, T. B. L. da, Nascimento, P. P. P. do, \& Cachioni, M. (2013). Emotional Regulation Questionnaire (ERQ): indicadores psicométricos e relações com medidas afetivas em amostra idosa. Psicologia: Reflexão e Crítica, 26(1), 10-18. https://doi.org/10.1590/S0102-79722013000100002

Baumeister, R. F., Vohs, K. D., \& Funder, D. C. (2007). Psychology as the Science of SelfReports and Finger Movements: Whatever Happened to Actual Behavior? Perspectives on Psychological Science, 2(4), 396-403. https://doi.org/10.1111/j.1745-6916.2007.00051.x

Bechara, A. (2004). The role of emotion in decision-making: Evidence from neurological patients with orbitofrontal damage. Brain and Cognition, 55(1), 30-40. https://doi.org/10.1016/j.bandc.2003.04.001

Bechara, A. (2007). Iowa Gambling Task Professional Manual. Psychological Assessment Resources.

Bechara, A. (2016). Iowa Gambling Task Professional Manual, version 2. Psychological Assessment Resources.

Bechara, A., Damasio, A. R., Damasio, H., \& Anderson, S. W. (1994). Insensitivity to future consequences following damage to human prefrontal cortex. Cognition, 50, 7-15.

Bechara, A., Damasio, H., \& Damasio, A. R. (2000). Emotion, Decision Making and the Orbitofrontal Cortex. Cerebral Cortex, 10(3), 295-307. https://doi.org/10.1093/cercor/10.3.295

Bechara, A., Damasio, H., Damasio, A. R., \& Lee, G. P. (1999). Different contributions of the human amygdala and ventromedial prefrontal cortex to decision-making. The Journal of Neuroscience: The Official Journal of the Society for Neuroscience, 19(13), 5473-5481. https://doi.org/0270-6474/99/19135473-09\$05.00/0

Bechara, A., Damasion, H., Tranel, D., \& Damasio, A. R. (1997). Deciding Advantageously Before Knowing the Advantageous Strategy. Science, 275(5304), 1293-1295. https://doi.org/10.1126/science.275.5304.1293

Boian, A. C., Soares, D. S. de M., \& Lima, J. (2009). Questionário de Regulação Emocional. https://spl.stanford.edu/sites/default/files/portuguese_brazilian.pdf 
Borges, L. M., \& Naugle, A. E. (2017). The role of emotion regulation in predicting personality dimensions. Personality and Mental Health, 11(4), 314-334. https://doi.org/10.1002/pmh.1390

Bornstein, R. F. (2012). Rorschach Score Validation as a Model for 21st-Century Personality Assessment. Journal of Personality Assessment, 94(1), 26-38. https://doi.org/10.1080/00223891.2011.627961

Bornstein, R. F. (2015a). Behavior-Based Assessment in Psychology: Going Beyond Self-Report in the Personality, Affective, Motivation, and Social Domains. In T. M. Ortner \& F. J. R. van de Vijver (Eds.), Behavior-based assessment in psychology. Hogrefe Publishing. https://doi.org/10.1027/00437-000

Bornstein, R. F. (2015b). Personality Assessment in the Diagnostic Manuals: On Mindfulness, Multiple Methods, and Test Score Discontinuities. Journal of Personality Assessment, 97(5), 446-455. https://doi.org/10.1080/00223891.2015.1027346

Bouazza, H., \& Bendella, F. (2017). Adaptation of a model of emotion regulation to modulate the negative emotions based on persistency. Multiagent and Grid Systems, 13(1), 19-30. https://doi.org/10.3233/MGS-170259

Brand, M., Recknor, E. C., Grabenhorst, F., \& Bechara, A. (2007). Decisions under ambiguity and decisions under risk: Correlations with executive functions and comparisons of two different gambling tasks with implicit and explicit rules. Journal of Clinical and Experimental Neuropsychology, 29(1), 86-99. https://doi.org/10.1080/13803390500507196

Brans, K., Koval, P., Verduyn, P., Lim, Y. L., \& Kuppens, P. (2013). The regulation of negative and positive affect in daily life. Emotion, 13(5), 926-939. https://doi.org/10.1037/a0032400

Braunstein, L. M., Gross, J. J., \& Ochsner, K. N. (2017). Explicit and implicit emotion regulation: A multi-level framework. Social Cognitive and Affective Neuroscience, 12(10), 1545-1557. https://doi.org/10.1093/scan/nsx096

Brennan, G. M., Crowley, M. J., Wu, J., Mayes, L. C., \& Baskin-Sommers, A. R. (2018). Neural processing of social exclusion in individuals with psychopathic traits: Links to anger and aggression. Psychiatry Research, 268, 263-271. https://doi.org/10.1016/j.psychres.2018.07.024

Brennan, R. L. (2000). Performance Assessments from the Perspective of Generalizability Theory. Applied Psychological Measurement, 24(4), 339-353. https://doi.org/10.1177/01466210022031796

Brennan, R. L. (2001). Generalizability theory: Statistics for social science and public policy. In New York: Springer-Verlag. (Vol. 30).

Brennan, R. L., \& Johnson, E. G. . (2005). Generalizability of Performance Assessments. Educational Measurement: Issues and Practice, 14(4), 9-12. https://doi.org/10.1111/j.17453992.1995.tb00882.x

Brevers, D., Cleeremans, A., Bechara, A., Greisen, M., Kornreich, C., Verbanck, P., \& Noël, X. (2013). Impaired Self-Awareness in Pathological Gamblers. Journal of Gambling Studies, 29(1), 119-129. https://doi.org/10.1007/s10899-012-9292-2 
Buckholtz, J. W., Callicott, J. H., Kolachana, B., Hariri, A. R., Goldberg, T. E., Genderson, M., Egan, M. F., Mattay, V. S., Weinberger, D. R., \& Meyer-Lindenberg, A. (2008). Genetic variation in MAOA modulates ventromedial prefrontal circuitry mediating individual differences in human personality. Molecular Psychiatry, 13(3), 313-324. https://doi.org/10.1038/sj.mp.4002020

Buelow, M. T. (2015). Predicting Performance on the Columbia Card Task. Assessment, 22(2), 178-187. https://doi.org/10.1177/1073191114539383

Buelow, M. T., \& Barnhart, W. R. (2018a). Test-retest reliability of common behavioral decision making tasks. Archives of Clinical Neuropsychology, 33(1), 125-129. https://doi.org/10.1093/arclin/acx038

Buelow, M. T., \& Blaine, A. L. (2015). The assessment of risky decision making: A factor analysis of performance on the Iowa Gambling Task, Balloon Analogue Risk Task, and Columbia Card Task. Psychological Assessment, 27(3), 777-785. https://doi.org/10.1037/a0038622

Buelow, M. T., \& Suhr, J. A. (2009). Construct Validity of the Iowa Gambling Task. Neuropsychology Review, 19(1), 102-114. https://doi.org/10.1007/s11065-009-9083-4

Buelow, M. T., \& Suhr, J. A. (2013). Personality characteristics and state mood influence individual deck selections on the Iowa Gambling Task. Personality and Individual Differences, 54(5), 593-597. https://doi.org/10.1016/j.paid.2012.11.019

Bull, P. N., Tippett, L. J., \& Addis, D. R. (2015). Decision making in healthy participants on the Iowa Gambling Task: New insights from an operant approach. Frontiers in Psychology, 6(APR). https://doi.org/10.3389/fpsyg.2015.00391

Cackowski, S., Reitz, A. C., Ende, G., Kleindienst, N., Bohus, M., Schmahl, C., \& Krause-Utz, A. (2014). Impact of stress on different components of impulsivity in borderline personality disorder. Psychol Med, 44(15), 3329-3340. https://doi.org/10.1017/S0033291714000427

Calvillo, D. P., \& Burgeno, J. N. (2015). Cognitive reflection predicts the acceptance of unfair ultimatum game offers. Judgment and Decision Making, 10(4), 332-341.

Campos-Vazquez, R. M., \& Cuilty, E. (2014). The role of emotions on risk aversion: A Prospect Theory experiment. Journal of Behavioral and Experimental Economics , 50(May), 1-9. https://doi.org/10.1016/j.socec.2014.01.001

Cancian, A. C. M., Souza, L. A. S. de, Silva, V. H. P. e, Machado, W. de L., \& Oliveira, M. da S. (2018). Psychometric properties of the Brazilian version of the Difficulties in Emotion Regulation Scale (DERS). Trends in Psychiatry and Psychotherapy, 00(October 2016), 1-9. https://doi.org/10.1590/2237-6089-2017-0128

Caputo, J. (1999). The Rorschach as a Neuropsychological Instrument: Historical precedents and future use. Communication Présentée Au 16th International Congress of Rorschach and Projective Methods, Amsterdam, 19-24. http://scholar.google.com/scholar?hl=en\&btnG=Search\&q=intitle:The+Rorschach+as+a+N europsychological+Instrument+:+Historical+Precedents+and+Future+Use\#0\%5Cnhttp://sc holar.google.com/scholar?hl=en\&btnG=Search\&q=intitle:The+Rorschach+as+a+Neuropsy chological+In 
Cardoso, C. D. O., Branco, L. D., Cotrena, C., Kristensen, C. H., Schneider Bakos, D. D. G., \& Fonseca, R. P. (2014). The impact of frontal and cerebellar lesions on decision making: evidence from the Iowa Gambling Task. Frontiers in Neuroscience, 8(8 APR), 1-10. https://doi.org/10.3389/fnins.2014.00061

Cardoso, C. de O., Carvalho, J. C. N., Cotrena, C., Bakos, D. di G. S., Kristensen, C. H., \& Fonseca, R. P. (2010). Estudo de fidedignidade do instrumento neuropsicológico Iowa Gambling Task. Jornal Brasileiro de Psiquiatria, 59(4), 279-285. https://doi.org/10.1590/S0047-20852010000400003

Cauffman, E., Shulman, E. P., Steinberg, L., Claus, E., Banich, M. T., Graham, S., \& Woolard, J. (2010). Age Differences in Affective Decision Making as Indexed by Performance on the Iowa Gambling Task. 46(1), 193-207. https://doi.org/10.1037/a0016128

Ceschi, A., Costantini, A., Zagarese, V., Avi, E., \& Sartori, R. (2019). The NOTECHS plus : A Short Scale Designed for Assessing the Non-technical Skills (and more) in the Aviation and the Emergency Personnel. Frontiers in Psychology, 10. https://doi.org/Artn 90210.3389/Fpsyg.2019.00902

Chen, K. H., Rusch, M. L., Dawson, J. D., Rizzo, M., \& Anderson, S. W. (2015). Susceptibility to social pressure following ventromedial prefrontal cortex damage. Social Cognitive and Affective Neuroscience, 10(11), 1469-1476. https://doi.org/10.1093/scan/nsv037

Chesney, S. A., \& Gordon, N. S. (2017). Profiles of emotion regulation: Understanding regulatory patterns and the implications for posttraumatic stress. Cognition and Emotion, 31(3), 598-606. https://doi.org/10.1080/02699931.2015.1126555

Chesney, S. A., Timmer-Murillo, S. C., \& Gordon, N. S. (2019). Establishment and replication of emotion regulation profiles: implications for psychological health. Anxiety, Stress and Coping, 32(3), 329-345. https://doi.org/10.1080/10615806.2019.1573990

Chohra, A., \& Madani, K. (2016). Biological Regulation and Psychological Mechanisms Models of Adaptive Decision-Making Behaviors: Drives, Emotions, and Personality. In Computational Collective Intelligence, Iccci 2016, Pt I (Vol. 9875, pp. 412-422). https://doi.org/10.1007/978-3-319-45243-2_38

Clore, G. L., Gasper, K., \& Garvin, E. (2001). Affect as information. In J. P. Forgas (Ed.), Handbook of affect and social cognition (pp. 121-144). Lawrence Erlbaum Associates Publishers.

Clyne, S. E. (2000). Executive function and cognitive style in adolescent college students, including those with learning disabilities. Massachusetts School of Professional Psychology, Boston.

Coan, J. A., \& Allen, J. J. B. (2007). Handbook of emotion elicitation and assessment. Oxford university press.

Cohen, R. J., Swerdlik, M. E., \& Sturman, E. D. (2014). Testagem e Avaliação Psicológica: Introdução a Testes e Medidas. AMGH Editora.

Cozby, P. C. (2003). Métodos de pesquisa em ciências do comportamento. São Paulo: Atlas. 
Cristofanelli, S., Pignolo, C., Ferro, L., Ando', A., \& Zennaro, A. (2016). Rorschach Nomological Network and Resting-State Large Scale Brain Networks. Rorschachiana, 37(1), 74-92. https://doi.org/10.1027/1192-5604/a000078

Cronbach, L. J., Gleser, G. C., Nanda, H., \& Rajaratnam, M. (1972). The Dependability of Behavioral Measurement: Theory of Generalizability for Scores and Profiles. (J. W. and Sons (ed.)). Inc.

Damásio, A. (2012). O erro de Descartes: emoção, razão e o cérebro humano. Editora Companhia das Letras.

De France, K., \& Hollenstein, T. (2017). Assessing emotion regulation repertoires: The Regulation of Emotion Systems Survey. Personality and Individual Differences, 119, 204215. https://doi.org/10.1016/j.paid.2017.07.018

De Martino, B., Camerer, C. F., \& Adolphs, R. (2010). Amygdala damage eliminates monetary loss aversion. Proceedings of the National Academy of Sciences, 107(8), 3788-3792. https://doi.org/10.1073/pnas.0910230107

De Panfilis, C., Schito, G., Generali, I., Gozzi, L. A., Ossola, P., Marchesi, C., \& Grecucci, A. (2019). Emotions at the border: Increased punishment behavior during fair interpersonal exchanges in borderline personality disorder. Journal of Abnormal Psychology, 128(2), 162-172. https://doi.org/10.1037/abn0000404

De Vries, M., Holland, R. W., \& Witteman, C. L. M. (2008). In the winning mood: Affect in the Iowa gambling task. Judgment and Decision Making, 3(1), 42-50. http://journal.sjdm.org/bb4.pdf

Desjardins, C. D. (2005). Profile Analysis of Multivariate Data in R: An Introduction to the profileR Package. Journal of Statistical Software, VV(II), 1-29.

Di Girolamo, M., Giromini, L., Winters, C. L., Serie, C. M. B., \& de Ruiter, C. (2017). The Questionnaire of Cognitive and Affective Empathy: A Comparison Between Paper-andPencil Versus Online Formats in Italian Samples. Journal of Personality Assessment, O(0), 1-12. https://doi.org/10.1080/00223891.2017.1389745

Diano, M., Celeghin, A., Bagnis, A., \& Tamietto, M. (2017). Amygdala response to emotional stimuli without awareness: Facts and interpretations. Frontiers in Psychology, 7(JAN), 113. https://doi.org/10.3389/fpsyg.2016.02029

Dixon-Gordon, K. L., Aldao, A., \& De Los Reyes, A. (2015). Repertoires of emotion regulation: A person-centered approach to assessing emotion regulation strategies and links to psychopathology. Cognition and Emotion, 29(7), 1314-1325. https://doi.org/10.1080/02699931.2014.983046

Dunn, B. D., Dalgleish, T., \& Lawrence, A. D. (2006). The somatic marker hypothesis: A critical evaluation. Neuroscience \& Biobehavioral Reviews, 30(2), 239-271. https://doi.org/10.1016/j.neubiorev.2005.07.001

Dvorak, R. D., Wray, T. B., Kuvaas, N. J., \& Kilwein, T. M. (2013). Mania and sexual risk: Associations with behavioral self-regulation. Journal of Affective Disorders, 150(3), 10761081. https://doi.org/10.1016/j.jad.2013.04.023 
Eftekhari, A., Zoellner, L. A., \& Vigil, S. A. (2009). Patterns of emotion regulation and psychopathology. Anxiety, Stress \& Coping, 22(5), 571-586. https://doi.org/10.1080/10615800802179860

Eid, M., \& Diener, E. (2006). Introduction: The need for multimethod measurement in psychology. In M. Eid \& E. Diener (Eds.), Handbook of Multimethod measurement in psychology (pp. 3-8). American Psychological Association.

Extremera, N., \& Rey, L. (2015). The moderator role of emotion regulation ability in the link between stress and well-being. Frontiers in Psychology, 6(OCT). https://doi.org/10.3389/fpsyg.2015.01632

Eysenck, M. W., \& Keane, M. T. (2017). Manual de Psicologia Cognitiva (7th ed.). Artmed Editora.

Farnia, F., Nafukho, F. M., \& Petrides, K. V. (2018). Predicting Career Decision-Making Difficulties: The Role of Trait Emotional Intelligence, Positive and Negative Emotions. Frontiers in Psychology, 9. https://doi.org/Artn 110710.3389/Fpsyg.2018.01107

Field, A. (2009). Descobrindo a estatística usando o SPSS-2. Bookman Editora.

Field, A. P., \& Wilcox, R. R. (2017). Robust statistical methods: A primer for clinical psychology and experimental psychopathology researchers. Behaviour Research and Therapy, 98, 19-38. https://doi.org/10.1016/j.brat.2017.05.013

Filardi, F., Alvarenga, N. B., Filardi Da Rocha, F., Alvarenga, N. B., Malloy-Diniz, L., Corrêa, H., Filardi, F., \& Rocha, D. (2011). Decision-making impairment in obsessive-compulsive disorder as measured by the Iowa Gambling Task. Ethics, 69(March), 642-647. https://doi.org/10.1590/S0004-282X2011000500013

Fonooni, B. (2007). Rational-emotional agent decision making algorithm design with OWA. 19th Ieee International Conference on Tools with Artificial Intelligence, Vol Ii, Proceedings, 63-+. https://doi.org/10.1109/Ictai.2007.123

Frazen, M. D. (2002). Reliability and Validity in Neuropsychological Assessment (2nd ed., Vol. 7, Issue 6). Springer Science + Business Media. https://doi.org/10.1093/arclin/7.6.561

Friedman, H. S., \& Schustack, M. W. (2004). Teorias da personalidade: da teria clássica à pesquisa moderna (2nd ed.). Prentice Hall.

Gansler, D. A., Jerram, M. W., Vannorsdall, T. D., \& Schretlen, D. J. (2011). Comparing alternative metrics to assess performance on the Iowa Gambling Task. Journal of Clinical and Experimental Neuropsychology, 33(9), 1040-1048. https://doi.org/10.1080/13803395.2011.596820

Gansler, D. A., Lee, A. K. W., Emerton, B. C., D’Amato, C., Bhadelia, R., Jerram, M., \& Fulwiler, C. (2011). Prefrontal regional correlates of self-control in male psychiatric patients: Impulsivity facets and aggression. Psychiatry Research: Neuroimaging, 191(1), 16-23. https://doi.org/10.1016/j.pscychresns.2010.09.003

Gansler, D. A., McLaughlin, N. C. R., Iguchi, L., Jerram, M., Moore, D. W., Bhadelia, R., \& Fulwiler, C. (2009). A multivariate approach to aggression and the orbital frontal cortex in psychiatric patients. Psychiatry Research: Neuroimaging, 171(3), 145-154. https://doi.org/10.1016/j.pscychresns.2008.03.007 
Gardener, E. K. T., Carr, A. R., MacGregor, A., \& Felmingham, K. L. (2013). Sex Differences and Emotion Regulation: An Event-Related Potential Study. PLoS ONE, 8(10), e73475. https://doi.org/10.1371/journal.pone.0073475

Gartenschlager, M., Schreckenberger, M., Buchholz, H. G., Reiner, I., Beutel, M. E., Adler, J., \& Michal, M. (2017). Resting Brain Activity Related to Dispositional Mindfulness: a PET Study. Mindfulness, 8(4), 1009-1017. https://doi.org/10.1007/s12671-017-0677-2

Gasper, K., \& Bramesfeld, K. D. (2006). Should I follow my feelings? How individual differences in following feelings influence affective well-being, experience, and responsiveness. Journal of Research in Personality, 40(6), 986-1014. https://doi.org/10.1016/j.jrp.2005.10.001

Ghasemi, A., \& Zahediasl, S. (2012). Normality tests for statistical analysis: A guide for nonstatisticians. International Journal of Endocrinology and Metabolism, 10(2), 486-489. https://doi.org/10.5812/ijem.3505

Giacomoni, C. H., \& Hutz, C. S. (1997). A mensuração do bem-estar subjetivo: escala de afeto positivo e negativo e escala de satisfação de vida [Resumos]. Sociedade Interamericana de Psicologia (Org.), Anais XXVI Congresso Interamericano de Psicologia, 313.

Gibson, W. A. (1959). Three multivariate models: Factor analysis, latent structure analysis, and latent profile analysis. Psychometrika, 24(3), 229-252. https://doi.org/10.1007/BF02289845

Gillath, O., \& Shaver, P. R. (2007). Effects of attachment style and relationship context on selection among relational strategies. Journal of Research in Personality, 41(4), 968-976. https://doi.org/10.1016/j.jrp.2006.11.003

Giromini, L., Porcelli, P., Viglione, D. J., Parolin, L., \& Pineda, J. A. (2010). The feeling of movement: EEG evidence for mirroring activity during the observations of static , ambiguous stimuli in the Rorschach cards. Biological Psychology, 85(2), 233-241. https://doi.org/10.1016/j.biopsycho.2010.07.008

Giromini, L., Viglione, D. J., Zennaro, A., \& Cauda, F. (2017). Neural activity during production of rorschach responses: An fMRI study. Psychiatry Research: Neuroimaging, 262(September 2016), 25-31. https://doi.org/10.1016/j.pscychresns.2017.02.001

Gómez-Ortiz, O., Romera, E. M., Ortega-Ruiz, R., Cabello, R., \& Fernández-Berrocal, P. (2016). Analysis of emotion regulation in spanish adolescents: Validation of the emotion regulation questionnaire. Frontiers in Psychology, 6(JAN), 1959. https://doi.org/10.3389/fpsyg.2015.01959

Gonzalez, V. M., Reynolds, B., \& Skewes, M. C. (2011). Role of impulsivity in the relationship between depression and alcohol problems among emerging adult college drinkers. Experimental and Clinical Psychopharmacology, 19(4), 303-313. https://doi.org/10.1037/a0022720

Gouveia, V. V., de Moura, H. M., de Oliveira, I. C. V., Ribeiro, M. G. C., Rezende, A. T., \& Brito, T. R. de S. (2018). Emotional Regulation Questionnaire ( ERQ ): Evidence of Construct Validity and Internal Consistency. Psico-USF, 23(3), 461-471.

Gratz, K. L., \& Roemer, L. (2004). Multidimensional assessment of emotion regulation and dysregulation. Journal of Psychopathology and Behavioral Assessment, 26(1), 41-54. https://doi.org/10.1023/B:JOBA.0000007455.08539.94 
Grecucci, A., \& Sanfey, A. G. (2014). Emotion regulation and decision making. In J. J. Gross (Ed.), Handbook of emotion regulation (2nd ed., pp. 140-153). Guilford Press.

Gross, J. J. (2002). Emotion regulation: Affective, cognitive, and social consequences. Psychophysiology, 39(2002), 281-291. https://doi.org/10.1017.S0048577201393198

Gross, J. J. (2014). Handbook of emotion regulation (J. J. Gross (ed.); 2nd ed.). Guilford publications.

Gross, J. J., \& Jazaieri, H. (2014). Emotion, Emotion Regulation, and Psychopathology. Clinical Psychological Science, 2(4), 387-401. https://doi.org/10.1177/2167702614536164

Gross, J. J., \& John, O. P. (2003). Individual differences in two emotion regulation processes: Implications for affect, relationships, and well-being. Journal of Personality and Social Psychology, 85(2), 348-362. https://doi.org/10.1037/0022-3514.85.2.348

Gruber, J., Mauss, I. B., \& Tamir, M. (2011). A Dark Side of Happiness? How, When, and Why Happiness Is Not Always Good. Perspectives on Psychological Science, 6(3), 222-233. https://doi.org/10.1177/1745691611406927

Gruber, June, Kogan, A., Quoidbach, J., \& Mauss, I. B. (2013). Happiness is best kept stable: Positive emotion variability is associated with poorer psychological health. Emotion, 13(1), 1-6. https://doi.org/10.1037/a0030262

Grucza, R. A., \& Goldberg, L. R. (2007). The comparative validity of 11 modern personality inventories: Predictions of behavioral acts, informant reports, and clinical indicators. Journal of Personality Assessment, 89(2), 167-187. https://doi.org/10.1080/00223890701468568

Hackenbracht, J., \& Gasper, K. (2013). Feeling More and Feeling Close: Affect Intensity Influences Judgments of Interpersonal Closeness. Social Cognition, 31(1), 94-105. https://doi.org/10.1521/soco.2013.31.1.94

Hall, C. S., Lindzey, G., \& Campbell, J. B. (2000). Teorias da personalidade (4th ed.). Artmed.

Hallion, L. S., Steinman, S. A., Tolin, D. F., \& Diefenbach, G. J. (2018). Psychometric properties of the difficulties in emotion regulation scale (DERS) and its short forms in adults with emotional disorders. Frontiers in Psychology, 9(APR), 1-12. https://doi.org/10.3389/fpsyg.2018.00539

Hamilton, K., Shih, S.-I., \& Mohammed, S. (2016). The Development and Validation of the Rational and Intuitive Decision Styles Scale. Journal of Personality Assessment, 98(5), 523-535. https://doi.org/10.1080/00223891.2015.1132426

Hamilton, K., Shih, S. I., \& Mohammed, S. (2017). The predictive validity of the decision styles scale: An evaluation across task types. Personality and Individual Differences, 119, 333340. https://doi.org/10.1016/j.paid.2017.08.009

Hammers, D. B., \& Suhr, J. A. (2010). Neuropsychological, impulsive personality, and cerebral oxygenation correlates of undergraduate polysubstance use. In Journal of Clinical and Experimental Neuropsychology (Vol. 32, Issue 6, pp. 599-609). Taylor \& Francis. https://doi.org/10.1080/13803390903379599 
Han, T., Alders, G. L., Greening, S. G., Neufeld, R. W. J., \& Mitchell, D. G. V. (2012). Do fearful eyes activate empathy-related brain regions in individuals with callous traits? Social Cognitive and Affective Neuroscience, 7(8), 958-968. https://doi.org/10.1093/scan/nsr068

Harenski, C. L., Kim, S. H., \& Hamann, S. (2009). Neuroticism and psychopathy predict brain activation during moral and nonmoral emotion regulation. Cognitive Affective \& Behavioral Neuroscience, 9(1), 1-15. https://doi.org/10.3758/CABN.9.1.1

Hawthorne, M. J., \& Pierce, B. H. (2015). Disadvantageous Deck Selection in the Iowa Gambling Task: The Effect of Cognitive Load. Europe's Journal of Psychology, 11(2), 335-348. https://doi.org/10.5964/ejop.v11i2.931

Hayley, A. C., Ridder, B. de, Stough, C., Ford, T. C., \& Downey, L. A. (2017). Emotional intelligence and risky driving behaviour in adults. Transportation Research Part F: Traffic Psychology and Behaviour, 49, 124-131. https://doi.org/10.1016/j.trf.2017.06.009

Heatherton, T. F., \& Wagner, D. D. (2011). Cognitive neuroscience of self-regulation failure. Trends in Cognitive Sciences, 15(3), 132-139. https://doi.org/10.1016/j.tics.2010.12.005

Hedge, C., Powell, G., \& Sumner, P. (2018). The reliability paradox: Why robust cognitive tasks do not produce reliable individual differences. Behavior Research Methods, 50(3). https://doi.org/10.3758/s13428-017-0935-1

Heilman, R. M., Crişan, L. G., Houser, D., Miclea, M., \& Miu, A. C. (2010). Emotion regulation and decision making under risk and uncertainty. Emotion, 10(2), 257-265. https://doi.org/10.1037/a0018489

Heilman, R. M., \& Miclea, M. (2015). The contributions of declarative knowledge and emotion regulation in the Iowa Gambling Task. Cognition, Brain, Behavior: An Interdisciplinary Journal, 19(1), 35-53. http://ovidsp.ovid.com/ovidweb.cgi?T=JS\&PAGE=reference $\& D=$ psyc12\&NEWS=N\&AN $=2015-14618-003$

Heiy, J. E., \& Cheavens, J. S. (2014). Back to basics: A naturalistic assessment of the experience and regulation of emotion. Emotion, 14(5), 878-891. https://doi.org/10.1037/a0037231

Helmsen, J., Koglin, U., \& Petermann, F. (2012). Emotion regulation and aggressive behavior in preschoolers: the mediating role of social information processing. Child Psychiatry Hum Dev, 43(1), 87-101. https://doi.org/10.1007/s10578-011-0252-3

Hiraishi, H., \& Haida, M. (2012). Differences of Prefrontal Cortex Activity Between PictureBased Personality Tests: A Near-Infrared Spectroscopy Study Differences of Prefrontal Cortex Activity Between Picture-Based Personality Tests : A Near-Infrared Spectroscopy Study. August, 37-41. https://doi.org/10.1080/00223891.2012.666597

Hisatugo, C. L. C. (2019). Desenvolvimento dos principais sistemas de Rorschach: contextos histórico e multicultural. In T. de C. Amaro \& C. L. C. Hisatugo (Eds.), Rorschach (1st ed., pp. 71-102). Hogrefe.

Howieson, D., \& Howieson, D. (2019). Current limitations of neuropsychological tests and assessment procedures assessment procedures. The Clinical Neuropsychologist, O(0), 1-9. https://doi.org/10.1080/13854046.2018.1552762 
Huebner, A., \& Lucht, M. (2019). Generalizability Theory in R. Practical Assessment, Research \& Evaluation, 24(5).

Hughes, B. L., \& Beer, J. S. (2012). Medial orbitofrontal cortex is associated with shifting decision thresholds in self-serving cognition. NeuroImage, 61(4), 889-898. https://doi.org/10.1016/j.neuroimage.2012.03.011

Hughes, C. D., \& Rizvi, S. L. (2019). Biases in Affective Forecasting and Recall as a Function of Borderline Personality Disorder Features. Journal of Social and Clinical Psychology, 38(3), 200-223. https://doi.org/10.1521/jscp.2019.38.2.200

Huh, H. J., Baek, K., Kwon, J.-H., Jeong, J., \& Chae, J.-H. (2016). Impact of childhood trauma and cognitive emotion regulation strategies on risk-aversive and loss-aversive patterns of decision-making in patients with depression. Cognitive Neuropsychiatry, 21(6), 447-461. https://doi.org/10.1080/13546805.2016.1230053

Ibraheim, M., Kalpakci, A., \& Sharp, C. (2017). The specificity of emotion dysregulation in adolescents with borderline personality disorder: comparison with psychiatric and healthy controls. Borderline Personality Disorder and Emotion Dysregulation, 4(1), 1. https://doi.org/10.1186/s40479-017-0052-X

Ishibashi, M., Uchiumi, C., Jung, M., Aizawa, N., Makita, K., Nakamura, Y., \& Saito, D. N. (2016). Differences in Brain Hemodynamics in Response to Achromatic and Chromatic Cards of the Rorschach. Rorschachiana, 37(1), 41-57. https://doi.org/10.1027/11925604/a000076

Jalilvand, A., Noroozabad, M. R., \& Switzer, J. (2018). Informed and uninformed investors in Iran: Evidence from the Tehran Stock Exchange. Journal of Economics and Business, 95, 47-58. https://doi.org/10.1016/j.econbus.2017.08.001

Jenkinson, P. M., Baker, S. R., Edelstyn, N. M. J., \& Ellis, S. J. (2008). Does autonomic arousal distinguish good and bad decisions? Healthy individuals' the Iowa gambling task. Journal of Psychophysiology, 22(3), 141-149. https://doi.org/10.1027/0269-8803.22.3.141

John, O. P., \& Eng, J. (2014). Three approaches to individual differences in affect regulation: Conceptualizations, measures, and findings. In J. J. Gross (Ed.), Handbook of emotion regulation (2nd ed., pp. 321-345). Guilford Press.

John, O. P., \& Gross, J. J. (2004). Healthy and unhealthy emotion regulation: Personality processes, individual differences, and life span development. Journal of Personality, 72(6), 1301-1333. https://doi.org/10.1111/j.1467-6494.2004.00298.x

Kahneman, D. (2003). A perspective on judgment and choice: Mapping bounded rationality. American Psychologist, 58(9), 697-720. https://doi.org/10.1037/0003-066X.58.9.697

Kahneman, D., \& Tversky, A. (2013). Prospect theory: An analysis of decision under risk. In L. C. MacLean \& W. T. Ziemba (Eds.), Handbook of the fundamentals of financial decision making: Part I (pp. 99-127). World Scientific.

Kalokerinos, E. K., Greenaway, K. H., \& Casey, J. P. (2017). Context shapes social judgments of positive emotion suppression and expression. Emotion, 17(1), 169-186. https://doi.org/10.1037/emo0000222 
Kapsomenakis, A., Simos, P. G., Konstantakopoulos, G., \& Kasselimis, D. S. (2018). In Search of Executive Impairment in Pathological Gambling: A Neuropsychological Study on Nontreatment Seeking Gamblers. Journal of Gambling Studies, 34(4), 1327-1340. https://doi.org/10.1007/s10899-018-9758-y

Kassambara, A. (2019). Inter-rater reliability essentials (Datanovia.com/en (ed.); 1st ed.).

Kermer, D. A., Driver-Linn, E., Wilson, T. D., \& Gilbert, D. T. (2006). Loss Aversion Is an Affective Forecasting Error. Psychological Science, 17(8), 649-653. https://doi.org/10.1111/j.1467-9280.2006.01760.x

Kerr, K. L., Avery, J. A., Barcalow, J. C., Moseman, S. E., Bodurka, J., Bellgowan, P. S. F., \& Simmons, W. K. (2015). Trait impulsivity is related to ventral ACC and amygdala activity during primary reward anticipation. In Social Cognitive and Affective Neuroscience (Vol. 10, Issue 1, pp. 36-42). Oxford University Press. https://doi.org/10.1093/scan/nsu023

Kiekens, G., Hasking, P., \& Boyes, M. (2019). Measurement Invariance of Three Brief Emotion Regulation Questionnaires in People With and Without a History of Non-Suicidal SelfInjury. European Journal of Psychological Assessment, 35(6), 835-841. https://doi.org/10.1027/1015-5759/a000464

Kim, M. Y., \& Kanfer, R. (2009). The joint influence of mood and a cognitively demanding task on risk-taking. Motivation and Emotion, 33(4), 362-372. https://doi.org/10.1007/s11031009-9147-z

Kluwe-Schiavon, B., Guimarães, I. S., Malloy-Diniz, L. F., \& Grassi-Oliveira, R. (2018). Julgamento e tomada de decisões: conceitos gerais. In Julgamento e tomada de decisão. Pearson Clinical Brasil.

Kovács, I., Richman, M. J., Janka, Z., Maraz, A., \& Andó, B. (2017). Decision making measured by the Iowa Gambling Task in alcohol use disorder and gambling disorder: a systematic review and meta-analysis. Drug and Alcohol Dependence, 181(September), 152-161. https://doi.org/10.1016/j.drugalcdep.2017.09.023

Kranz, T. T., Teschner, F., \& Weinhardt, C. (2014). User Heterogeneity in Trading Systems: Assessing Trader's Market Predisposition via Personality Questionnaires. 2014 47th Hawaii International Conference on System Sciences (Hicss), 1230-1239. https://doi.org/10.1109/Hicss.2014.159

Kron, A., Cohen, A., Benziman, H., \& Ben-Shakhar, G. (2009). What is it that color determinants determine? The relation between the Rorschach Inkblot method and cognitive object-recognition processes. Journal of Personality Assessment, 91(2), 137-142. https://doi.org/10.1080/00223890802634233

Kuhnle, C., Sinclair, M., Hofer, M., \& Kilian, B. (2014). Students' Value Orientations, Intuitive Decision Making, and Motivational Interference, and Their Relations to Regret. The Journal of Experimental Education, 82(3), 375-390. https://doi.org/10.1080/00220973.2013.813363

Kumari, V., Uddin, S., Premkumar, P., Young, S., Gudjonsson, G. H., Raghuvanshi, S., Barkataki, I., Sumich, A., Taylor, P., \& Das, M. (2014). Lower anterior cingulate volume in seriously violent men with antisocial personality disorder or schizophrenia and a history of childhood abuse. Australian \& New Zealand Journal of Psychiatry, 48(2), 153-161. https://doi.org/10.1177/0004867413512690 
Kusev, P., Purser, H., Heilman, R., Cooke, A. J., Van Schaik, P., Baranova, V., Martin, R., \& Ayton, P. (2017). Understanding Risky Behavior: The Influence of Cognitive, Emotional and Hormonal Factors on Decision-Making under Risk. Frontiers in Psychology, 8(February). https://doi.org/10.3389/fpsyg.2017.00102

Kwon, H., Yoon, K. L., Joormann, J., \& Kwon, J. (2013). Cultural and gender differences in emotion regulation: Relation to depression. Cognition and Emotion, 27(5), 769-782. https://doi.org/https://doi.org/10.1080/02699931.2013.792244

Lazarus, R. S. (1999). Th cognition-emotion debate: a bit of history. In T. Dalgleish \& M. J. Power (Eds.), Handbook of Cognition and Emotion (pp. 3-20). John Wiley \& Sons, Ltd.

Le, B. M., \& Impett, E. A. (2013). When Holding Back Helps: Suppressing Negative Emotions During Sacrifice Feels Authentic and Is Beneficial for Highly Interdependent People. Psychological Science, 24(9), 1809-1815. https://doi.org/10.1177/0956797613475365

Lempert, K. M., \& Phelps, E. A. (2014). Neuroeconomics of emotion and decision making. In P. W. Glimcher \& E. Fehr (Eds.), Neuroeconomics: Decision making and the brain (2nd ed., pp. 219-236). Academic Press.

Lerner, J. S., Li, Y., Valdesolo, P., \& Kassam, K. S. (2015). Emotion and Decision Making. Annual Review of Psychology, 66(1), 799-823. https://doi.org/10.1146/annurev-psych010213-115043

Leshem, R., \& Yefet, M. (2019). Does impulsivity converge distinctively with inhibitory control? Disentangling the cold and hot aspects of inhibitory control. Personality and Individual Differences, 145, 44-51. https://doi.org/10.1016/j.paid.2019.03.003

Lin, C.-H., Chiu, Y.-C., Lee, P.-L., \& Hsieh, J.-C. (2007). Is deck B a disadvantageous deck in the Iowa Gambling Task? Behavioral and Brain Functions, 3(1), 16. https://doi.org/10.1186/1744-9081-3-16

Lin, C.-H., Song, T.-J., Chen, Y.-Y., Lee, W.-K., \& Chiu, Y.-C. (2013). Reexamining the Validity and Reliability of the Clinical Version of the Iowa Gambling Task: Evidence from a Normal Subject Group. Frontiers in Psychology, 4(MAY), 22. https://doi.org/10.3389/fpsyg.2013.00220

Lin, C., Lin, C., Chiu, Y., \& Huang, J. (2015). Growing evidence of prominent deck B phenomenon in Iowa Gambling Task Growing evidence of prominent deck B phenomenon in Iowa Gambling Task. December.

Locander, D. A., Mulki, J. P., \& Weinberg, F. J. (2014). How Do Salespeople Make Decisions? The Role of Emotions and Deliberation on Adaptive Selling, and the Moderating Role of Intuition. Psychology \& Marketing, 31(6), 387-403. https://doi.org/10.1002/mar.20702

Lockenhoff, C. E., Rutt, J. L., Samanez-Larkin, G. R., O’Donoghue, T., \& Reyna, V. F. (2019). Preferences for Temporal Sequences of Real Outcomes Differ Across Domains but do not Vary by Age. Journals of Gerontology Series B-Psychological Sciences and Social Sciences, 74(3), 430-439. https://doi.org/10.1093/geronb/gbx094

Loewenstein, G., \& Lerner, J. S. (2003). The role of affect in decision making. In R. J. Davidson, K. R. Scherer, \& H. H. Goldsmith (Eds.), Handbook of Affective Sciences. Oxford University Press. 
Lopes, P. N., Mestre, J. M., Guil, R., Kremenitzer, J. P., \& Salovey, P. (2012). The Role of Knowledge and Skills for Managing Emotions in Adaptation to School. American Educational Research Journal, 49(4), 710-742. https://doi.org/10.3102/0002831212443077

Lopes, P. N., Nezlek, J. B., Extremera, N., Hertel, J., Fernández-Berrocal, P., Schütz, A., \& Salovey, P. (2011). Emotion Regulation and the Quality of Social Interaction: Does the Ability to Evaluate Emotional Situations and Identify Effective Responses Matter? Journal of Personality, 79(2), 429-467. https://doi.org/10.1111/j.1467-6494.2010.00689.x

Lougheed, J. P., \& Hollenstein, T. (2012). A Limited Repertoire of Emotion Regulation Strategies is Associated with Internalizing Problems in Adolescence. Social Development, 21(4), 704-721. https://doi.org/10.1111/j.1467-9507.2012.00663.x

Lucas, R. E., \& Baird, B. M. (2006). Global self-assessment. In M. Eid \& E. Diener (Eds.), Handbook of Multimethod measurement in psychology (1st ed.). American Psychological Association.

MacIntyre, J. M., Ruscio, A. C., Brede, E., \& Waters, A. J. (2018). Emotion dysregulation and negative affect: Laboratory and EMA investigations in smokers. Addictive Behaviors Reports, 7(September 2017), 65-70. https://doi.org/10.1016/j.abrep.2018.01.001

Magar, E. C. E., Phillips, L. H., \& Hosie, J. A. (2008). Self-regulation and risk-taking. Personality and Individual Differences, 45(2), 153-159. https://doi.org/10.1016/j.paid.2008.03.014

Mair, P., \& Wilcox, R. (2019). Robust statistical methods in R using the WRS2 package. Behavior Research Methods, 36(10), 1336-1338. https://doi.org/10.3758/s13428-01901246-w

Malloy-Diniz, L. F., Leite, W. B., De Moraes, P. H. P., Correa, H., Bechara, A., \& Fuentes, D. (2008). Brazilian Portuguese version of the Iowa Gambling Task: Transcultural adaptation and discriminant validity. Revista Brasileira de Psiquiatria, 30(2), 144-148. https://doi.org/10.1590/S1516-44462008005000009

Malone, J. C., Stein, M. B., Slavin-Mulford, J., Bello, I., Sinclair, S. J., \& Blais, M. A. (2013). Seeing red: Affect modulation and chromatic color responses on the Rorschach. Bulletin of the Menninger Clinic, 77(1), 70-93. https://doi.org/10.1521/bumc.2013.77.1.70

Mardaga, S., \& Hansenne, M. (2012). Personality and skin conductance responses to reward and punishment. Journal of Individual Differences, 33(1), 17-23. https://doi.org/10.1027/16140001/a000057

Maroco, J., \& Garcia-Marques, T. (2013). Qual a fiabilidade do alfa de Cronbach? Questões antigas e soluções modernas? Laboratório de Psicologia, 4(1), 65-90. https://doi.org/10.14417/lp.763

Marroquín, B., Boyle, C. C., Nolen-Hoeksema, S., \& Stanton, A. L. (2016). Using emotion as information in future-oriented cognition: Individual differences in the context of state negative affect. Personality and Individual Differences, 95, 121-126. https://doi.org/10.1016/j.paid.2016.02.033

Martin, L. N., \& Delgado, M. R. (2011). The Influence of Emotion Regulation on Decisionmaking under Risk. Journal of Cognitive Neuroscience, 23(9), 2569-2581. https://doi.org/10.1162/jocn.2011.21618 
Masumoto, K., Taishi, N., \& Shiozaki, M. (2016). Age and Gender Differences in Relationships Among Emotion Regulation, Mood, and Mental Health. Gerontology and Geriatric Medicine, 2(1-8), 233372141663702. https://doi.org/10.1177/2333721416637022

Matsuda, R. (2019). Multiple Emotion Regulation in Rorschach Color Responses: A Study Using IAT and Self-Report. Rorschachiana, 40(2), 112-130. https://doi.org/10.1027/11925604/a000116

Matsumoto, D., Yoo, S. H., \& Nakagawa, S. (2008). Culture, emotion regulation, and adjustment. Journal of Personality and Social Psychology, 94(6), 925-937. https://doi.org/10.1037/0022-3514.94.6.925

McCrae, R. R., \& Costa, P. T. J. (2008). The five-factor theory of personality. In O. P. John, R. W. Robins, \& L. A. Pervin (Eds.), Handbook of personality: Theory and research (Third edic). Guilford Press.

Mcrae, K., Ochsner, K. N., Mauss, I. B., Gabrieli, J. J. D., \& Gross, J. J. (2008). Gender Differences in Emotion Regulation: An fMRI Study of. Group Process \& Intergroup Relations, 11(2), 143-162. https://doi.org/10.1177/1368430207088035

Meyer, G. J. (2016). Neuropsychological Factors and Rorschach Performance in Children. Rorschachiana, 37(1), 7-27. https://doi.org/10.1027/1192-5604/a000074

Meyer, G. J. (2017). What Rorschach performance can add to assessing and understanding personality. International Journal of Personality Psychology, 3(1), 36-49. http://ijpp.rug.nl/article/viewFile/29881/27195

Meyer, G. J., \& Eblin, J. J. (2012). An Overview of the Rorschach Performance Assessment System (R-PAS). Psychological Injury and Law, 5(2), 107-121. https://doi.org/10.1007/s12207-012-9130-y

Meyer, G. J., Finn, S. E., Eyde, L. D., Kay, G. G., Moreland, K. L., Dies, R. R., Eisman, E. J., Kubiszyn, T. W., \& Reed, G. M. (2001). Psychological testing and psychological assessment: A review of evidence and issues. American Psychologist, 56(2), 128-165. https://doi.org/10.1037/0003-066X.56.2.128

Meyer, G. J., Viglione, D. J., Mihura, J. L., Erard, R. E., \& Erdberg, P. (2017). R-PAS: Sistema de avaliação por performance no Roschach (1st ed.). Hogrefe.

Miguel, F. K., Giromini, L., Colombarolli, M. S., Zuanazzi, A. C., \& Zennaro, A. (2016, October). A Brazilian Investigation of the 36- and 16-Item Difficulties in Emotion Regulation Scales. Journal of Clinical Psychology, 00(0), 1-14. https://doi.org/10.1002/jclp.22404

Mihura, J. L., \& Meyer, G. J. (2018). Introdução ao R-PAS. In J. L. Mihura \& G. J. Meyer (Eds.), Uso do sistema de avaliação por performance no Rorschach (R-PAS) (1st ed.). Hogrefe.

Mihura, J. L., Meyer, G. J., Dumitrascu, N., \& Bombel, G. (2013). The validity of individual Rorschach variables: Systematic reviews and meta-analyses of the comprehensive system. Psychological Bulletin, 139(3), 548-605. https://doi.org/10.1037/a0029406 
Miller, M. B., DiBello, A. M., Lust, S. A., Meisel, M. K., \& Carey, K. B. (2017). Impulsive personality traits and alcohol use: Does sleeping help with thinking? Psychology of Addictive Behaviors, 31(1), 46-53. https://doi.org/10.1037/adb0000241

Miranda, D., \& Kim, J. (2015). Peer contagion, lenient legal-ethical position, and music piracy intentions in emerging adults: Mindfulness as a protective factor. Musicae Scientiae, 19(1), 3-22. https://doi.org/10.1177/1029864914550665

Mitchell, D. G. V. (2011). The nexus between decision making and emotion regulation: A review of convergent neurocognitive substrates. Behavioural Brain Research, 217(1), 215231. https://doi.org/10.1016/j.bbr.2010.10.030

Moeller, S. K., \& Robinson, M. D. (2010). Cognitive sources of evidence for neuroticism's link to punishment-reactivity processes. Cognition \& Emotion, 24(5), 741-759. https://doi.org/10.1080/02699930902978436

Mohammed, S., \& Schwall, A. (2009). Individual differences and decision making: What we know and where we go from here. In G. P. Hodgkinson \& J. K. Ford (Eds.), International review of industrial and organizational psychology (Vol. 24, pp. 249-312). John Wiley \& Sons, Ltd.

Morin, A. J. S., Meyer, J. P., Creusier, J., \& Biétry, F. (2016). Multiple-Group Analysis of Similarity in Latent Profile Solutions. Organizational Research Methods, 19(2), 231-254. https://doi.org/10.1177/1094428115621148

Muhlert, N., \& Lawrence, A. D. (2015). Brain structure correlates of emotion-based rash impulsivity. NeuroImage, 115, 138-146. https://doi.org/10.1016/j.neuroimage.2015.04.061

Muñoz Centifanti, L. C., Kimonis, E. R., Frick, P. J., \& Aucoin, K. J. (2013). Emotional reactivity and the association between psychopathy-linked narcissism and aggression in detained adolescent boys. Development and Psychopathology, 25(2), 473-485. https://doi.org/10.1017/S0954579412001186

Must, A., Horvath, S., Nemeth, V. L., \& Janka, Z. (2013). The Iowa Gambling Task in depression - what have we learned about sub-optimal decision-making strategies? In Frontiers in Psychology (Vol. 4, Issue OCT, pp. 1-6). https://doi.org/10.3389/fpsyg.2013.00732

Muzio, E. (2004). Le Rorschach Système Intégré en Neuropsychologie : articulation du cognitif et de l'affectif. Psychologie Française, 49(1), 33-49. https://doi.org/10.1016/j.psfr.2003.11.003

Muzio, E. (2016). Inkblots and Neurons: Correlating typical cognitive performance with brain structure and function. Rorschachiana, 37(1), 1-6. https://doi.org/10.1027/1192$5604 / \mathrm{a} 000073$

Nguyen, Y., \& Noussair, C. N. (2014). Risk Aversion and Emotions. Pacific Economic Review, 19(3), 296-312. https://doi.org/10.1111/1468-0106.12067

Nunnally, J. C., \& Bernstein, I. H. (1978). Psychometric theory (J. C. Nunnally \& I. H. Bernstein (eds.); 3rd ed.). McGraw-Hill New York. 
Nylund-Gibson, K., \& Choi, A. Y. (2018). Ten frequently asked questions about latent class analysis. Translational Issues in Psychological Science, 4(4), 440-461. https://doi.org/10.1037/tps0000176

Nylund, K. L., Asparouhov, T., \& Muthén, B. O. (2007). Deciding on the Number of Classes in Latent Class Analysis and Growth Mixture Modeling: A Monte Carlo Simulation Study. Structural Equation Modeling: A Multidisciplinary Journal, 14(4), 535-569. https://doi.org/10.1080/10705510701575396

Oberski, D. (2016). Mixture Models: Latent Profile and Latent Class Analysis (pp. 275-287). https://doi.org/10.1007/978-3-319-26633-6_12

Osieko, O. M., Maru, L., Bonuke, R., \& Otinga, H. (2017). Emotional Self-Regulation , Organization Commitment and Strategic Decision Making in Private School Enterprises , Nairobi County, Kenya. International Journal of Economic Papers, 2(November), 1-6.

Palomäki, J., Laakasuo, M., \& Salmela, M. (2013). “Don’t Worry, It's Just Poker!”-Experience, Self-Rumination and Self-Reflection as Determinants of Decision-Making in On-Line Poker. Journal of Gambling Studies, 29(3), 491-505. https://doi.org/10.1007/s10899-0129311-3

Panno, A., Donati, M. A., Milioni, M., Chiesi, F., \& Primi, C. (2018). Why Women Take Fewer Risk Than Men Do: The Mediating Role of State Anxiety. Sex Roles, 78(3-4), 286-294. https://doi.org/10.1007/s11199-017-0781-8

Pasquali, L. (2017). Psicometria: teoria dos testes na psicologia e na educação (4th ed.). Editora Vozes.

Passanisi, A., D’Urso, G., \& Pace, U. (2019). The Interplay Between Maladaptive Personality Traits and Mindfulness Deficits Among Adolescent Regular Gamblers: A Mediation Model. Journal of Gambling Studies, 35(1), 93-105. https://doi.org/10.1007/s10899-018-9811-x

Paulus, M. P., Perry, W., \& Braff, D. L. (1999). The nonlinear, complex sequential organization of behavior in schizophrenic patients: Neurocognitive strategies and clinical correlations. In Biological Psychiatry (Vol. 46, Issue 5, pp. 662-670). Elsevier Science. https://doi.org/10.1016/S0006-3223(99)00086-4

Pessotto, F., \& Primi, R. (2018). Evidências de validade convergente para o teste de Wartegg. Psico, 49(1), 73. https://doi.org/10.15448/1980-8623.2018.1.26935

Peterson, E., \& Welsh, M. C. (2014). The Development of Hot and Cool Executive Functions in Childhood and Adolescence: Are We Getting Warmer? In S. Goldstein \& J. A. Naglieri (Eds.), Handbook of Executive Functioning (pp. 45-65). Springer New York. https://doi.org/10.1007/978-1-4614-8106-5_4

Phillips, W. J., Fletcher, J. M., Marks, A. D. G., \& Hine, D. W. (2016). Thinking styles and decision making: A meta-analysis. Psychological Bulletin, 142(3), 260-290. https://doi.org/10.1037/bul0000027

Pianowski, G., Meyer, G. J., de Villemor-Amaral, A. E., Zuanazzi, A. C., \& do Nascimento, R. S. G. F. (2019). Does the Rorschach Performance Assessment System (R-PAS) Differ from the Comprehensive System (CS) on Variables Relevant to Interpretation? Journal of Personality Assessment, O(0), 1-16. https://doi.org/10.1080/00223891.2019.1677678 
Pianowski, G., Meyer, G. J., \& Villemor-Amaral, A. E. de. (2016). The Impact of R-Optimized Administration Modeling Procedures on Brazilian Normative Reference Values for Rorschach Scores. Journal of Personality Assessment, 98(4), 408-418. https://doi.org/10.1080/00223891.2016.1148701

Pignolo, C., Giromini, L., Ando', A., Ghirardello, D., Di Girolamo, M., Ales, F., \& Zennaro, A. (2017). An Interrater Reliability Study of Rorschach Performance Assessment System (RPAS) Raw and Complexity-Adjusted Scores. Journal of Personality Assessment, 99(6), 619-625. https://doi.org/10.1080/00223891.2017.1296844

Pinon, A. (2019). Why most psychologists should assess and report personality. Frontiers in Psychology, 10(AUG), 1-3. https://doi.org/10.3389/fpsyg.2019.01982

Pinquart, M., Stotzka, C., \& Silbereisen, R. K. (2008). PERSONALITY AND AMBIVALENCE IN DECISIONS ABOUT BECOMING PARENTS. Social Behavior and Personality: An International Journal, 36(1), 87-96. https://doi.org/10.2224/sbp.2008.36.1.87

Pinto, A. L. de C., \& Pasian, S. R. (n.d.). Transcultural Adaptation of the Following Affective States Test (FAST) for the Brazilian Context. Psico-USF, 1-35.

Piotrowski, Z. A. (1957). Perceptanalysis; a fundamentally reworked, expanded, and systematized Rorschach method. (Z. A. Piotrowski (ed.); 1st ed.). Routledge.

Porcelli, P., \& Meyer, G. J. (2002). Construct validity of rorschach variables for alexithymia. Psychosomatics, 43(5), 360-369. https://doi.org/10.1176/appi.psy.43.5.360

Potenza, M. N., Steinberg, M. A., Skudlarski, P., Fulbright, R. K., Lacadie, C. M., Wilber, M. K., Rounsaville, B. J., Gore, M. C., \& Wexler, B. E. (2003). Gambling urges in pathological gambling - A functional magnetic resonance imaging study. Archives of General Psychiatry, 60(8), 828-836. https://doi.org/DOI 10.1001/archpsyc.60.8.828

R Core Team. (2020). $R$ : A language and environment for statistical computing. $R$ Foundation for Statistical Computing, Vienna, Austria. http://www.r-project.org/index.html

Raykov, T. (1997). Estimation of Composite Reliability for Congeneric Measures. Applied Psychological Measurement, 21(2), 173-184. https://doi.org/10.1177/01466216970212006

Reiss, S., \& Reips, U.-D. (2016). Online assessment. In K. Schweizer \& C. DiStefano (Eds.), Principles and methods of test constuction (pp. 120-131). Hogrefe.

Resende, A. C. (2008). Método de Rorschach: referências essenciais (1st ed.). Dimensão.

Reynolds, L. M., Lin, Y. S., Zhou, E., \& Consedine, N. S. (2015). Does a brief state mindfulness induction moderate disgust-driven social avoidance and decision-making? An experimental investigation. Journal of Behavioral Medicine, 38(1), 98-109. https://doi.org/10.1007/s10865-014-9582-5

Richards, D. W., Fenton-O'Creevy, M., Rutterford, J., \& Kodwani, D. G. (2018). Is the disposition effect related to investors' reliance on System 1 and System 2 processes or their strategy of emotion regulation? Journal of Economic Psychology, 66, 79-92. https://doi.org/10.1016/j.joep.2018.01.003 
Roberts, B. W., Kuncel, N. R., Shiner, R., Caspi, A., \& Goldberg, L. R. (2007). The Power of Personality: The Comparative Validity of Personality Traits, Socioeconomic Status, and Cognitive Ability for Predicting Important Life Outcomes. Perspectives on Psychological Science, 2(4), 313-345. https://doi.org/10.1111/j.1745-6916.2007.00047.x

Rorschach, H. (1942). Psychodiagnóstics - A diagnóstic test based on perception. Scholar Select.

Rose, P., \& Segrist, D. J. (2014). Negative and positive urgency may both be risk factors for compulsive buying. Journal of Behavioral Addictions, 3(2), 128-132. https://doi.org/10.1556/JBA.3.2014.011

Rosenberg, J. M., Beymer, P. N., Anderson, D. J., \& Schmidt, J. A. (2018). tidyLPA: An R Package to Easily Carry Out Latent Profile Analysis (LPA) Using Open-Source or Commercial Software. Journal of Open Source Software, 3(30), 978. https://doi.org/10.21105/joss.00978

Rovenpor, D. R., \& Isbell, L. M. (2018). Do emotional control beliefs lead people to approach positive or negative situations? Two competing effects of control beliefs on emotional situation selection. Emotion, 18(3), 313-331. https://doi.org/10.1037/emo0000353

Rovinski, S. L. R., Schneider, A. M. de A., Pariz, J., Santos, Á. Z., \& Bandeira, D. R. (2018). Respostas de agressividade no Rorschach (R-PAS) de homens autores de violência conjugal. Revista Avaliação Psicológica, 17(2), 199-204. https://doi.org/10.15689/ap.2018.1702.13998.05

RStudio Team. (2020). RStudio: Integrated Development for R. RStudio, PBC, Boston, MA. http://www.rstudio.com/

Sala, M. N., Molina, P., Abler, B., Kessler, H., Vanbrabant, L., \& van de Schoot, R. (2012). Measurement invariance of the Emotion Regulation Questionnaire (ERQ). A cross-national validity study. European Journal of Developmental Psychology, 9(6), 751-757. https://doi.org/10.1080/17405629.2012.690604

Sallum, I., Mata, F., Miranda, D. M., \& Malloy-Diniz, L. F. (2013). Staying and shifting patterns across IGT trials distinguish children with externalizing disorders from controls. Frontiers in Psychology, 4(DEC), 1-8. https://doi.org/10.3389/fpsyg.2013.00899

Schmitt, M., Hofmann, W., Gschwendner, T., Gerstenberg, F., \& Zinkernagel, A. (2015). A model of moderated convergence between direct, indirect, and behavioral measures of personality traits. In T. M. Ortner \& F. J. R. van de Vijver (Eds.), Behavior-based assessment in psychology (1st ed.). Hogrefe.

Schmitz, F., Kunina-Habenicht, O., Hildebrandt, A., Oberauer, K., \& Wilhelm, O. (2018). Psychometrics of the Iowa and Berlin Gambling Tasks: Unresolved Issues With Reliability and Validity for Risk Taking. Assessment. https://doi.org/10.1177/1073191117750470

Schott, G. D. (2014). Revisiting the Rorschach ink-blots: from iconography and psychology to neuroscience. Journal of Neurology, Neurosurgery \& Psychiatry, 86(6), 699. https://doi.org/10.1136/jnnp-2013-305672

Schreiber, L. R. N., Grant, J. E., \& Odlaug, B. L. (2012). Emotion regulation and impulsivity in young adults. Journal of Psychiatric Research, 46(5), 651-658. https://doi.org/10.1016/j.jpsychires.2012.02.005 
Schultebraucks, K., Deuter, C. E., Duesenberg, M., Schulze, L., Hellmann-Regen, J., Domke, A., Lockenvitz, L., Kuehl, L. K., Otte, C., \& Wingenfeld, K. (2016). Selective attention to emotional cues and emotion recognition in healthy subjects: the role of mineralocorticoid receptor stimulation. Psychopharmacology, 233(18), 3405-3415. https://doi.org/10.1007/s00213-016-4380-0

Schwarz, N. (2010). Feelings-as-Information Theory. P. Van Lange, A. Kruglanski, \& E. T. Higgins (Eds.), Handbook of Theories of Social Psychology. Sage., January, 1-32.

Servaas, M. N., Aleman, A., Marsman, J. B. C., Renken, R. J., Riese, H., \& Ormel, J. (2015). Lower dorsal striatum activation in association with neuroticism during the acceptance of unfair offers. Cognitive Affective \& Behavioral Neuroscience, 15(3), 537-552. https://doi.org/10.3758/s13415-015-0342-y

Shavelson, R., \& Webb, N. (1991). Generelizablity Theory: A Primer. Sage Publications.

Shrout, P. E., \& Fleiss, J. L. (1979). Intraclass correlations: Uses in assessing rater reliability. Psychological Bulletin, 86(2), 420-428. https://doi.org/10.1037/0033-2909.86.2.420

Shukla, M., Rasmussen, E. C., \& Nestor, P. G. (2019). Emotion and decision-making: Induced mood influences IGT scores and deck selection strategies. Journal of Clinical and Experimental Neuropsychology, 41(4), 341-352. https://doi.org/10.1080/13803395.2018.1562049

Slick, D. J. (2006). Psychometrics in neuropsychological assessment.pdf. In E. Straus, E. M. Sherman, \& O. Spreen (Eds.), A compendium of neuropsychological tests: Administration, norms and commentary. (3rd ed., pp. 3-30). Oxford University Press.

Smoski, M. J., Salsman, N., Wang, L., Smith, V., Lynch, T. R., Dager, S. R., LaBar, K. S., \& Linehan, M. M. (2011). Functional imaging of emotion reactivity in opiate-dependent borderline personality disorder. Personality Disorders: Theory, Research, and Treatment, 2(3), 230-241. https://doi.org/10.1037/a0022228

Sokol-Hessner, P., Camerer, C. F., \& Phelps, E. A. (2013). Emotion regulation reduces loss aversion and decreases amygdala responses to losses. Social Cognitive and Affective Neuroscience, 8(3), 341-350. https://doi.org/10.1093/scan/nss002

Soloff, P. H., Chowdury, A., \& Diwadkar, V. A. (2019). Affective interference in borderline personality disorder: The lethality of suicidal behavior predicts functional brain profiles. Journal of Affective Disorders, 252, 253-262. https://doi.org/10.1016/j.jad.2019.04.050

Spaapen, D. L., Waters, F., Brummer, L., Stopa, L., \& Bucks, R. S. (2014). The Emotion Regulation Questionnaire: Validation of the ERQ-9 in two community samples. Psychological Assessment, 26(1), 46-54. https://doi.org/10.1037/a0034474

Steingroever, H., Wetzels, R., \& Wagenmakers, E.-J. (2014). Absolute performance of reinforcement-learning models for the Iowa Gambling Task. Decision, 1(3), 161-183. https://doi.org/10.1037/dec0000005

Stevens, J. S., \& Hamann, S. (2012). Sex differences in brain activation to emotional stimuli: A meta-analysis of neuroimaging studies. Neuropsychologia, 50(7), 1578-1593. https://doi.org/10.1016/j.neuropsychologia.2012.03.011

Suchy, Y. (2011). Clinical neuropsychology of emotion. Guilford Press. 
Suhr, J. A., \& Tsanadis, J. (2007). Affect and personality correlates of the Iowa Gambling Task. Personality and Individual Differences, 43(1), 27-36. https://doi.org/10.1016/j.paid.2006.11.004

Suhr, J., \& Hammers, D. (2010). Who Fails the Iowa Gambling Test (IGT)? Personality, Neuropsychological, and Near-Infrared Spectroscopy Findings in Healthy Young Controls. $\begin{array}{llll}\text { Archives of } \quad \text { Clinical 293-302. } & \text { 25(4), }\end{array}$ https://doi.org/10.1093/arclin/acq017

Sul, S., Kim, J., \& Choi, I. (2013). Subjective Well-Being and Hedonic Editing: How Happy People Maximize Joint Outcomes of Loss and Gain. Journal of Happiness Studies, 14(4), 1409-1430. https://doi.org/10.1007/s10902-012-9379-6

Sutherland, M. T., Carroll, A. J., Salmeron, B. J., Ross, T. J., \& Stein, E. A. (2013). Insula's functional connectivity with ventromedial prefrontal cortex mediates the impact of trait alexithymia on state tobacco craving. Psychopharmacology, 228(1), 143-155. https://doi.org/10.1007/s00213-013-3018-8

Thunholm, P. (2004). Decision-making style: habit, style or both? Personality and Individual Differences, 36(4), 931-944. https://doi.org/10.1016/S0191-8869(03)00162-4

Tibon-Czopp, S., Appel, L., \& Zeligman, R. (2016). Assessing Personality Patterns of Functioning in a Decision-Making Ambiguous Task: The Rorschach Reality-Fantasy Scale (RFS-2). Group Decision and Negotiation, 25(1), 65-75. https://doi.org/10.1007/s10726015-9432-Z

Tisu, L., Lupșa, D., Vîrgă, D., \& Rusu, A. (2020). Personality characteristics, job performance and mental health the mediating role of work engagement. Personality and Individual Differences, 153(July 2019), 109644. https://doi.org/10.1016/j.paid.2019.109644

Tull, M. T., Forbes, C. N., Weiss, N. H., \& Gratz, K. L. (2019). An investigation of the effect of trauma script exposure on risk-taking among patients with substance use disorders and posttraumatic stress disorder. Journal of Anxiety Disorders, 62, 77-85. https://doi.org/10.1016/j.janxdis.2019.01.002

Vanderbos, G. R. (2010). Dicionário de psicologia da APA. Tradução: Bueno, D.

Vaz, C. E. (1997). O Rorschach: teoria e desempenho II. São Paulo: Casa Do Psicólogo.

Vega, D., Soto, À., Amengual, J. L., Ribas, J., Torrubia, R., Rodríguez-Fornells, A., \& MarcoPallarés, J. (2013). Negative reward expectations in Borderline Personality Disorder patients: Neurophysiological evidence. Biological Psychology, 94(2), 388-396. https://doi.org/10.1016/j.biopsycho.2013.08.002

Verdejo-Garcia, A., Bechara, A., Recknor, E. C., \& Perez-Garcia, M. (2006). Decision-Making and the Iowa Gambling Task: Ecological validity in individuals with substance dependence. Psychologica Belgica, 46(1-2), 55. https://doi.org/10.5334/pb-46-1-2-55

Verdejo-García, A., Bechara, A., Recknor, E. C., \& Pérez-García, M. (2007). Negative emotiondriven impulsivity predicts substance dependence problems. Drug and Alcohol Dependence, 91(2-3), 213-219. https://doi.org/10.1016/j.drugalcdep.2007.05.025 
Verdejo-García, A., del Mar Sánchez-Fernández, M., Alonso-Maroto, L. M., FernándezCalderón, F., Perales, J. C., Lozano, Ó., \& Pérez-García, M. (2010). Impulsivity and executive functions in polysubstance-using rave attenders. Psychopharmacology, 210(3), 377-392. https://doi.org/10.1007/s00213-010-1833-8

Vieira, P. G., \& Villemor-Amaral, A. E. (2015). Evidence of validity of Rorschach Performance Assessment System in the diagnosis of schizophrenia. Revista Avaliação Psicológica, 14(1), 53-62. https://doi.org/10.15689/ap.2015.1401.06

Viglione, D. J., Blume-Marcovici, A. C., Miller, H. L., Giromini, L., \& Meyer, G. (2012). An inter-rater reliability study for the rorschach performance assessment system. Journal of Personality Assessment, 94(6), 607-612. https://doi.org/10.1080/00223891.2012.684118

Von Neumann, J., \& Morgenstern, O. (1945). Theory of games and economic behavior. Bull. Amer. Math. Soc, 51(7), 498-504.

Wachelke, J., Natividade, J., Andrade, A. de, Wolter, R., \& Camargo, B. (2014). Caracterização e Avaliação de um Procedimento de Coleta de Dados Online (CORP). Avaliação Psicológica, 13(1), 143-146. http://pepsic.bvsalud.org/pdf/avp/v13n1/v13n1a17.pdf

Wagar, B. M., \& Dixon, M. (2006). Affective guidance in the Iowa gambling task. Cognitive, Affective and Behavioral Neuroscience, 6(4), 277-290. https://doi.org/10.3758/CABN.6.4.277

Watson, D. (2004). Stability versus change, dependability versus error: Issues in the assessment of personality over time. Journal of Research in Personality, 38(4), 319-350. https://doi.org/10.1016/j.jrp.2004.03.001

Webb, N. M., Shavelson, R. J., \& Haertel, E. H. (2006). Reliability Coefficients and Generalizability Theory. In Handbook of Statistics (Vol. 26, Issue 06, pp. 81-124). https://doi.org/10.1016/S0169-7161(06)26004-8

Weiner, I. B. (2000). Princípios da interpretação do Rorschach. São Paulo: Casa Do Psicólogo.

Weiss, N H, Darosh, A. G., Contractor, A. A., Schick, M. M., \& Dixon-Gordon, K. L. (2019). Confirmatory validation of the factor structure and psychometric properties of the Difficulties in Emotion Regulation Scale-Positive. Journal of Clinical Psychology, 75(7), 1267-1287. https://doi.org/10.1002/jclp.22768

Weiss, Nicole H., Tull, M. T., Viana, A. G., Anestis, M. D., \& Gratz, K. L. (2012). Impulsive behaviors as an emotion regulation strategy: Examining associations between PTSD, emotion dysregulation, and impulsive behaviors among substance dependent inpatients. Journal of Anxiety Disorders, 26(3), 453-458. https://doi.org/10.1016/j.janxdis.2012.01.007

Werner, N S, Duschek, S., \& Schandry, R. (2009). Relationships between affective states and decision-making. International Journal of Psychophysiology, 74(3), 259-265. https://doi.org/10.1016/j.ijpsycho.2009.09.010

Werner, Natalie S, Duschek, S., \& Schandry, R. (2009). Relationships between affective states and decision-making. International Journal of Psychophysiology, 74(3), 259-265. https://doi.org/10.1016/j.ijpsycho.2009.09.010 
Xiao, L., Koritzky, G., Johnson, C. A., \& Bechara, A. (2013). The cognitive processes underlying affective decision-making predicting adolescent smoking behaviors in a longitudinal study. Frontiers in Psychology, 4(OCT), 1-9. https://doi.org/10.3389/fpsyg.2013.00685

Xu, S., Korczykowski, M., Zhu, S., \& Rao, H. (2013). Assessment of risk-taking and impulsive behaviors: A comparison between three tasks. Social Behavior and Personality, 41(3), 477486. https://doi.org/10.2224/sbp.2013.41.3.477

Yazigi, L., \& Gazire, P. (2002). Avaliação cognitiva e Rorschach. Psico-USF, 7(1), 109-112. https://www.researchgate.net/profile/Latife_Yazigi/publication/239532638_Avaliacao_cog nitiva_e_Rorschach/links/54ef7e810cf25f74d7227c66/Avaliacao-cognitiva-eRorschach.pdf

Young, A. T. (2016). Police Hostage (Crisis) Negotiators in the US: A National Survey. Journal of Police and Criminal Psychology, 31(4), 310-321. https://doi.org/10.1007/s11896-0169193-x

Young, A. T., Hennington, C., \& Eggleston, D. (2018). US SWAT operator experience, personality, cognitive-emotion regulation and decision-making style. Policing: $A n$ International Journal, 41(2), 247-261. https://doi.org/10.1108/PIJPSM-10-2016-0156

Zajonc, R. B. (1980). Feeling and thinking: Preferences need no inferences. American Psychologist, 35(2), 151-175. https://doi.org/10.1037/0003-066X.35.2.151

Zanon, C., Bastianello, M. R., Pacico, J. C., \& Hutz, C. S. (2013). Desenvolvimento e validação de uma escala de afetos positivos e negativos. Psico-USF, 18(2), 193-201. https://doi.org/10.1590/S1413-82712013000200003

Zanon, C., \& Hutz, C. S. (2014). Escala de Afetos Positivos e Afetos Negativos (PANAS). In C. S. Hutz (Ed.), Avaliação em psicologia positiva. Artmed.

Zimmermann, G. (2010). Risk perception, emotion regulation and impulsivity as predictors of risk behaviours among adolescents in Switzerland. Journal of Youth Studies, 13(1), 83-99. https://doi.org/10.1080/13676260903173488 
APÊNDICES 
APÊNDICE A - Relatório Individual Participantes do Estudo I

\section{CENTRO DE PESOUISA EM PSICODIAGNÓSTICO - CPP}
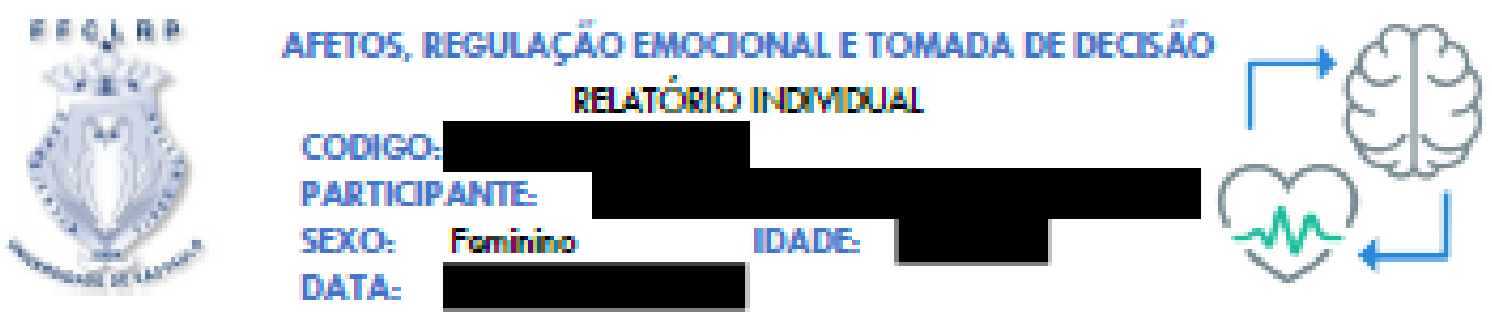

Care participants,

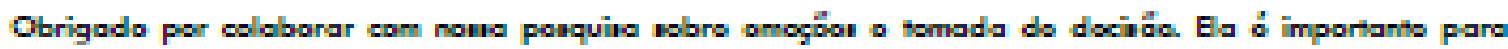

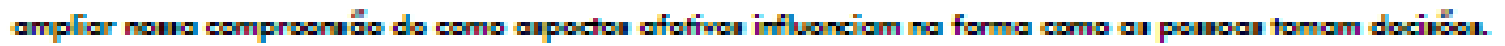

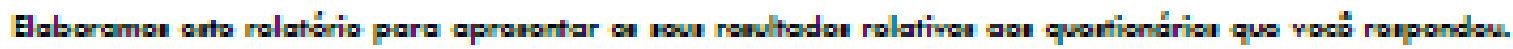

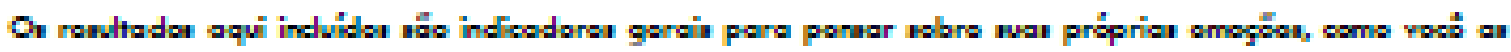

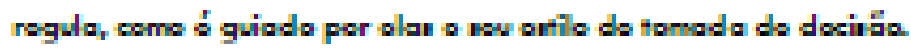

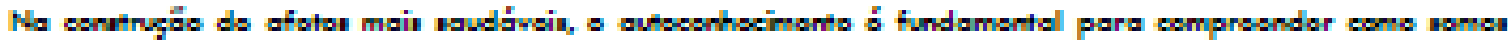

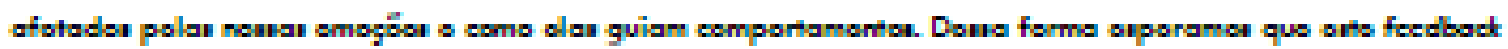

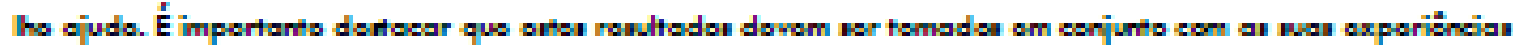
o outrau fontea ds infermogio.

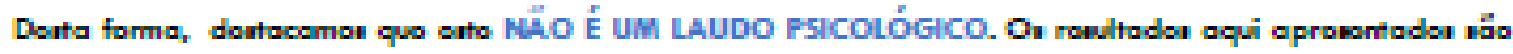

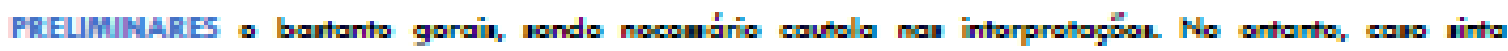

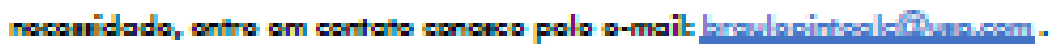

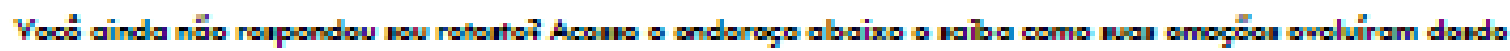
artán.

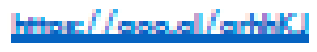

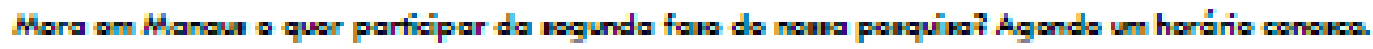

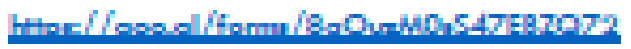

Fenquinadorca renpennåncie

Douterande: Andrö Lür de Carvalho Braule Finto GP: $10 / 02695$ - 06/0682-15

Oriontadora: Profa. Dr. Sania Ragina Parian Profourara Ansededa Dapariamonto da Phiedogie

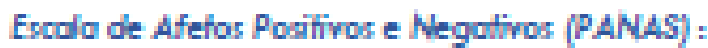

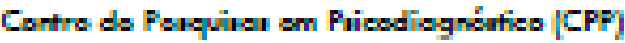

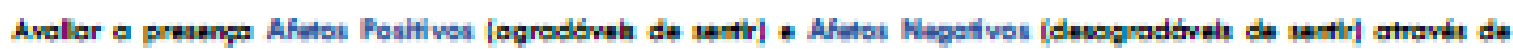

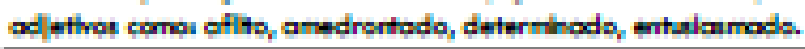

\begin{tabular}{|c|c|c|}
\hline Caractańtico & Das'fioapo & hitarprotapoo \\
\hline Afotor Portines & Bains & 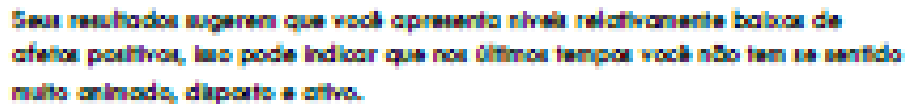 \\
\hline
\end{tabular}

Afatos llogutios H/o

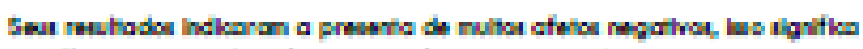

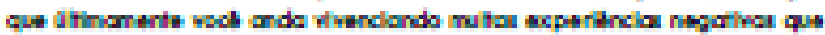

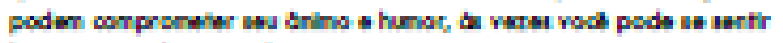
loptromente dewimats 
Evodla de Afefor (EA) :

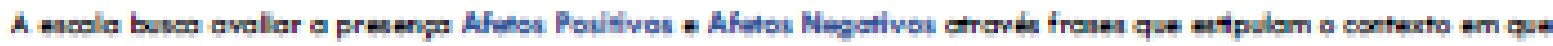

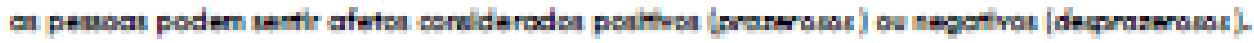

\begin{tabular}{|c|c|c|}
\hline Carodarítico & Oasifiogoro & Iitarprotago \\
\hline Afatos Positios & Bnino & 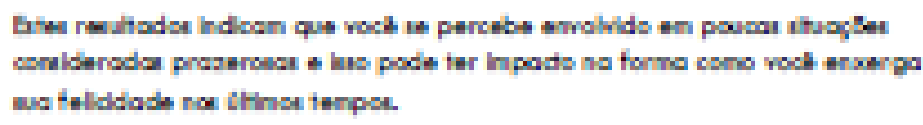 \\
\hline Afores llagatios & Ato & 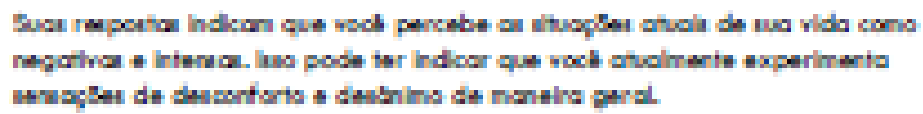 \\
\hline
\end{tabular}

\section{Quesfionónio de Regulapổo Emocional (ERQ):}

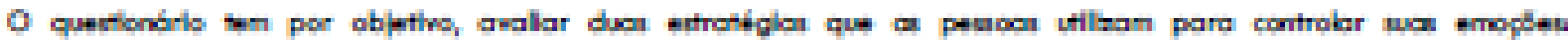

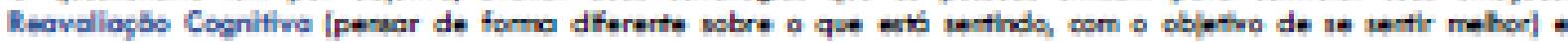

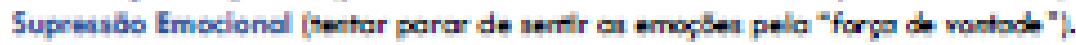

\begin{tabular}{|c|c|c|}
\hline Coroutańtico & Dosifiogóo & Intorprotogó \\
\hline $\begin{array}{l}\text { Pagualiogóo } \\
\text { Cogrifio }\end{array}$ & Melio & 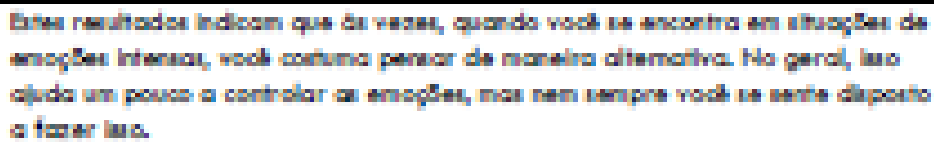 \\
\hline
\end{tabular}

\begin{tabular}{|c|c|c|}
\hline $\begin{array}{l}\text { Suprocobo } \\
\text { Emacional }\end{array}$ & Medo & 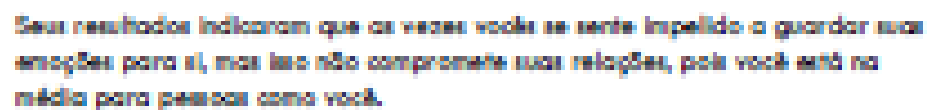 \\
\hline
\end{tabular}

\section{Evadla de Dificulabdes de Regulogto Emociond (DERS):}

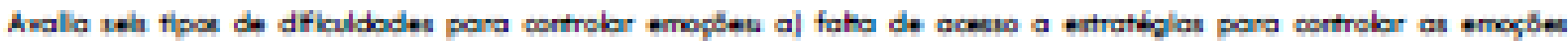

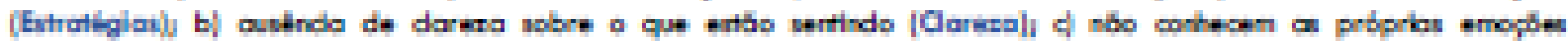

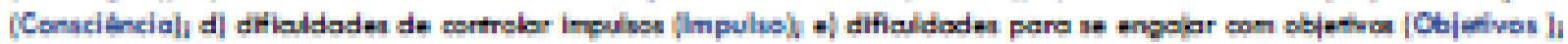

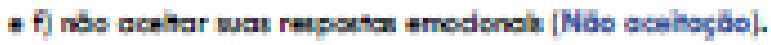

\begin{tabular}{|c|c|c|}
\hline Canadarítica & Dasifoopo & htorpiotagoo \\
\hline 1460 acoitogos & Medio & 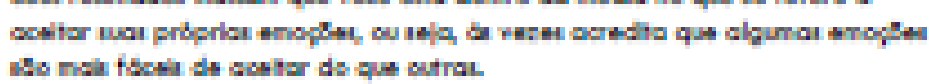 \\
\hline
\end{tabular}

\begin{tabular}{|c|c|c|}
\hline Dbiotinos & Aho & 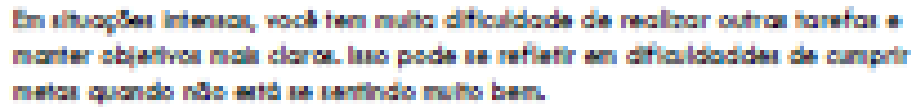 \\
\hline
\end{tabular}

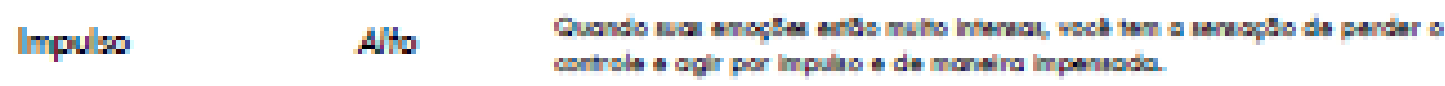

Conciáncio Mélo

Clarano

Ato

Entratógia

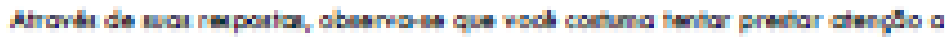

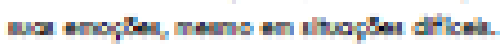

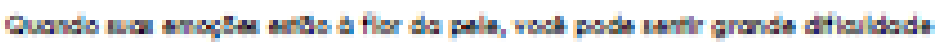

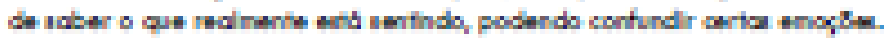

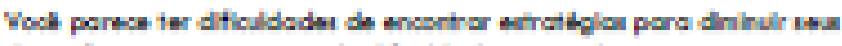

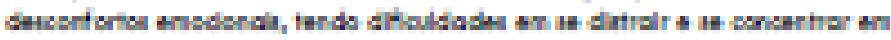
arta atthilodis. 
Following Affistive States Tert (FAST):

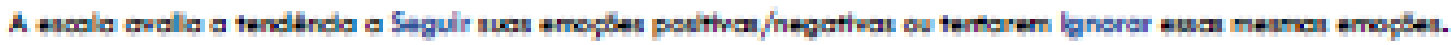

\begin{tabular}{|c|c|c|}
\hline Canadarística & Dosaficopoio & ntorprotogóo \\
\hline $\begin{array}{l}\text { Soguir Efotos } \\
\text { Positivos }\end{array}$ & Boino & 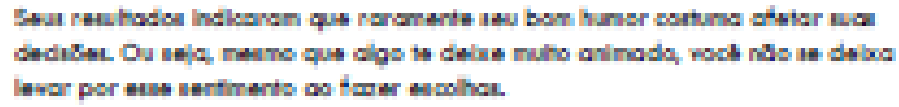 \\
\hline $\begin{array}{l}\text { Ignorar Afotos } \\
\text { Positivas }\end{array}$ & Médo & 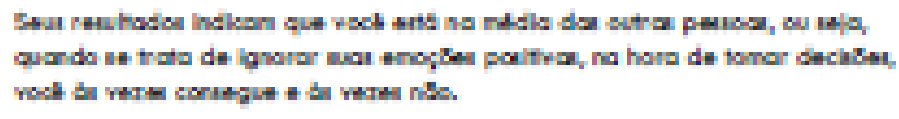 \\
\hline $\begin{array}{l}\text { Soguir afotos } \\
\text { Itogutivos }\end{array}$ & Ato & 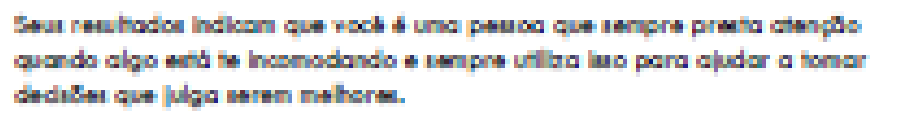 \\
\hline $\begin{array}{l}\text { lgnorar Afates } \\
\text { Itbgutivos }\end{array}$ & Ato & 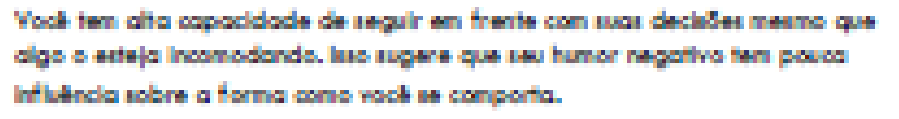 \\
\hline
\end{tabular}

Evalo de Etilas de Decino (DSS):

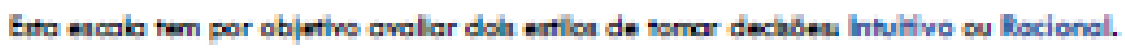

\begin{tabular}{|c|c|c|}
\hline Eanodaritica & Danifoopó & Htarprotoros \\
\hline Rodional & Medio & 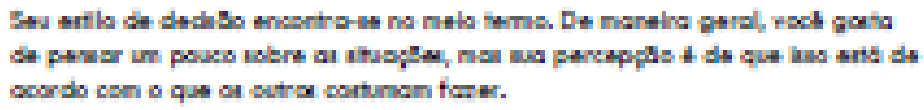 \\
\hline Intuiting & Bning & 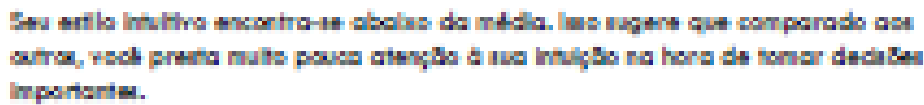 \\
\hline
\end{tabular}

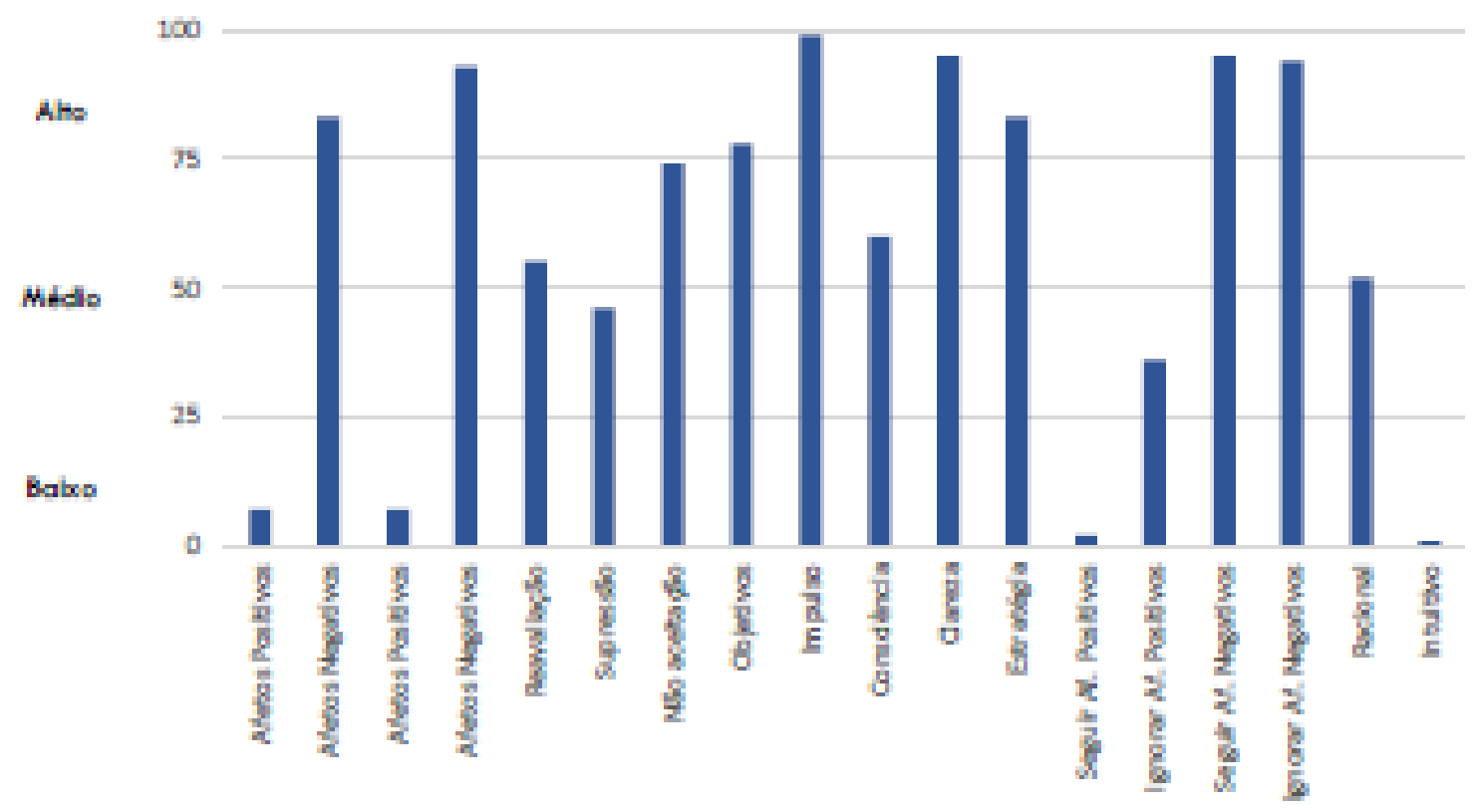




\section{APÊNDICE B - Termo de Consentimento Livre e Esclarecido (Estudo I)}

Você está sendo convidado a participar como voluntário da pesquisa intitulada "Indicadores de tomada de decisão e regulação emocional no método de Rorschach, sistema R-PAS”, que tem por objetivo estudar a relação entre controle das emoções, tomadas de decisão e características de personalidade de maneira a contribuir com a avaliação dessas características no contexto brasileiro. Esta pesquisa faz do Doutorado do psicólogo André Luiz de Carvalho Braule Pinto, sob orientação da Profa. Dra. Sonia Regina Pasian, do Departamento de Psicologia da Faculdade de Filosofia, Ciências e Letras de Ribeirão Preto, na Universidade de São Paulo (USP). Nesse trabalho você responderá um questionário com perguntas sobre suas características de vida e econômicas, além de dois instrumentos que solicitam informações sobre sua forma de controlar emoções e tomar decisões. Estimando-se um tempo de 30 minutos para sua realização. Decorridos 15 dias você será solicitado a responder novamente informações sobre sua forma de controlar emoções, estimando-se um tempo de 5 minutos. O risco decorrente de sua participação na pesquisa é considerado mínimo, vinculado a possível incômodo que as perguntas possam lhe causar. O pesquisador estará a sua disposição para quaisquer dúvidas ou necessidades. Se você aceitar participar da pesquisa não receberá benefícios diretos, mas estará contribuindo para o conhecimento científico sobre o tema. Você não terá nenhuma despesa, caso haja, você será ressarcido, porém não receberá nenhuma remuneração por participar dessa pesquisa.

Você poderá desistir da pesquisa em qualquer momento, tendo o direito e a liberdade de retirar seu consentimento em qualquer fase, seja antes ou depois da coleta dos dados, independente do motivo e sem nenhum prejuízo a sua pessoa.

Os resultados da pesquisa serão analisados de modo geral, procurando-se identificar características comuns aos participantes, sendo garantido o sigilo sobre a identidade dos participantes do estudo. Após as devidas análises, os dados serão publicados, mas sua identidade não será divulgada, sendo garantido o sigilo de suas respostas.

O pesquisador se coloca disponível para eventuais dúvidas e necessidades, pelo telefone (91) 9 9157-9945 e do email braulepintoalc@usp.br. Além disso, você poderá ter informações específicas sobre questões éticas dessa pesquisa diretamente no Comitê de Ética em Pesquisa da Faculdade de Filosofia, Ciências e Letras de Ribeirão Preto - FFCLRP-USP, no telefone (16) 3315-4811. Avenida Bandeirantes, 3900 - Bloco 23 - Casa 37 - 14040-901 Ribeirão Preto - SP - Brasil, Fone: (16) 3315-4811, E-mail: coetp@ffclrp.usp.br

Desde já agradecidos, contamos com sua participação.

\footnotetext{
Prof. Dra. Sonia Regina Pasian

Orientadora - Docente do Departamento de Psicologia da FFCLRP-USP
}

André Luiz de Carvalho Braule Pinto
Doutorando e Pesquisador Principal

\section{CONSENTIMENTO}

A partir das informações recebidas, declaro que fui informado sobre o que o pesquisador quer fazer e porque precisa da minha colaboração, e entendi a explicação. Por isso, eu concordo em participar da pesquisa, sabendo que não vou ganhar nada e que posso sair quando quiser.

Aceito participar como voluntário nessa pesquisa

Não aceito participar como voluntário e não quero que meus dados sejam utilizados

Pesquisadores Responsáveis:

- $\quad$ André Luiz de Carvalho Braule Pinto (CRP: 20/03.695) Psicólogo e doutorando no Departamento de Psicologia da FFCLRP-USP / E-mail: braulepintoalc@usp.br

- $\quad$ Profa. Dra. Sonia Regina Pasian - Docente do Departamento de Psicologia da FFCLRP-USP

Centro de Pesquisas em Psicodiagnóstico - Departamento de Psicologia - Faculdade de Filosofia, Ciências e Letras da

Universidade de São Paulo - Av. Bandeirantes, 3900 - Monte Alegre - Ribeirão Preto (SP) - CEP: 14.040-901

E-mail: srpasian@ffclrp.usp.br 


\section{APÊNDICE C - Termo de Consentimento Livre e Esclarecido (Estudo II)}

Você está sendo convidado a participar como voluntário da pesquisa intitulada "Indicadores de tomada de decisão e regulação emocional no método de Rorschach, sistema R-PAS”, que tem por objetivo estudar a relação entre controle das emoções, tomadas de decisão e características de personalidade de maneira a contribuir com a avaliação dessas características no contexto brasileiro Esta pesquisa faz parte do Doutorado do psicólogo André Luiz de Carvalho Braule Pinto, sob orientação da Profa. Dra. Sonia Regina Pasian, do Departamento de Psicologia da Faculdade de Filosofia, Ciências e Letras de Ribeirão Preto, na Universidade de São Paulo (USP). Nesse trabalho você será convidado a dizer suas interpretações sobre cartões com manchas de tinta e a participar de uma atividade formada por um jogo de cartas. Prevê-se um tempo de 60 minutos paras essas atividades, que serão realizadas apenas após sua devida autorização, nas dependências do Centro de Pesquisa em Psicodiagnóstico (CPP). O risco decorrente de sua participação na pesquisa é considerado mínimo, vinculado ao possível incômodo que as perguntas e os cartões possam lhe causar. O pesquisador estará a sua disposição para quaisquer dúvidas ou necessidades. Será combinado, previamente horário de sua conveniência. Se você aceitar participar da pesquisa não receberá benefícios diretos, mas estará contribuindo para o conhecimento científico sobre o tema. Você não terá nenhuma despesa, caso haja despesas com transporte e/ou alimentação, você será ressarcido, porém não receberá nenhuma remuneração por participar dessa pesquisa.

Você poderá desistir da pesquisa em qualquer momento, tendo o direito e a liberdade de retirar seu consentimento em qualquer fase, seja antes ou depois da coleta dos dados, independente do motivo e sem nenhum prejuízo a sua pessoa. Os resultados da pesquisa serão analisados de modo geral, procurando-se identificar características comuns aos participantes, sendo garantido o sigilo sobre a identidade dos participantes do estudo. Após as devidas análises, os dados serão publicados, mas sua identidade não será divulgada, sendo garantido o sigilo de suas respostas.

O pesquisador se coloca disponível para eventuais dúvidas e necessidades, pelo telefone (91) 9 9157-9945 e do email braulepintoalc@usp.br. Além disso, você poderá ter informações específicas sobre questões éticas dessa pesquisa diretamente no Comitê de Ética em Pesquisa da Faculdade de Filosofia, Ciências e Letras de Ribeirão Preto - FFCLRPUSP, no telefone (16) 3315-4811. Avenida Bandeirantes, 3900 - Bloco 23 - Casa 37 - 14040-901 - Ribeirão Preto - SP Brasil, Fone: (16) 3315-4811, E-mail: coetp@ffclrp.usp.br

Desde já agradecidos, contamos com sua participação.

Prof. Dra. Sonia Regina Pasian

Orientadora - Docente do Departamento de Psicologia da FFCLRP-USP
André Luiz de Carvalho Braule Pinto

Doutorando e Pesquisador Principal

\section{CONSENTIMENTO}

A partir das informações recebidas, declaro que fui informado sobre o que o pesquisador quer fazer e porque precisa da minha colaboração, e entendi a explicação. Por isso, eu concordo em participar da pesquisa, sabendo que não vou ganhar nada e que posso sair quando quiser. Este documento é emitido em duas vias que serão ambas assinadas por mim e pelo pesquisador, ficando uma via com cada um de nós. 1201

Nome Completo

Assinatura

\section{RG}

Pesquisadores Responsáveis:

- $\quad$ André Luiz de Carvalho Braule Pinto (CRP: 20/03.695) Psicólogo e doutorando no Departamento de Psicologia da FFCLRP-USP / Email: braulepintoalc@usp.br

- $\quad$ Profa. Dra. Sonia Regina Pasian - Docente do Departamento de Psicologia da FFCLRP-USP

Centro de Pesquisas em Psicodiagnóstico - Departamento de Psicologia - Faculdade de Filosofia, Ciências e Letras da Universidade de São Paulo - Av. Bandeirantes, 3900 - Monte Alegre - Ribeirão Preto (SP) - CEP: 14.040-901 E-mail: srpasian@ffclrp.usp.br 


\section{APÊNDICE D-E -_Divulgação Da Pesquisa Por E-Mail E Em Redes Sociais}

Colaboração em Pesquisa - CONTROLE EMOÇõES e TOMADA DE DECISÃO

$\underline{\underline{\mathbf{B}}}$

@irinalizadas/AcadémicolPPG USP $x$ @Finalizadas/Pessoas/Sonia Pasian $x$

Sonia Regina Pasian <srpasian@ffclrp.usp.br>

para avalpsi, ASBRo, IBAP, mim, okino, castro.pf, Monalisa $/$

\section{- Bom dia, prezados colegas!}

Escrevo hoje para solicitar a gentileza de divulgarem o link para a pesquisa de Doutorado que estamos orientando nesse momento. Estamos investigando como as pessoas controlam suas emoções e como isso influencia na forma como elas tomam decisões.

Para PARTICIPAR DO ESTUDO, basta clicar no link https:/lgoo. gl/JhrJzc

Basta possuir idade mínima de 18 anos e concordar com os termos da pesquisa.

Certa da contribuição, desde já agradeço a todos.

Forte abraço

\section{Sonia Regina Pasian}

Professora Livre-Docente do Departamento de Psicologia

Faculdade de Filosofia, Ciências e Letras de Ribeirão Preto

Universidade de São Paulo

(16) $3315-3785$

Olá

Gostaria de CONVIDÁ-LO A PARTICIPAR da minha pesquisa de Doutorado em Psicologia pela USP

Estamos investigando como as pessoas controlam suas emoções e como isso influencia na forma como elas tomam decisões

Se quiser PARTICIPAR DO ESTUDO, basta clicar no link abaixo e

responder algumas perguntas rápidas.

Além disso, se puder divulgar entre SEUS CONHECIDOS, seria de grande ajuda.

Desde já, obrigado pela contribuição.

Abraços

https://goo.gl/JhrJzc

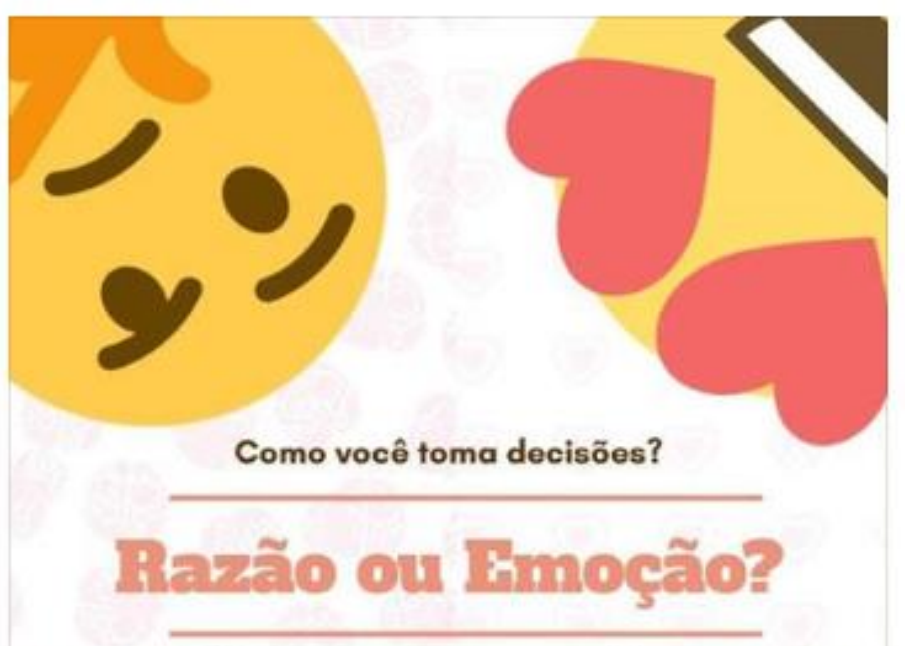

Participe da pesquisa e nos ajude a entender melhor sobre tomada de decisões e regulação emocional

https://goo.gl/JhrJzc 
APÊNDICE F - Exemplo de Primeira Página do Instrumento ERQ na Plataforma

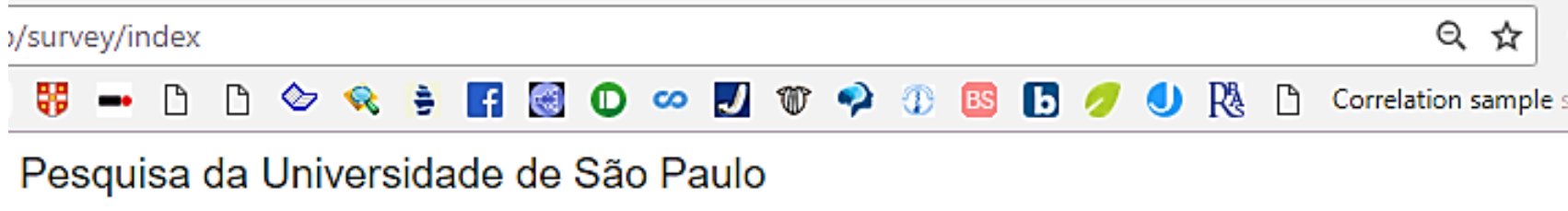

Personalidade, Regulação Emocional e Tomada de Decisão

BEM-VINDO! Por favor, use o navegador Firefox ou Chrome. Evite o Explore

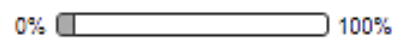

Questionário de Regulação Emocional (ERQ)

O Questionário de Regulação Emocional foi concebido para avaliar as diferenças individuais no uso cotidiano, em duas estratégias para compreender as emoções.

Instruções:

Gostaríamos de fazer algumas questões sobre a sua vida emocional, em particular, como controla as suas emoções (isto é, como as regula e conduz). As questões abaixo envolvem duas situações diferentes sobre sua vida emocional. A primeira refere-se à sua experiência emocional, isto é, o modo como se sente. A segunda refere-se à expressão emocional, ou seja, a forma como demonstra as suas emoções, ao falar, gesticular ou atuar. Apesar de algumas questões parecerem semelhantes, diferem em importantes aspectos.

\begin{tabular}{|c|c|c|c|c|c|c|c|c|}
\hline \multirow[t]{2}{*}{$\begin{array}{c}1 \\
\text { Discordo } \\
\text { Totalmente }\end{array}$} & $\begin{array}{c}2 \\
\text { Discordo } \\
\text { Muito }\end{array}$ & $\begin{array}{c}3 \\
\text { Discordo } \\
\text { Levemente }\end{array}$ & $\begin{array}{c}4 \\
\text { Não concordo } \\
\text { nem discordo L }\end{array}$ & $\begin{array}{c}5 \\
\text { Concordo } \\
\text { Levemente }\end{array}$ & $\begin{array}{l}\text { Concordo } \\
\text { Muito }\end{array}$ & $\begin{array}{l}\text { Concordo } \\
\text { Totalmente }\end{array}$ & \multicolumn{2}{|c|}{ + Concordo } \\
\hline & $\begin{array}{l}\text { Discordo } \\
\text { Totalmente }\end{array}$ & $\begin{array}{c}\text { Discordo } \\
\text { Muito }\end{array}$ & $\begin{array}{l}\text { Discordo } \\
\text { Levement }\end{array}$ & $\begin{array}{c}\text { Não } \\
\text { concordo } \\
\text { Nem } \\
\text { discordo }\end{array}$ & & $\begin{array}{l}\text { Concordo } \\
\text { Levemente }\end{array}$ & $\begin{array}{c}\text { Concordo } \\
\text { Muito }\end{array}$ & $\begin{array}{l}\text { Concordo } \\
\text { Totalmente }\end{array}$ \\
\hline $\begin{array}{r}\text { Quando quero sentir mais } \\
\text { emoções positivas (como } \\
\text { alegria ou } \\
\text { contentamento), mudo o } \\
\text { que estou pensando. }\end{array}$ & 0 & 0 & 0 & o & & O & O & 0 \\
\hline $\begin{array}{l}\text { Eu conservo as minhas } \\
\text { emocões dara mim. }\end{array}$ & O & 0 & O & 0 & & 0 & o & 0 \\
\hline
\end{tabular}


APÊNDICE G - Precisão entre avaliadores independentes para todas as variáveis do Rorschach RPAS (n=30) por meio do Coeficiente de Correlação Intraclasse

\begin{tabular}{|c|c|c|c|c|c|}
\hline \multicolumn{3}{|c|}{ Sumário Escores Página 1} & \multicolumn{3}{|c|}{ Sumário Escores Página 2} \\
\hline Variável & ICC & Classificação & Variável & ICC & Classificação \\
\hline \multicolumn{3}{|c|}{ Administração, Comportamento e Observações } & \multicolumn{3}{|c|}{ Engajamento e Processamento Cognitivo } \\
\hline $\operatorname{Pr}$ & 0,8 & Excelente & $\mathrm{W} \%$ & 0,83 & Excelente \\
\hline $\mathrm{Pu}$ & 0,86 & Excelente & $\operatorname{Dd} \%$ & 0,66 & Bom \\
\hline $\mathrm{CT}$ & 0,99 & Excelente & SI & 0,72 & Bom \\
\hline \multicolumn{3}{|c|}{ Engajamento e Processamento Cognitivo } & IntCont & 0,22 & Pobre \\
\hline Complexity & 0,92 & Excelente & $\mathrm{Vg} \%$ & 0,18 & Pobre \\
\hline $\mathrm{R}$ & 0,83 & Excelente & V & 0,6 & Bom \\
\hline $\mathrm{F} \%$ & 0,84 & Excelente & FD & 0,15 & Pobre \\
\hline Blend & 0,65 & Bom & $\mathrm{R} 8910 \%$ & 0,9 & Excelente \\
\hline Sy & 0,78 & Excelente & WSumC & 0,84 & Excelente \\
\hline $\mathrm{MC}$ & 0,89 & Excelente & $\mathrm{C}$ & 0,18 & Pobre \\
\hline MC-PPD & 0,81 & Excelente & Mp_Prp & 0,54 & Fraco \\
\hline M & 0,91 & Excelente & \multicolumn{3}{|c|}{ Percepção e Problemas de Pensamento } \\
\hline M_Prp & 0,85 & Excelente & $\mathrm{FQu} \%$ & 0,13 & Pobre \\
\hline WSumC & 0,84 & Excelente & \multicolumn{3}{|c|}{ Estresse and Distress } \\
\hline \multicolumn{3}{|c|}{ Percepção e Problemas de Pensamento } & PPD & 0,83 & Excelente \\
\hline EII_3 & 0,61 & Bom & YTVCpr & 0,67 & Bom \\
\hline TP Comp & 0,65 & Bom & CBlend & 0,69 & Bom \\
\hline WSumCog & 0,36 & Pobre & Cpr & 0,77 & Excelente \\
\hline SevCog & 0,16 & Pobre & CritCont $\%$ & 0,73 & Bom \\
\hline $\mathrm{FQm} \%$ & 0,59 & Fraco & \multicolumn{3}{|c|}{ Representação de si e dos outros } \\
\hline WD\% & 0,58 & Fraco & SumH & 0,92 & Excelente \\
\hline FQo\% & 0,73 & Bom & NPH_Prp & 0,77 & Excelente \\
\hline Popular & 0,54 & Fraco & refl & 0,81 & Excelente \\
\hline Estresse and D & & & p_Prp & 0,14 & Pobre \\
\hline $\mathrm{mY}$ & 0,54 & Fraco & AGM & 0,68 & Bom \\
\hline Y & 0,44 & Fraco & $\mathrm{T}$ & 0,49 & Fraco \\
\hline MOR & 0,6 & Bom & PER & 0,47 & Fraco \\
\hline SC_Comp & 0,79 & Excelente & An & 0,97 & Excelente \\
\hline \multicolumn{6}{|c|}{ Representação de si e dos outros } \\
\hline ODL\% & 0,78 & Excelente & & & \\
\hline SR & 0,6 & Bom & & & \\
\hline MAP\% & 0,84 & Excelente & & & \\
\hline PHR_Prp & 0,76 & Excelente & & & \\
\hline $\mathrm{Mm}$ & 0,78 & Excelente & & & \\
\hline AGC & 0,66 & Bom & & & \\
\hline V_Comp & 0,8 & Excelente & & & \\
\hline $\mathrm{H}$ & 0,87 & Excelente & & & \\
\hline $\mathrm{COP}$ & 0,68 & Bom & & & \\
\hline MAH & 0,58 & Fraco & & & \\
\hline
\end{tabular}


ANEXOS 
ANEXO A - Autorização da Pesquisa no Comitê de Ética Em Pesquisa.

\section{Universidade de São Paulo \\ Faculdade de Filosofia, Ciências e Letras de Ribeirão Preto \\ Comitê de Ética em Pesquisa}

Of.CEtP/FFCLRP-USP/021-dgfs.

Campus de Ribeirão Preto

Ribeirão Preto, 30 de março de 2017.

Prezado(a) Pesquisador(a),

Comunicamos a V. Sa. que o projeto de pesquisa intitulado "Indicadores de tomada de decisão e regulação emocional no método de Rorschach sistema R-PAS" foi analisado pelo Comitê de Ética em Pesquisa da FFCLRP-USP, em sua $164^{\mathrm{a}}$ Reunião Ordinária, realizada em 23.03.2017, e enquadrado na categoria: APROVADO (CAAE n 62744516.3.0000.5407).

Solicitamos que eventuais modificações ou emendas ao projeto de pesquisa sejam apresentadas ao CEP, de forma sucinta, identificando a parte do projeto a ser modificada e suas justificativas. De acordo com a Resolução $n^{\circ} 466$ de 12/12/2012, devem ser entregues relatórios semestrais e, ao término do estudo, um relatório final sempre via Plataforma Brasil.

Atenciosamente,

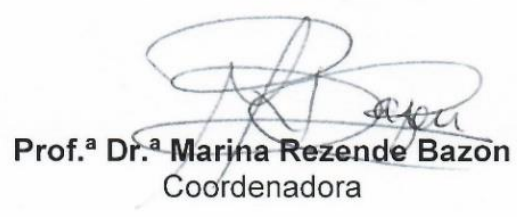

Ao(À) Senhor(a)

André Luiz de Carvalho Braule Pinto

Programa de Pós-graduação em Psicologia da FFCLRP/USP.

CEP - Comitê de Ética em Pesquisa da FFCLRP USP

Fone: (16) 3315-4811

Avenida Bandeirantes, 3900 - bloco 23 - casa 37 - 14040-901 - Ribeirão Preto - SP - Brasil

Homepage: http://www.ffclrp.usp.br - e-mail: coetp@ffclrp.usp.br 
ANEXO B - Questionário Socioeconômico

\section{DADOS PESSOAIS}

E-mail:

Sexo: ( ) Masculino ( ) Feminino

Local de Nascimento: Cidade:

País:

Escolaridade - Curso em andamento:

Semestre em andamento:

Faculdade:

Profissão/Ocupação:

Estado Civil: ( ) solteiro ( ) casado ( ) união estável ( ) viúvo ( ) separado/divorciado

DADOS ECONÔMICOS (ABEP, 2016)

Indicadores de classificação econômica familiar atual, marcar com X:

\begin{tabular}{l|l|l|l|l|l}
\hline Itens Domésticos & $\begin{array}{c}\text { Não } \\
\text { Tem }\end{array}$ & $\mathbf{1}$ & $\mathbf{2}$ & $\mathbf{3}$ & $\begin{array}{c}\mathbf{4} \text { ou } \\
\mathbf{+}\end{array}$ \\
\hline Televisão em cores & & & & & \\
\hline Rádio (não incluir do carro) & & & & & \\
\hline Banheiro & & & & & \\
\hline Automóvel & & & & & \\
\hline Empregada mensalista & & & & & \\
\hline Máquina de lavar & & & & & \\
\hline Vídeo cassete/DVD & & & & & \\
\hline Geladeira & & & & & \\
\hline Freezer (parte do duplex) & & & & & \\
\hline
\end{tabular}

ata de Nascimento: 西

I

Período: ( ) diurno ( ) noturno Estado: 